Portland State University

PDXScholar

Spring 6-4-2013

\title{
Seeing Crucibles: Legitimizing Spiritual Development in the Middle Grades Through Critical Historiography
}

Audrey Lingley

Portland State University

Follow this and additional works at: https://pdxscholar.library.pdx.edu/open_access_etds

Part of the Curriculum and Social Inquiry Commons, Educational Methods Commons, and the Social and Philosophical Foundations of Education Commons

Let us know how access to this document benefits you.

\section{Recommended Citation}

Lingley, Audrey, "Seeing Crucibles: Legitimizing Spiritual Development in the Middle Grades Through Critical Historiography" (2013). Dissertations and Theses. Paper 1048.

https://doi.org/10.15760/etd.1048

This Dissertation is brought to you for free and open access. It has been accepted for inclusion in Dissertations and Theses by an authorized administrator of PDXScholar. Please contact us if we can make this document more accessible: pdxscholar@pdx.edu. 
Seeing Crucibles:

Legitimizing Spiritual Development in the Middle Grades

Through Critical Historiography

by

Audrey Lingley

A dissertation submitted in partial fulfillment of the requirements for the degree of

\author{
Doctor of Education \\ in \\ Educational Leadership: Curriculum and Instruction
}

Dissertation Committee:

Karen Noordhoff, Chair

Micki M. Caskey

Samuel Henry

Yves Labissiere

Dot McElhone

Portland State University

2013 
(C) 2013 Audrey Lingley 
Advocates of middle grades reform in the United States argue that curriculum and instruction, as well as leadership, organization, and community relationships, should be informed by knowledge of the developmental characteristics of 10 to 15 year-olds within physical, social, emotional, psychological, cognitive, and moral domains. Noticeably absent from their conception of human development are spiritual developmental characteristics of young adolescents.

This interdisciplinary research was a critical constructivist (Kincheloe, 2008) inquiry of the following question: What is the educational relevance of spiritual development in middle grades education? To study this question, critical historiographical research methods (Villaverde, Kincheloe, \& Helyar, 2006) were used to interrogate the academic discourses of three fields related to the research question: (a) the middle grades concept; (b) spirituality as a developmental domain; and (c) holistic education. Foundational texts from these fields served as sources of data. I present the result of the data analyses as narratives on the paradigms that influenced the (hi)stories of these three academic fields. These narratives were analyzed for common epistemological and ontological perspectives.

Amongst the paradigms of the three fields, three meta-paradigms are shared: Ecological Epistemology, Holistic Ontology, and Positivist Ontology. In addition, a discursive interrelationship within each field — a dynamic of paradox — was found between the three meta-paradigms. These results offer encouragement for the relevance of spiritual development as part of the middle grades concept, as they suggest that 
integration of knowledge of adolescent spiritual development is theoretically supported by commitments to caring relationships in schools and constructivist learning theory. The results also suggest a paradigm revolution $(\mathrm{Kuhn}, 1996)$ that might allow for a new discourse of possibility (Giroux, 1981) for spirituality in education. This dissertation research could serve as a basis for further research that focuses on how to integrate knowledge of adolescent spiritual development in public schools in the United States. 


\section{ACKNOWLEDGEMENTS}

Although the work presented here is mine, it would not have been possible without the contributions, participation, and generous support of many people. From my community at Portland State University, I would like to first thank my cohort members, Edgar Solares, Bernd Ferner, Jennifer Wells, Sarah Lundy, and Katie Toppel, for the unique experience of a loving intellectual camaraderie. It was an experience made possible by the wise and visionary leadership of Drs. Karen Noordhoff and Samuel Henry. Karen, thank you also for serving as the lead chair on my committee and for legitimizing spirituality as an educational issue through your courageous work in the world.

Several members of the faculty in the Curriculum and Instruction department were particularly generous with their time, advice, and mentoring: thank you Drs. Micki M. Caskey, Emily de la Cruz, Christine Chaille, and Olivia Murray. A special thank you to Drs. Dot McElhone and Yves Labissiere for serving on my dissertation committee and bringing their valuable perspectives to this work. I am deeply grateful to Leslee Peterson for our partnership work. Finally, I owe a big hug to the students and faculty of the 2009 EdD cohort, who made the first two years both fun and stimulating.

Outside of PSU, I am grateful to the multiple communities who have encouraged and cheered me on for the past four years. The original Oxbow 6-April, Dan, Rachael LKK, Rachael T, and Sharon-helped crystalize my scholarly interests in the developmental foundations of the middle school concept. I was given a room of my own 
to write in by my friend and neighbor, Dr. Jonathan Cohen. Comrades too numerous to mention by name supported my singleness of purpose, both in and out of fellowship halls. I offer a deep bow to Gaby, Carol, and Catherine, whose collective contributions towards my spiritual health and healing are invaluable.

Jon, Lucy and Maya: through this work I came to know in my heart how much I love my family. Thank you for everything. 


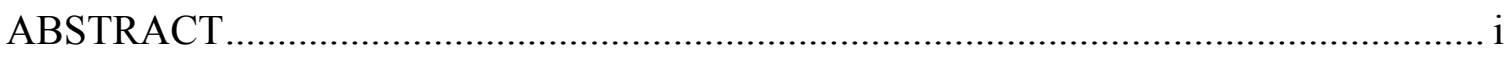

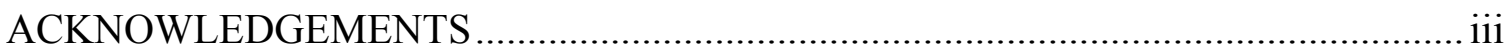

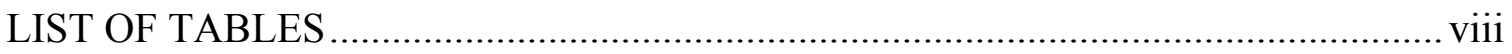

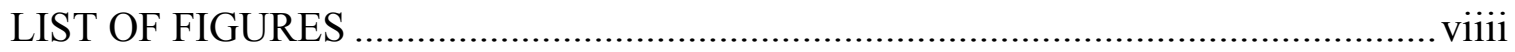

\section{CHAPTER I: INTRODUCTION}

Spiritual Development and Middle Grades Education ................................................. 1

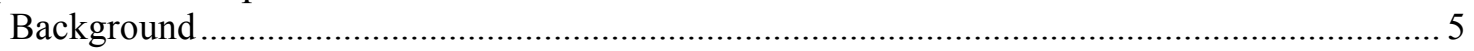

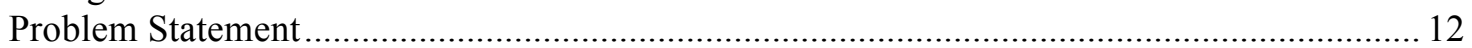

Research Purposes and Design ........................................................................................ 19

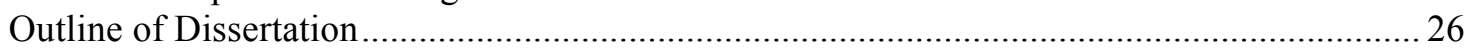

\section{CHAPTER II: LITERATURE REVIEW}

Conceptual Framework of the Related Literature......................................................... 29

The Middle Grades Concept: A Developmental Framework .................................................... 31

Spirituality as a Domain of Human Development............................................................. 44

Holistic Education: Addressing Spiritual Development........................................................ 56

Researching Educational Relevance of Spiritual Development ................................................ 70

\section{CHAPTER III: RESEARCH DESIGN}

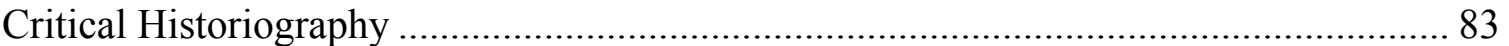

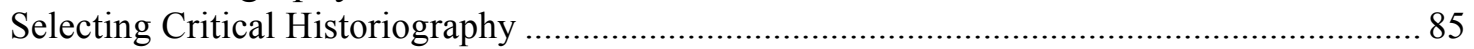

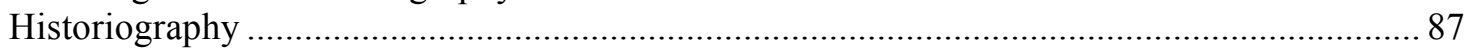

Critical Historiography: Principles and Techniques ............................................................. 97

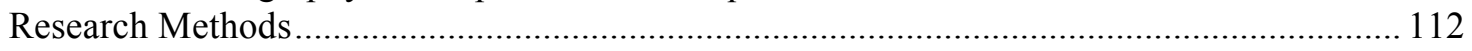

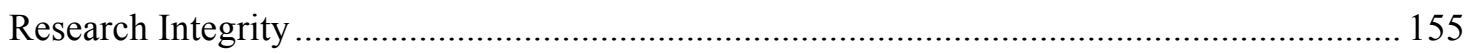

\section{CHAPTER IV: DESCRIPTION OF RESULTS}

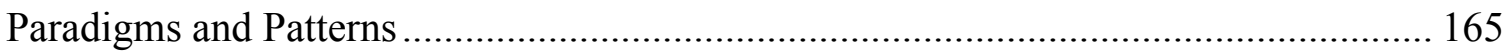

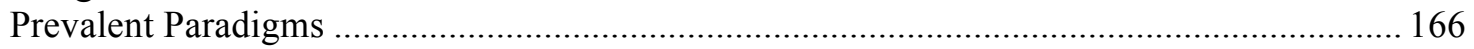

Results of Contrapuntal Reading - The Nexus...……………………………………...... 211

CHAPTER V: DISCUSSION OF RESULTS

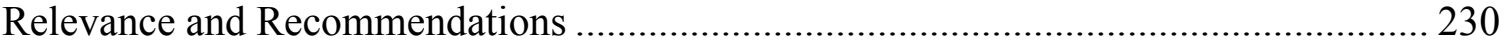

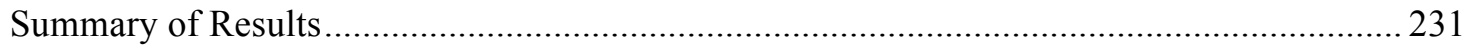

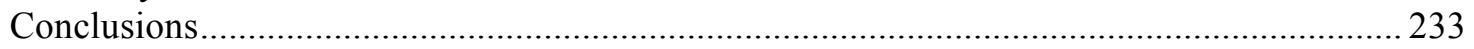

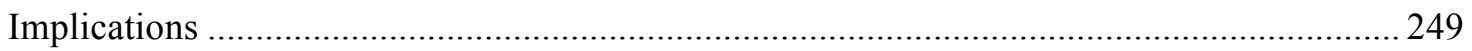

\section{CHAPTER VI: CONCLUSION}

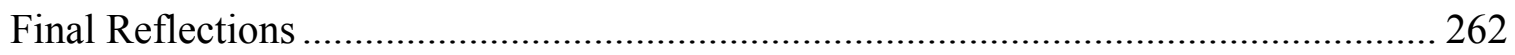

My Transformation as an Educator …………………………………………….....2. 262

Application in the Field of Middle Grades Education .......................................................2. 264

Final Thoughts on The Purpose of Education ..................................................................2. 265 


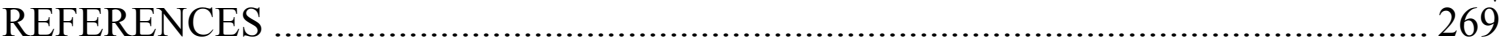

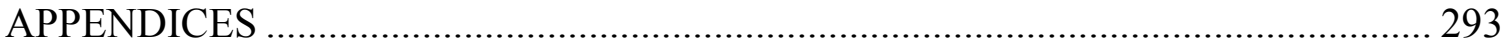

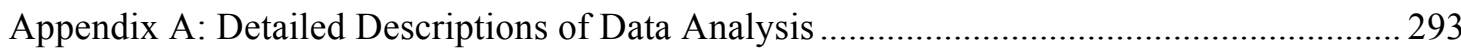

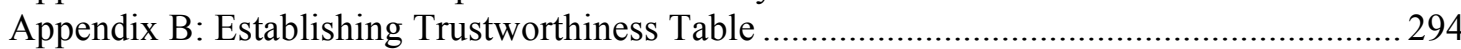

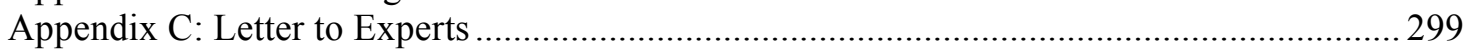

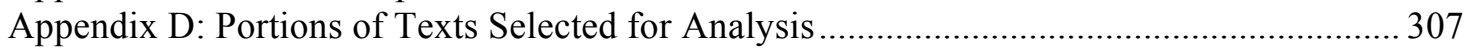

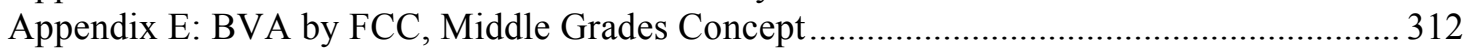

Appendix F: BVA by FCC, Spirituality as a Developmental Domain .................................. 328

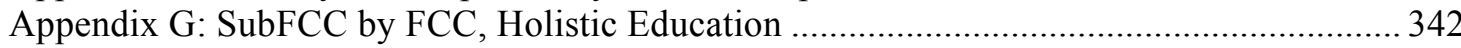

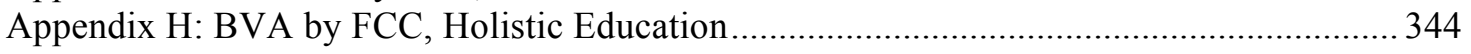


LIST OF TABLES

Table

1 Developmental Characteristics of Young Adolescents $\ldots \ldots \ldots \ldots \ldots \ldots \ldots . . . \ldots 33$

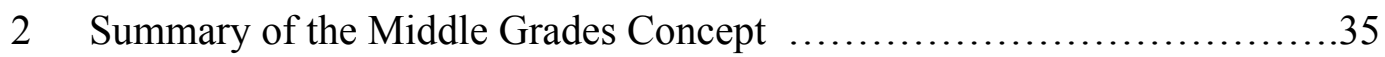

3 Benson's Definition of Spiritual Development $\ldots \ldots \ldots \ldots \ldots \ldots \ldots \ldots \ldots \ldots 47$

4 Definition of Spiritual Development (Fowler \& Dell, 2006) ...............49

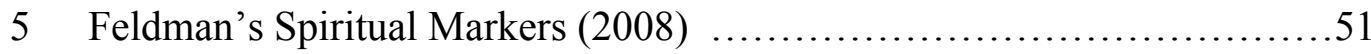

6 Comparison Between the 'Real' and Unreal' Individual ..................79

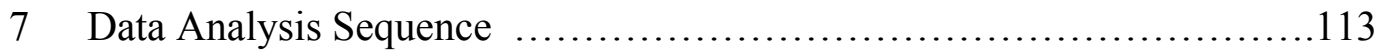

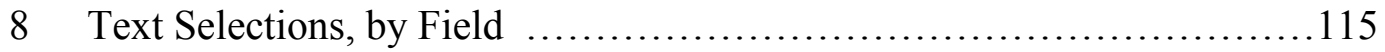

9 Frequency Data for Initial Coding of Middle Grades

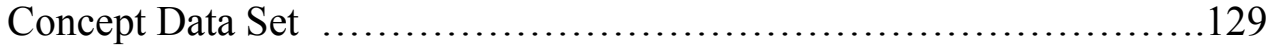

10 Frequency Data for Initial Coding of Spirituality as a

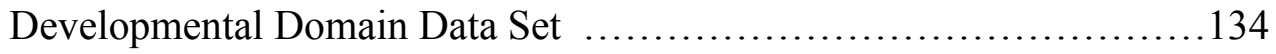

11 Sub-categories by Potential Focused Content Codes $\ldots . \ldots \ldots \ldots \ldots \ldots \ldots . . . \ldots 136$

12 Frequency Data for Initial Coding of Holistic Education

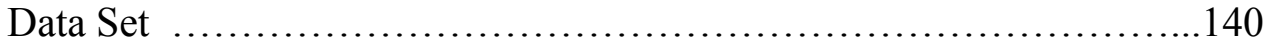

13 Analytical Tool for Contrapuntal Reading across Paradigm

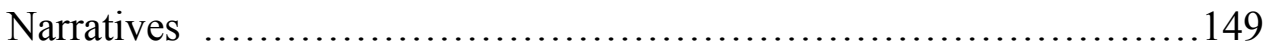

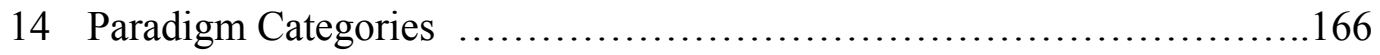




\section{LIST OF FIGURES}

Figure

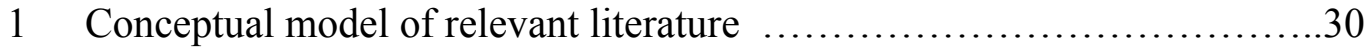

2 Revised analytic tool for exploring interrelationships

between inter-discursive and inter-textual patterns $\ldots \ldots \ldots \ldots \ldots \ldots \ldots . \ldots 154$

3 Visual illustration of the conceptual contents of the nexus ..............212

4 Prevalent paradigms for each of the three (hi)stories $\ldots \ldots \ldots \ldots \ldots \ldots . . . .231$ 


\section{CHAPTER I}

\section{INTRODUCTION}

\section{Spiritual Development and Middle Grades Education}

Learning, then, is a process in which students are involved in discovering themselves in relation to others, to their surrounding environment, and to the ultimate. Therefore, spirituality is an inherent issue of education. (Belousa, 2006, p. 217)

In the United States, the Establishment Clause of the federal Constitution prohibits public institutions from supporting religious activities. So, for many in this country, questions of legitimacy immediately arise when faced with the notion of spirituality as a matter of educational relevance. As constructs, spirituality and religion may overlap, but they are not identical. Based on my review of the literature and my own experiences as a classroom teacher for almost twenty years, the intentional inclusion of spirituality/spiritual development is advantageous for students and teachers. As Belousa (2006) implied in the opening quotation, to ask students to leave their spiritual development at the classroom door violates the essence of the educative process.

My purpose in this research is to articulate the educational relevance of the spiritual development of middle grades students as a curriculum and instruction issue. Relevance implies legitimacy; in this research, I sought to establish a clear understanding about the legitimacy of addressing student spiritual development in the context of public schooling. I situated this understanding at the nexus of three scholarly fields of inquiry: middle grades reform, spirituality as a developmental domain, and holistic education. In this study, I investigated the conceptual contents of this nexus using an interdisciplinary approach, critical historiography (Villaverde, Kincheloe, \& Helyar, 2006). I describe my 
research as interdisciplinary rather than multidisciplinary because it involves more than

merely the presence of more than one discipline. Kincheloe (2001) defined interdisciplinary as "a process where disciplinary boundaries are crossed and the analytical frames of more than one discipline are employed by the researcher" (p. 685). Given the relative acceptance of the explicit incorporation of spirituality in private, parochial, and homeschool settings (Benami, 2006; Revell, 2008), in this paper, I will situate my work within the public school context in the United States.

In the field of middle grades education, pedagogical emphasis has been on designing and implementing practices referred to as developmentally appropriate (e.g., NMSA, 2010). This reform movement is known as the middle grades concept. In aligning specific practices with early adolescent developmental theory, much of the literature describes the characteristic developmental traits for the cognitive, social, emotional, psychological, physical, and moral domains (e.g., Caskey \& Anfara, 2007; Roeser, Eccles \& Sameroff, 2000; Van Hoose, Strahan, \& L'Esperance, 2001). In the middle grades literature, the spiritual domain of human development is not referenced.

The exclusion of the spiritual domain of development is the problem I have identified for this study. The cognitive, affective, physical, moral, and psychological domains of human development are defined, by their explicit inclusion, as the relevant, or legitimate, domains to address in middle grades education. Additionally, a core foundational element of the field of middle grades reform is that educational experiences address the needs, interests, and abilities of young adolescents (ages 10-15) as a distinct developmental group (NMSA, 2010). I have no significant challenge to this stance. What I question is the wisdom of excluding spiritual development, a developmental domain 
that I see as equally foundational in terms of academic achievement and student engagement.

In framing the problem in this way, I seek to advance the claim made by Nakkula and Toshalis (2006), whose work represents the only mainstream literature on middle grades education that explicitly addresses the spiritualty of young adolescents as an educational issue:

When we speak of faith as the dynamic and symbolic frame of orientation or the ultimate concern to which a person is committed and from which one derives purpose in life, it is clear how critical it is that we prepare ourselves to work with adolescents as they develop in this domain. (p. 222)

Nakkula and Toshalis' call for teacher preparation that includes knowledge of student spiritual development reflects an important distinction that I make as well. In this research, I distinguish between teaching spirituality in schools and leveraging knowledge of spirituality in schools - I am focusing on the latter, not the former. The middle grades concept is not about teaching young adolescents about their developmental stage, even though at times explicit reference to experiences common to young adolescents such as feeling unique may be useful. It is about purposively teaching with those developmental traits in mind. What I suggest is the explicit inclusion of the spiritual domain when teaching with developmental characteristics in mind.

I take this position to enhance instruction and curriculum in the same ways that leveraging knowledge of the characteristics of the other, more commonly referenced domains of development enhances instruction and curriculum. In this work, I posit that it can be just as hazardous (Felner, Seitsinger, Brand, Burns, \& Bolton, 2007) for teachers 
to disregard or be ignorant of the spiritual development as it can be to ignore the

intellectual, socio-emotional, psychological, moral, and biological needs, interests, and abilities of young adolescents.

I contend that effective teachers acknowledge that students do not leave parts of themselves at the door when they enter a classroom. I argue it is not healthy to expect learners to compartmentalize essential parts of themselves during the messy, confusing, exhilarating process of learning. Indeed, the process of learning is just when students need all of their human resources. To help young adolescents navigate the many developmental challenges experienced during middle school, teachers can draw upon a more holistic educational perspective. Because the field of holistic education distinguishes itself from other attempts to address affective qualities of students by its explicit inclusion of spirituality and spiritual development (Miller, 2007), my hope for this work is that it offers a rationale and a language for a more holistic middle grades concept.

For this research, I used a critical historiographical study (Villaverde, Kincheloe, \& Helyar, 2006) to investigate my primary research question and its subquestions. In the design of my research, I was guided by the work of Kincheloe on critical constructivism (2008) and interdisciplinary research $(2001,2005)$, as well as Popkewitz's (1991) theory of social epistemologies. My primary research question was: What is the educational relevance of spiritual development in middle grades education? To address this main question, I investigated two subquestions:

a) What prevalent paradigms underlie the academic discourse on spirituality as a developmental domain, the middle grades concept, and holistic education? 
b) What are the inter-textual and inter-discursive relationships within the convergence of the paradigms of the three fields?

In this chapter, I address the complex definitional issues regarding spirituality and spiritual development, then offer a rationale for researching the relationship between spirituality and education in the field of curriculum and instruction at this time. I identify a serious problem in the experience of being a middle grades student in the United States today, as well as a critique of how the middle grades reform movement has conceptualized the solution to this problem. Further, I explore the interdisciplinary connection between the fields of middle grades education and applied developmental psychology. I introduce my research design by explaining how I came to an uncommon methodology in educational research, historiography. I also explain my personal and professional interests in this topic. I conclude the chapter by outlining the sections of this dissertation.

\section{Background}

Defining spiritual development. Defining spirituality is a task fraught with complexity, nuance, and diplomacy. It is one thing to describe the typical physical characteristics of early adolescent development, although painful and confusing at the time one goes through them; the physiological shifts of the human body are accepted within academia as something knowable, and by implication, describable, in empirical terms (e.g., Lerner, 2006). Situating spirituality within an academic context, however, is much more controversial. The literature describes why this is so: a fear of invoking resistance (DeBlasio, 2011; Kessler, 2000), the difficulty of describing spirituality in developmental terms (Nakkula \& Toshalis, 2006), and the perception that spirituality 
involves indoctrination of religious dogma (Tacey, 2006), among others, which I

address in my review of the literature on spirituality and education.

In his dissertation on the relationships between spirituality and ELL pedagogy, Bradley (2011) used Palmer's (1998) rationale for the importance of having a definition of spirituality, even one that is imprecise: “...it performs a key function of any good definition by giving us a place from which to launch an exploration" (Palmer, 1998, p. 377). My exploration attempts to respond to Kessler's (2000) epochal question: “The most important challenge has always been not whether we can address spiritual development in secular schools but how," (p. ix, author's emphasis). Part of the how is clarifying what is meant by the terms spirituality and spiritual development in an educational context.

I reviewed theoretical, empirical, and historical literature about spirituality and spiritual development for definitional guidance. (A more detailed review of this literature also follows in the next chapter.) I immediately ran into a problem: the terms "spirituality" and "spiritual development" were often used interchangeably (e.g., Wintersgill, 2008). This transposition became problematic for me as I sought definitional clarity in the literature. Initially I used them interchangeably myself; however, further review of the literature yielded a more precise distinction between the two.

Spirituality is an embedded, universal human quality that reflects how the self relates with and is concerned with matters of the spirit: a sense of awe and wonder, a sense of being connected with something greater than oneself, a sense of reverence and mystery (Miller, 2007). Identifying or describing a person's spirituality is examining that person's orientation towards issues of transcendence, ultimate concerns, and intimate 
beliefs. Theoretical models of spirituality can involve factors such as the essence of (self) awareness; interconnectedness with humanity, nature, and the cosmos; and a relationship with an Ultimate Other (Hamilton \& Jackson, 1998).

Spiritual development is a dynamic process of human development. This process involves an evolution of knowing one's purpose, experiencing interconnectedness, and discovering meaning. The study of spiritual development is within the jurisdiction of the science of human development. Spiritual development is conceptualized as a stagestructural theory (e.g., Fowler, 1981) and as a developmental systems theory (e.g., Lerner, 2006).

Many authors made an explicit distinction between spirituality and religion (e.g., Hay, Reich, \& Utsch, 2006; Johnson, 2008; King \& Benson, 2006; King \& Roeser, 2009; Orr, 2005; Revell, 2008; Scott, 2006). Tacey (2006) conceptualized spirituality as a bridge to religion, after frequently observing his college-level students specify that they were spiritual, but not religious. Tacey argued that a definition of spirituality emphasizing critical thought, self-reflection, and direct experiences of the sacred belongs in educational contexts. He explained the rise of interest in spirituality in secular venues along similar lines of logic that Kessler (2000) and Palmer (1998) used: spirituality is there all the time whether we name it or not and will make itself known. As Tacey wrote, speaking of a Western cultural context: "Secular society alienates people from traditional religious forms, but it cannot entirely alienate people from their souls" (p. 204).

That said, the overlap between religion and spirituality as theoretical constructs has practical considerations in the United States and therefore for my research. According to the Pew Forum on Religion and Public Life (2008), approximately $80 \%$ of the adult 
population in the U.S. identifies as a member of a religion. The First Amendment of the U.S. Constitution prohibits the state from establishing any religion. The Establishment Clause has been applied to public education in several key Supreme Court decisions in the later half of the $20^{\text {th }}$ century (e.g., Everson v. Board of Education, 1947; McCullom v. Board of Education, 1948). Recently, the school district of Encinitas, California was sued for violating the Establishment Clause by teaching yoga as part of its physical education program. Some parents were concerned that yoga promotes Hindu religious beliefs. Because of the legal issues and cultural biases at stake, it is crucial in my research that I am clear in my distinction between religiosity/religious development and spirituality/spiritual development.

King and Roeser (2009) observed "debate over the substantive and functional distinctions between religiousness and spirituality is one of a number of central challenges...that bears centrally on developmental science theories of religious and spiritual development" (p. 440, authors' emphasis). In their review of the literature on the distinctions between the two constructs, they advocated for an approach used by Koenig, McCullough, and Larson (2001): to research religion at the societal level and to research spirituality at the individual level. As such, individuals can have a spirituality that is "moored" to specific religion or a spirituality that is "unmoored" to a specific religion (p. 18). But to study spirituality does not automatically mean to study religion. The point is that religion and spirituality are overlapping but not synonymous constructs, and I do not treat them as synonymous in my research of the educational relevance of spiritual development as a curriculum and instruction issue. 
Given the data about religious affiliations in the U.S., the Establishment Clause

of the Constitution, and the complexity of distinguishing between religion and spirituality in a Western cultural context, I see the definitional issue as inexorably linked to the education relevance issue. How can middle grades teachers apply their knowledge of young adolescent spiritual development, if desirable, if they are unclear about what is meant by spirituality and/or spiritual development? While the empirical and theoretical literature suggests a nascent consensus on an operational definition of spirituality and spiritual development in the fields of psychology (e.g., Benson, 2006) and nursing (e.g., de Jager Meezenbroek, Garssen, van den Berg, Tuytel, van Dierendonck, Visser, \& Schaufeli, 2012), the literature on middle grades education does not reflect the same level of understanding and acceptance.

The field of middle grades education. The education of young adolescents, youth who are 10 and 15 years old, in the United States has only relatively recently been considered worthy of special distinction and attention. The field of middle grades education emerged with its own identity in the 1960s, with an increased understanding of the unique developmental characteristics of young adolescents (Lounsbury \& Vars, 2003) and dissatisfaction with the junior high program (Smith \& McEwin, 2011). Evidence abounds of the field's emergence as an authority on curriculum and instruction, teacher education, teacher certification, school organization, and building and district leadership. For example, 46 U.S. states and the District of Columbia offer licensure or endorsement for the middle grades as a level distinct from elementary and secondary education (McEwin, 2007). The movement to recognize the middle grades as distinct from elementary and secondary education emerged from a combination of leadership from the 
field of higher education and the day-to-day experiences of middle school principals and classroom teachers (Erb, 2006). George (2009) described the rise of the middle grades concept as a grassroots movement, with a national leadership evolving out of a need for greater coordination of regional efforts to improve middle grades schools. In the years since 1963, when William Alexander first called for the term middle school to be used as a replacement for junior high school (Alexander, 1963; Lounsbury \& Vars, 2003), several national organizations, such as the Association for Middle Level Educators (AMLE, formerly known as the National Middle School Association) and the National Forum to Accelerate Middle Grades Reform, have provided professional networks for administrators, practitioners, and researchers. National organizations have also tried to influence policy at federal, state, and local levels, with some success in the 1970s and 1980s (Toepfer, 2011). These efforts have had mixed long-term results, with many of the central components of the middle grades movement (e.g., common planning time for teamed teacher cohorts) jeopardized by technocratic federal and state educational policies (e.g., No Child Left Behind). Also, the U.S. Department of Education, despite lobbying efforts by the AMLE, still only recognizes two levels of K-12 education-elementary and secondary. One major advocacy organization, the National Association for Secondary School Principals, recognized the middle level distinction by issuing a position paper about leadership practice as it relates to the middle grades (NASSP, 2006). To date there is not a national principals' organization for the middle grades although the AMLE has an inclusive membership of administrators, teachers, researchers, and teacher educators.

The field of middle grades education is an example of a reform movement in education. The reform goal was to improve leadership, organization, and instruction for 
middle grades students by advocating for developmentally appropriate practices

(Carnegie Council on Adolescent Development, 1989). The movement's main criticism of education for young adolescents in the first half of the $20^{\text {th }}$ century was that it did not address the unique developmental needs, interests, and abilities of students of ages 10 and 15 year olds as a critical period of development. In their position papers, four of the major middle level advocacy groups make frequent references to the developmental characteristics of young adolescents. In the following section, I describe the ideas drawn from the developmental sciences for application by middle grades reform advocates. In the literature review, I address specific developmental theories that correspond to how middle grades advocates have interpreted the implementation of developmentally appropriate practices.

Middle grades connection to the field of developmental psychology. Human development theory informs and guides practice with young adolescent students. This is not to argue that developmental theory is of more importance in the middle grades as it might be in other grades. The danger lies in not distinguishing between children, young adolescents, and older adolescents when considering pedagogy. Nakkula and Ravich (1998) used the term applied developmentalists to describe how middle grades teachers should approach their professional practice. When applying human development theory to middle grades education, the typical characteristics of intellectual, social, emotional, psychological, moral, and physical changes are used to inform school-related practices such as assessment, curriculum, instruction, leadership, and organization.

For example, one of the key social developmental needs and interests of young adolescents is interpersonal engagement (Eccles \& Roeser, 2009). An implication for 
practice within the classroom is the incorporation of learning activities that involve a

high degree of peer collaboration (Caskey \& Anfara, 2007). An implication for school organization is a regular advisory program in which student gatherings are guided and supported by teachers who are knowledgeable about young adolescents (NASSP, 2006; NMSA, 2010). An implication for building-level leadership is principals who engage directly with students in frequent, informal, and collegial ways (Gentilucci \& Muto, 2007).

Eccles and Roeser (2009) framed the relationship between developmental theory and educational practice within the stage-environment fit theory (Eccles \& Midgley, 1989). They posited that a good match, or fit, must exist between the learner and his or her social environment to facilitate academic motivation, engagement, and growth. A significant implication of this theory, as middle level advocates have argued for decades, is that a poor fit between young adolescents and their school context has disastrous consequences in the short and long term (Eccles et al., 1993). Mental health problems, adjustment difficulties, and problem behaviors faced later on as older adolescents and young adults have their roots in young adolescence (Eccles et al., 1993).

\section{Problem Statement}

Alienation in the middle grades. My primary audience for this research is the field of middle grades education. There are many good reasons to focus on the middle grades. The middle grades are seen as a critical and transformational period (e.g., NASSP, 2006). Outcomes impacted by the middle grades experience include college readiness and success (Balfanz, 2009), opportunities to catch up, especially for low- 
income and minority students (Bondy \& Ross, 2008), and integration of health-

promoting behaviors (Feldman, 2008).

A current problem in the middle grades is the alienation of students. Middle grades students experience a deep perception of disconnection within the context of their formal education in public schools in the United States. The alienation of many young adolescents in middle grades schools as a phenomenon has been well documented (Beachum, Dentith, McCray \& Boyle, 2008; Daniels, 2005; Juvonen, 2007; Lee \& Smith, 1993; Osterman, 2000). Reasons for their alienation range from instructional strategies that do not provide opportunities for dialogue and discourse (Juvoven, 2007) to organizational practices such as "ability-based" tracking and departmentalization (Osterman, 2000).

In my analysis of the literature on young adolescents and their need for belonging in their school context, I identified the causes and conditions of belonging, and its near enemy, alienation. From that analysis, I came to the conclusion that the absence of the spiritual development of middle grades students within the foundational literature on middle grades education is problematic. I made this connection between alienation and spiritual development through analyzing the specific recommendations made by middle grades advocates for promoting a sense of belonging (e.g., NMSA, 2010). These recommendations, such as using strong relationships to foster and promote a culture of learning, were justified by invoking students' developmental needs. Each specific recommendation was strengthened when teachers and administrators were addressing the developmental domains as a holistic entity. Using the same logic as middle grades advocates, the impact of the developmental model could be strengthened with the 
inclusion of the spiritual needs, interests, and abilities of young adolescents. I saw that potential most clearly when studying belonging.

I highlight some of the ways in which alienation manifests, as well as some of the reasons for this problem. This review is not meant to be an exhaustive summary of the problem. I have limited my scope to the aspects of alienation that are most directly benefited by a middle grades concept that explicitly includes the spiritual domain.

In the developmental sciences, spiritual development is considered a component of human psychology (Roehlkepartain, Benson, King, \& Wagener, 2006). The psychological health of middle grades students is threatened by the phenomenon of alienation. As the second leading cause of death amongst adolescents, suicide is one of the most threatening consequences of alienation; the link between alienation and "various forms of emotional distress including loneliness, violence, and suicide" (Osterman, 2000, p. 343) is established in the literature (Nichols, 2008). A lack of belonging is associated with other at-risk behaviors such as drug and alcohol abuse, nicotine use, absenteeism, cheating, and/or associations with negative peer groups (Nichols, 2008; Osterman, 2000; Roeser et al., 2000). In her review of the literature, Nichols (2008) found that "the consistent finding that belonging is inversely related to negative belief systems...suggests that belonging may be a critical variable that contributes to students' capacities to adapt to school cultures in psychologically positive ways" (p. 148).

Middle grades students are aware of their own experiences of alienation and the importance of their perception of belonging in their school context. Doda and Knowles (2008) analyzed more than 2,700 middle grades student free-write essays on their school experience, collected from 30 different middle level schools in the United States and 
Canada. Doda and Knowles identified two patterns, in terms of student expectations

about their education, from their analysis of the data: middle grades students want supportive and rewarding healthy relationships with teachers and other students, as well as learning experiences that are personally relevant and challenging. However, Doda and Knowles (2008) found that the relationships the young adolescents aspired to "are the exception rather than the norm" (p. 27) and "according to the data represented here, teachers too often underestimate...the capacities of young adolescents, and, at times, use the perils of puberty to dismiss student disengagement," (p. 29).

Interpreting student disengagement as an indication of a student's personal failings (i.e., lack of effort, poor moral fiber, bad upbringing) is one frame through which to develop strategies for increasing engagement. From the perspectives of the students in Doda and Knowles (2008) study, it is a lens through which student behavior is commonly viewed. Osterman (2000) offered an alternative: what if student disengagement and alienation was an indicator of the failings of the schools to provide for the basic psychological needs of, in this case, young adolescents? This shift in perspective is a crucial one to explore in terms of the problem of alienation of middle grades students, as many in the literature (Juvoven, 2007; Lee \& Smith, 1993; Osterman, 2000) strongly argued for middle level schools as the best place to focus on how students experience belonging.

Another way in which alienation is negatively affecting young adolescents relates to their academic achievement. In her review of the literature on student belonging at all three levels of K-12 education, Nichols (2008) found that "although it is not always evident, some researchers found that belonging beliefs relate significantly to achievement 
in middle school settings" (p. 148). Academic achievement is impacted by student perceptions about their academic life. While the literature does not indicate a direct relationship between belonging and academic achievement, it does suggest that alienation inhibits motivation for academic pursuits (Nichols, 2008; Osterman, 2000; Roeser et al., 2000).

A sense of connection to teachers has a stronger relationship with academic achievement than a sense of connection with peers or family (Osterman, 2000): "How students feel about school and their coursework is in large measure determined by the quality of their relationship with their teachers in specific classes" (p. 344). Palmer (1997) also found that when he asks people to describe good teachers, responses vary in terms of the techniques teachers used, "but all of them describe people who have some sort of connective capacity, who connect themselves to their students, their students to each other, and everyone to the subject being studied," (p. 27, author's emphasis). Palmer's observation, made in the context of his larger work on the spirituality of teachers, invokes one of the three elements of spirituality—a sense of interconnectedness with humanity.

For middle grades students, experiencing belonging is a developmental need that contributes to their psychological health, their level of engagement in school, and their academic achievement. While addressing the social, emotional, psychological, and moral developmental domains when designing curriculum and instruction can go a long way toward decreasing alienation and increasing belonging (Durlak, Weissberg, Dymnicki, Taylor, \& Schellinger, 2011; Jewett, 2009; Juvoven, 2007; Van Hoose et al., 2001), I 
argue that the exclusion of the spiritual domain is a failure to take full advantage of the middle grades reform concept of a developmentally responsive education.

Domain of spiritual development is missing. The second problem I have identified in the field of middle grades education is the exclusion of the spiritual domain of human development from the middle grades concept of developmentally responsive education. I see this exclusion as related to the problem of alienation. A more holistic approach to developmentally responsive middle grades education, one that explicitly includes spiritual development, could be a way to reduce student experiences of alienation. In framing this problem in the field of middle grades education, I conceive of spirituality as a developmental resource (Nakkula \& Toshalis, 2006), and see the middle grades concept as reflective of the stage-environment fit component (Eccles \& Midgley, 1989) of developmental systems theory.

I think the question about including the domain of spiritual development as a curriculum and instruction issue reflects epistemological debates about how students learn, as well as the regulatory relationship between power and knowledge production (Kincheloe, 2008; Popkewitz, 1991). Believing only two ways of knowing count in a classroom-empirical and rational—discounts the immense value of instruction that address what Hart (2004) called, the "third" way of knowing: how learners draw upon intuition, emotion, creativity, and sensation. Hart categorized this third way of knowing as contemplative or spiritual. In other words, middle grades instruction looks one way if teachers are only targeting empirical and rational ways of knowing, and looks another way if they are leveraging students' spiritual ways of learning. I argue that a holistic consideration of the middle grades concept can increase the ability of middle grades 
students to fulfill their potential as human beings through academic achievement and student engagement.

Today, the field of middle grades education, like the students it serves, needs to use all of its resources to face significant challenges. Perhaps the most daunting challenge to the middle level concept, with its emphasis on meaningful relationships, is the federal emphasis on accountability as measured by standardized, high-stakes assessments (Greene et al., 2008; Juvoven, 2007). Another challenge comes from the field of teacher education. Many schools of education reflect state licensing policies and offer their students a choice between an elementary program and a secondary program, with few electives that focus on the middle grades (Caskey, 2003). Organizing teacher preparation programs in this way impedes the cultivation of a middle grades teaching force that values young adolescents and is specifically prepared to do so (NMSA, 2010). Successful implementation of developmentally appropriate practices is challenged on many fronts: emotionally distant adults, outdated fidelity to 42 -minute class periods, punitive restrictions on lunchtime behaviors, and limited opportunities for public celebration of success (Van Hoose et al., 2001). In my view, it is crucial that middle grades educators explore and embrace a more holistic developmental theory that can address these challenges.

Van Hoose, Strahan, and L'Esperance (2001) used the musical metaphor of harmony to characterize a developmentally appropriate fit between young adolescents and middle grades school practices. In my research design, I also employed a musical metaphor. As part of my analysis of the data, I integrated the metaphor of counterpoint, a compositional technique in music that uses interdependent harmonies to create polyphony 
of melodic interaction. In my metaphor, the interdependent features are the paradigms of

the middle grades concept, spirituality as a developmental domain, and holistic education. With that, I introduce my rationale for using historiography by explaining how I came to connect my research purposes and questions with this uncommon methodology.

\section{Research Purposes and Design}

Research purposes and questions. My overarching research purpose was to understand more explicitly the educational relevance of spiritual development, specifically as a curriculum and instructional issue in the middle grades. I was also motivated by the following purposes: (a) to understand how the inclusion of spirituality as a domain in early adolescent developmental theory manifests in teacher practice; (b) to situate spirituality as a developmental domain within a developmentally responsive pedagogical framework; and (c) to understand how practicing teachers perceive the educational relevance of spirituality. I used my literature review to learn more about the theoretical literature related to these three purposes, and to learn more about how related fields researched questions that reflected my own research purposes.

The lack of research literature on the educational relevance of spiritual development in education in general, and regarding spiritual development at the middle grades in particular, is documented (Roehlkepartain et al., 2006). In addition to cultural and political resistance for locating spirituality within education, another contributing factor is the challenge associated with using established research methodologies to study spirituality in education (Benson, 2004, 2006). An additional methodological challenge is designing research that is culturally-sensitive to take into account the socio-cultural effects on spiritual development (Nicholas \& DeSilva, 2008). As Borgman (2006) 
observed, "Moving from opinions to behavior to morals to spirituality poses increasing

levels of difficulty for social scientists. A wide range of research techniques and disclaimers is required to get at perplexing problems in and between human beings" ( $\mathrm{p}$. 436). Despite these challenges, a growing body of empirical literature on spirituality in education exists. Examples are reviewed in the next chapter, with particular focus on the literature on adolescent spiritual development.

What I noticed in the literature was an absence of a rigorous interrogation of the interrelationship between human development theories, middle grades education, and spirituality/spiritual development. I read literature that addressed each of those three fields independently, but none that explored (theoretically or empirically) the conceptual space between and among the three academic fields.

Noting the absence of such literature, I became curious along critical (McLaren, 2009) lines of inquiry. I explored my curiosity by posing hunch-inspired questions that led, eventually, to my research questions. I wondered, what social and/or political factors contribute to this absence in the literature? Who benefits from a developmentally based model of middle grades education that neglects the spiritual domain of development? Who benefits from a model of human development that does not include spirituality? Who is harmed through this omission in theory and practice? Historically, what has led to this absence? What has led me to imagine a middle grades concept that explicitly incorporates the spiritual domain?

While exploring these questions, I reflected upon how my cultural identity influences my choice of research questions and methodology. As an upper/middle class White female teacher, I am an insider in the field of education. I take for granted many 
practices in education, such as the dominance of critical rational epistemologies and positivist research methodologies, because they align with the values, perspectives, and assumptions of my cultural and economic background. These practices are invisible to me, and I am less likely to interrogate them because they seem natural and normal. Yet, as Rury (2006) argued, new interpretive stances in educational research are important because they offer different ways of thinking about and practicing education.

Research design. In the course of designing this research, I was influenced by my review of the literature, as well as preparations for a teacher training I volunteered to conduct in Nepal. In this section, I describe how both experiences influenced my research design.

During the months I was reviewing the literature, I was mostly aware of research methods that reflected academic approval in the field of education such as statistical analysis (e.g., Muijs, 2011), case study (e.g., Yin, 2009), and ethnography (e.g., Wolcott, 2008). Although I did not encounter Kincheloe's (2008) Critical Constructivism until I began to read more deeply on critical historiography as a research methodology, this quotation from his chapter on research describes my stance during my literature review: "Critical constructivism openly attempts to subvert the researcher's perception of her stable location in the web of reality" (p. 120). As an attempt to subvert my perception, I volunteered as a teacher trainer in Nepal during the summer of 2011. I partnered with an NGO run by Nepali teachers and administrators. My hope was that being an outsider in another country's educational system would allow me to become aware of new approaches to conceptualizing and researching spirituality in U.S. education. I chose 
Nepal intentionally, a nation without the same kind of cultural distinctions between secular and spiritual human activities that are made in the United States.

The initial stages of my turn from field-based research methods (such as grounded theory and case study) to study my research question toward a conceptual methodology of research began during my preparations for Nepal. As I sought to co-construct professional development curriculum that would be relevant and desirable to the Nepali teachers, I used historical (e.g., Lohani, Singh, \& Lohani, 2010) and historiographical literature (e.g., Carney \& Bista, 2009) on educational reform in Nepal to inform my preparation. The literature was helpful not only in terms of providing historical background, but also in terms of identifying prominent paradigms that influenced educational policy and practice in Nepal. Knowing more about guiding paradigms proved essential to my professional work as an educator in Nepal because that knowledge provided me with some keys to understanding unfamiliar interactional dynamics. For example, during the teacher training I experienced confusing interactions with my male co-facilitator and with male workshop participants. Knowledge of prevalent paradigms influencing the importance of male authority in Hindu Nepali families and the related concept of teacher as guru, or spiritual guide helped me negotiate those interactions.

Returning to my doctoral work, I wrestled with imposing field-based research methods on my research purposes. I recalled the utility of historiographical approaches to inquiry as a means of providing me with the kind of clarity that contributed to the effectiveness of my professional interactions in Nepal. Encountering Popkewitz's (1997) metaphor of scaffolding as a means of conducting historiography helped me understand 
the potential of conceptual research methods for this study. His analogy is expressed in

the following passage, which I rewrote as a poem:

My traveling

Among different sets of ideas

Is to think of them

As part of a scaffolding

To think of them

As a grid or overlay

Of historically formed ideas

Whose pattern

Gives intelligibility

To today's debates

(Popkewitz, 1997, p. 18)

My "different sets of ideas" is the gathering of holistic education, spiritual development, and the middle grades concept. I was looking for any pattern that is created when I laid their historiographies over each other in the hopes that doing so would "give intelligibility to today's debates."

Integration of the personal with the professional. The work represented in this research is a result of almost 20 years of reflective practice as a classroom teacher, administrator, and emergent scholar. Five years into my teaching career, I began to notice how a personal mindfulness meditation practice was having a positive effect on my professional practice. I observed in myself more ease, more joy, and an increased ability to respond effectively to the challenges of working with young adolescent learners. 
Because I conceive of meditation as a spiritual practice, I became curious about how the spiritual development of a teacher affects her professional performance. Later in my career when I was an administrator in a middle grades school, I also became interested in the study of how a teacher's knowledge of adolescent developmental issues affects student learning. As I saw less distinction between my personal and professional identities, my work as an educator came from a less fragmented orientation, and my students and colleagues seemed the better for it. The works of hooks (1994, 2003), Palmer (1998), Bateson (1994), Mezirow (2000), Miller (2007), and Kessler (2000) shaped and informed how I conceptualize the relationship between spirituality as a developmental domain and the implementation of the middle grades concept.

The connection between how the personal experiences of teachers is woven into the fabric of their professional pedagogy is one that has been explored before (Palmer, 1998). My work differs from Palmer's (1998) in that I situate human developmental theory within the dynamic between the personal and professional aspects of teaching. My positionality is well-expressed by Nakkula and Toshalis (2006), whose work on the middle grades concept includes a rare reference to students' inner lives:

A constructionist perspective argues that people work with one another in creating development... development is conceived of as fundamentally relational. [This approach] is intended to help educators recognize how their own development, professional and personal, is affected by their relationships with students...From this perspective, the core meaning of adolescent development lies fundamentally in the interpretations adolescents make of themselves and their worlds. It argues that the 
meaning they make of their experience is theirs, and that we as educators

can play key roles in the meaning youth make of their lives, just as they

can play that role in the meaning we make of ours. (p. x-xi)

I have an earned respect for the courage, confusion, and curiosity of students who are 10 to 15 years old. My hope is that this research can offer an increased awareness of the inner resources students have always possessed and direction for middle grades teachers who understand and value the inner life.

My experiences as a student and as an educator support my use of critical historiography as a dissertation research method. Critical historiography complements my own positionality regarding the social construction of written history. As someone who was educated in history and historical methods in the poststructural era of the 1980s and 1990s, and who has taught middle and high school level history classes since 1994, I approach the study of history as a highly complex, socially mediated endeavor regulated by power relations. Also, my approach aligns with the critical historiographical privileging of the interrelationship between past, present, and future. I agree wholeheartedly that a critical knowledge of the past can empower and mobilize transformative action for a more just and equitable future (Villaverde, Kincheloe, \& Helyar, 2006). My support of such a position has been one of the motivating forces for my work as an educator with adolescents, a group I have found to be delightfully ambitious in their quest for justice and fairness.

I have long believed that how people understand current challenges and victories strongly shapes how history is constructed and transmitted (e.g., Henry, 2006). Perhaps this is especially true in education (e.g., Rury, 2006), where contemporary policy 
discussions reframe or ignore past reform movements in an effort to persuade the public of the necessity of the most current reform policy. Kaestle (1997) argued for the connection between contemporary perspectives and historical writing in his historiography of education history. Although Kaestle is not writing from a critical perspective, his conclusion about the value of historiography as a method in educational research affirms my researcher's goal of transformative collective and individual empowerment.

\section{Outline of Dissertation}

The problem I have identified in the field of middle grades education is the exclusion of the spiritual domain of human development from the middle grades concept of developmentally responsive education. I see the exclusion as a problem, given the potential of a more holistic approach to developmentally responsive middle grades education as a way to reduce student experiences of alienation. To address this problem, I am investigating the question: What is the educational relevance of spiritual development in middle grades education? The two subquestions I also addressed in my inquiry were:

a) What prevalent paradigms underlie the academic discourse on spirituality as a developmental domain, the middle grades concept, and holistic education?

b) What are the inter-textual and inter-discursive relationships within the convergence of the paradigms of the three fields?

In framing the research questions, I focused on literature in three fields: (a) applied developmental theory; (b) middle grades education; and (c) spirituality and spiritual development. In Chapter Two, I re-present this literature as three overlapping fields, with the creation of three inner fields that result from my re-presentation. The 
three inner fields are: (a) spirituality as a domain of human development; (b) the middle grades concept; and (c) holistic education, which explicitly situates spirituality as relevant to education (e.g., Miller, 2007).

In Chapter Three, I describe in detail my research paradigm of critical constructivism (Kincheloe, 2008), and how my research questions befit an interdisciplinary, conceptual research design. After a general explication of historiography as a methodology in educational research, I define how I am using the term paradigm as a unit of historiographical analysis in this research. I describe the principles and techniques of critical historiography (Henry, 2006; Rury, 2006; Villaverde, Kincheloe, \& Helyar, 2006). Finally, I provide a detailed account of the processes and issues of my data collection and analysis strategies.

Chapter Four is a narrative-based rendering of the results of my analysis for prevalent paradigms and inter-discursive patterns within and amongst the three (hi)stories of the middle grades concept, spirituality as a developmental domain, and holistic education. This chapter is divided by the two research subquestions: (a) 15 narratives of the paradigm categories, and (b) the conceptual contents of the nexus of the three fields.

In Chapter Five, I discuss the conclusions I reached based on the results described in Chapter Four. In that discussion, I focus my conclusions on articulating the educational relevance of the spiritual domain of development for middle grades education. In the second part of Chapter Five, I offer implications for practice in middle grades education. I also address implications for historiographical research in education, given the rarity of its application as an educational method. 
I conclude this dissertation by reflecting on the transformative experiences I

encountered in the course of conducting critical constructivist research, summarizing the potential application of this work for the field of middle grades education, and exploring the purpose of education as it relates to the results of this research. 


\section{LITERATURE REVIEW}

How and why [spiritual development] happens, and how and why it gets compromised, remain mysteries. Mystery may be an interesting part of spiritual development. But, keeping it a mystery in the academy is shortsighted, irresponsible, and compromises our understanding of what it means to be human. (Benson, 2006, p. 494)

\section{Conceptual Framework of the Related Literature}

In my process of designing a literature review, the two fields that seemed most relevant were middle grades education and spirituality/spiritual development. As I read in those two fields, I noticed a gap; the literature on middle grades education rarely included spirituality as a relevant developmental domain, and the literature on spirituality and spiritual development rarely addressed the middle grades. I also noticed an interesting linguistic issue: in the middle grades literature, phenomena that were categorized as moral, social, and/or emotional topics were identified in the literature on spirituality as spiritual issues. For example, an adolescent's exploration around having a sense of a greater purpose was labeled in the middle grades literature as a socio-emotional issue (e.g., Van Hoose et al., 2001), while it was considered spiritual phenomena in the spiritual development literature (e.g., Fowler, 1981).

For the fields of middle grades education and spirituality/spiritual development, a related literature is human developmental psychology. In this chapter, I re-present the literature from those three fields as overlapping circles. Figure 1, as a conceptual model, illustrates the relationships between the fields. 


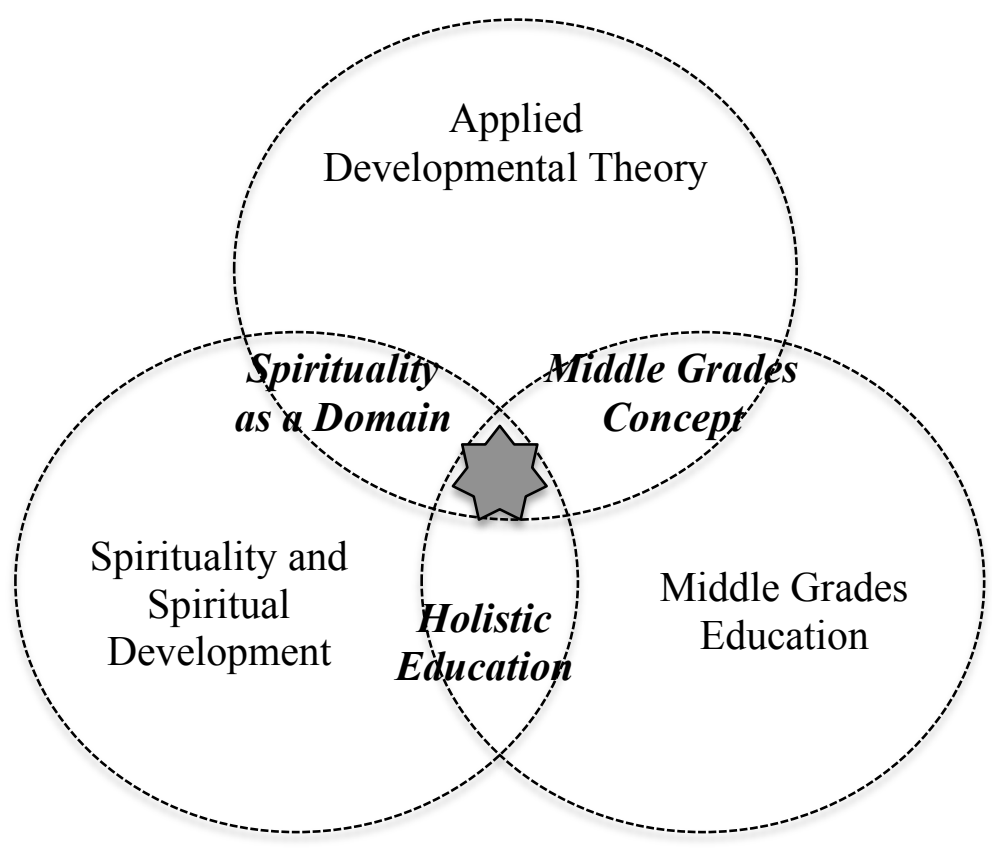

Figure 1. Conceptual model of relevant literature. This Venn diagram shows the fields of literature read for this review. It also re-presents my conceptual framing of the relationships between the related fields.

Three inner fields become visible in my conceptual model in the areas of overlap: the middle grades concept, spirituality as a developmental domain, and holistic education. My research interprets for the conceptual contents of the convergence of the three inner fields.

This chapter begins with the literature on the middle grades concept, with an emphasis on the field's foundational belief in the educational relevance of the developmental characteristics of young adolescents. The section is not meant to be an exhaustive review of the literature on middle grades education. Rather, I use this section to introduce and explain how human development theories have influenced and informed what is considered to be exemplary middle school practice - the middle grades concept of developmentally appropriate education. 
In the second section of this chapter, I highlight efforts to craft and refine

definitions of spirituality and spiritual development within the context of the scientific study of human development. Such work attempts to identify patterns and describe processes of spiritual development. I explore two developmental frameworks are employed in this field: stage-structural theory and developmental systems theory. Finally, I speak to a call in the literature for spiritual development research and theory that is culturally responsive.

The third inner field of my conceptual model is holistic education. Holistic education is a field that describes itself as explicitly inclusive of spirituality. I describe the linkages and distinctions between holistic education and social-emotional education, then describe the ways in which spirituality is conceptualized as educationally relevant within the holistic framework.

I conclude Chapter Two with a review of the literature on research methods used to study spiritual development, as well as the findings generated by that work. I first review empirical studies conducted within the field of developmental sciences, then describe studies conducted on spirituality in an educational context.

\section{The Middle Grades Concept: A Developmental Framework}

In this section, I describe recommendations made by middle grades advocates. The middle grades concept links theory with practice and emphasizes the needs, interests, and abilities of young adolescents. Then, I explore the applied developmental theories that influence the middle grades concept. The concept of developmental appropriateness in an educational context has connections to developmental stage theory (e.g., Piaget, 1967) and developmental systems theory (e.g., Eccles \& Midgley, 1989; King \& Benson, 
2006; Lerner, 2006; Search Institute, 2011). I then synthesize the main sources of challenge to full implementation of the middle grades concept in public schools in the United States.

Middle grades reform. The field of middle grades education in the last 60 years has reflected the following set of positions: (a) young adolescents, ages 10 and 15 years old, have developmental characteristics that are distinct from those of young children and older adolescents; (b) educational practices should be tailored to developmental theory; and (c) middle grades schools should, therefore, be developmentally appropriate in terms of instruction, curriculum, organization, leadership, and school climate (George, 2009; Jackson \& Davis, 2000; NASSP, 2006; National Forum to Accelerate Middle Grades Reform, n. d.; NMSA, 2010). Advocates of the middle grades concept believe that middle grades teachers should be knowledgeable about the developmental characteristics associated with young adolescents, and should teach with that knowledge in mind. This section describes these characteristics and their corresponding applications in middle grades education.

Developmental theory and recommended practice. In aligning specific practices with young adolescent developmental theory, much of the literature describes the characteristic developmental traits for the cognitive, social, emotional, psychological, physical, and moral domains (Caskey \& Anfara, 2007; Roeser et al., 2000; Van Hoose et al., 2001). The characteristic markers for young adolescents (Caskey \& Anfara, 2007) are summarized in Table 1. 
Table 1

Developmental Characteristics of Young Adolescents

\begin{tabular}{|c|c|}
\hline Developmental Domain & Typical Characteristics \\
\hline Physical Development & $\begin{array}{l}\text { - Refinement of fine and gross motor skills } \\
\text { - Rapid physical growth } \\
\text { - Biological maturity }\end{array}$ \\
\hline Intellectual Development & $\begin{array}{l}\text { - Increased capacity for abstract, conceptual } \\
\text { thought patterns and problem-solving } \\
\text { - Builds upon prior knowledge and experiences to } \\
\text { develop broader conceptualization of the world } \\
\text { - New artistic, recreational, and academic interests } \\
\text { emerge frequently and can change rapidly }\end{array}$ \\
\hline Moral Development & $\begin{array}{l}\text { - Developing ability to make choices based on an } \\
\text { emerging consciousness of personal values, } \\
\text { principles, and ethics } \\
\text { - Moving from being mostly self-centered to an } \\
\text { awareness of the needs and perspectives of } \\
\text { others } \\
\text { - Interest in wrestling with moral dilemmas } \\
\text { - Beginning recognition of cause and effect in } \\
\text { personal behaviors }\end{array}$ \\
\hline $\begin{array}{l}\text { Emotional/Social } \\
\text { Development }\end{array}$ & $\begin{array}{l}\text { - Increasing need to experience an authentic sense } \\
\text { of belonging to a group, usually a peer group } \\
\text { - Adult authority (especially parental) is } \\
\text { challenged in immature ways, at the same time } \\
\text { affirmation, approval, and/or recognition from } \\
\text { significant adult figures (such as teachers) is } \\
\text { sought }\end{array}$ \\
\hline Psychological Development & $\begin{array}{l}\text { - Self-centered without much perspective: } \\
\text { sensitive to criticism, lack self-esteem, believe } \\
\text { personal experiences and feelings are unique } \\
\text { - Erratic moods and inconsistent behavior } \\
\text { - Exploring independence from parents and } \\
\text { conceptualizing their own potential adult identity }\end{array}$ \\
\hline
\end{tabular}


An example of how developmental theory is connected to practice is the

pedagogical implications of the physical developmental characteristic of rapid bone growth. Bone growth during young adolescence is not always matched by equally rapid growth in the muscular tissues, resulting in what is colloquially referred to as growing pains. The aches and pains resulting from this kind of growth can leave middle grades students feeling restless and uncomfortable, as well as making it physically painful to remain seated in hard chairs. A developmentally responsive approach to classroom instruction, especially in 80-minute block classes, would be to incorporate movement or kinesthetic learning activities. One science teacher I used to work with created a series of dance movements that symbolized the steps of the water evaporation cycle. The eighth grade students were introduced to the content through more physically passive activities, such as reading and listening to a lecture, then invited to stand and jump around making certain shapes with their bodies that represented the water cycle along with a rhythmic chant.

The main idea behind developmentally appropriate education is that students are more likely to be academically successful and possess positive perceptions of their school climate if middle grades leaders and teachers are knowledgeable about and able to address developmental needs, interests, and abilities (Hamm et al., 2010). The practices advocated by leaders in the field of middle grades education (Jackson \& Davis, 2000; NASSP, 2006; NFAMGR, 2010; NMSA, 2010) and their relation to appropriate developmental characteristics are summarized in Table 2. 
Table 2

Summary of the Middle Grades Concept

\begin{tabular}{|c|c|c|}
\hline $\begin{array}{l}\text { Educational } \\
\text { Category }\end{array}$ & Recommended Practice & $\begin{array}{l}\text { Developmental } \\
\text { Characteristic }\end{array}$ \\
\hline Teaching & $\begin{array}{l}\text { Qualified }{ }^{1} \text { middle level teachers employ a } \\
\text { variety of active learning strategies, } \\
\text { communicate high expectations for all } \\
\text { students, and differentiate instructional } \\
\text { approaches in response to student diversity. }\end{array}$ & $\begin{array}{l}\text { Seeks affirmation or } \\
\text { approval from peers } \\
\text { and adults; rapid } \\
\text { physical growth; } \\
\text { beginning recognition } \\
\text { of personal } \\
\text { responsibility }\end{array}$ \\
\hline Curriculum & $\begin{array}{l}\text { Challenging, relevant, integrative, rigorous, } \\
\text { high-standards curriculum. A variety of } \\
\text { continuous and authentic assessments } \\
\text { (summative and formative) are used to } \\
\text { promote quality learning. }\end{array}$ & $\begin{array}{l}\text { Increased capacity for } \\
\text { conceptual thought } \\
\text { patterns; new interests } \\
\text { emerge frequently; } \\
\text { builds upon prior } \\
\text { knowledge }\end{array}$ \\
\hline Community & $\begin{array}{l}\text { School community is organized to cultivate } \\
\text { safe, supportive, caring, healthy } \\
\text { relationships based on mutual respect, } \\
\text { shared purpose, and intellectual } \\
\text { development. Adults offer advocacy and } \\
\text { guidance via small learning communities. } \\
\text { Families and the greater community are } \\
\text { actively involved as partners and resources } \\
\text { for learning. }\end{array}$ & $\begin{array}{l}\text { Self-centered without } \\
\text { much perspective; } \\
\text { sensitive to criticism }\end{array}$ \\
\hline Leadership & $\begin{array}{l}\text { Participatory management model guides all } \\
\text { leadership levels: administrators and } \\
\text { teachers, teachers \& students, students \& } \\
\text { students, school personnel and families. A } \\
\text { shared vision guides decisions. }\end{array}$ & $\begin{array}{l}\text { Exploring } \\
\text { independence; } \\
\text { conceptualizing } \\
\text { potential adult identity }\end{array}$ \\
\hline
\end{tabular}

Each of the recommendations in Table 2 can be linked back to a specific developmental characteristic (or a specific combination of characteristics). For example, a differentiated instructional approach allows for the diversity in rates of developmental growth within

\footnotetext{
1 "Qualified" in this context means teachers who are knowledgeable not only about their
} 
and across the domains. Such differentiation is crucial in the middle grades, when a

potential consequence of asking a student to attempt an assessment (formative or summative) that is beyond their cognitive development can damage the student's positive self-identity as a learner.

Challenges to implementation. While the wisdom of using developmental theory as a foundation for the middle grades concept is not challenged by the field, I found evidence of ways in which implementation of the model is challenged in the United States today (Erb, 2000; Felner et al., 2007; Hamm et al., 2010; Woolley \& Bowen, 2007). Some of the challenges to implementation of developmentally appropriate practices can be addressed by a more explicit incorporation of spiritual development in teacher professional development. In my reading of the literature on implementation of the middle grades concept, I see three main ways in which it is impeded.

First, the recommendations are implemented piecemeal, as if the presence of one or two is sufficient (Erb, 2000; Lounsbury \& Vars, 2003). The problem with a piecemeal approach is that it constructs the students' needs and abilities as checklists. If we have an advisory period, we've got the social and emotion needs met - Check! If we have rigorous expectations we've got the cognitive needs met - Check! The field of applied developmental theory, as I review in more detail in the next section, suggests that human development does not work that way. While different domains of development are identified, their distinction does not imply that the domains exist in a vacuum. The developmental domains are viewed as interrelated (Caskey \& Anfara, 2007; NMSA, 2010). Instead of picturing the domains as independent silos, a more accurate metaphor would be the domains, and the practices that address them in a school context, as threads 
in a spider web (Jewett, 2009). In a web metaphor, the whole hangs together based on

the integrity of the individual strands, the strands themselves stick to each other, and there is a mysterious and luminous quality to the genius of its engineering. I see the spiritual domain as being distinct from other domains while also being interrelated. Inclusion of this domain in teacher preparation and professional development programs may help teachers and administrators envision more ways in which the domains interact with each other, especially because, as I describe in the literature on spiritual development and holistic education, one of the defining traits of spirituality is being aware of the interconnectedness in life.

Second, educational reform is often seen as a structural or organizational issue (Felner et al., 2007) not as a professional development issue (Hamm et al., 2010; Jackson \& Davis, 2000). While organizational health (Roney, Coleman, \& Schlichting, 2007) and good leadership (Leithwood, Louis, Anderson, \& Wahlstrom, 2004) are important, the effect of teacher-student relationships on young adolescents cannot be disregarded (Osterman, 2000). Simply altering structural elements of a school without also tending to the knowledge, skills, and dispositions of the teachers is insufficient. An example of this problem is how teaming, a highly recommended practice in middle grades schools, is implemented. When teachers are placed in teams without also given the necessary resources (e.g., professional development training in the co-teaching models), the efficacy of teaming is compromised (Erb, 2000; Parker, Allen, Alvarez McHatton, \& Rosa, 2010). As Juvoven (2007) reported, "Students may continue to feel isolated or disconnected even in schools that rely on teaming practices and advisory programs" (p. 198). Middle grades teachers must be supported through ongoing professional 
development as they connect developmentally responsive practices with young adolescent developmental traits.

Last, the increasing emphasis on standards-based accountability has jeopardized many of the affective aspects of the recommended practices (Juvoven, 2007; Woolley \& Bowen, 2007). Greene and associates (2008) found that in Oregon, middle grades teachers felt challenged to implement many of the elements of the middle school concept because of the pressures put on them to prepare students for high-stakes, standardized testing, even when they knew how valuable the recommended practices were in terms of academic achievement and student engagement. This last area of implementation challenge gives the inclusion of the spiritual domain a delicate, yet powerful, opportunity for application. Leveraging knowledge of young adolescent spiritual development may create openings for more holistic assessment practices, as well as a new understanding of what it means to be accountable to middle grades students.

Contributions from developmental psychology. The middle school concept emerged in part from the lived experiences of middle grades teachers (George, 2009). The recommendation that a school should be responsive to the developmental needs and abilities of its students also reflects connections made by middle school pioneers (e.g., William Alexander) to the field of applied developmental psychology. In framing what I see as the problem of alienation in the field of middle grades education, I conceive of spirituality as a developmental resource (Nakkula \& Toshalis, 2006), and see the middle grades concept as reflective of the stage-environment fit component (Eccles \& Midgley, 1989) of developmental systems theory. 
To identify the middle grades as a distinct period of human development reflects

the works of Piaget (1967), Erikson (1968), and Kohlberg (1981), each of whom articulated a stage theory of human development. The metaphor of a stage theory implies that human beings have distinct periods during which certain tasks must be resolved or accomplished to successfully progress to the next stage of development. Middle grades advocates argue that the middle grades should be treated differently from the elementary and secondary programs to facilitate successful navigation of the developmental tasks characteristic for young adolescents.

In the field of psychology, stage theory has been augmented in recent years by developmental systems theories, which emphasize the dynamic between the individual and the environment (Lerner, 2006). In this section, I summarize key aspects of developmental systems theory, and the related constructs of stage-environment fit theory (Eccles \& Midgley, 1989) and developmental assets (Search Institute, 2011). Later, I return to the stage theory model of human development in my review of the literature on spirituality as a developmental domain. The developmental systems framework is helpful in terms of understanding some of the short- and long-term implications of failing to implement the middle school concept. Some authors in the field of middle grades education have even gone as far as to describe middle grades schools that are not sensitive to the distinct abilities and needs of young adolescents as systems which are “developmentally hazardous" (Felner et al., 2007; Juvoven, 2007).

Developmental systems theory. Developmental systems theory hinges on the adaptive nature of the relationship between an individual and the community (Lerner, 2006). Adaptive, in this context, is described as health-promoting or beneficial. The ideal 
goal of this theoretical framework, in an adolescent context, is what is referred to as positive youth development (Lerner, 2006). King and Benson (2006) identified thriving as an outcome of positive youth development. King and Benson defined thriving as "more than positive functioning...A thriving young person not only grows and flourishes as an individual but also contributes to family, community, and/or society," (p. 385). The theory is that an individual adapts to his or her environment, and the environment (community, context, society, and so on) adapts based on the behavior of the individual, for the mutual benefit (and detriment) of both. As a classroom teacher, and as a student, this idea makes perfect sense to me. Students make adaptations to fit into a teacher's classroom all the time, and teachers make adaptations to their classrooms in response to the students.

Lerner, Roeser, and Phelps (2008) characterized this reciprocal relationship between self and society as one of mutual commitment: the individual commits to making positive contributions to his or her context, and the community commits to fostering an environment that is healthy for all individuals. In King and Benson's work (2006), the outcome of growth, in the developmental systems framework, is contingent upon the values of the developing subject's environment: "Youth whose interactions with their contexts are adaptive commit to a sense of identity that yields fidelity to an ideology that promotes reciprocity with their family, community, and society" (p. 386). In short, a developmental systems theory situates an individual's developmental integrity within a larger framework of integrity within a community, for the mutual benefit of both.

Using this framework to understand the recommendations of middle grades advocates, the recommended practices become the manifestations of the community's 
commitment to positive youth development. The middle grades concept emerged as a reaction against educational practices that were not adaptive enough to the needs of young adolescents. In a developmental systems framework, mutuality is a key principle. According to the middle grades advocates, for middle schools to be successful, the needs of the students and the needs of the school/community must be considered simultaneously. Their claim, along the lines of developmental systems theory, is that a developmentally responsive middle grades school will inspire students to be willing to contribute to the greater good of their communities.

Stage-environment fit theory. The stage-environment fit theory (Eccles \& Midgley, 1989), as an example of a systems theory, frames schools as social contexts within which development takes place. The implications of this theory are (a) that schools as organizations and those who work in them must be mindful of how the developmental needs of students change from elementary to middle to high school, and (b) that if policy-makers, administrators, and classroom teachers are not mindful of providing an developmentally-appropriate academic environment, students will respond in self-protective ways that inhibit or prevent full access to educational opportunities and resources (Eccles \& Roeser, 2009; Loukas \& Murphy, 2007; Mulhall, 2007). For example, an extreme self-protective response is dropping out of school. The connection between a developmentally inappropriate practice (i.e., ability-based tracking) and a selfprotective response is described by Mulhall (2007): "the images, perceptions, and interactions of lower tracked students compared to the upper tracked students...may create deeper and profound feelings of superiority, resentment, and even racism...given the sensitive nature and vulnerable feelings of young adolescents" (p. 12). 
Hamm and associates (2010) tested this hypothesis using a quantitative study in

a rural school with a professional development intervention. They concluded that "helping teachers to develop a more developmentally oriented perception of their students, and strategies to interact with students in ways aligned with students' developmental needs and level, are necessary to interventions that aim to support early adolescent school adjustment" (p. 346). While Hamm and associates identified statistically significant gains in both school adjustment and student perception of the school's social and academic climate for both Native American and White students when teachers engaged in professional development, gaps between Native American and White students were reduced more for the students whose teachers were subject to the intervention. Additionally, gains were higher for Native American students than for White students, confirming results elsewhere (e.g., Felner et al., 2007; Mertens \& Flowers, 2003; Woolley \& Bowen, 2007) about how minority students seem to benefit more than majority students from the middle school concept.

As Balfanz (2009) and others (Bondy \& Ross, 2008; Gutman \& Eccles, 2007; Juvoven, 2007; Osterman, 2000) have argued, experiences, both positive and negative, during the middle grade years serve as jumping off points for longitudinal outcomes. So, a poor fit between a middle grades student and his/her school can contribute to the emergence of serious problems further along the trajectory of his or her lifetime.

Developmental assets theory. A related extension of the stage-environment fit theory is the developmental assets framework developed by the Search Institute (King \& Benson, 2006; Scales, Benson, Leffert, \& Blyth, 2000; Search Institute, 2011). Developmental assets are resources that facilitate positive behavioral outcomes during 
developmental transition periods. The Search Institute (2011), which has been working

on its developmental assets framework since 1990, identified eight resources that are valuable during developmental growth. Four are external resources: support, empowerment, boundaries and expectations, and constructive use of time. Four are considered internal resources: commitment to learning, positive values, social competencies, and positive identity. An implied assumption of the developmental assets framework is that these assets can be cultivated; that these resources can be acquired, they are not exclusively intrinsic. The asset metaphor also implies that these traits need to be actively promoted: "The Search Institute has advanced the proposition that healthy youth development requires the investment of all people who care about youth" (Nakkula $\&$ Toshalis, 2006, p. 74). The goal of using developmental theories with educational practice, from the perspective of enhancing assets, is to create and sustain middle grades school that are resource-rich for youth who are in the midst of massive developmental challenges and opportunities (NMSA, 2010).

The developmental assets theory has been tested empirically with positive results. Scales, Benson, Leffert, and Blyth (2000) used regression analysis in a large sample ( $\mathrm{N}=$ $6,000)$ to determine the predictor effect of developmental assets on adolescent thriving. Scales and associates asserted that the developmental assets accounted for a large amount of the variance ( $47 \%-54 \%$ across ethnic groups) in thriving outcomes. They also claimed that some of the assets positively predicted more than one thriving outcome (e.g., school success). Scales and associates (2000) concluded their study with this word of caution: “These findings underscore Benson's (1997) admonition that numerous assets work both directly and in combination to account for positive adolescent development. Each 
'molecule' is necessary to ensure that the resulting whole person is more than the sum of 44 his or her deficits and assets" (p. 44). This last point reinforces the argument of other middle grades advocates (Felner et al., 2007; Jackson \& Davis, 2000; NMSA, 2010) for the importance of holistic implementation of a developmentally appropriate middle grades experience.

In sum, developmental psychologists seem to be in agreement about the holistic and deeply integrated nature of development. Two major processes of development are the interaction within an individual (Magnusson \& Cairns, 1996) and the interaction between the individual and the social context (Eccles \& Midgley, 1989; Lerner, 2006). From the perspective of an advocate for the middle grades concept, the lesson to be learned from the work of developmental psychologists is that failure to implement fully and faithfully an educational program that is designed with the needs, interests, and abilities of young adolescents breeds alienation in the short term (Bondy \& Ross, 2008), with long-term maladaptations to the demands and expectations of society (Feldman, 2008).

\section{Spirituality as a Domain of Human Development}

I now turn to the literature on spirituality as a domain of human development, one of the three 'inner' fields created by the convergence of the fields of human development theory and spirituality. In this section, I review the literature read from the developmental sciences that addresses the constructs of spirituality and spiritual development. Although the majority of my review is of work that considers the entire human life span, given the focus of this research I included a brief review of the literature on young adolescent spiritual development. 
Definitional literature. Spirituality as an accepted subject of inquiry within the

developmental sciences has been a relatively recent phenomenon. In a study of the six most significant journals on human development, no articles on spiritual development during childhood and adolescence were published between 1990 and 2002 (Benson, Roehlkepartain, \& Rude, 2003). Using the same methods, similar results were produced in a follow up study by King and Roeser (2009).

In this section, I review some of the key definitional literature on spirituality as a developmental domain. Embedded within that literature is theoretical discussion of spirituality in operational terms. Much of the literature on spiritual development, in or out of an educational context, begins with a qualification about the challenges of defining spirituality within the academy. This qualification usually precedes a clarification by the author(s) about their definition of spirituality and spiritual development. Entire dissertations have been written just on the search for a common understanding of spirituality within academia (e.g., Niederman, 1999; Van Rooyen, 2007).

Among the definitions of spirituality I read there was more overlap and similarity than difference; differences usually arose from a shift in the purpose of the text. For this review, I decided to include authors who have offered frameworks for understanding spiritual development that are particularly rich, clarifying, and/or reflect my overall purposes in this study. Based on a preliminary review of this literature, I identified authors whose work seems to be seminal in this field. This section draws almost exclusively from the developmental sciences. The next section of this chapter includes works that define spirituality in the context of education. 
Dynamics of human development. I start with the work of Peter Benson, who is by all accounts one of the founding fathers in the field of spiritual development. In his review of the definitional literature, Benson (2006) advocated for a definition that reflects the "three dynamics of human development" (p. 485): processes, outcomes, and influences. Benson captured the complexity of the distinction between "definition and theory" in the developmental sciences by characterizing their relationship to each other as "symbiotic" (p. 486). Benson defined spiritual development while at the same time attempting to establish its place within the scientific study of human development. His strategy for doing both tasks was to embed a definition within the pre-established context of human development theory. To illustrate how he used human development theory as a definitional tool for spiritual development, I have drawn upon two works authored by Benson, as seen in Table 3. Benson (2006) defended his definition of spiritual development on the grounds that it encapsulates the universality of how humans experience spirituality. 
Table 3

Benson's Definition of Spiritual Development

Human Development Dynamic

Benson, 2006, p. 485
Element of Spiritual Development

Benson, Roehlkepartain, \& Rude, 2003, p. 205 206
Central processes: "core developmental processes are at play that are deemed intrinsic to the nature of human life"

Developmental outcomes: "goals and purposes of development"

Environmental influences: "contexts than inform how developmental processes play themselves out"
"Spiritual development is the process of growing the intrinsic capacity for selftranscendence, in which the self is embedded in something larger than the self, including the sacred."

"[Spiritual development] is the developmental 'engine' that propels the search for connectedness, meaning, purpose, and contribution."

"[Spiritual development] is shaped both within and outside of religious traditions, beliefs, and practices."

Expanding upon some of Benson's seminal ideas, Roehlkepartain, Benson, King, and Wagener (2006) edited a collection of scholarly works on the spiritual development of children and adolescents. Roehlkepartain and associates set the boundaries of their collection within the following four assumptions about spiritual development:

- $\quad$ spiritual development is a universal human process

- $\quad$ spiritual development is a multidimensional, multilayered domain

- spiritual development is an ongoing, iterative process

- $\quad$ spirituality is a life-shaping force

These two works (Benson, 2006; Roehlkepartain et al., 2006) reflect the definition of spiritual development I am using in this research. I refer to spiritual development as a legitimate domain of human development, therefore subject to the same criteria for 
establishing human experiences that are developmental. This point will be expanded upon with Feldman (2008). I conceptualize spiritual development as a universal process with diverse manifestations and multiple sources of external influence. While my definition is aligned with stage-based, progressive theories of spiritual development, it also sees the developmental process as iterative - more akin to spiral metaphors than linear ones. Finally, I define spiritual development as an essential developmental process for making meaning of one's life, experiencing transcendence from self, constructing an interpretive narrative, and knowing joy, peace, and mystery.

Stage theory. In its inclusion of influences, Benson's definition seems closely aligned with the developmental systems perspectives described in the preceding section (i.e., stage-environment fit theory). However, spiritual development was initially conceived of within the tradition of stage-based theories of human development. A pioneer in developing a stage-based theory for what he termed faith development, Fowler (1981) worked with Lawrence Kohlberg, Carol Gilligan, and Sharon Parks at Harvard in the 1970s and 1980s in the fields of cognitive, moral, and spiritual development. Fowler, who like Kohlberg was influenced by Jean Piaget's staged developmental theory, proposed a faith development theory based on the progression through sequential stages. Fowler, with Dell (2006) later qualified his theory of stage progression with the caveat that human development in the spiritual domain occurs within a broader context of biological, emotional, and cognitive development and ecological influences, such as family and culturally-based gender expectations. Fowler was making explicit references to the application of his theory in an educational context long before others were (Fowler \& Dell, 2006). 
Fowler used the word faith when describing this domain of development;

however, others (e.g., Benson, 2006) have referenced him in the context of discussion on spiritual development, as I also do in this research. Like Benson, Roehlkepartain, and Rude (2003), Fowler conceived faith as not necessarily inclusive of religious beliefs and practices. He described faith development as an "unfolding pattern [that] can be characterized in terms of developing emotional, cognitive, and moral interpretations and responses. Our ways of imagining and committing in faith correlate significantly with our ways of knowing and valuing more generally" (Fowler \& Dell, 2006, p. 36). Using Benson's (2006) model for the dynamics of human development, I have highlighted key elements of Fowler's definition of faith/spiritual development in Table 4.

Table 4

Definition of Spiritual Development (Fowler \& Dell, 2006)

\begin{tabular}{ll}
\hline $\begin{array}{l}\text { Human Development Dynamic } \\
\text { Benson, 2006, p. 485 }\end{array}$ & $\begin{array}{l}\text { Element of Faith [Spiritual] Development } \\
\text { Fowler \& Dell, 2006, p. 36 }\end{array}$ \\
\hline $\begin{array}{l}\text { Central processes: "core developmental } \\
\text { processes are at play that are deemed } \\
\text { intrinsic to the nature of human life" }\end{array}$ & $\begin{array}{l}\text { "An integral, centering process, underlying the } \\
\text { formation of beliefs, values, and meanings." } \\
\text { "...relying on that which has the quality of } \\
\text { ultimacy in their lives." }\end{array}$ \\
$\begin{array}{l}\text { Developmental outcomes: "goals and } \\
\text { purposes of development" }\end{array}$ & $\begin{array}{l}\text { "Give[s] coherence and direction to persons" } \\
\text { lives." } \\
\text { "Enables [persons] to face and deal with the } \\
\text { challenges of human life and death..." }\end{array}$ \\
$\begin{array}{l}\text { Environmental influences: "contexts } \\
\text { that inform how developmental } \\
\text { processes play themselves out" }\end{array}$ & $\begin{array}{l}\text { "[Faith development] link[s] [persons] in } \\
\text { shared trusts and loyalties in a sense of } \\
\text { relatedness to a larger frame of reference." }\end{array}$ \\
\hline
\end{tabular}

Fowler (1981) acknowledged that his construct of faith might cause dissent between those who embrace the stages of faith theory on the grounds of its clinical 
application and those who, for theological reasons, resist this definition on the grounds

that it makes faith/spirituality too universal and groundless. In the context of describing this point of contention, Fowler (Fowler \& Dell, 2006) made the same case that I make in this paper regarding the educational relevance of the spiritual development (in my research, relevance as it pertains to middle grades students in particular):

The stage theory makes its contribution...by helping to match the competencies of each stage - and the operations of mind and emotion that characterize them with ways of teaching and with the symbols, practices, and contents of faith at different levels of reflective inquiry and complexity. Educators of this mind-set find faith development theory helpful for preparing persons to teach at different age and stage levels, and to match their methods and communicative practices with the groups' probable state or range of stages. (p. 43)

In this passage, Fowler and Dell (2006) articulated my research interest in the educational relevance of the spiritual domain of human development. In keeping with the overall vision of exemplary middle grades education being responsive to the developmental needs, interests, and abilities of the students, I think that explicit inclusion of the spiritual domain can help teachers design and implement curriculum and instruction that builds upon what teachers already know about human development in the biological, cognitive, and psychological domains.

Advancing Fowler's faith theory, Feldman (2008) used a set of criteria for establishing whether or not a phenomenon is developmental. This distinction is crucial in the context of situating spirituality within the developmental sciences. Feldman's criteria for developmental processes are: change is positive and qualitative, sequential, 
irreversible, large-scale and/or pervasive, has profound emotional implications, and emerges through intentional efforts. Using his criteria, he identified what he called spiritual markers establishing spiritual development as falling within the range of developmental domains. Feldman's spiritual markers are summarized in Table 5.

Table 5

Feldman's Spiritual Markers (2008)

\begin{tabular}{ll}
\hline Criteria & Spiritual Development Marker \\
\hline $\begin{array}{l}\text { Positive } \\
\text { Qualitative }\end{array}$ & $\begin{array}{l}\text { Intrapersonal, reflective understandings "expressed } \\
\text { through more mature and better explanations" (p. 187) }\end{array}$ \\
$\begin{array}{l}\text { Sequential } \\
\text { Irreversible }\end{array}$ & $\begin{array}{l}\text { Increasingly complex questions about the "great } \\
\text { questions of existence", such as the meaning of life (p. } \\
187)\end{array}$ \\
$\begin{array}{l}\text { Large-scale } \\
\text { Pervasive }\end{array}$ & $\begin{array}{l}\text { "Evidence of application of broad principles across a } \\
\text { variety of situations" (p. 187) }\end{array}$ \\
Emotional Implications & $\begin{array}{l}\text { Emotional responses as "reflections of activity in the } \\
\text { spiritual domain" (p. 188) }\end{array}$ \\
"The drive toward more adequate understandings of \\
the realm of the spiritual" (p. 189)
\end{tabular}

Feldman (2008) seemed to be interested not only in exploring spirituality as a developmental domain but also in posing suggestions for research strategies and areas of inquiry. For example, when considering the last criteria, intentionality, he suggested qualitative approaches that study "the kinds of questions asked, the kinds of answers sought, and the kinds of structures that form as expressions of intentionality" in regard to spiritual development (Feldman, 2008, p. 189). In the middle grades, collecting 
qualitative data such as he suggests from students might yield a rich understanding of the markers for young adolescent spiritual development.

I include Feldman's (2008) work here as another example of how the literature on spirituality as a domain of human development conceptualizes the contents and processes of what is meant by spiritual development. Both Feldman (2008) and Fowler (1981) offered theories that embrace progressive growth marked by identifiable stages, such as Feldman's (2008) characterization of questions as increasingly complex. Their work is significant to my research because I assume it is possible to describe young adolescent spiritual development in similar ways that the other domains are described (e.g., Caskey \& Anfara, 2007).

An inclusive framework. The foundational work of Fowler (1981) and others (e.g., Oser, 1991) has been criticized on the grounds that it is exclusive to Western research perspectives and paradigms. A consequence of this limited perspective is claims for universal theories of spiritual development (e.g., Oser, 1991) that might not adequately represent all people. Given the additional challenges that young adolescents who are ethnic minorities face in schools (Beachum, Dentith, McCray, \& Boyle, 2008; Brown \& Leaman, 2007; Bondy \& Ross, 2008; Jewett, 2009; Walker \& Shuangye, 2007; Woolley \& Bowen, 2007), it is important to address spiritual development frameworks that are culturally responsive. In this section, I address some of the ways in which the literature responds to the question of an inclusive framework for spiritual development.

Mattis, Ahluwalia, Cowie, and Kirkland-Harris (2006) critiqued the field of spiritual development on the grounds that it is infused with Western (white, European) values at the expense of other cultural perspectives. This exclusion is problematic, Mattis 
and associates argued, because constructs that are central to the field of inquiry—-such as selfhood, chronology, and secularism—reflect assumptions that are not universally held. For example, while the Western model may look to the biological beginning of a person's life to track his or her spiritual development (e.g., Oser, 1991), in some African and Caribbean communities a young child may display traits that identify him in his community as an "old soul" (Mattis, Ahluwalia, Cowie, \& Kirkland-Harris, 2006, p. 287), with a spiritual development that may have begun long before this particular incarnation appeared. In any cultural context, factors in addition to biological age can exert profound influence on a young person's spiritual development (e.g., life-span transitions, non-parental community members, creative and artistic popular expressions, and local and national policy). Mattis and her associates argued that as such, scholarly research must address those factors when constructing a model for adolescent spiritual development. Juang and Syed (2008) also recommended that future research more deeply investigate the intersection of adolescent ethnic and spiritual identities, as well as how ecological context affects identity formation.

The Search Institute's Center for Spiritual Development has put forth a culturally responsive framework for understanding spiritual development that was generated through a collaborative process involving participants from all over the world. Their goal was to develop a construct that could transcend diverse cultures, traditions, disciplines, and worldviews (Search Institute, 2011). Using literature review, focus groups, and survey data, the Search Institute's investigators constructed a definition of spiritual development that involves three core processes: awakening, belonging, and a way of living. Their framework stipulated that spiritual development is a universal process, but 
each of the three core processes may manifest in different ways depending upon the

cultural context in which human development is occurring. Their framework also emphasized the interconnection between spiritual development and other developmental domains, as well as the significant influence of the interconnection between the individual and the environment.

Young adolescent spiritual development. Thus far in my review of the literature on spirituality and spiritual development, I have emphasized literature from across the human lifespan. I will now address the literature I reviewed on adolescent spiritual development. In my review of that literature, I found few texts (e.g., Lerner, Roeser, \& Phelps, 2008; Roehlkepartain et al., 2006) dedicated to adolescent spiritual development, and the theoretical, programmatic, and empirical work being done in that sub-specialty. More widely read publications, such as the Handbook of Child Psychology and the Journal of Adolescence addressed adolescent spiritual development more explicitly than they have in the past (Roehlkepartain et al., 2006). For example, in 2006, for the first time in its 60-year publication, the editors of the Handbook on Child Psychology dedicated a chapter to spiritual development (Oser, Scarlett, \& Bucher, 2006).

Likewise, in 2009, for the first time in its history of publication, the editors of The Handbook of Adolescent Psychology included a chapter on adolescent spiritual development (King \& Roeser, 2009). The chapter is mostly a review of the theoretical and empirical literature on adolescent spiritual (and religious) development. King and Roeser's review is situated within other factors of adolescent development, such as health, education, and family. King and Roeser reported six ways in which adolescent 
spiritual development was conceptualized: (a) as a relational system; (b) as a meaning

system; (c) as the creation of cognitive-conceptual schema; (d) as an identity-motivation system; (e) as the experience of various states of transcendent awareness; and (f) as a "dynamic developmental systems perspective in which [spiritual development] is seen in relation to multiple contexts, people, symbol systems, and opportunities and risks" (p. 440). For example, when King and Roeser addressed the cognitive-conceptual strand of literature, they relate the early adolescent emergent capacity for meta-cognition, abstract thought, and reflection to how adolescents during this period are re-examining intuitive spiritual beliefs from childhood.

The interaction between cognitive and spiritual development in adolescence is the central theme of Good and Willoughby's (2008) theoretical paper on adolescent spiritual development. The authors argued "Adolescence may be a sensitive period for spiritual development" (p. 32). They meant that from a developmental perspective, there are attributes of adolescents that may leave them more likely or prone to exploring and questioning aspects of their spirituality. Good and Willoughby identified several of these developmental characteristics, including the ability to think in abstractions, experience intense emotional states, and limited impulse control. They contended that some of these traits have been treated in the empirical literature as negative, and suggested "that these same characteristics could also make adolescents more likely to engage in spiritual experiences, which may be a positive behavior that promotes well-being for some adolescents" (p. 36). Lerner, Roeser, and Phelps (2008) made a similar case in their introduction to Positive Youth Development and Spirituality. They located adolescence as an "ideal portion of the life span within which to seek this new spiritual knowledge" 
because of the "profound convergence of quantitative and qualitative changes" in the developmental domains (p. 8).

In conclusion to my review of the literature on the constructs of spirituality and spiritual development, I re-emphasize that my purpose for reviewing this literature is to contextualize the topic of spirituality and education. Without the work done in the developmental sciences to formulate and refine working definitions and theories of spirituality as a domain of human development, the challenge to situate spiritual development in an educational context is much, much greater, in my opinion. However, even with the growing evidence of the academy's acceptance and the publication of foundational work (e.g., Benson, 2004; King \& Roeser, 2009; Oser et al., 2006) my impression is that within the developmental sciences there is not consensus on an empirical theory of spiritual development. Perhaps this lack of consensus speaks to the enduring nature of some of the questions that are associated with matters of the spirit. However, in my research I agree with Peter Benson, who stated that while mystery may be part of spiritual development, keeping it a mystery in the academy is not useful. In the context of this research, the lack of definitional clarity about young adolescent spiritual development hinders the field further its understanding of how to respond holistically to middle grades students.

\section{Holistic Education: Addressing Spiritual Development}

A holistic perspective in education is one that explicitly situates spirituality as a relevant issue (e.g., Miller, 1997; Miller, 2007). In this section of my review of the literature, I explore works that address the topic of spirituality in education from multiple perspectives. 
As with the lack of definitional clarity in the field of spiritual development,

literature that addresses spirituality and education falls under differently named fields. All these fields emphasize seeing students' emotional, social, psychological, moral, and spiritual growth as deeply related to learning in schools. Much of the literature I reviewed on spirituality and education referred to human development theory. For example, Kessler (2000) argued that healthy spiritual development supports integration of and healthy development in other domains, such as social development.

In organizing this part of my review, I chose to begin with literature from two clearly defined fields that, from my perception, have experienced more acceptance in the United States than the concept of spiritual development in the middle grades. I then review what I have identified as relevant literature on spirituality as an issue in education. This literature ranges from practitioner-based theory and program description (e.g., Kessler, 2000) to frameworks for understanding the social justice implications of addressing student spirituality (e.g., Ryoo, Crawford, Moreno, \& McLaren, 2009).

In my conceptual model of the literature (see Figure 1), the field of holistic education lies between the overlapping circles of the fields of spirituality and (middle grades) education. I have categorized this overlapping conceptual area as holistic education for two reasons: (a) the field of holistic education specifically situates spirituality and spiritual development within education; and (b) the conceptual model of overlapping fields re-presents my interpretation of the ways in which the ideas relevant for this research are interrelated with each other. As a model specific to this research, I make no definitive claims about holistic education being the only body of literature that could be conceptualized as sharing ideas with spirituality/spiritual development and 
(middle grades) education. My model is imperfect, in that the field of holistic education is not specific to the middle grades - it addresses schooling at all levels, from pre-school through adult education (e.g., Miller, 2007). While this review will include literature not explicitly self-defined as from the field of holistic education (e.g., Hunter \& Solomon, 2002), I use holistic education as signifier for literature that sees spirituality as relevant to education.

Socio-emotional education and holistic education. The fields of socioemotional education (Cohen, 2008) and holistic education (Miller, 2007) are distinct, though similar, responses to the accepted practice of human fragmentation in educational contexts. As ancillaries to what is considered "education" in this country, both fields have experienced a degree of acceptance. What I find interesting about the very existence of fields such as socio-emotional education or holistic education is the implied assumption that when talking about education as a concept, a descriptive qualifier is added if what is meant is education that addresses the affective qualities of being human. In the field of holistic education, a central principle is that human beings of any age cannot be sectioned off into separate parts as a condition of formal learning in school (e.g., Palmer, 1998).

In the context of middle grades education, the affective needs of young adolescents are paramount (Gentilucci \& Muto, 2007; Jewett, 2009; Mulhall, 2007; Nichols, 2008; Van Hoose et al., 2001). As reflected in their position papers (Carnegie Council on Adolescent Development, 1989; NASSP, 2006; NFAMGR, 2003; NMSA, 2010), advocates of the middle level concept called for schools to be organized in ways that promote healthy, supportive, and meaningful interactions between community 
members—-such as students, teachers, administrators, support staff, families, and

community partners - to address the affective needs of the students.

Valuing the affective needs of students is not exclusive to the middle grades.

Cohen (2008), a leading pioneer in the field of socio-emotional education across the K-12 spectrum, made the case that an education inclusive of social, emotional, moral, ethical, and academic capabilities and needs is a human right. He explicitly addressed this implication of this position: when schools fail to treat students as multi-dimensional beings, an injustice is done to the students and to the greater society. Connecting his case for socio-emotional education to a democratic society, teacher education, and the aims of education, he drew upon a large body of theoretical and empirical literature. He identified the goals of socio-emotional education as "the promotion of social-emotional competencies and ethical dispositions on the one hand, and the creation of a safe climate for learning on the other" (p. 205). He cited a partnership between educators and mental health professionals as critical to more fully conceptualizing and designing effective practices for social emotional learning.

One of Cohen's (2008) points is particularly relevant, especially for readers who are skeptical of the place of spirituality in public schools. Drawing upon one of his earlier works, Cohen stated that one of the strategies characterizing the successful inclusion of socio-emotional education in an academic context was "purposively teaching children to be more socially, emotionally, ethically, and cognitively competent" (p. 209). What I find significant about this description is his use of the word purposively. If I apply Cohen's logic to how I have defined the problem in middle grades education (the absence of explicit inclusion of spiritual domain), I see purposive teaching as the intentional 
incorporation of knowledge of the spiritual developmental characteristics of young

adolescents into curriculum and instruction.

In a meta-analysis of the effectiveness of 213 school-based socio-emotional educational programs, Durlak and associates (2011) found that compared to controls, students in the experimental group showed significant gains in social and emotional competencies and in academic achievement. Noting the current political climate in education (i.e., NCLB), they cited the $11 \%$ gain in academic performance as good news for teachers who value an education that is more inclusive of affective needs but are told to emphasize academic needs. The Durlak and associates' finding indicated, as Cohen (2008) and others have argued, that academic needs are being met when affective needs are being met as well. The results from Durlak and associates (2011) suggested that academic rigor versus nurture is a false dichotomy, and believing in it has perilous implications for students as well as societal goals.

In the field of holistic education, I identified Ron Miller (1990; 1999) and John P. Miller $(2005,2007)$ as leading advocates. Nel Noddings (1988) is also a prominent figure in the field. One helpful distinction between the fields of holistic education and socialemotional education is provided by Miller (2005); in his distinction between educational approaches that are inclusive of more than the domain of intellect (e.g., Cohen, 2008), he stated that holistic education's inclusion of spirituality is what makes it unique from socio-emotional education. Miller (2005) described holistic education as having three core principles. The first, connectedness, references a criticism of the attempts to fragment curriculum and instruction, and, therefore teachers and students. Dewey (1902) also critiqued the disconnection between "the unity and completeness" of the student's 
life and the same student who "goes to school, and various studies divide and fractionalize the world for him" (p. 10). The second principle, inclusion, refers to the use of multiple and varied instructional and assessment techniques in order to meet the educative needs and abilities of all students. Inclusion also denotes a conceptualization of content as integrated across subjects, a key element of the middle grades concept. Balance, the third holistic education principle, refers to the "complementary energies" (Miller, 2005, p. 6) of the rational and the intuitive. Drawing from the Eastern philosophy of Taoism, Miller (2005) advocated for balance via a critique of dominant social values: "Generally, our education has been dominated by yang energies such as a focus on rationality and individual competition, and has ignored yin energies such as fostering intuition and cooperative approaches to learning" (pp. 2-3).

To re-iterate, because holistic education is defined by its inclusion of human spirituality, in my conceptual model of the literature that is related to my research, I use the term holistic education to refer to an educational approach that addresses spirituality. I now turn to the various sources that explore spirituality as an educational concern, but may not explicitly self-identify as part of the field of holistic education.

Spirituality as an educational concern. Many authors wrote of spiritual development as an under-utilized yet powerful resource for students and teachers (Hunter \& Solomon, 2002; Palmer, 1998; Schoonmaker, 2009). Much of the literature on spirituality and education opened with some form of explicit justification for the pairing. I think this pattern reflects the reality that current scholars, practitioners, and researchers interested in spirituality in education are operating within a greater social, political, and educational context which privileges secularism in the name of postmodern critical 
rationality. Critiquing public education's response to societal inequities, Purpel (1999)

wrote, "What would seem to be required is a pedagogy of moral and spiritual transformation, but instead our profession has fashioned a pedagogy of control and standardization focused on technology, competitiveness, and materialism" (p. 59). This theme of situating the educational relevance of spiritual development within a specific socio-political context led me to choose a research approach that foregrounds historical context as part of data analysis strategies.

Few works focused on spirituality and middle grades students. One book on middle grades education (Nakkula \& Toshalis, 2006) has a chapter on spiritual development. Two additional works (de Souza, 2006; Miller et al, 2005) address adolescent spirituality in the context of its relevance in education, but not the middle grades specifically. Therefore, I expanded my area of inquiry beyond the middle grades specifically, and looked at the literature on spirituality in K-12 education. While there is a growing body of literature on spirituality in higher education, I chose not to include any of it here (with the exception of Palmer, 1998) because the debate over the educational relevance of spirituality is slightly different in an adult learning context than it is in a young adolescent learning context.

Identifying spirituality as an educational concern is not a new issue. In his review of the historical context of spirituality in education, Miller (2007) cited Plato, Rousseau, and Tolstoy as historical contributors to holistic education. In the 20th century, Gandhi promoted a holistic educational approach that explicitly identified student spirituality in his prolific writing on educational philosophy (e.g., Gandhi, 1953). The foundational assumptions supporting Gandhi's Nai Talim, or, "New Education," are: all children can 
learn; learning happens through one's mind, spirit, and body; the teacher/student

relationship is mutual, reciprocal, and grounded in trust; and deep learning happens in community, not just in solitude (Gandhi, 1953). For Gandhi, the traditional "3 R's" were head, heart, and hand. From these core assumptions, a theory of education emerged from him that advocates for equitable practices, strong community and family partnerships, varied modalities for instruction, an integration of intellectual, spiritual, and physical curriculum, adults as intentional role models for character and morality, and servicelearning to nurture student growth and development in schools (Gandhi, 1953). When I first encountered Nai Talim, I was struck by some of the parallels between what Gandhi proposed as educational reform in a post-independent India and the reforms for middle grades schools in the United States. Both emerge from a critique of the current system as overly mechanical, ineffective, and inappropriate to the point of being demeaning to the students it is supposed to serve. Both offer alternatives grounded in compassionate, health-affirming human relationships, curriculum and instruction that are integrated and engaging, and a culture of dignity, integrity, and mutual growth.

Pathways. Rachael Kessler (2000), has written eloquently about spirituality, and her work is frequently referenced by others working within the field of holistic education (e.g., Bruce \& Cockerham, 2004). Kessler noted that while educators and community members argue over whether or not it is a good idea to bring spirituality into the schools, children and adolescents are bringing their spiritualities with them right along with their bodies, hearts, and minds. In this position she resembles another often-referenced author in the field of spirituality and education, Parker Palmer (1998). For Kessler and Palmer, the more salient question is how do educators skillfully work with students as they 
grapple with universal questions, seek transcendent experiences, and discover their own sacredness.

Kessler (2000) rejected the excuse that schools can blame "persistent violent and self-destructive behavior" on larger societal ills. She acknowledged the impact of poverty, racism, and neglect, but argued "We cannot really understand or heal from these plagues if we do not begin to recognize and meet the spiritual needs of our children. Do we need periodic reminders from sawed-off shotguns to show us that these young people feel?"' (p. xii). In fact, Kessler called for schools to give students tools with which to deal with poverty, racism, and neglect. Palmer (1998) made a similar case, although the focus on his work is how teachers can recognize and meet their own spiritual needs, especially as they work in schools that are deeply affected by poverty, racism, and neglect for the purpose of being able to connect with their students.

Kessler's theoretical framework for addressing the spirituality of students (which she refers to as their soul) used the metaphor of passages and pathways. She developed a "passages" program in California in the mid-1980s that used ritual, symbolic play, community dialogue, and skillful adult facilitation to support adolescents as they considered the mysteries of the human experience during their times of transition (i.e., adolescence). From that work, and her subsequent experience as an educator in Colorado, she devised a model that identifies seven gateways, or pathways, to addressing the spiritual development of young people in a school context.

In her model, there are overlapping pathways (e.g., creativity, connection) to students finding and experiencing the central pathway to the soul: meaningful relationships with themselves and with other people. In this way, her model for spiritual 
development parallels the construct of developmental domains described in the fields of middle grades reform and applied developmental psychology; domains are to be treated as overlapping and interactive rather than distinct and independent. Kessler arranged the gateways using circles to illustrate the non-sequential nature of her model. Teachers can guide students to access their spiritual natures using any of the pathways; some will be more or less attractive to different students based on their individuality. Kessler's model appealed to many holistic educators who seek to address the spiritual needs of their students (e.g., Nakkula \& Toshalis, 2006). Her model allows for differentiation and honors the iterative process of teaching and learning. In addition, her explanation of how the creative gateway functions reflects a theme in the literature on spirituality: a recommendation to access students' spirituality through creativity (Azevedo \& Gil de Costa, 2006; Colalillo Kates, 2005; Nakkula \& Toshalis, 2006).

Implications. Several authors have identified frameworks for understanding the implications of spiritual development within education. Hunter and Solomon (2002), writing for school administrators, argued that educational leaders who do not take into account their own spirituality and the spirituality of their staff miss opportunities to foster the level of motivation and morale that positively impacts preK-12 students. They constructed spirituality as part of a person's meaning system that influences ideas of professional and personal roles and responsibilities: "We suggest that it is important for individuals to be aware that drawing upon personal spiritual meaning systems is a valid means of conceptualizing, framing, and approaching work" (p. 38). Hunter and Solomon's article focused on the interrelationship between school leadership and addressing spirituality. Hunter and Solomon's (2002) ideas about using the frame of 
spirituality as a means for administrators to support the integration of teachers' personal and professional meaning systems reflects the type of leadership advocated by middle grades leaders (e.g., NMSA, 2010).

Schoonmaker (2009) framed spirituality as something that can be seen in classrooms as an interpretive lens guiding practice. Her metaphor of a lens with which to see spirituality is drawn from Huebner (1999), who explored spirituality and education in the context of curriculum theory: "Different images of the same landscape enable us to see different possibilities, different relationships,” (p. 404). Schoonmaker (2009) offered a construct that situates spiritual matters squarely in the realm of public education. She made the case that learning is inherently a spiritual endeavor; it is a search for meaning, understanding, and connection occuring within a context that is greater than oneself. Like Kessler (2000), Schoonmaker dismissed the question about whether or not spirituality is in the classroom, but instead offered suggestions for how teachers can intentionally work with the spiritual development of themselves and their students. Her suggestions included having a personal sense of one's own spirituality through practices and fostering recollections of one's own spiritual development. Through personal work, Schoonmaker claimed that teachers would be better positioned to see the sacred in the classroom, experience moment-to-moment awareness, and more deeply understand learning through the perspective of children.

Milojevic (2005) proposed a three-tiered approach to understanding how the inclusion of spirituality can impact education. She argued that inclusion of spirituality locates the educational process within the inner life of a student, expands the structure of education to life-long activities in and out of schools, and brings closer the content of 
education to the same preoccupations of living. Her work echoes the middle grades recommendations for authentic learning activities that draw from a student's previous sources of knowledge.

De Souza (2006), writing in the context of the Australian educational system, argued that because of the decline in the influence of institutions that have historically tended to the needs of spirituality (e.g., a search for meaning), a need has arisen for other institutions, such as schools, to respond. De Souza (2006) illustrated as clearly as Kessler (2000) the specific teacher practices and student benefits that come from tending to the spiritual development of students. Her work is useful in the NCLB climate of the United States because she used the language of standards-based "learner outcomes" to distinguish between cognitive, affective, and spiritual outcomes in a holistic pedagogy. In addition, echoing both developmental psychologists (Fowler \& Dell, 2006) and middle grades advocates (NMSA, 2010), de Souza (2006) brought forward the claim that since educators have a responsibility to design and sustain learning environments that respond to and address all of the needs of learners, knowledge about the spiritual development of learners can improve a teacher's work. Citing the interdependence of all of the developmental domains as well as different learning modalities, de Souza proposed a model for teachers to consider when designing learning environments. Her theoretical model emphasizes the interplay between inner-reflective and the outer-relational activities within and among intellectual, emotional, and spiritual ways of thinking, feeling, and intuiting. In her model, spirituality is at the core (center) of the other two ways of knowing and learning. 
Because de Souza's (2006) premise about the potential value of integrating

spiritual development in an educational context aligns so closely with my own, I return to it in my discussion of the results. One distinction between her work and my own is that while we are both working within a Western cultural context, I intend for this research to be firmly grounded within the context of public middle grades education in the United States. Her work is highly complementary to my own, but I still see a need for the development of a model that is tailored for middle grades educators working in the public system in the United States.

Critical spiritual pedagogy. An additional framework for understanding the relevance of spiritual development in relation to middle grades education is one that facilitates critical thinking and reflective action (Adarkar \& Keiser, 2007; Hill, Herndon, \& Karpinska, 2006; hooks, 1994, 2003; Orr, 2005; Ryoo, Crawford, Moreno, \& McLaren, 2009). Sometimes referred to as critical spiritual pedagogy (CSP), this line of argument contends that a truly transformative education must stimulate critical inquiry and reflection at the intuitive, non-verbal levels (i.e., spiritual) as well as the intellectual and emotional levels. Orr (2005) claimed: "Antioppressive pedagogy...must involve teaching the whole person. Simply teaching a more acceptable set of ideas to replace discriminatory ones will not suffice if that teaching fails to address the emotional, bodily, behavioral, and spiritual aspects of those ideas in a student's life," (p. 88). Like de Souza's (2006) model, the CSP framework reflects an epistemology of interdependent domains of knowing and learning. An implication of critical spiritual pedagogy is a critique of the dominance of positivist epistemology in education in the United States. 
This critique identifies how certain types of knowing have been privileged over other types in ways that sustain certain socio-political economic groups in the U.S.

Ryoo, Crawford, and Moreno (2009), working with the ideas of critical theorist Peter McLaren (2009), distinguished critical spiritual pedagogy from critical pedagogy by grounding CSP in spirituality, as a supplement to critical pedagogy's emphasis on humanity and power (Freire, 1993; McLaren, 2009). Like Orr (2002), Ryoo and associates critiqued critical pedagogy on the grounds that it is incomplete, and therefore insufficient as a challenge to dominant power paradigms: "To create a revolutionary spiritual pedagogy, educators must move beyond the constructs of critical pedagogy to incorporate an acknowledgement and respect for the spiritual and sacred in teaching and learning" (pp. 136-137).

Explicit inclusion of the students' spiritual development can counteract hegemonic practices in schools (Gatto, 1999; hooks, 2003; Ryoo et al., 2009; Sherrod \& Spiewak, 2008; Simmer-Brown, 1999). Owen Wilson (2005) offered an alternative way that schools can utilize the metaphor of benchmarks. Instead of applying that metaphor only to academic gains (or physical gains, such as in gym class), Owen Wilson called for the integration of rites of passage rituals that reach the hearts and souls of adolescents. Her rationale is that rites of passage make schooling more personal and meaningful for students by providing an opportunity for an ethnically identified diverse population to see their home culture reflected in their school context. She strongly critiqued the domination of the industrialized Western factory model—what Freire, 1993, called the banking system of education —on the grounds that it is impersonal, oppressive, and outdated. Citing Hill (1991), Owen Wilson argued that the stakes are high in a system where "the 
benefits of custom, ceremonies, faith, and ritual acculturation have been

discarded...[and so] we have educated away from ourselves" (p. 68).

Throughout the literature are similar claims that warn of the dangers of psychological fragmentation in a learning context, i.e., schools (de Souza, 2006; Kessler, 2000; Palmer, 1998; Pearmain, 2005; Ryoo et al, 2009). This warning invokes the importance of the problem I propose to study: what is the cost of continuing to separate a student from their spirituality? What the literature on holistic education, as reviewed in this section, seems to suggest is such a separation is not an inevitable practice. The literature suggests that integration of the spiritual domain of human development can happen in many ways: through creativity (Kessler, 2000), as a lens for guiding practice (Schoonmaker, 2009), or as an interplay between inner-reflective and outer-relational learning activities (de Souza, 2006).

\section{Researching Educational Relevance of Spiritual Development}

In this section, I turn to the literature on research methods used to study spiritual development. I begin with work from the developmental sciences because it was in this field that I found more literature on how to research spirituality. I then review the methods used to research spiritual development and spirituality in education, as well as the empirical findings related to the research cited.

Developmental sciences. In the developmental sciences, research on spiritual development has faced definitional, theoretical, and methodological challenges (Benson, 2004, 2006; Benson \& King, 2006; Borgman, 2006; Gorsuch \& Walker, 2006; Nicholas \& DeSilva, 2008). Benson (2006) conceptualized the challenges, as well the 
opportunities, of researching spirituality by summarizing the main questions of the field of spiritual development, in a developmental psychology context:

As a developmental concept, what part of human development are we addressing with the adjective spiritual? Is it a modifier we use for naming and claiming a heretofore neglected domain or dimension within human development theory and research? Is spiritual used to describe the processes by which persons integrate the social, moral, and cognitive dimensions of development? (p. 485)

Benson's question reflects a theme of the empirical literature: what is being studied when spirituality and spiritual development are the focus? Benson (2006), who demonstrated pioneering leadership on this matter within the developmental sciences, advocated for research efforts that generate new theory and re-evaluate existing ones (such as Fowler's stage theory). He also strongly advocated for collaboration between practitioners, theorists, and researchers in the social sciences, education, and counseling with practitioners, theorists, and researchers in religious and spiritual fields. He pointed out that in the researcher's quest to operationalize and quantify in order to systematically study, caution should be exercised so as not to lose the essence of spirituality. Finally, Benson encouraged researchers in the field of spiritual development to be mindful of the person-context dynamic, especially when considering the diverse ways in which spiritual development manifests and is influenced.

The literature reflected suggestions for researching spiritual development. Gorsuch and Walker (2006), in their review of the literature on researching Western, Christian-based spiritual development, identified measurement, design, and analysis issues. They used examples from the literature to illustrate theoretical and technical 
measurement issues such as how to define measurement domains and applying different

developmental stage theories. For example, in their discussion on measurement, Gorsuch and Walker (2006) argued that regardless of what is being measured, the measurements must be "unambiguous" (p. 93). While unambiguous measurement is a standard for any quantitative study, the point Gorsuch and Walker made is that this standard must be intentionally monitored in spiritual development research. For example, when researchers are investigating the association between two factors in different, though perhaps related domains, the measurement tools for both of those factors must be distinct from each other. "Only by having some measures that are in the motivation domain and some in the behavior domain can we explore the relationships of spiritual motivation to behavior" ( $\mathrm{p}$. 93). This example also illustrates the domain interrelationships in a human development theory that addresses spiritual development.

Gorsuch and Walker (2006) also mined the empirical literature for examples of design and analysis issues. They explored four different design and analysis categories: cross-sectional design, longitudinal design, a combination of the two, and intervention designs. Most of the literature they reviewed was quantitative, which seems to be the standard in the field of developmental psychology. While they acknowledged the value of qualitative methodologies in the context of the humanities, they took the position that using qualitative approaches to avoid the problems inherent in studying spirituality quantitatively does not make the problems go away. I interpreted a potential bias against qualitative research in this position, as they inferred that qualitative research is sometimes used as a way to avoid the rigorous reliability criteria for quantitative methodologies. 
The issues related to creating a reliable instrument for measuring spiritual development are reflected in the work of Stoyles, Stanford, Caputi, Keating, and Hyde (2012), who developed an instrument for measuring children's spiritual sensitivity. The strategies they used to develop this instrument were: (a) design clustered questions by drawing from major theoretical constructs - the researchers used Hay and Nye's (2006) 'relational consciousness,' among others; (b) interpret results taking into account the cognitive capacities of the participants as a reflection of the interrelationship between cognitive and spiritual development; (c) measure an aspect of spirituality (in this case, spiritual sensitivity) instead of trying to account for the entire domain; and (d) use companion measures, in this case, constructs of hope and self-esteem, with which to explore through statistical analysis potential relationships between spirituality and aspects of being human that contribute to healthy development. Although this instrument was implemented in a religious school setting, the questions were not tied to a specific religion (e.g., "I am amazed by the things around me, like nature, music, or sport," Stoyles et al, 2012, p. 209).

Using only one method, such as in the example above, was not recommended by Warren, Lerner, and Phelps (2012). In their collection on spiritual development and thriving among adolescents, they advocate for the use of multiple data collection strategies used in conjunction with the principle of triangulation. Their reasoning is that multiple methods will allow the researcher to "identify what is unique and what is common" ( $\mathrm{p} 15$ ) about connections between adolescent spiritual development and other phenomenon such as thriving. Warren and colleagues also called for more longitudinal 
studies, as a means of recognizing that variables involved with spiritual development “are not static," (p. 15).

Finally, Nicolas and DeSilva (2008) called for research on adolescent spiritual development that is culturally responsive. They argued that failure to do so leads to results that misrepresent the lived experiences of spiritual development among adolescents. Nicolas and DeSilva advised that researchers interested in conducting culturally responsive research must have "patience, commitment, and passion about the work" (p. 318). Using an ecological perspective, they offered ways to address the unique socio-cultural and individual contexts for ethnic-minority adolescents in the course of studying their spiritualities. One strategy for conducting culturally-responsive research is to take steps to ensure and respect diversity within study participants by (a) using a community-based approach; (b) paying attention to the composition of the sample as well as the means of recruitment; and (c) selecting and administering measurements that reflect an understanding of the norms and expectations of linguistic and behavioral practices. Nicolas and DeSilva (2008) reminded me of Freire's (1993) call for liberation through engaged dialogue with members of the oppressed community. In essence, Freire, as well as Nicolas and DeSilva, appeared to reflect the critical paradigm of research as a tool for transformation and liberation. In my research, I attempted to address the concerns raised by Nicholas and DeSilva with a historiographical research design that employs critical interpretation as an analysis strategy. My attempts were somewhat theoretical, however, because Nicolas and DeSilva's (2008) guidelines are for field-based research, not historiographical research. 
In these examples of spiritual development research in the developmental

sciences, the following principles are reflected: (a) spiritual development research should be conducted in collaboration with practitioners; (b) quantitative methodologies are preferred over qualitative ones; (c) operationalizing what is meant by spiritual development is a challenge; and (d) spiritual development research methodology must be culturally responsive. While there is a growing body of research on spiritual development in non-Christian contexts (e.g., Sallquist, Eisenberg, French, Purwono, \& Suryanti, 2010) historically, the theory and research base has been within Christian contexts.

Educational research. In the field of education, researching spiritual development has had similar challenges as in the developmental sciences. However, in the field of public education, the issue of relevance is foregrounded in introductory and concluding remarks. In reports of empirical research, the issue of relevance was addressed with an explicit defense of its inclusion in the field. Spiritual development's inclusion as a legitimate area of research centered around three rationale: (a) improving teacher practice and effectiveness (Benami, 2006; Fraser, 2007) by (b) reducing students' experience of alienation and personal fragmentation (Long, 2008; Pearmain, 2005; Revell, 2008); and (c) increasing access points to the academic curriculum (Belousa, 2006; Cottingham, 2005; Deakin Crick \& Jelfs, 2011; Leopold \& Juniu, 2008).

In my review of the literature on how spirituality and spiritual development have been researched in an educational context, I did not find many studies. Much of what I did find was qualitative (e.g., Pearmin, 2005), with results reported in thick narrative descriptions. Like the research done in the developmental sciences on spirituality, challenges facing the educational research included definitional clarity of 
spirituality/spiritual development (e.g., Fraser, 2007); a challenge specific to educational research is research validity (e.g., Cottingham, 2005).

The empirical literature I reviewed focused on how school community members, including teachers, principals, and adolescent students, perceive the relevance of spirituality in schools. Research on teacher perceptions of spirituality (e.g., Conti, 2002) addressed the educational relevance question directly. For example, Benami (2006), using a mixed-method approach, studied teacher perceptions about the educational relevance of spiritual development before and after an intervention. The intervention was a workshop describing multiple models of “spiritual education” (Benami, 2006, p. 3). Benami had 20 subjects in his study; all taught academic courses at a parochial religious school in the U.S. Midwest. Benami sampled two of the teachers from the larger sample, and conducted pre- and post-interviews for qualitative analysis. The individual interviews and workshop sessions were transcribed; these transcripts, as well as written definitions of spirituality collected pre- and post-workshops, were analyzed using three levels of qualitative strategies (e.g., coding). He used two validated surveys with the experimental and control groups to measure teacher burnout and teacher perception of the school environment. Variance and co-variance statistical analyses were conducted using SPSS software. Benami found that the teachers who participated in workshops on spiritual development reported a change in how they perceived its educational relevance from their pre-intervention conceptions, as well as the ability to incorporate instructional strategies that met their students' spiritual needs. In the discussion of his findings, Benami called for his study to be replicated with teachers in a public school. 
In a qualitative study (Revell, 2008) included private religious and public school teachers in Chicago to research how teachers conceptualized spirituality in an educational context. Revell interviewed 28 principals and teachers. She used semi-structured interviews for data collection, but did not disclose her data analysis method. A primary difference she found between the two groups, public and private religious, was that the former emphasized the universality of spiritual development, whereas the latter situated spiritual development and expression of spirituality within a specific religious context. Revell found that the public school teachers thought that its universality was a significant asset in a school that had high levels of ethnic, cultural, economic, and racial diversity for it could serve as a bridge between members of a diverse population. As such, the teachers favored addressing the spiritual development of their students in their curriculum and instruction.

Interestingly, Revell (2008) found similarities in the ways the research participants talked about spirituality, despite the definitional inconsistencies of the academic literature:

The similarities between the definitions of spirituality lie both in the way teachers identified spirituality as a component of community building within their schools but also in the significance they attributed to it. In every interview teachers talked about the debilitating consequences of educating children where there was no community and associated opportunities for spiritual reflection as a way of enabling pupils to negotiate the demands of modern American society. (p. 115) 
The teachers and principals in this study viewed the spiritual development of their students as a form of "counter-narrative" (p. 111) to the alienating aspects of being a young person in the United States. In other words, the educators in this study frame the relevance question as one that is situated in a particular social, political, and economic context - and in that specific context, they view spirituality as a critical component of formal schooling.

In contrast to Benami (2006) and Revell's (2008) work with teachers, Wintersgill (2008) conducted a five-year qualitative study that sought to understand how adolescents perceive spirituality, especially in comparison to how (adult) theorists described adolescent spirituality. Using questionnaires, Wintersgill collected data on their understanding of terms (e.g., spirit, spirituality, and spiritual development) and their perception about what specific aspects of school contributed to their spiritual development. The questionnaire, which was piloted, had four open-ended questions and one closed question. She also collected data from a smaller sample $(n=34)$ of volunteers from the larger sample $(\mathrm{N}=385)$ through semi-structured interviews, which were transcribed for analysis. Wintersgill used grounded theory (Strauss \& Corbin, 1998) data analysis methods (e.g., open coding).

In her analysis, Wintersgill (2008) interpreted adolescent understanding of spirituality as a "dynamic force" (p. 372) that actively facilitated "belief, developing relationships, self-understanding, acceptance, and the search for meaning" (p. 372). Spirituality was distinguished from spirit as being more active; spirit was viewed by participants as "passive in that it "just is"” (p. 373). The research participants likened spirit to "the real me inside" (p. 373). The participants distinctions between the "real me 
inside' and the 'unreal me' are summarized in Table 6. Finally, in terms of what aspects of school contributed to their spiritual development, the students more frequently reported that humanities and creative arts classes were the ones that best addressed their spiritual development.

Table 6

Comparison Between the 'Real' and Unreal' Individual (Wintersgill, 2008, p. 373)

\begin{tabular}{ll}
\hline The 'real' me (i.e., spirit) & The 'unreal' me \\
\hline Seat of the emotion & The physical person \\
The authentic self & A deceptive self \\
Depth & Superficiality \\
Secret/hidden, except to close friends and & Revealed to the world \\
family & \\
Transcendent and timeless & Follows social conventions \\
Pure & Corrupt
\end{tabular}

Pearmain (2005) also studied adolescents' perception of their spiritual development while they attended a Quaker summer program and a yogic meditation retreat. The purpose of her study was to investigate how participants described their exposure to spiritual educational experience. Using Interpretive Phenomenological Analysis, she concluded that the participants $(\mathrm{N}=18)$ described their experience as an inner experience of safety, sacredness, and transformation. In her analysis of the narratives, she noted the use of the metaphor of home, as a place where one feels comfortable, known, and safe. In discussing the relevance of this "safe haven" (p. 289), 
she argued that adolescents in particular are in need of these experiences, given the

pressures, threats, and demands they face in their daily lives:

We could imagine this environment phenomenologically as like living in a two-dimensional space where you have a front and a back, but no inner space, no inner recesses or interior domains... When things have to be hidden or suppressed, life is flatter. (p. 288)

For Pearmain, and others (Good \& Willoughby, 2008), adolescents are in particular need of having their spiritual needs addressed because of the challenges presented to them internally (human development) and externally (socio-political context). These conclusions are consistent with and reflect the developmental theory of state-environment fit (Eccles \& Midgley, 1989).

Finally, the empirical literature also reflected qualitative research on the relevance of spirituality as it relates to classroom instruction and direct work with adolescent students. Cottingham (2005) conducted qualitative research with his 11-14 year old students, using a case study approach with four of his classes. Cottingham's results are interesting, but suspect because his disclosure of research methods is incomplete. He stated that "ethical procedures" (p. 58), e.g., pseudonyms and student permission, were used. However, nowhere in the article did he provide details or rationale regarding his methods for either data collection or data analysis. I chose to include his study here because his results, though unreliable, suggest specific strategies for addressing spiritual development in an academic context.

Using descriptions of curricular materials, class instruction, and student interactions with the content and each other, Cottingham (2005) found that an 
interdisciplinary approach to history curriculum incorporating visual and performing arts

is an effective way to address the spiritual development of the students. He argued that an arts-based history curriculum is a vehicle for tending to abilities and dispositions that make up part of a student's spiritual development: dealing with cognitive conflict, cultivating reflective empathy, and being in community with a shared sense of purposein this case, intellectual and emotional discourse. In his review of the literature on historical inquiry, history pedagogy, and history, literature, and spirituality, Cottingham claimed that history, as a middle school subject, offered many entry points for contributing to students' spiritual development. An example of one of the entry points is: "the process of historical meaning-making and the indeterminancy of the literary text [that] create a climate of cognitive conflict through which students engage with the complexity of questions at the essence of the human condition" (p. 49). Cottingham's work notes the use of creativity as a gateway (Kessler, 2000) to student's spirituality in its use of an arts-based approach.

Deakin Crick and Jelfs (2011) researched spiritual development as it related to students' capacities for meta-cognition. They drew from design experiment principles, which emphasize theory building from inductive rather than deductive reasoning. In this mixed methods study, pre- and post-test data on learning profiles (e.g., dispositions and identities as learners) and engagement were statistically analyzed using SPSS. Data were also collected qualitatively through teacher focus groups and student interviews. The intervention was a highly personalized inquiry project in three classrooms in a Christian school with students in eighth and ninth grades. Unlike the Cottingham (2005) article, the 
report on this research study was thorough and complete, in terms of full disclosure of methods for data collection and analysis, ethical issues, limitations, and validity issues.

The results from Deakin Crick and Jelfs' (2011) study suggested the personalized inquiry project facilitated connection with self, others, and a sense of something greater than self, as well as self-awareness and personal meaning-making. In the discussion of their results, they advocated for "an approach to learning that involves the engagement of a combination of different modes of knowing, both cognitive and non-cognitive, while also honoring the different narratives from which children and young people derive their sense of meaning," (p. 211). A limitation of this study, as the authors fully acknowledged, is the challenge of using, as they did here, a relatively novel pedagogy as an intervention. In the discussion of their results, the authors cite the difficulty of making claims with so many potential intervening variables, even in a design experiment study.

In sum, the empirical literature on spirituality as a developmental domain and spirituality in an educational context highlights the definitional, measurement, and validity challenges of empirical research in these areas. This literature also illustrates the need for additional research as a means of more skillfully situating spirituality as an educational concern.

What the findings of these limited studies suggest is that teachers and students are aware of the relevance of spiritual development as an educational concern. The findings also suggest that the aspects of spiritual development that teachers and students find particularly relevant are cultivating a sense of interconnectedness, developing coping strategies, relating to something greater than self (transcendence), and exploring personal way of making meaning. 


\section{CHAPTER III}

\section{RESEARCH DESIGN}

History...cannot simply be an act of recognition, of fitting events into fixed patterns, of just seeing the light. It must begin, rather, by apprehending the sources of light and the present objects they shed or illuminate, and follow with an active, incessant engagement in the process of naming and renaming, covering and uncovering, consuming and producing new relations, investigating hierarchies of power and effect: distilling light into sun, moon and fire. (Alcalay, 1993, p. 2)

\section{Critical Historiography}

In this chapter, I describe the design used for this research and provide a detailed account of the processes used. I begin by explaining what informed my decision to select critical historiography as the research method. I then outline the main features of historiography as a method of research in the social sciences, as well as its application in educational research. After identifying how critical constructivism influences my paradigm as a researcher, I describe the underlying principles and specific techniques associated with critical historiography. As part of my description of the techniques, I present the processes used for data collection and analysis, addressing validation issues (Creswell, 2007) when appropriate. Embedded within my description of the research methods employed in this project is my rationale for critical historiography as the research methodology. I conclude this section by addressing issues related to the integrity of my research.

Within the humanities, historiography is the study of the writing of history and written histories. It is distinguished from the actual writing of history in most of the definitional literature (e.g., Burke, 2001). However, in some cases a secondary definition involves historiography as the writing of history as well (Oxford Dictionary of English, 
2011). The blending of the two activities is a reflection of the 'new' history of the last half of the $20^{\text {th }}$ century, a perspective on historical inquiry that incorporates techniques previously associated with historiography such as cultural relativism (Burke, 2001).

The distinction between studying the writing of history and the act of writing history is relevant to my study, because I was not attempting to construct a history of spiritual development as a curricular and instructional issue in the middle grades. My research purpose was to better understand the educational relevance of spiritual development as it relates to the core principles of the middle grades concept of developmentally responsive education. My primary inquiry question was: What is the educational relevance of spiritual development in middle grades education? Two subquestions were addressed in my inquiry: (a) What prevalent paradigms underlie the academic discourse on spirituality as a developmental domain, the middle grades concept, and holistic education? and (b) What are the inter-textual and inter-discursive relationships within the convergence of the paradigms of the three fields?

I produced new knowledge as a means of achieving my research purpose. I used a historiographical approach in order to interpret the foundational literature of (a) spirituality as a developmental domain; (b) the middle grades concept; and (c) holistic education. A historiographical approach, as I explain in greater detail in this chapter, allowed me to interpret and interrogate the ways in which these three fields have been constructed. My intention, as Alcalay (1993) wrote in the quotation cited at the beginning of this chapter, was to "apprehend the sources of light and the present objects they shed or illuminate" (p. 2). My expectation was that a critical interpretation of the prevalent paradigms that have influenced the shaping of these fields, followed by an interpretation 
of the paradigms' inter-discursive relationships, would offer definitional clarity to the educational relevance of the domain of spiritual development and implications for practice in the field of middle grades education.

\section{Selecting Critical Historiography}

In this section, I briefly address some of the methods I considered using to investigate my research question, and explain my rationale for choosing a critical historiographical study.

The literature I read on researching spirituality in education guided me toward qualitative methodologies such as case study, narrative study, and grounded theory. Experimental and non-experimental quantitative research methodologies were more common as research methods in the developmental sciences. The latter methodologies I rejected for this study because I was not comfortable operationalizing spirituality through measurable indicators. That said, I could envision quantitative approaches having potential as a strategic methodology to call upon, given the supremacy of the positivist paradigm in Western society.

In considering a qualitative approach, I found two main reasons from the literature to select a method from that research framework. First, I wanted to articulate an explicit understanding of the educational relevance of spiritual development and one way

to do that is by exploring personal perspectives of teachers and students (e.g., Wintersgill, 2008). Qualitative methods such as case study, grounded theory, and phenomenology are better suited in terms of what counts as data and data analysis methods for a study that seeks to more deeply understand a phenomenon in a naturalistic setting (Creswell, 2007; Guba \& Lincoln, 2005; Janesick, 2011). 
Second, one repeated theme in the literature was the way in which creativity was

used to access and address adolescent spirituality. A relatively recent research approach in the qualitative field is arts-based research (Leavy, 2009). Given the anecdotal strength of the relationship between creativity and spirituality, incorporating an arts-based research approach holds tremendous promise for the purpose of understanding the educational relevance of spiritual development in the middle grades.

Although both of the reasons aforementioned justify grounds for qualitative work that involved collecting data (e.g., interviews, student work, observations) from human subjects, such an approach felt incomplete as well as premature, given the lack of theoretical literature on spirituality in middle grades education. In future research that is guided by the results of this study, I will collect and analyze data directly from the field that could offer a glimpse into educators' understanding of the spiritual lives of their students. The results of this research can also be used to design professional development curriculum for middle grades teachers (e.g., Benami, 2006) and test the effectiveness of a specific professional development intervention. But, from my review of the literature, there is a stronger need at this time for establishing a clear rationale for situating spirituality in public schools through conceptual work that generates new knowledge.

Therefore, I selected an interdisciplinary conceptual research approach, critical historiography (Villaverde, Kincheloe, \& Helyar, 2006). This critical constructivist approach, as I present in detail in this chapter, offers data collection and analysis methods that I used to identify, interpret, and synthesize the issues relating to my inquiry. Many disciplinary fields overlap and interpenetrate each other in this topic, as demonstrated by my review of the literature. In addition to the challenge of keeping track of these 
theoretical interactions, I have been challenged to clearly articulate the social and

historical contexts in which the ideas are situated, and the ways in which those contexts influence or affect each other. An interdisciplinary research approach can be used to unpack effectively these areas of intersection (and collision) as well as raise to the surface the underlying assumptions and paradigms (Kuhn, 1996) that guide the foundational literature.

Zeichner (1999) argued that one of the great benefits of historical research is the conceptual knowledge it contributes to a field that seeks to advocate for its interests and respond strategically to challenges. From my perspective, today's debates in the middle grades include the following three challenges: (a) how to honor the intent of the middle grades concept in an era of policies that jeopardize its relational aspects; (b) how to be more developmentally responsive in the middle school's organization and leadership; and (c) how to recognize and respond to the whole child in the classroom. What potential could a more holistic understanding of the developmental needs, interests, and abilities offer to these debates? I think that while this question could be addressed in part by empirical, field-based methods, the landscape for this topic is much larger than those methods facilitate inquiry into.

\section{Historiography}

The focus of a historiographical analysis is ideas, assumptions, values, beliefs, and worldviews of the historian-author, although precise definitions of historiography are influenced by academic discipline. For example, sociologists describe studying historiography as studying "the methodological (including epistemological) questions 
raised by the writing of historical accounts" (Scott \& Marshall, 2009). Critical theorists

emphasize the constructed, socially and politically mediated nature of the writing of history; for them, historiography "refers to the interpretation and articulation of those events" (Buchanan, 2010). In both examples, however, the writing of history is viewed from a hermeneutic perspective in which the subject of historical accounts is de-centered (Foucault, 1973; Kuhn, 1996). "The objective of the decentering of the subject is to understand how the subject is constituted within a field that relates knowledge and power" (Popkewitz \& Brennan, 1998, pp. 10-11).

Historiography as a research method reflects a constructivist epistemology (subjectivist) and ontology (relativist). More specifically, critical historiography, as I describe in more detail later, is a type of historiography characterized by its stance of inquiry as a political act (Villaverde, Kincheloe, \& Helyar, 2006). Similar to Foucault's genealogy, a critical historiography explores "[academic] discipline as a discursive system within arbitrary and exclusive boundaries" (Kincheloe, 2001, p. 684).

To illustrate the practice of historiography, we can look at a historiography of cuisine (Smith, 2003). Such an account examines: (a) the ways in which food preparation has been recorded through out time (from recipes to thematic cookbooks to scholarly journals); (b) the various research methodologies (content analysis, recipe re-enactment); and (c) the evolution of research purposes (from inventorying cookbooks to studying how food reflects socioeconomic relationships). In a historiographical inquiry, questions of methodological rigor and researcher trustworthiness arise. For example, in the first half of the $20^{\text {th }}$ century, the Americans used imprecise and informal strategies for researching cuisine whereas the British established a variety of conceptual frameworks and 
methodologies within which to study food and drink. A historiographical account of the

history of cuisine ends by situating the study of cuisine as its own field of academic inquiry as well as its inclusion in other more established fields such as global history and sociology. A historiography is an interpretation of what was problematized, the types of research questions asked, the kinds of methods used to investigate the problems, and the worldview(s) reflected in the conclusions drawn. In the example above, cuisine is not the subject of the historiography; the subject of inquiry is the (constructed) history of cuisine, with its attendant researchers and methodologies.

Kaestle's (1997) historiographical account of the history of education in the United States is a useful example to explore in the context of this dissertation proposal, for his account models some of the techniques I propose for my inquiry. He begins by justifying his use of this method: "beliefs about the historical role of schooling in America are encountered everyday as arguments for educational policies" (Kaestle, 1997, p. 75). As I am proposing to do in the context of my topic, he identifies and interprets paradigms (Kuhn, 1996) that guided the writing of the history of education in the United States. He searched for indirect evidence of the paradigms by interpreting the assumptions (his term; they could also be characterized as values) held by historians, and categorizing those assumptions.

He used analytical categories to describe different historical stances. Applying a genealogical analysis (Foucault,1973) to Kaestle's (1997) work, his categorization of historical stances generated a discursive construct of ideas about education, as illustrated by the labels Kaestle chose for the analytical categories. Kaestle divided the history of education into two analytical categories: traditional education history, a period he locates 
in the first half of the $20^{\text {th }}$ century, and revisionist educational history, which took hold

in the 1960s. With the literature/data in my research on the relevance of spirituality in middle grades education, I used the same kind of historiographical approach Kaestle used with his categorization of one stance as traditional and the other as revisionist. I view categorization as both a communication strategy and a productive deployment of power (Popkewitz \& Brennan, 1998): “a political as well as an intellectual strategy for disrupting that knowledge/power relation through making visible and open to resistance the systems of ideas that construct the subject" (p. 20). This description of the research design is not the place to critique the binary implied by Kaestle's (1997) analytical categories of "traditional" and "revisionist." My point is to call attention to the intentionality behind and the effects of analytical categories in historiographical study. In my research, the analytical categories of paradigms I interpret from the data offered, to borrow Huebner's (1999) metaphor, a new landscape of education for middle grades advocates:

Different images of the same landscape enable us to see different possibilities, different relationships, and perhaps enable us to imagine new phenomena in that educational landscape. A new image must be articulated or described so others can move within the landscape as they did in the past, but with greater freedom and new awareness of their choices and limitations. (p. 404)

Kaestle (1997) interpreted categories of the assumptions/values held by educational histories. He used those categories as indirect evidence of paradigms (beliefs) that guided educational policies, practices, and research. In Kaestle's analysis, 
"traditional" educational historians wrote from the following assumptions/values: (a)

education is public, formal schooling; (b) education promotes democracy and freedom; (c) more education is better; and (d) historical evidence comes from educational leaders and institutions, not practitioners and students. Kaestle interpreted two strands of "revisionism" in the writing of education history. One strand expands upon the activities and forms included in the term education. A second strand critiques the previously unquestioned assumption that educational leaders acted as promoters of freedom and democracy. In his historiographical approach, Kaestle interrogated how the history of education has been written and constructed a narrative of his findings. In doing so, he identified the positionality of the historians, the types of sources used in the creation of written histories, and the socio-political contexts in which history is constructed.

Paradigms as a unit of historiographical analysis. Like Kaestle, I used a historiographical method to interpret paradigms that guide the major theoretical literature on the middle grades concept, spirituality as a developmental domain, and holistic education. As a term, paradigm is fraught with complexity in its varied usage (Guba, 1990). In Guba's (1990) introductory chapter on the paradigms in educational research, he defined the term in "its most common or generic sense: a basic set of beliefs that guide action" (p. 17), advocating for definitional plasticity. Because interpretation of paradigms is a keystone of my research, it is necessary for me to briefly review definitions of paradigm and clearly state how I used paradigm in my research. I begin by first examining the concept of the researcher's paradigm and identifying my paradigm as a researcher. 
Researcher paradigm. For researchers, Guba (1990) offered three types of framing questions (i.e., ontological, epistemological, and methodological) that indicate the paradigm from which a researcher conducts his or her inquiry. Applying Guba's paradigm test, I characterize my own researcher paradigm as critical constructivist (Kincheloe, 2008):

When it comes to analysis of the construction of self or the nature of texts, critical constructivists are aware of the discursive practices in which self or text is embedded and the context in which self or text operates. Whether one is attempting to make sense of a novelist, an interviewee or a historical manuscript, discourse and context are central dimensions of the act of knowledge construction. (p. 148)

To describe in more detail the critical constructivist paradigm, I draw from Guba's descriptions of the critical and the constructivist researcher paradigms. Guba (1990) described a critical theory paradigm as reflecting the following statements:

Because they are human constructions, paradigms reflect the values of their human constructors (p. 23)....If values do enter into every inquiry, then the question immediately arises as to what values and whose values shall govern. If the findings of studies can vary depending on the values chosen, then the choice of a particular value system tends to empower and enfranchise certain persons while disempowering and disenfranchising others. (p. 24)

By viewing paradigms as reflective of values, as a critical researcher I interpret the ways certain values are privileged over others. My hunch, as I designed this research project, 
was that the gap within the middle grades literature on the spiritual domain of development had political and social roots.

I chose a critical constructivist lens to explore this hunch because it is an interpretive lens that foregrounds deployment of power and knowledge. An implication of a critical constructivist lens, as suggested by Guba (1990), is that the findings of any study depend upon the values privileged by the researcher's interpretive lens. I have embraced the term findings to describe the results of my research, but my usage reflects Guba's subjectivist meaning as opposed to a positivist connotation of the term. I do not use the term findings to suggest that as a result of this research I have found something that existed before I gave expression to its existence. The results of this work are very much a construction of knowledge rendered from systematic, trustworthy inquiry.

The constructivist aspect of my researcher paradigm, as described by Guba (1990), is reflected in my stance on methodology: "The constructivist proceeds in ways that aim to identify the variety of constructions that exist..." (p. 26). Contrasting critical constructivist methods with positivist ones, Kincheloe (2008) highlighted the main deficiencies of positivist research:

Here, knowledge production is reduced to a notion of rigor that relies exclusively on fidelity to the scientific method. Thus, knowledge production is no longer an act of insight, contextual analysis, intuition and creative brilliances as much as it is a procedure. Critical constructivists demand something more. (p. 102)

Guba described the constructivist methodology as having two processes: hermeneutics and dialectics. As previously stated, hermeneutics is one component of historiographical 
inquiry. In my description of my specific research methods, I outline in more detail how I applied hermeneutics, drawing from constructivist grounded theory data analysis techniques (Charmaz, 2006) and dialectics, drawing from Said's (1993) contrapuntal reading technique for text interrogation.

Defining paradigm. When using the term "paradigm" as a unit of historiographical analysis, I refer to the work of Kuhn $(1996,2000)$. Kuhn (1996), in his historiographical account of the history of science, brought paradigm as a unit of conceptual analysis to the forefront of Western intellectual discourse (Burke, 2001). Kuhn described scientific inquiry as a collective endeavor to understand the natural world, a field of practice characterized by relative consensus disrupted by periods of paradigm "revolution" (p. 92). Kuhn (1996) described the relationship of paradigmatic beliefs with systematic inquiry as directive. He used the metaphor of maps to articulate the ways in which paradigms influence practice:

Paradigms provide [natural] scientists not only with a map but also with some of the directions essential for map-making. In learning a paradigm the scientist acquires theory, methods, and standards together, usually in an inextricable mixture. Therefore, when paradigms change, there are usually significant shifts in the criteria determining the legitimacy both of problems and of proposed solutions. (p. 109)

In the second edition of The Structure of Scientific Revolutions, published in 1970, Kuhn offered further clarification of his definition of paradigm, as a response to the criticism that his use of the term was inconsistent in the $1^{\text {st }}$ edition (e.g., Masterman, 1970). He wrote that he saw two definitions of paradigms. The first was sociological: "it stands for 
the entire constellation of beliefs, values, techniques, and so on shared by the members of a given community" (p. 175). The second usage was more scientific: "on the other hand, it [paradigm] denotes one sort of element in that constellation, the concrete puzzlesolutions which, employed as models or examples, can replace explicit rules as a basis for the solution of the remaining puzzles" (p. 175). In the example I cited about paradigms as maps, both usages are illustrated — paradigms are, according to Kuhn, acquired and sustained within a shared intellectual community through education and application. For me, Kuhn's definition(s) of paradigm reflects Popkewitz's construct of a social epistemology: "A social epistemology enables us to consider the word learning not as standing alone, but as embodying a range of historically constructed values, priorities, and dispositions toward how one should see and act toward the world" (Popkewitz \& Brennan, 1998, p. 9). Like Kuhn's (1996) construct, a social epistemology considers paradigms as discursive practices, i.e., tacit rules that are socio-historical constructions.

I find Kuhn's (1996) theory regarding the role of paradigms in the natural sciences to be a compelling one for my research in the social sciences. Shortly after he died in 1996, an edited collection (Kuhn, 2000) of his work from the last decade of his life reflected refinement but not repudiation of his seminal 1962 theory. In an essay on the natural and social sciences, Kuhn addressed the ways in which his theory regarding paradigm wars could be applicable in both sets of disciplines: "No more in the natural than in the human sciences is there some neutral, culture-independent, set of categories within which the population — whether of objects or of actions — can be described" (p. 220). In my research, I applied Kuhn's theory on the role of paradigms within an academic field as a framing device that complements Popkewitz's (1991) social 
epistemology framework. An implication of that decision was that I interpreted the data for evidence of paradigms.

Interpreting paradigms as a unit of historiographical analysis is akin to a historian's use of artifacts as sources of data. Historians use artifacts to tell a story; historiographers use paradigms to interrogate how a history has been constructed. As artifacts, paradigms are examples of historically contingent practices. For example, Husen (1999) described paradigms as a social and cultural practice: "a paradigm could be regarded as a cultural artifact, reflecting the dominant notions about scientific behavior in a particular scientific community... at a particular point in time" (p. 31). Knowledge of a paradigm, as constructed by the researcher, becomes a unit of historiographical analysis. Popekewitz's $(1991,1997)$ construct of a social epistemology also reflected the historiographer's treatment of paradigms as cultural artifacts, but with the added element of praxis, or action based on reflection (knowledge). Popkewitz (with Brennan, 1998) reframed knowledge "as social practice that generates action and participation" (p. 5). My position as a historiographical researcher in education is that knowledge of the paradigms guiding the (hi)stories of the middle grades concept, spirituality as a developmental domain, and holistic education will potentially generate action among middle grades advocates.

I see great value in the historiographical enterprise of trying to identify dominant historical paradigms in the fields that guide and inform practice in the middle grades. First, the act of naming the basic beliefs privileged in education, and other social science fields that influence education, challenges the ways in which current practices and policies are seen as natural, predetermined, and inevitable (Kincheloe, 2008). Naming 
these basic beliefs allows for alternative and underrepresented perspectives, such as the relevance of spiritual development in public education, to be more seriously considered. Researchers Novoa and Yariv-Mashal (2003) bemoaned the ahistorical characteristic of research in education, characterizing it as "vaporous thinking" (p. 430).

Not only is it impossible to analyse any educational problem without a clear understanding of its historical location, but this way of thinking and here the metaphor of the gas (authors' emphasis) is useful - occupies the totality of the space available, therefore eliminating the possibility of alternative methods and approaches. (p. 430)

A second reason for using paradigms as units of historiographical analysis relates to my research purpose. The topic of spirituality, and its educational relevance, lacks definitional clarity in the field of education in general as well as in the specific sub-field I am trying to influence, middle grades education. A systematic approach, such as the one I conducted, to interrogate rigorously the (hi)stories of spirituality as a developmental domain, the middle grades concept, and holistic education, offers the potential for illuminating areas of confusion and misunderstanding. From my review of the related literature, little knowledge has been produced on the inter-discursive nexus of the three aforementioned fields. I hope that the results of this research will address this gap in the field of middle grades education.

\section{Critical Historiography: Principles and Techniques}

My attempt to create space for alternative visions of middle grades education and bring more clarity to the relevance of spiritual development was well served by a specific type of historiography, the methodology of critical historiography. A primary architect of 
critical historiography in educational research is Kincheloe, who outlines the method in his works on bricolage $(2001,2005)$ and critical constructivism (2008), as well as his work directly on critical historiography (Villaverde, Kincheloe, \& Helyar, 2006). Using Wolcott's (2001) distinction between methodology and method, I describe and justify critical historiography by identifying the underlying principles (methodology), and then by surveying the specific techniques (methods) associated with critical historiography.

Principles. The principles, or dimensions, underlying critical historiography are criticality, affirmative presentism, bricolage, and mutlilogicality (Villaverde, Kincheloe, \& Helyar, 2006). Criticality refers to the perspective that historical discourses reflect constructed relationships between individuals and societal structures that are influenced by power and privilege; that is, history is not a forward march through pre-determined events with definitive causes. In the context of educational reform, Popkewitz (1991) refered to the principle of criticality as "an approach for considering 'change' as social ruptures in ongoing patterns, rather than as an evolution or a chronology of events that seems inevitably or potentially progressive" (p. 3).

Criticality challenges the linear, one-dimensional notion of time (e.g., Greenblatt, 1998) by expanding it to accommodate overlapping and simultaneous experiences. Indeed, the relationship between the past, the present, and the future is fluid, multidimensional, and co-constructed with affirmative presentism. The present is viewed as a process of transformation between past and present, not simply a static period in time (Novoa \& Yariv-Mashal, 2003). This perspective is crucial to my research, as I attempt to interpret the layered effect of situating three previously disparate conceptual fields "as a grid or overlay of historically formed ideas" (Popkewitz, 1997, p. 18). 
Affirmative presentism is a response to the charge that good history does not use

contemporary values and understandings by which to make assertions about the past. An affirmative presentism acknowledges that present values and understandings shape how we construct our transmission of the past. As with the qualitative researcher who acknowledges her subjectivity (e.g., Janesick, 2011) the value of this acknowledgment, from the perspective of a critical historiographer, is to bring more integrity to the researcher's analysis than that of a researcher who claims pure neutrality and objectivity (Henry, 2006). Also, affirmative presentism reflects my critical constructivist paradigm in terms of my relativist ontology and subjectivist epistemology.

What affirmative presentism does not do is substitute fidelity to the data with either cultural relativism or a "rhetoric of blame" (Said, 1993, p. 18). Criteria for establishing rigor and trustworthiness are necessary. For example, Rury (2006) made the distinction between a "sufficient" (p. 330) and a "necessary or definitive explanation" (p. $329)$ in historical inquiry. Rury wrote, "Often it is necessary to move persistently forward and find new evidence to address questions that arise until there is an interpretive frame and descriptive account that seems satisfactory. It is only at this point that investigation abates." (p. 330). Rury's application of the qualitative principle of saturation (Creswell, 2007) to historical research was reflected in my research through my use of constantcomparative analysis (Charmaz, 2006).

The third principle of critical historiography, bricolage, comes from the French verb bricoler; the literal translation is to tinker or fiddle with something. It is also a term used in the context of the visual arts and in humanities research. In both contexts, it means crafting something by using many different resources that are available 
(Kincheloe, 2001, 2005). In the context of critical historiography, it can involve "making connections between apparently disparate ideas" (Villaverde, Kincheloe, \& Helyar, 2006, p. 334) through the use of multiple research methods that draw from different disciplines. This principle of critical historiography supported my intention to re-present three apparently disparate fields as an overlapping grid and my use of interdisciplinary research methods to interpret inter-textual and inter-discursive patterns in the conceptual nexus. As a bricoleur, I borrowed data analysis techniques from constructivist grounded theory (Charmaz, 2006) and literature theory (Said, 1993). In the next section on the techniques of critical historiography, I describe my data analysis strategies in more detail.

The fourth principle, multilogicality, refers to the valuing of different perspectives, particularly those of indigenous people who have been historically silenced through marginalization and oppression. One method of valuing under-represented perspectives is to select primary sources of data generated by marginalized people. I did not select this type of data in this research. Instead, I selected data from sources recognized as authoritative by the audience I wish to address. Because my primary audience is middle grades advocates in the United States, I used as criteria for my data published texts that are foundational to the fields of middle grades reform, spiritual development, and holistic education. After applying these criteria, I was left with texts that were written by authors primarily from the United States, with one Canadian author (Jack Miller) and two European authors (Anton Bucher and Fritz Oser).

However, I honored the principle of multilogicality by applying the data analysis strategy of contrapuntal reading (Said, 1993). As an analysis technique, contrapuntal 
reading involves seeing multiple discourses within a text. The technique of contrapuntal

reading presumes the existence of a tension between dominant discourse and a discourse of resistance (Said, 1993), and foregrounds that tension. Through a critical interpretation of the data, and my re-presentation of the values and beliefs guiding the recommendations of the three fields, the perspectives of marginalized peoples was valued.

These four principles, criticality, affirmative presentism, bricolage, and multilogicality ground this conceptual work in the realm of educational practice. Privileging relationships, having an appreciation of simultaneity, drawing from diverse skill sets, and honoring individual perspectives are all part of my repertoire as a classroom teacher. Although in the next section I describe a primarily conceptual research project, this research is conceived within and intended for middle grades classrooms.

Techniques. The three main research techniques (methods) used in critical historiography are meta-analysis, critical interpretation, and asking unique questions. I describe each technique in the context of how I used each one in my research. In this section I also describe in more detail the data selection/collection and analysis strategies.

Meta-analysis. The first main technique, meta-analysis, has a meaning in critical historiography that is slightly different than the meaning used in the context of quantitative research. In the context of critical historiography, meta-analysis involves looking at the breadth of relevant data sources (e.g., written texts) for what has been included and what has been excluded. In addition, with foundational texts as sources of data, meta-analysis involves interpreting for ways in which the data sources reflect 
challenge and/or acceptance of dominant paradigms. "Meta-analysis instills a critical distance through which to create a bird's eye view of the entire slice of history while simultaneously producing an insider's perspective" (Villaverde, Kincheloe, \& Helyar, 2006, p. 315). The purpose of this technique is to generate knowledge, in the form of a narrative or a conceptual model, based on the production of existing analyses of the related literature. My review of the literature as presented in Chapter 2 is a meta-analysis (in the critical historiographical meaning) that generated a conceptual model of the interfield relationships between applied developmental psychology, middle grades education, and spirituality/spiritual development (see Figure 1). In my meta-analysis, I focused on what has been included. Then, in my data analysis, I focused on the other two parts of a critical historiographical meta-analysis: what has been excluded and how the foundational literature has challenged and/or sustained dominant paradigms. Metaanalysis was crucial to my research design in terms of how I was able to conceptualize and organize the convergence of the fields relevant to my research.

Critical interpretation. Critical interpretation is a second technique of critical historiography (Villaverde, Kincheloe, \& Helyar, 2006). My critical interpretation of the data consisted of looking for evidence of prevalent paradigms for the middle grades concept, holistic education, and spirituality as a developmental domain. My sources of data for a critical interpretation were three to four foundational texts from each of the three fields.

In my critical interpretation, I was guided by the work of Henry (2006), who described contemporary educational historiography as the "revisioning [of] extant bodies of thought, analyzing existing data in new ways" (p. 339). Through Henry's (2006) work 
I was introduced to Said's (1993) data analysis strategy of contrapuntal reading. Henry,

like other critical historiographers (e.g., Kincheloe, 2001, 2005) advocated bricolage as a research principle for rigorous inquiry, and it is from that perspective she cited Said (1993). My historiographical research was also informed by Rury (2006), who situated the importance of hermeneutics in educational research: "Education is a complex, valueladen social phenomenon, of course; thus the role of interpretation has been especially important in the history of education" (p. 326). What Rury drew attention to is the promise of conceptual work for practitioners. I hope to have offered a practical language for thinking and talking about responding to the spiritual development of middle grades students.

I analyzed the data through the lens of criticality using hermeneutics and dialectics, both used by historiographers as research methods. As offered earlier, my paradigm as a researcher is critical constructivism (Kincheloe, 2008). Returning to Guba's (1990) framing questions for researcher paradigms, the following passage describes the use of hermeneutics and dialectics in constructivist methodology:

The hermeneutic/dialectic methodology aims to produce as informed and sophisticated a construction [of the data] as possible. Simultaneously the methodology aims to keep channels of communication open so that information and sophistication can be continuously improved.

Constructivism thus intends neither to predict and control the 'real' world nor to transform it but to reconstruct (author's emphasis) the world at the only point at which it exists: in the minds of constructors. It is the mind that is to be transformed, not the 'real' world. (p. 26-27) 
This passage illustrates the constructivist aspect of my research. My research purpose is better understanding through knowledge production. Both main outcomes of the previous statement, i.e., understanding and knowledge production, are generated through the act of reconstruction within the mind. I now describe how I applied hermeneutics and dialectics during my analysis of the data.

Hermeneutics is "an indispensable branch of historiography" (Bauman, 1978, p. 8). Maclean (1982) described how hermeneutics were applied by $19^{\text {th }}$ century German historiographer Droysen in language that parallels my own application of hermeneutics: "It follows that historical understanding as a method is not an abstract academic exercise but rather the very basis of human praxis brought to the level of scholarly reflection" ( $\mathrm{p}$. 360). Maclean argued that Droysen's "methodology of understanding" (p. 348) pioneered a subjective ontological approach to historical studies in the midst of a field dominated by Hegelian positivism: "Droysen initiated that tradition [in Germany] and established the basic character of the methodology of understanding in defense of history's moral legacy against the strident claims of positivism's technocratic intellectualism" (p. 348).

Droysen's use of hermeneutics as a rejection of the positivist traditions of his time is seen also in the critical constructivist perspective on the value of hermeneutics in research. Kincheloe addresses this point in the following passage:

Critical constructivist scholar-teachers informed by hermeneutics become rigorous researchers of context, perspective and discourse. Drawing on the concept of bricolage, they understand that they must use multiple research tradition and theoretical tools to understand the way these factors influence how we make sense of the world around us. Bricoleurs 
appreciate that any research that fails to account for these dynamics cannot

produce a complex, thick and textured picture of a phenomenon. (p. 24)

To meet Kincheloe's standards for critical constructivist research, I employed three rounds of data analysis in research. I reported the results of my analysis using detailed narrative descriptions.

To explicate my rationale for drawing from constructivist grounded theory analysis strategies, I describe and explore the work of Charmaz (2006). My decision to borrow data analysis techniques from grounded theory, and constructivist grounded theory in particular, was influenced by the approach's safeguards against unproblematized researcher assumptions, perspectives, and preconceptions. These safeguards are (as I summarize them): in vivo codes, constant comparative analysis, coding each datum independently from the others, focused coding, and allowing for ambiguity during the data analysis phase. In short, by choosing to use critical historiographical research as a method for investigating my research question, my data analysis emphasized a critical constructivist interpretation of the data for socio-political beliefs, historically-contextualized values, and ontological and epistemological assumptions. The data analysis techniques and strategies of constructivist grounded theory gave me a vehicle for carrying out this focus in my critical constructivist interpretation.

Constructivist grounded theory, when compared with grounded theory methods advocated by Strauss and Corbin (1998) or other qualitative coding strategies, had many characteristics that were advantageous for this research. The approach allows for ambiguity during the research process, which was useful here given the plasticity of some 
of the major constructs relevant to my research (e.g., spirituality) as well as the unexplored conceptual territory into which I ventured. Charmaz (2006) was direct about the need for a high tolerance of ambiguity during constructivist grounded theory research:

Your observations and ideas do matter. Do not dismiss your own ideas if they do not mirror the data. Your ideas may rest on covert meanings and actions that have not entirely surfaced yet. Such intuitions form another set of ideas to check. Our task is to make analytic sense of the material, which may challenge taken-for-granted understandings. (p. 54)

In addition to being an advantageous strategy for my research, I also see Charmaz's call for researchers to be willing to hold loosely ideas in gestation as the qualitative validation strategy of researcher reflexivity (Creswell, 2007).

From Creswell (2007) I found another reason for this critical constructivist research study to borrow from constructivist grounded theory. He characterized constructivist grounded theory as being about "learning about the experience within embedded, hidden networks, situations, and relationships, and making visible hierarchies of power, communication, and opportunity" (p. 65). This point is not to say that other qualitative methods do not also employ strategies for illuminating subtle themes; Creswell's point here is that constructivist grounded theory techniques have an emphasis on bringing to the surface critical issues related to the ways in which power is replicated through unproblematized assumptions and worldviews. Charmaz (2006) argued this point when she wrote, "coding should inspire us to examine hidden assumptions in our own use of language as well as that of our participants" (p. 47) and initial coding "help[s] you refrain from imputing your motives, fears or unresolved personal issues to your 
respondents and to your collected data" (p 54). Grounded theory's emphasis on findings

coming from the data, as opposed to seeking data to test a pre-conceived hypothesis, appealed to me as another means for addressing researcher reflexivity.

Grounded theory is used when the research purpose is to produce new knowledge, in the form of a theory. I did not produce a theory, nor was I researching a phenomenon described by human subjects, so my research is not exclusively grounded theory. However, in keeping with the critical principle of bricolage, it is appropriate and desirable for me to draw from "multiple methods of inquiry... with diverse theoretical and philosophical notions of the various elements encountered in the research act" (Kincheloe, 2001, p. 682).

As Charmaz (2006) explained, constructivist grounded theory also embodies a dialectical aspect: "You [the researcher] act upon your data rather than passively read them' (Charmaz, 2006, p. 59). However, my application of dialectics will draw from another method of analysis, a contrapuntal reading (Said, 1993) across the three fields. Contrapuntal reading is a technique used by literary theorists, borrowed by critical historiographers (e.g., Henry, 2006). Contrapuntal is the adjective form of counterpoint, a musical technique in which a central melody is harmonized with other independent melodies. Said (1993) described contrapuntal reading as a means of analyzing the “intertwined and overlapping histories" (p. 18) within (the reader's interpretation of) a text. The researcher reads with "a simultaneous awareness both of the metropolitan history that it narrates and of those other histories against which (and together with) the dominant discourse acts" (p. 51). Said's direction for adopting a "simultaneous 
awareness" strongly influenced how I framed one of my major findings in this research:

my interpretation of a dynamic of paradox amongst dichotomous paradigms.

Said's (1993) postcolonial discourse analysis method is consistent with my critical constructivist researcher paradigm: "Informed by local knowledges from multiple social and cultural locations, critical constructivists avoid the grand narrative of Western discourses that are monological in their dismissal of histories and cultural concerns of non-Western peoples" (Kincheloe, 2008, p. 125). The technique of contrapuntal reading is not explicitly referenced by Popkewitz in his work on social epistemology $(1991,1997$, with Brennan, 1998). However, the idea of contrapuntal reading is reflected in Popkewitz's (1991) analysis of “the multiple productive elements of power" (p. 14):

Fixed in the rhetoric of reform, the patterns of schooling and teacher education, and the sciences of pedagogy are multiple and regionally organized procedures, rules, and obligations that organize and discipline how the world is seen, acted on, felt, and talked about. Power, in this positive sense, rests in the complex sets of relations and practices by which individuals construct their subjective experiences and assume an identity in social affairs. (p. 14)

Popkewitz implicitly refers to Said's (1993) contrapuntal reading of texts by identifying the discursive function of educational reform rhetoric, paralleling Said's interpretation of the synergistic tension between discourses of imperialism and discourses of resistance.

Asking unique questions. I conclude this description of and rationale for the techniques of critical historiography with the third technique, asking unique questions. I 
used this technique throughout my research process, including the drafting of my results and how I situated those results within socio-political context.

At the beginning of my research process, I engaged in this technique in the ways in which I framed this topic — as a scaffolding of overlapping fields constructed through my positioning apparently disparate ideas in proximity to each other (see Figure 1). Given the uniqueness of how I view the topic of the educational relevance of the spiritual development of middle grades students, I considered this technique to be both strategic and complementary of my aims and intentions. Asking unique questions gave me direction and permission to challenge hegemonic beliefs about spirituality, academic writing and research, and human development theory and research.

I also employed the technique of asking unique questions when crafting narratives to describe the results of my data analysis, and as a framing device for the discussion of my findings. Villeverde, Kincheloe, and Helyar (2006) described asking unique questions as "an inquiry based method [which] is at the core of a meaningful research endeavor; it fuels curiosity, and recognizes problematic practices and beliefs before considered 'natural' or part of the 'norm"' (p. 315). My composition of the narrative descriptions of the prevalent paradigms for the three (hi)stories of the middle grades concept, spirituality as a developmental domain, and holistic education was guided by this technique's direction to explicitly interrogate the bases upon which claims were made within those (hi)stories. Asking unique questions also encourages the use of my imagination (White, 1987, as cited by Villeverde, Kincheloe, and Helyar, 2006) in order to articulate a discourse of possibility (Giroux, 1981). My discussion of the results of my research is 
framed by the possibilities suggested by including spirituality as a developmental domain relevant for the practice of middle grades education.

Within my discussion of the findings in the context of the middle grades, I addressed how the research illustrates Popkewitz's (1991) social epistemology by making links between the three main paradigms (ecological epistemology, holistic ontology, and positivist ontology) and their discursive interrelationship, and the constitution of two subjects of schooling: developmental domains in the context of middle grades reform and the relevance of spirituality in education. In relating social epistemology to reforms in education, Popkewitz and Brennan (1998) argued, "exploration of these reform themes...provides detailed evidence of the ways in which the connection of knowledge to power operates to constitute the subject[s] of schooling" (p. 23). By making the link between knowledge and power explicit in my discussion of the research findings, I represent spiritual development and middle grades education in unique ways.

Given the fact that the design of this dissertation research for an EdD degree is uncommon (unique), in my discussion of the methodological implications of this study, I also explore in my discussion of the findings how this work fits in with the purpose and format of a professional doctorate in education. Therefore, to conclude my discussion of this research, I address the methodological contributions of this research project to the field of historiography in educational research.

Finally, I conclude this dissertation by addressing how asking unique questions was a strategy for lifting the veil on paradigms that were so deeply embedded in my own consciousness that I was blind to their influence over my powers of interpretation and analysis. Choosing constructivist grounded theory coding strategies supported my 
intention to interrogate not only the normative frameworks of the middle grades concept, spiritual developmental theory, and holistic education but my own paradigms as well: "[grounded theory] coding should inspire us to examine hidden assumptions in our own use of language as well as that of our participants" (Charmaz, 2006, p. 47). Through my use of Charmaz's (2006) instruction for researcher memo-writing before, during, and after the analysis process, I documented my own transformation as a scholar, teacher, and educational leader. While my larger purpose in this research is to influence the field of middle grades education, I address how my endeavors in this project changed me as I entered into “.... a space of transformation where previously excluded perspectives operate to change consciousness of both self and the world. Thus, critical constructivist research changes not only what one knows but who one actually is" (Kincheloe, 2008, p. 132). Before concluding this section on my research design, I want to re-emphasize the purpose of this endeavor: to illuminate what I see as an area of missed opportunity in the field of middle grades education, that is, the explicit inclusion of the spiritual domain as a part of young adolescent development. As I saw it when conceptualizing this research, this oversight was connected to (dominant) cultural understandings about spirituality that are reflected in public education in the United States. By employing a research methodology that allowed me to unearth both the content of the paradigms influencing the related fields and the discursive interrelationships amongst those paradigms, I was able to challenge the illusion of inevitability regarding the exclusion of spiritual development from the middle grades concept. This research is important at this time when cultural understandings about spirituality seem to be shifting to reflect more inclusivity than during previous eras in academia (a bigger tent, so to speak). While my 
research design is certainly not the only way to explore the educational relevance of

spiritual development in middle grades education, based on my professional experiences as a middle and secondary classroom teacher and as an emergent scholar in higher education, a critical historiography felt both timely and responsive to the needs of the field of middle grades education.

\section{Research Methods}

In this section of Chapter Three, I expand upon my rationale for the research methods, and describe the specific processes used during the three rounds of data analysis: initial coding, focused coding, and contrapuntal reading. The account of my specific processes was rendered using the memos I wrote before, during, and after data analysis. Because of the uniqueness of my research design, I decided to include in the Appendix several artifacts from my data analysis processes. I include these artifacts not only as documentation for this account of my research methods during data analysis, but also as references for future critical historiographical research projects.

In Table 7, I outline the activities for each round of analysis, and the products that were generated at the conclusion of each round of analysis. I have included a more detailed delineation of the activities conducted during each of the three rounds in Appendix A. 
Table 7

Data Analysis Sequence

\begin{tabular}{ll}
\hline Round of Analysis & Description of Activity and Product(s) \\
\hline Round One & Initial Coding (Charmaz, 2006) \\
& Each text coded for content and interpreted for assumptions, \\
values, and beliefs; passage-level coding (lengths of passages \\
varied) \\
Product: List of Initial Codes that summarized and accounted \\
for main ideas/theories; quotations that illustrate each \\
datum/Initial Code; belief, value, and assumptions \\
interpretations for each datum/Initial Code \\
\\
Focused Coding (Charmaz, 2006) \\
Constant comparative method across data within each data \\
set; Focused Content Codes constructed from Initial Codes; \\
Paradigm Codes constructed from FCCs and BVA \\
interpretations \\
Product: List of focused Paradigm Codes for each of the three \\
data sets; brief summative memos for each Paradigm Code \\
Product: Lengthy, written interpretive narratives of the \\
paradigms for each of the three fields (5 paradigms per data \\
set) \\
Contrapuntal Reading (Said, 1993) \\
Read across the data sets contrapuntally (analyzing paradigm \\
narratives for evidence of inter-textual and inter-discursive \\
patterns) \\
Product: Written interpretive narrative of the inter-textual and \\
inter-discursive relationships between the paradigms of the \\
three fields. \\
Product: Conceptual diagram of the inter-discursive \\
relationships between the paradigms of the three fields. \\
Round Three
\end{tabular}

I organized my description of the research methods by the order of the three rounds of data analysis, with one exception. The product from the focused coding, the paradigm narratives, are both results of my analysis of the data as well as source materials used for analysis in the third round, contrapuntal reading. Throughout this 
research, consistent with the principles of critical historiography, I have generated

results that were then used as source materials for further loops of the hermeneutic cycle. Except for the paradigm narratives, these results/source materials are included in this chapter. The paradigm narratives are presented in Chapter Four because they represent the findings I used to answer my first research subquestion: What prevalent paradigms underlie the academic discourse on spirituality as a developmental domain, the middle grades concept, and holistic education? I suggest that the reader read one or two of these narratives (in Chapter Four) before reading my account of my contrapuntal reading process in this chapter.

Meta-analysis: data collection/text selection. The findings from my literature review informed my selection of data for this research. I sampled three to four major, foundational works of authority using criteria described below. In Table 8, I list the texts by data set (academic field): 
Table 8

Text Selections, by Field

\begin{tabular}{|c|c|c|}
\hline Middle Grades Concept & $\begin{array}{l}\text { Spirituality as a } \\
\text { Developmental Domain }\end{array}$ & Holistic Education \\
\hline $\begin{array}{l}\text { Alexander, W. M., } \\
\text { Williams, E. L., Compton, } \\
\text { M., Hines, V. A., \& } \\
\text { Prescott, D. (1968) The } \\
\text { emergent middle school. }\end{array}$ & $\begin{array}{l}\text { Fowler, J. (1981) Stages of } \\
\text { faith: The psychology of } \\
\text { human development and the } \\
\text { quest for meaning. }\end{array}$ & $\begin{array}{l}\text { Miller, R. (1997) What Are } \\
\text { Schools For: Holistic } \\
\text { Education in American } \\
\text { Culture }\end{array}$ \\
\hline $\begin{array}{l}\text { Lounsbury, J. H. \& Vars, G. } \\
\text { F. (1978) A Curriculum for } \\
\text { the Middle School Years }\end{array}$ & $\begin{array}{l}\text { Benson (2006) "The } \\
\text { Science of Child and } \\
\text { Adolescent Spiritual } \\
\text { Development: Definitional, } \\
\text { Theoretical, and Field- } \\
\text { Building Challenges" }\end{array}$ & $\begin{array}{l}\text { Kessler, R. (2000) The Soul } \\
\text { of Education }\end{array}$ \\
\hline $\begin{array}{l}\text { Carnegie Council on } \\
\text { Adolescent Development } \\
\text { (1989) Turning Points: } \\
\text { Preparing American Youth } \\
\text { for the } 21^{\text {st }} \text { Century }\end{array}$ & $\begin{array}{l}\text { Oser, F. W., Scarlett, W. G., } \\
\text { \& Bucher, A. (2006) } \\
\text { "Religion and Spiritual } \\
\text { Development Throughout } \\
\text { the Lifespan" }\end{array}$ & $\begin{array}{l}\text { Miller, J. (2007) The } \\
\text { Holistic Curriculum }\end{array}$ \\
\hline $\begin{array}{l}\text { NMSA (2010) This We } \\
\text { Believe: Keys to Educating } \\
\text { Young Adolescents }\end{array}$ & & \\
\hline
\end{tabular}

My decision to sample major foundational works from the wider scope of literature was a historiographical one. In seeking to interpret the paradigms of the (hi)stories of the middle grades concept, spirituality as a developmental domain, and holistic education, I treated foundational literature as historical accounts. Using specific foundational texts as representative of the (hi)stories of academic fields was a historiographical strategy used by Kuhn (1996). Historicizing foundational literature is also consistent with Popkewitz's (1991) social epistemology construct. Popkewitz's 
approach "entails placing particular events in schooling within a historical formation that presupposes relations of power/knowledge. Thus, the focus is on historical conditions, institutional practices, and epistemologies..." (p. 3). Some of my data explicitly incorporates historical background (e.g., Benson, 2006; Miller, 2007). An important implication of my decision to use foundational work as historical accounts is that my data selection process had to employ rigorous validation strategies.

In establishing a set of criteria for data collection, I recalled a lesson from quantitative research: if my inputs are garbage, my analysis will be garbage as well (M. Hara, personal communication, 2011). Although I recognize that my findings will not represent a generalizable "truth" about the world "out there" (a standard desirable by many practitioners in education, e.g., U.S. Department of Education, 2001), the standards of historiographical research require just as much rigor, integrity, and reliability as any other method in educational research. Indeed, as my primary audience is one that resides in a dominant cultural context that is skeptical of spirituality as an educational concern, I was doubly motivated to establish criteria for my inputs (i.e., foundational literature) that meet validity, or trustworthiness, tests. Historiography is neither a qualitative nor a quantitative method, though a historiographer may liberally draw from both research paradigms. For addressing validity issues, I turn to Creswell (2007), an authority in the field of qualitative research. He strongly recommends that investigators explicitly specify their validation strategies as a goodness test for research. Even Wolcott (2001), who rejects validity on the grounds that it is not relevant for a qualitative paradigm, at least addresses the matter directly even if only to refute it. Therefore, I address validation strategies recommended by Creswell (2007) in my description of my research techniques. 
I used the following criteria to select data sources from the fields of the middle

grades concept, spirituality as a developmental domain, and holistic education. I

employed the term field to describe a bounded theoretical and empirical area of academic study. This description is qualified by my acknowledgement that boundaries between academic disciplines are human constructs (Kincheloe, 2008), and therefore are subject to debate. From a social epistemological perspective (Popkewitz, 1991), academic fields are a description and embodiment of the "relation of knowledge and power that structures our perceptions and organizes our social practices," (p. 1). Certainly for the data used in this research, Popkewitz's characterization of academic fields as embodiments of how knowledge is organized as a social practice held true - this phenomenon was seen most clearly in the field of holistic education, which was the most self-conscious about its construction (of the three fields included in this research). With these qualifications and clarifications in mind, I employ the term field.

The data sources were:

- published as a written text;

- from one of the following three fields: spirituality as a developmental domain, the middle grades concept, and holistic education;

- descriptive of the main theories, constructs, and/or ideas of the field;

- written by a recognized authority in the field; and

- written by an advocate of the field.

I now elaborate on the finer points of these criteria for data selection. "Published as a written text" refers to works that have been published in either peer-reviewed journals or as a book. While I could have accessed the publication's content electronically, I did not 
select data that was only published electronically because I wanted to limit my data

sources to texts that had been subjected to a more rigorous review process before being published.

From conducting my literature review, or, as I have described it previously in this section, my meta-analysis, I was confident in my informed ability to (a) categorize a data source as belonging to one of the three fields, and (b) distinguish descriptive literature that speaks to the major ideas of the field from literature that is more narrowly focused.

In my literature review, I observed a range in the breadth and depth of specific pieces of literature. The programmatic and empirical literature was focused primarily on a specific study, such as Greene et al. (2008), "Caught in the Middle Again: Accountability and the Changing Practice of Middle School Teacher," or program implementation, such as Cohen (2005), "Journal Writing in Mathematics Education: Communicating the Affective Dimensions of Mathematics Learning." The theoretical literature ranged from an expansive treatment of the work's topic, such as Benson (2006), "The Science of Child and Adolescent Development: Definitional, Theoretical, and FieldBuilding Challenges" to a highly focused discussion, such as Ryoo et al. (2009): "Critical Spiritual Pedagogy: Reclaiming Humanity Through a Pedagogy of Integrity, Community, and Love." Drawing upon my knowledge of the literature, I selected literature that was theoretical (not empirical or programmatic), comprehensive (wide in scope), and descriptive (of the major ideas of the field) to use as data sources.

In the process of determining whether or not a text met the criteria "descriptive of the main theories, constructs, and/or ideas of the field," three texts were seriously considered, but rejected from this research because I did not think they met this criteria. 
Nel Noddings' (2005) seminal text, The Challenge to Care in Schools: An Alternative

Approach to Education, was suggested by my consultant on the Holistic Education data set; I also recognized it as a hugely influential text for educators and scholars who describe themselves as holistic. However, the Noddings (2005) work is not, in my analysis, descriptive of the field of holistic education as much as it is a significant contributing text for holistic practitioners. I acknowledge that in any comprehensive bibliography of texts for holistic educators, Noddings' (2005) work should be included. However, for this research, I determined it did not meet the descriptive criteria. A second text for the Holistic Education data set, Huebner (1985), was rejected for inclusion as well. In the case of Huebner (1985), my concern was that this work was more closely tied with exploring curriculum theory rather than describing the field of holistic education. Additionally, although Huebner may be influential in the (relatively) small circle of curriculum theorists in the United States, his work is not widely recognized by middle grades educators. In my review of the literature on the middle grades concept, I rarely saw Huebner cited. The final text that was rejected on the grounds of not describing the main ideas of the field was a chapter by King and Roeser (2009). Like the Noddings (2005) text, the King and Roeser (2009) piece is something that should be included as a key reading in a bibliography for adolescent development and/or contemplative pedagogy; but it does not fit the descriptive criteria established for this research. In selecting texts for the spirituality as a developmental domain data set, I made a distinction between texts that focus on spirituality as a developmental domain and those that have a more limited focus (i.e., adolescent spiritual development), rejecting those with a limited focus from this study. 
The last two criteria address the ambitious task of claiming that a source carries

authority and advocacy, included because my primary audience for my research is people working within the field of middle grades education. So, I considered sources of data that are considered authoritative as a communication strategy, i.e., texts to which my audience would be more receptive. The advocacy criteria were important because I was looking for literature (data) that is not merely descriptive but also foundational, that is, influential in the field.

With this research, I assign no definitive claims regarding authority and advocacy. However, to make well-informed decisions, I applied specific strategies for ascertaining authority within and advocacy for the fields, seeking to meet Rury's (2006) standard of "sufficiency" (p. 330) in terms of historiographical research.

Here are the tests I applied to the authors of potential data:

- number of publications in peer-reviewed journals; and

- professional position/history in the academic community.

Here are the tests I applied to the publication itself:

- number of times cited by other authors in peer-reviewed journals; and

- number of times used in syllabi for courses in education (holistic education and middle grades concept texts) and psychology (spirituality as a developmental domain texts)

I also conducted:

- consultations in person or via email with academics I recognized as experts in each of the three fields. 
The tests for the degree of a data source's authority and advocacy met two of Creswell's (2007) eight "validation strategies" (p.207). For qualitative research, Creswell recommended "at least two of them in any given study" (p. 209). The first, triangulation, I addressed by using multiple sources (i.e., publications and record of professional history) to discern the authority of the sources of the data. Using primarily frequency data, Appendix B summarizes the results of the tests I ran on the authors and on the publications.

A second strategy, peer review, I addressed by consulting with expert scholars in each of the three categories of data to verify the appropriateness of my data selection, based on the aforementioned criteria. I consulted: Dr. Micki M. Caskey (middle grades concept); Dr. Robert W. Roeser (spirituality as a developmental domain); and Dr. John (Jack) P. Miller (holistic education). The first two are tenured faculty at Portland State University in Oregon; the third is a tenured faculty member at the University of Toronto in Ontario, Canada. All three are nationally and internationally recognized as expert scholars in their respective fields. After determining strong candidates for inclusion in each data set, I sent an email to each consultant with an abstract of my dissertation research proposal, my list of potential texts, and these five questions:

1. In what ways does each text represent the major theories, constructs, and/or ideas of holistic education (middle grades concept/spirituality as a developmental domain)?

2. In your opinion, is the text authored by an authority in the field? Please explain.

3. In your opinion, is the text authored by an advocate of the field? Please explain. 
4. Although I am not conducting a chronological historiography, do my selections adequately represent a sampling of major works from 1965 and 2012?

5. Given my goal of limiting the selections to four texts, would you make any additions or subtractions to the list?

Two of the three consultants (Dr. Caskey and Dr. Miller) responded in writing; the third, Dr. Roeser was not able to respond in writing, but was available to meet with me in person to discuss my data selections. For that consultation, I took notes during and immediately following the conversation. See Appendix C for the full text of what was sent to the three consultants, the written responses from Dr. Caskey and Dr. Miller, and my post-meeting notes from Dr. Roeser.

After finalizing my text choices, I strategically sampled passages of the longer texts to analyze. The longer texts were: Alexander, Williams, Compton, and Hines $(1968)^{2}$, Lounsbury and Vars (1978), Fowler (1981), Kessler (2000), Miller (1997) and Miller (2007). The four remaining texts were analyzed in their entirety. Decisions about which passages of the longer texts to include were made in accordance with my research purpose: to articulate the educational relevance of the domain of spiritual development in middle grades education by means of interpreting for the conceptual contents of the nexus of the fields of the middle grades concept, spirituality as a developmental domain, and holistic education. Because I was beginning by interpreting for paradigms, I selected passages of the texts that focused on the main ideas, constructs, and/or theories of the related field of study. During this process, I also kept a log of text selections that might be used for a direct contrapuntal reading that is, portions of text that directly addressed

\footnotetext{
${ }^{2}$ From the remainder of this dissertation, this text will be cited as Alexander (1968).
} 
socio-historical issues related to the field. However, as I will explain when I address the limitations of this study, the selections for a direct contrapuntal reading were never analyzed.

For each text, I documented (a) the initial selections of text passages for analysis, (b) my rationale for my selections, and (c) any changes I made to the initial selections. This documentation can be found in Appendix D. In that documentation process, I also revisited some of the choices I had made about which texts to include as data in this study. For example, after initial coding of NMSA (2010) and Carnegie (1989), but while making selections for Alexander (1968) and Lounsbury and Vars (1978), I wondered if I had already collected enough data on the middle grades concept to move forward in the next round of analysis. I made the decision to keep those data.

Typically, I used these passage selection memos to reaffirm the purpose of my overall research and the specific methods I was using to address my main research question. For example, when re-evaluating my selections for Fowler (1981), I wrote: I agree with all of my initial selections (as listed above). But I want to add the italicized stage summaries at the end of each chapter in Part IV. I still think I should be focusing on the paradigms that undergird the theories on spirituality as a dev. domain; but I think that some of that analysis can be done by interpreting for the BVAs reflected in the descriptions of the stages. I liken the descriptions of the stages to the content of the middle grades concept. (i.e., NMSA's 16 characteristics)

The stages I referred to in the above memo were Fowler's stages of faith development. His descriptions of the stages were lengthy and not focused as much as other sections of 
his text on spirituality as a domain of human development. As I noted in one of my text selection memos, keeping the initial coding manageable was a consideration when making passage selections. As it was, the timeline for initial coding (three weeks for all ten texts) proposed in March, 2012 was completely unrealistic. It took me 15 nonconsecutive weeks of focused time to complete the initial coding for all three data sets.

Critical interpretation: Initial and focused coding processes. This subsection has two parts: in the first, I explain the procedures of and my rationale for drawing from constructivist grounded theory (Charmaz, 2006). In the second section, which is further divided into three parts, I describe the processes of initial coding and focused content coding I used for each of the three data sets. My descriptions are organized by data set, and presented in the same order I conducted these first two rounds of analysis: (a) middle grades concept; (b) spirituality as a developmental domain; and (c) holistic education.

Constructivist grounded theory procedures. I applied hermeneutics in my initial two rounds of analysis of the data by interpreting the data (Rury, 2006) from the fields of the middle grades concept, spirituality as a developmental domain, and holistic education. The data from each field (the three to four texts) comprised one data set; in total, I had three data sets. As a bricoleur (Kincheloe, 2001, 2005), I borrowed initial coding strategies from constructivist grounded theory (Charmaz, 2006) to generate codes for the content (main ideas, theories, and constructs of the field) and to interpret for beliefs, values, and assumptions (BVA interpretations).

Initial coding and BVA interpretation occurred during the first round of data analysis. I coded one text at a time by passage level. The length of each passage varied, depending on the content of the passage and the text itself. For example, in a shorter text 
(e.g., NMSA, 2010) the main ideas, theories, and constructs were expressed more

densely than in a longer text (e.g., Fowler, 1981). Therefore, I made the decision to initial code smaller datum (passage) for the denser text. The initial codes and the BVA interpretations served as indirect evidence for categories of paradigms, and were the materials used in the second round of data analysis.

In constructivist grounded theory (Charmaz, 2006), initial coding involves analyzing the data for implicit meaning, tacit knowledge, and assumptions using codes that capture actions and processes. Although Charmaz described initial and focused coding processes with data that are transcripts of interviews, her guidelines for coding worked for my data as well. In constructivist grounded theory coding, the researcher approaches the data without an extant theory in mind. Rather, grounded theorists (e.g., Glaser, 1978) argued that a subject's description of actions, for example, yield initial codes that are highly generative for the purposes of theorizing about the data. Researchers are advised to use gerunds as codes instead of nouns to avoid making codes into topics too early in the analysis process. In my initial coding, I tried to use only gerunds; however with some data I chose to use nouns as initial codes because they seemed to capture my interpretation. The emphasis on fidelity to the data by avoiding naming topics too early seems greater in grounded theory than found in other qualitative coding strategies. Therefore, it was more useful for my research purposes.

One specific initial coding technique is in vivo code names (Charmaz, 2006). In vivo codes "serve as symbolic markers" (p. 55) of the language and meaning of the authors of the texts. In vivo codes are as close to the actual language used within the data as possible. For example, an initial code from Miller (2007) was "merging reason and 
intuition," (p. 8). The datum that this in vivo code came from is: "A more holistic approach calls for a merging of reason and intuition. When these two elements are connected, student thinking is enriched," (Miller, 2007, p. 8). In this example, I used an in vivo code by quoting directly from the datum.

Charmaz (2006) offers three suggestions to keep in mind when applying in vivo coding as an initial coding technique: "Those general terms everyone 'knows' that flag condensed but significant meanings; a participant's innovative shorthand term that captures meanings or experience; [and] insider shorthand terms specific to a particular group that reflect their perspective" (p. 55). Charmaz's strategies kept my analysis grounded in the data and, at the crucial initial stage of data analysis, enabled me to produce analytical codes that were reliable for further analysis. Initial codes were refined, verified in terms of how well they capture the data, and expanded in the next round of data analysis, focused coding.

Focused coding, also an analytic technique of constructivist grounded theory (Charmaz, 2006) analysis technique, occurred during the second round of data analysis. The purpose of focused coding is:

...to synthesize and explain larger segments of data. Focused coding means using the most significant and/or frequent earlier codes to sift through large amounts of data. One goal is to determine the adequacy of those codes. Focused coding requires decisions about which initial codes make the most analytic sense to categorize your data incisively and completely. (p. 57-58) 
Focused coding, as implied by the preceding quotation, is not a linear process.

Constant comparative analysis is used as part of focused coding - it is an iterative form of data analysis that involves looping back and forth between the data, the codes and the "emergent" categories (e.g., Charmaz, 2006, p. 45). Refinement of the categories is part of the purpose of focused coding. Examples of specific constant comparative methods are: comparing data with other data for similarities and differences, analyzing within data comparisons, making sequential comparison between data coded early on and data coded last, and comparison within each data set (Charmaz, 2006), in my case, different texts.

For this research, I went through two sub-rounds of focused coding: using just the initial codes, I constructed focused content codes (FCCs). Then in a second sub-round of focused coding, I analyzed the beliefs, values, and assumptions interpretations that accompanied each initial code by categorizing all the BVA interpretations by the FCCs. This process of data analysis was strongly guided by the technique of constantcomparative analysis. I rendered paradigm categories from the two sub-rounds of data analysis; I composed brief paradigm memos immediately following focused coding to document my analysis. After completing initial and focused coding for all three data sets, I wrote thick descriptions of the paradigms in each of the three fields, as interpreted through my critical constructivist lens. In these narratives, the paradigm categories were illustrated by quotations from the texts as evidence supporting my interpretation of the data.

I now turn to a description of the analytical procedures I went through for this research. Because this study uses a research approach, critical historiography, not common to educational scholarship, especially as it relates to K-12 settings, I have 
chosen to lay out in detail the analytic procedures I employed and to make transparent the two levels of interim codes that led to the paradigms categories and their resulting descriptions. I also describe some of the tensions and issues I navigated in the process. Not only does my doing so create credibility for the findings described in Chapter Four, but doing so further contributes to the usability of this approach by other educational researchers who may not initially see it as an option in a world that privileges empirical studies.

Because I analyzed the data one data set, or field, at a time, I present each in the same order, addressing methods and issues that arose for each data set. For each data set, I provide frequency data for the initial codes (ICs) and beliefs, values, and assumptions interpretations (BVA interpretations), identify the focused content codes (FCCs), and identify the paradigm categories.

Middle grades concept. For this data set, 220 initial codes were generated during the first round of interpretive analysis. For each initial code, which described the content of each datum, excerpts from the same selection of text that illustrated the initial code were identified and documented on the coding sheets. I selected 293 quotations to illustrate the initial codes. Each datum was also interpreted for the beliefs, values, and assumptions, using a critical constructivist interpretive lens. In the Middle Grades Concept data set, I documented 135 interpretations of beliefs, 189 interpretations of values, and 71 interpretations of assumptions. Table 9 shows the frequency of initial codes, quotations, and BVA interpretations for each text in the Middle Grades data set. 
Table 9

Frequency Data for Initial Coding of Middle Grades Concept Data Set

\begin{tabular}{lccccc}
\hline Text & $\begin{array}{c}\text { Initial } \\
\text { Codes }\end{array}$ & Quotations & Beliefs & Values & Assumptions \\
\hline Alexander 1968 & 47 & 53 & 33 & 51 & 17 \\
Lounsbury/Vars 1978 & 45 & 62 & 23 & 25 & 20 \\
Carnegie 1989 & 69 & 95 & 47 & 65 & 32 \\
NMSA 2010 & 59 & 83 & 32 & 48 & 22 \\
\hline
\end{tabular}

My analysis of the body of initial codes yielded eight focused content codes (FCCs) that reflected themes in the content of the middle grades concept, as rendered from the four texts. Developing the final eight FCCs involved looping back and forth amongst the ICs of all four texts, as well as referencing the quotations as needed to further refine and distill the FCCs to ensure that I captured the main themes of the middle grades concept. The eight FCCs for this data set are:

1. The middle grades as a critical period, for individuals and for society

2. School mediates growth and development/Developmentally responsive education/Process over product

3. Integration and interrelationships among domains and types of knowledge

4. Relationships (people)/collaboration and community

5. Intrapersonal development/Courage and empowerment

6. Social constructivist learning theory

7. Middle grades as educational reform

8. Differentiation/Seeing the sum, seeing the parts 
As this was the first set of data I analyzed, the names of these FCCs were less refined than the FCCs of the other two data sets. A tension I experienced in the focused coding process was between distillation of analytical expression and fidelity to the data. In my process of analyzing the body of initial codes, I sought to group together content themes that were related (i.e., "Relationships (people) and Collaboration and Community") even if that made the FCCs cumbersome. I decided to use FCC names that retained the subtle distinctions of the themes. With the knowledge that my goal in the hermeneutic circle was to develop a manageable number of paradigm categories, I also wanted to keep the number of FCCs manageable without over-generalizing the content themes in the process. Another factor in my thinking about the FCC names for this data set was an awareness that the process of crafting FCCs was not the final product in the overall research project. Focused coding - in this research as in a more traditional constructivist grounded theory research project-is an important, but still intermediary step in a larger interpretive analytical process. Categories, at this stage of analysis are emergent (Charmaz, 2006). In reviewing my focused coding several months afterwards, I chose to leave the labels as I had constructed them at the time (May - June, 2012).

Another tension I navigated during this part of the data analysis was focusing on content and capturing that aspect of the data. In my research notes, I documented moments when I worked through distinctions between describing content as processes, i.e., FCC 'school mediates growth and development' and labeling the data with terms and concepts not used in the data. The latter suggested data analysis that emphasized naming topics over describing processes. Social constructivism was described in many places in the texts and hence, I include it as one of the final eight FCCs, but the term "social 
constructivism" was not used in most of that data. As a strategy for effectively

communicating to my audience using terminology with which I assumed they would be familiar, I chose to depart from in vivo coding for two of the focused content codes: 'Social constructivist learning theory' and 'Differentiation.'

As I moved to the next round of data analysis - interpreting for paradigms-I was aware of the need to produce a set of FCCs that conveyed the substance of the middle grades concept without inserting too much of my interpretation of the beliefs, values, and assumptions that guided the advocates of the middle grades concept. The development of focused content codes functioned as a validity strategy, as well as an analysis technique, to keep the paradigm categories firmly grounded in the content of the middle grades concept. As units of historiographical analysis, the paradigm categories needed to reflect the particular ideas and positions of the middle grades advocates.

I used the eight FCCs to categorize the 395 BVA interpretations (See Appendix E for BVA Interpretations by FCCs). At the end of the categorization process, a small number of BVA interpretations were left uncategorized (i.e., did not "fit," according to my analysis, with one of the eight FCCs). Accounting for the uncategorized BVA interpretations in this data set proved to be a valuable check on my fidelity to the data. However, in keeping with Charmaz's (2006) counsel to be comfortable with ambiguity during this stage, I decided to allow those uncategorized BVA interpretations to remain unaccounted for as I moved on to the next phase of interpretive data analysis.

Once most of the BVA interpretations were categorized by FCC, I began to analyze those tables to articulate paradigms for the middle grades concept. During this last round of analysis, the FCCs were re-evaluated once again as part of the process of 
developing paradigm categories. For example, the FCC "Middle Grades as critical period" corresponded to very few supporting BVA interpretations from three of the four texts; only the analysis of Carnegie (1989) yielded frequent BVA interpretations. However, there were sufficient initial codes to support "Middle grades as a critical period" as an FCC. In my analytical notes on this FCC I wrote, "I don't think this data reflects a complete [focused content code] category. Right now it is a partial category...the uncategorized BVA statements are related to this data...Turbulence of ya [young adolescents], turbulence of society, threats, fears, perils...[As a paradigm] this category could include 'mgc as ed reform' It is also related to, but separate from, 'Nurturing the Nature"' (Analytic Notes, 5/24/12). By screening the eight FCCs with the BVA interpretations, I was in a position to suggest paradigm categories that were supported by the data. My analysis of the BVA interpretations categorized under the FCCs "Middle grades as critical period" and "Middle grades as educational reform" suggested the paradigm code "Perceiving Perils." I used my handwritten notes, found mostly on the hard copies of the categorized BVA interpretations, during this phase of interpretive analysis as a resource for developing paradigm categories (e.g., applying the term 'perils' as part of one of the final MGC paradigm categories).

In the course of analyzing the FCC-categorized BVA interpretations for paradigms, I began to account for the BVA interpretations from this data set that I had not categorized by FCC. After developing some initial ideas about potential paradigms, I went back through the uncategorized BVAs with the nascent paradigm categories in mind. Thirty of the sixty-four uncategorized BVAs (e.g., "Belief - race, SES, family structure, geographic location, and ELL impact educational opportunities/experiences;" 
BVA interpretation from Carnegie, 1989, pp. 20-21) seemed to correspond with the emergent paradigm category "Perceiving Perils." This analysis lent support to the robustness of the emergent paradigm category, and is a good example of how I applied the constant-comparative method to establish the trustworthiness of my data analysis. Some BVA interpretations (e.g., "Value—aligning [teacher] preparation with purpose/function of mg schools;" BVA interpretation from Alexander, 1968, pp. 97-99) were left uncategorized in one of the eight FCCs, and did not seem to support the emergent paradigm categories, according to my analysis.

After analyzing the BVA interpretations as categorized by the eight FCCs, accounting for uncategorized BVAs, and re-examining the FCC categories, I rendered five paradigm categories: Separating and Re-Integrating, Nurturing the Nature, Perceiving Perils, Be-Coming Together, and Empowering Education.

Spirituality as a domain of human development. For this data set, 117 initial codes were generated during the first round of interpretive analysis. For each initial code, which described the content of each datum, excerpts from the same selection of text that illustrated the initial code were identified and documented on the coding sheets. I selected 147 quotations to illustrate the initial codes. Each datum was also interpreted for the beliefs, values, and assumptions, using a critical constructivist interpretive lens. In the Spirituality as a Developmental Domain data set, I documented 123 interpretations of beliefs, 69 interpretations of values, and 43 interpretations of assumptions. Table 10 shows the frequency of initial codes, quotations, and BVA interpretations for each text in the Spiritual Development data set. 
Table 10

Frequency Data for Initial Coding of Spirituality as a Developmental Domain Data Set

\begin{tabular}{lccccc}
\hline Text & $\begin{array}{l}\text { Initial } \\
\text { Codes }\end{array}$ & Quotations & Beliefs & Values & Assumptions \\
\hline Fowler 1981 & 47 & 58 & 48 & 31 & 16 \\
Benson 2006 & 33 & 45 & 35 & 19 & 12 \\
$\begin{array}{l}\text { Oser, Scarlett, \& } \\
\text { Bucher 2006 }\end{array}$ & 37 & 44 & 40 & 19 & 15 \\
\hline
\end{tabular}

During my process of interpreting beliefs, values, and interpretations for the Oser, Scarlett, and Bucher (2006) text, I faced a research decision. This text is unique from the other texts in my research in that, as a chapter in a handbook on child and adolescent development, it includes a review of the literature on the prevailing scholarly explanations of child and adolescent spiritual development. According to the memo I wrote on October 10, 2012, I needed to decide which author's perspective I was interpreting for beliefs, values, and assumptions. Therefore, the decision I had to make was: am I interpreting for the BVA of Oser, Scarlett, and Bucher? Or, am I interpreting for the BVA of the authors Oser, Scarlett, and Bucher have identified as prominent contributors to the field of spiritual development? My decision and my rationale are reflected in this quotation from my research journal: "I think (from a researcher perspective) it's OK to switch the focus of my BVA interpretation b/c [because] THE AIM of the data collection and data analysis is to create a picture/story of the field of spiritual development" (Oct. 10, 2012). In my analysis, I shifted the focus of my BVA interpretation between the authors of the chapter and the authors referenced in the 
chapter. Although the various theories on spiritual development were critiqued by Oser, Scarlett, and Bucher (2006), the inclusion of the specific theories and their authors in an authoritative handbook in the field of developmental sciences was interpreted by me as primary evidence of how the "story" of the field of spirituality as a domain of human development is told. Critical questions such as Whose voice is heard? Which knowledge is legitimized? were still relevant in my interpretation of this text for beliefs, values, and assumptions.

My analysis of the body of initial codes yielded five focused content codes, which reflected themes in the content of the field of spirituality as a domain of human development, as rendered from the three texts. As with the previous data set, developing the final FCCs involved looping back and forth amongst the ICs of all three texts, as well as referencing the quotations as needed to further refine and distill the FCCs to ensure that I captured the main themes of the field. The five FCCs for this data set are:

1. Constructing spirituality (in the academy)

2. Theorizing about human development

3. Paradox as a heuristic

4. Crucibles of spiritual development

5. Contents of domain of spiritual development In an effort to craft focused codes that distilled my analysis without sacrificing my fidelity to the data, I used a new strategy during this phase of coding. After generating lists of potential focused codes and applying constant comparative analysis in conjunction with memo-writing, I constructed a table that categorized the longer list of focused codes with my potential FCCs. The longer list of focused codes represented the 
sub-categories for each FCC; trying to sort the sub-categories by the focused code

categories enabled me to account for the data and test the strength of the FCCs. The table became a tool of my data analysis process.

Table 11

Sub-categories by Potential Focused Content Codes

\begin{tabular}{|c|c|c|c|c|}
\hline $\begin{array}{l}\text { Constructing } \\
\text { spirituality }\end{array}$ & $\begin{array}{l}\text { Theorizing } \\
\text { about human } \\
\text { development }\end{array}$ & $\begin{array}{l}\text { Paradox as a } \\
\text { heuristic }\end{array}$ & $\begin{array}{l}\text { Crucibles of } \\
\text { spiritual } \\
\text { development }\end{array}$ & $\begin{array}{l}\text { Contents of } \\
\text { domain of } \\
\text { spdev }\end{array}$ \\
\hline $\begin{array}{l}\text { Function/role } \\
\text { of [spdev]/ } \\
\text { spirituality }\end{array}$ & $\begin{array}{l}\text { Relying on } \\
\text { empiricism }\end{array}$ & $\begin{array}{l}\text { Paradoxes } \\
\text { abound }\end{array}$ & $\begin{array}{l}\text { Social } \\
\text { constructivist } \\
\text { epistemologies }\end{array}$ & $\begin{array}{l}\text { Lenses/ } \\
\text { Frameworks/ } \\
\text { Orientations }\end{array}$ \\
\hline $\begin{array}{l}\text { Needing } \\
\text { scholarship }\end{array}$ & $\begin{array}{l}\text { Universal } \\
\text { process of } \\
\text { human } \\
\text { development }\end{array}$ & Heuristic & $\begin{array}{l}\text { Interplays: } \\
\text { between domains } \\
\text { (moral, cognitive, } \\
\text { social, emotional); } \\
\text { between person \& } \\
\text { cultural context; } \\
\text { between structures } \\
\text { and contents }\end{array}$ & $\begin{array}{l}\text { Myth-making/ } \\
\text { Narratives }\end{array}$ \\
\hline $\begin{array}{l}\text { Spirituality and } \\
\text { Religion as } \\
\text { constructs }\end{array}$ & $\begin{array}{l}\text { Stage-structural } \\
\text { and } \\
\text { developmental } \\
\text { systems }\end{array}$ & $\begin{array}{l}\text { Domain } \\
\text { independent/ } \\
\text { Inter- } \\
\text { dependent }\end{array}$ & Crucibles & Transcendence \\
\hline \multirow{2}{*}{$\begin{array}{l}\text { Historical/ } \\
\text { Contemporary } \\
\text { perceptions } \\
\text { about } \\
\text { spirituality }\end{array}$} & $\begin{array}{l}\text { Structures vs } \\
\text { content of } \\
\text { spdev }\end{array}$ & $\begin{array}{l}\text { Creating/ } \\
\text { Inheriting }\end{array}$ & Interplays & Pathways \\
\hline & $\begin{array}{l}\text { Strengths } \\
\text { emphasized } \\
\text { over deficits }\end{array}$ & $\begin{array}{l}\text { Universality/ } \\
\text { Diversity }\end{array}$ & & $\begin{array}{l}\text { Trust/Mutuality } \\
\text { / Attachment }\end{array}$ \\
\hline
\end{tabular}


The table illustrates one way I sorted through the emerging codes using inductive reasoning. As a snapshot of my data analysis, it also illustrates how I developed an emergent interpretation of the paradigms for this data set. For example, as a content code, FCC 'Crucibles of Spiritual Development' foreshadowed the paradigm category 'Seeing Crucibles.” In this phase of my analysis, I captured the specific 'crucibles' (e.g., interplays between person and context) that were identified as part of spiritual development (e.g., interplays between person and context). In the next phase of analyzing the BVA interpretations for evidence of paradigms, I incorporated my content analysis to yield an interpretation that made explicit how the authors saw crucibles as part of their explanations of spiritual development.

In the process of categorizing the 235 BVA interpretations by the five focused content codes, I found that several BVA interpretations fit under more than one FCC. In my research journal I characterized this overlapping categorization as "fuzziness," especially between the FCCs 'Constructing spirituality' and 'Contents of the domain of spiritual development.' When I went back to review the initial codes and corresponding quotations from the data, however, my rendering of these two focused content codes as distinct from each other was affirmed by the data. I added a parenthetical clarification of "in the academy" to the FCC 'Constructing spirituality' as a result of re-analyzing the ICs and quotations. I accounted for the fuzziness in BVA categorization by labeling the mutli-categorized BVA interpretations using italics and colors (See Appendix F for Spiritual Development BVA by FCC).

In hindsight, I was not too surprised to experience BVA interpretation overlap between the focused content codes that captured the data on definitional aspects of 
spirituality. From my review of the literature on spirituality in education and theories of spiritual development, I was aware that definitional ambiguity in Western cultures was a major theme in the empirical, theoretical, and programmatic literature. Therefore, beliefs, values, and assumptions related to constructs of spirituality in an academic context were bound to show up in focused content codes that addressed data reflecting the construction of spirituality. For the purposes of this research, parsing the distinctions in terms of aligning content with beliefs, values, and assumptions was less strategic than allowing for areas of overlap in this stage of data analysis. As with the data set on the middle grades concept, where I encountered BVA interpretations that did not "fit" into one of the FCCs, my decision to allow for ambiguity at this stage was guided by the principles of constructivist grounded theory.

In the course of analyzing the FCC-categorized BVA interpretations for paradigms related to spirituality as a domain of development, I was able to clarify the boundaries of my analytical codes that captured data on defining spirituality by reframing these data in the language of paradigms. My research memos on emergent paradigms for the categorized BVA interpretations from the FCC 'Contents of the domain of spiritual development' illustrate my analytical process in this transition from focused content codes to focused paradigm codes. When documenting my analysis of the patterns in the BVA interpretations, I interpreted 2 subcategories: ways of characterizing what happens during spiritual development and ways of characterizing how spiritual development happens. In my memo from October 22, 2012, I observed:

It's interesting that what emerged is those 2 subcategories...because I don't think I would have 'captured' the data in such a way before sitting 
down to review the BVA [interpretations]. I still see a major distinction between [a] describing the paradigms behind theorizing about spdev [spiritual development] and [b] describing the paradigms behind the theories of spdev [spiritual development]. Because this [arrow pointing to the former subcategory] seems to be a major Focused Content Code. And I've observed that in my review of the literature on spdev theory, spdev research, spirituality \& education...basically, wherever 'spirituality' is addressed in the social sciences.

In rendering the paradigm categories, the two categories that resulted from the part of my analysis described above are: Legitimizing Spiritual Development and Aligning Heart and Will. The other three paradigm categories, Mapping the Human Journey, Allowing Paradox, and Seeing Crucibles, encompassed some of the definitional themes as well.

Holistic education. For this data set, 100 initial codes were generated during the first round of interpretive analysis. For each initial code, which described the content of each datum, excerpts from the same selection of text that illustrated the initial code were identified and documented on the coding sheets. I selected 108 quotations to illustrate the initial codes. Each datum was also interpreted for the beliefs, values, and assumptions, using a critical constructivist interpretive lens. In the Holistic Education data set, I documented 93 interpretations of beliefs, 98 interpretations of values, and 39 interpretations of assumptions. Table 12 shows the frequency of initial codes, quotations, and BVA interpretations for each text in the Holistic Education data set. 
Table 12

Frequency Data for Initial Coding of Holistic Education Data Set

\begin{tabular}{lccccc}
\hline Text & $\begin{array}{l}\text { Initial } \\
\text { Codes }\end{array}$ & Quotations & Beliefs & Values & Assumptions \\
\hline R. Miller 1997 & 38 & 40 & 34 & 35 & 21 \\
Kessler 2000 & 40 & 41 & 37 & 39 & 13 \\
J. Miller 2007 & 22 & 27 & 22 & 24 & 5 \\
\hline
\end{tabular}

When I began the first round of initial coding, I only analyzed the J. Miller (2007) and R. Miller (1997) texts, because I had second thoughts about including the Kessler (2000) text in my data set. I hesitated because the focus of Kessler's text is less on the field of holistic education, and more on classroom-based practices to implement holistic education. I made the decision to proceed with the first three rounds of interpretive analysis (initial coding, focused content coding, and categorizing BVA interpretations by FCC) without the Kessler text. After doing so, I did not feel like I had analyzed sufficient data to render paradigm categories. I based this decision on my review of the focused content codes and categorized BVA interpretations. My initial analysis of just the two Miller texts seemed incomplete in two emergent focused content codes: a cultural critique of education and ontological/epistemological beliefs. I made strategic selections from the Kessler (2000) text that focused more on the theory of holistic education than on specific classroom-based practices. I interpreted the Kessler data for initial codes and beliefs, values, and assumptions. I then re-analyzed the set of initial codes that now included the Kessler data for focused content codes. I also re-categorized the BVA interpretations by FCC with the Kessler data in the set. In other words, I did not simply integrate the 
Kessler ICs and BVA interpretations into the focused content coding analysis from just the J. Miller (2007) and R. Miller (1997) data analysis. I essentially started the focused content coding and BVA categorization all over from the beginning with the expanded data set. With the inclusion of the Kessler data, the FCCs were more robust, and I was satisfied that I had analyzed sufficient data to interpret for paradigms.

I briefly compared the focused content coding and BVA categorization that resulted from the two data sets (one without Kessler, one with Kessler), to see if I could interpret any differences. The main difference I noticed was that with the inclusion of the Kessler data, the FCCs 'Educating in community' and 'Conceptualizing spirituality' were more substantially supported by the data in terms of both initial codes and BVA interpretations. I also noticed the ways in which Kessler's K-12 practitioner voice fleshed out the story of holistic education that was told by the higher education academics, John Miller and Ron Miller. My comparative analysis was brief, however, and only conducted as validation strategy for my analysis of the data.

In rendering the focused content codes, I used the same procedures I used for the data set on Spiritual Development. After reading through the entire list of initial codes, I composed a list of potential FCCs based on my impressions (without referring back to the ICs). Then, I went through the ICs a second time, to create a new list of potential FCCs while concurrently referring to the ICs. After revising both lists a third time while in constant contact with the ICs and the quotations, I began to articulate potential main FCCs and subcategories of FCCs. As with the Spiritual Development data set, I categorized the subcategories by the emergent main FCCs in order to organize my 
analysis and evaluate the fidelity of my analysis to the data (see Appendix G for this document).

I rendered five focused content codes for the Holistic Education data set:

1. Seeking Balance/Transforming Culture

2. Spiritual Epistemology

3. Educating in Community

4. Conceptualizing Spirituality

5. Re-Framing Accountability

I then categorized the beliefs, values and assumptions interpretations by the five FCCs. I did not find as many BVA interpretations that overlapped with more than one FCC (as I had found in the Spiritual Development data set). The most frequent area of overlap was the BVA interpretations for the FCCs 'Re-framing accountability' and 'Seeking balance/transforming culture.' For the BVAs that did overlap, I used the same process of color-coding in the BVA by FCC table to keep track of that analysis. I used the BVA by FCC table to interpret for patterns that might reflect paradigms (Appendix H). As with the other two data sets, I documented initial impressions and emergent analysis with analytic memos in my research journal.

After analyzing the BVA interpretations as categorized by the five FCCs, accounting for the few uncategorized BVAs in this data set, and re-examining the FCC categories, I rendered five paradigm categories: Claiming Ontological Truths, Knowing with Wholeness, Schooling for Cultural Consensus, Re-Framing Accountability, and Beliefs About What it Means to be Human. 
Critical interpretation: Contrapuntal reading. The third round of data

analysis involved a contrapuntal reading (Said, 1993) of the paradigm narratives. In this section of my description of my research methods, I first describe the procedures of and my rationale for contrapuntal reading as a data analysis technique, then I describe the processes I used in this research.

For readers unfamiliar with Said's (1993) work on contrapuntal reading, I can offer an example from his application of this analytical technique in the context of his work in the field of literary theory. Applying a contrapuntal reading to Joseph Conrad's Heart of Darkness, first published in 1899, Said notes:

Conrad is so self-conscious about situating Marlow's tale in a narrative moment that he allows us simultaneously to realize after all that imperialism, far from swallowing up its own history, was taking place in and was circumscribed by a larger history, one just outside the tightly inclusive circle of Europeans on the deck of the Nellie. As yet, however, no one seemed to inhabit that region, and so Conrad left it empty (p. 24). This passage reflects a critical historiographical approach akin to the one I used for this research. In his analysis of the text, Said addressed the positionality of the author by accounting for how Conrad's cultural status in England in the late 1800s affected his work: "your self-consciousness as an outsider can allow you actively to comprehend how the machine works, given that you and it are fundamentally not in perfect synchrony or correspondence" (p. 25). Said also named how the white narrator, Marlow, wields power over the text's (European) audience in their reliance upon Marlow as a source of authority on indigenous peoples of Africa. In later passages, Said addressed the ways in 
which he sees the inter-discursive relationship between the imperial discourse and the

discourse of resistance when he interpreted the narrator's unwillingness to view "nonEuropean 'darkness' [as] in fact a non-European world resisting imperialism so as to one day regain sovereignty" (p. 30).

Said was insistent on not polarizing the two forms of discourse into the binaries of oppressor and oppressed (a "rhetoric of blame," p. 18); instead he urged for a contrapuntal reading that sees the connections saying: "We must be able to think through and interpret together experiences which are discrepant, each with its particular agenda and pace of development, its own internal formations, its internal coherence and system of external relationships, all of them co-existing and interacting with others" (p. 32). Doing so, he argued, “enables us to appreciate [ideology's] power and understand [ideology's] continuing influence" (p. 33). Said's emphasis on connection over polarization directed my analysis of the data towards an interpretation of inter-textual and inter-discursive patterns within the categories of paradigms. Said's direction aligned with my research purpose of better understanding educational relevance of spiritual development, as opposed to an investigation of the extent to which issues of spirituality have been silenced in education in the United States.

I had three reasons for my decision to draw from Said (1993) as a data analysis strategy in critical historiographical research. First, the technique of contrapuntal reading is consistent with the principles of critical historiography—for instance, criticality and multilogicality. In contrast to multilogicality, criticality emphasizes the constructed and regulatory nature of social and historical discourse (Henry, 2006; Popkewitz, 1991; Villaverde, Kincheloe, \& Helyar, 2006) whereas the latter emphasizes the perspectives 
that have not been valued in the dominant discourse construction. Said (1993)

acknowledged the former, criticality, and provides a discourse analysis strategy for hearing the voices of the latter, multilogicality.

Second, the contrapuntal strategy of reading for the tension between a discourse of imperialism and a discourse of resistance (Said, 1993) offered me direction as I interpreted for the discursive practices of the convergence among the paradigms of the middle grades concept, spirituality as a developmental domain, and holistic education while being aware of the cultural/historical context in which these texts were produced and are read. Said described contrapuntal reading as "a procedure [that] entails reading the canon as a polyphonic accompaniment to the expansion of Europe" (p. 60). In my discussion of my findings, I address how the canons of the three fields I investigated could be read as an accompaniment to educational reform priorities in the United States.

Third, the metaphor of counterpoint fits well with my conceptual model of the inter-relationships between and among the related fields (Figure 1). My researcher's hunch during the design of this project was that a better understanding of the educational relevance of spiritual development lies within that nexus. But to illuminate its contents, a data analysis strategy that resembled counterpoint in music was useful as I sought to create melody out of disparate yet interrelated strands of harmony. Contrapuntal reading starts from the perspective that texts have many layers of meaning that can be deconstructed and then reassembled into a coherent narrative. Said's (1993) instruction to read contrapuntally, instead of univocally, reflects how, as a critical constructivist, I have conceptualized where a better understanding of the educational relevance of spirituality is to be found. 
Although Said (1993) offered guidance on how to contrapuntally read a

narrative, my use of the specific analysis strategy of interpreting for inter-textual and inter-discursive patterns is a reflection of how I operationalized contrapuntal reading for the purposes of this critical constructivist research. Said does not use the specific terms "inter-textual" and "inter-discursive" but I find similar meanings in his written descriptions of contrapuntal reading. Both Said and Kincheloe (2008) write about data analysis that is deeply critical in its emphasis on making explicit power dynamics and tacit rules, as well as deeply constructivist in its subjectivist ontology.

When I first conceived of this research design, I wrote of inter-textual and interdiscursive as two categories by which to organize my analysis. However, when I actually began this analysis, I re-conceived inter-textual and inter-discursive as two interpretive lenses by which to analyze the narratives. The inter-textual lens allowed me to interpret for textual expressions such as specific terms or phrases, metaphors or analogies, ideas, or positions that were commonly shared by the three data sets. Kincheloe's (2005) definition of inter-textual referred to "the complicated interrelationship connecting a text to other texts in the act of textual creation or interpretation" (p. 329). In my analysis of the paradigm narratives, I focused on the second part of the interrelationship (interpretation), while in my discussion of the implications of the conceptual contents of the nexus of the three fields, I incorporated the interrelationship that connected the texts in the acts of their creation (i.e., their historical contexts).

The inter-discursive lens allowed me to interpret for paradigms that were commonly shared by all three data sets. In this research, I defined paradigms as discursive practices in accordance with Kincheloe's (2008) definition of inter-discursive: 
"Discursive practices are defined as a set of tacit rules that regulate what can and cannot be said, who can speak with the blessing of authority and who must listen, whose socioeducational constructions are scientific and valid and whose are unlearned and unimportant" (p. 36). This definition was also in accordance with Kuhn's (1996) analogy of paradigms as maps as well as the rules for map-making. By combining Kincheloe's (2008) definition of discursive practices with Kuhn's (1996) definition of paradigms, I crafted a critical historiographical data analysis strategy that interrogated and made explicit the ways in which the ideas and positions of the fields have been constructed. By analyzing the results of my constructivist grounded theory analysis for commonly held paradigms, or inter-discursive patterns, I was able to generate knowledge about the conceptual nexus of the three fields as a strategy for exploring the educational relevance of the spiritual domain of development in middle grades education.

Here are the procedures I used for the contrapuntal reading of the paradigm narratives. During the third round of data analysis, I mainly worked with one of the products from the second round of the analysis: the thick narrative description of the paradigm categories. Because I was working with source material that was two steps removed from the data, it was very important that the first two rounds of data analysis had integrity. As mentioned before, this is why I chose to use constructivist grounded theory techniques for initially coding the data and for refining those initial codes and generating categories. During the contrapuntal reading of the paradigm narratives, I employed the constant-comparative method (Charmaz, 2006) to return to the focused content codes, the BVA interpretations, the quotations I had selected from the texts, the initial codes, and even back to the texts themselves as a series of checks on my 
interpretation of the narratives. Even though I had used quotations to illustrate the initial

codes and BVA interpretations, I often returned to the full passage from which I had extracted an excerpt of text, to confirm (or re-assess) how I interpreted the context and meaning of the data. This process was facilitated by my decision to use extensive in-text and parenthetical citations in the paradigm narratives.

During initial and focused coding, I kept a record of potential inter-textual patterns. For example, while analyzing the Holistic Education data set, I interpreted two potential inter-textual patterns between the Holistic Education Initial Codes and the Middle Grades Concept Initial Codes: intra-personal teacher growth and education as developmentally responsive. I used a Word document to document my leads; upon completion of all initial and focused coding, I had a list of six potential inter-textual patterns.

I used these six potential inter-textual patterns as starting places for the contrapuntal reading of the paradigm narratives. My first steps were to expand upon these patterns and identify other potential shared themes, using text from the paradigm narratives. Because I had re-conceived of the inter-textual and inter-discursive as interpretive lenses, I shifted the level of analysis upward/outward to capture over-arching themes that might be interpreted for inter-textual and inter-discursive patterns. I re-read through the paradigm narratives and identified themes that were common to all three fields (e.g., Human Development), and then explored in writing that theme from an intertextual perspective and from an inter-discursive perspective. Using the example of the Human Development theme, one of the potential inter-textual patterns was 'conceptions of the developing human.' I then interpreted six potential inter-discursive patterns within 
that theme: 'growth influenced by internal and external processes,' 'developmental

theory as normative,' 'integrated domains of development,' 'each domain has a function,'

'universal aspects, diverse expressions,' and 'responding to development.' (I provide

these results as examples to illustrate my process; a much fuller explication of them can

be found in the third section of Chapter Four.)

My next step was to create a tool for organizing and making sense of my data

analysis as it expanded. I used a table to organize and keep track of my analysis process;

Table 13 is an excerpt from that table.

Table 13

Analytical Tool for Contrapuntal Reading across Paradigm Narratives

\begin{tabular}{lll}
\hline Theme & Inter-textual & Inter-discursive \\
\hline Epistemology & What is knowledge? & Ecological \\
& & metaphor/ \\
& framework, \\
& Ecological \\
& & epistemology
\end{tabular}

Data from MGC p. 21 Be-Coming Together, as a paradigm code, encompasses the meeting place between learning and interpersonal relationships, where collaboration is a both means and as a goal.

p. 23-24 In my analysis, locating a source of authority within classroom teachers reflects an epistemological belief (and therefore paradigmatic) about whose knowledge "counts" when crafting curriculum theory.

Data from $\mathrm{SpDev} \quad$ p. 35 Benson goes on to claim that spiritual development occurs because of and is influenced by, "...the ecologies one chooses to be the primary crucibles for development," (p. 490).

p. 37 Seeing Crucibles, as a paradigm code, captures the fundamental valuing of interaction, the assumption that something of substance happens in the 'inbetween' space, and the belief that human development occurs because of and within these crucibles.

Data from HolEd p. 46 Knowing is described as subjective, multidimensional, and interconnected (e.g., Miller, 1997, pp. 199-201; Miller, 2007, pp. 190-192).

p. 50-51 Miller (2007) calls this "organic accountability" (p. 193), reflecting the ways in which advocates of holistic education reject the factory/machine metaphors of teaching and learning in favor of metaphors that emphasize biology, nature, and ecology. 
To test the robustness of my analysis, I used the last three columns to document and keep track of text from the paradigm narratives; the page numbers cited for each datum are from a draft hard copy. As I did with the quotations from the data during initial coding, the quotations from the paradigm narratives were meant to illustrate data that I was connecting to the inter-textual and inter-discursive patterns, not to represent all of the text that supported my analysis. In other words, while in some cells I included more than one quotation from the Paradigm Narratives, I did so to more illustrate how I interpreted each specific excerpt as part of the whole pattern, not to make a claim regarding the quantitative amount of text that supported my analysis.

As a new researcher, this process was an interesting part of the hermeneutic cycle — working with the results of data analysis that had multiple layers of data compression, as well as constant-comparative looping between raw data (the texts), initial codes, focused content codes, and paradigm narratives. I was aware more than ever of the dual challenge of returning to the data (texts) to maintain fidelity while simultaneously synthesizing vast amounts of data analysis to enable clarity of expression. The principles of constructivist grounded theory (Charmaz, 2006), such as using constant comparative analysis and allowing for ambiguity during the process, were helpful guides as I navigated the complex terrain. The use of tables to document, organize, and evaluate my data analysis was a useful validity strategy, as well as an analysis tool.

After working with the six potential inter-textual patterns documented during initial and focused coding, I applied contrapuntal reading to the paradigm narratives, adding potential themes, inter-textual and inter-discursive patterns as I interpreted the narratives. The documentation of the inter-textual and inter-discursive patterns on the 
table marked a return to my initial conceptualization of the inter-textual and interdiscursive patterns as categories by which to organize the results of my analysis. At the conclusion of this round of data analysis, I identified 19 potential themes, with 18 potential inter-textual patterns and 24 potential inter-discursive patterns. At this stage, I still considered these themes and patterns as potential results; eight of the potential interdiscursive patterns were not fully supported by evidence from all three sets of paradigm narratives (e.g., developmental theory as normative was not supported by analysis from the Holistic Education data set).

The next step of my analysis was to review the table and construct claims about the contents of the conceptual nexus between the fields of the middle grades concept, spirituality as a developmental domain, and holistic education. In this phase of data analysis, I used visual organizers to document and work with my evolving analysis. I read over all entries in the table, took notes in my research journal as I was analyzing, then drew initial visual outlines for the inter-textual and inter-discursive patterns that were supported by my analysis of the paradigm narratives. Using these outline-memos, I drew more complex representations of the conceptual relationships between the patterns. From the outline-memos, I rendered eight inter-textual patterns and eight inter-discursive patterns that were supported by data from all three data sets, and created a visual model that was more formalized than the outline-memos as another way to work with the results. I used labels to capture the patterns and give myself a concise way to write about my findings (e.g., integration as an inter-discursive pattern; empiricism as an inter-textual pattern). I created a digital version of the visual model to work with my emergent findings; I moved around various text boxes around as I tried to conceptualize the 
interrelationships between the inter-textual and inter-discursive patterns, which I

consider a primary level of analysis. That analysis yielded an interpretation of three primary paradigms: Ecological Epistemology, Holistic Ontology, and Positivist Ontology.

A secondary level of concurrent analysis involved accounting for the discursive interrelationship between two of the meta-paradigms, Ecological Epistemology and Holistic Ontology, and with a third meta-paradigm, Positivist Ontology. I say discursive interrelationship, not inter-discursive relationship, to distinguish between the patterns that are inter-discursive between the three fields/data sets (inter-discursive relationship) and the discursive interrelationship between Ecological Epistemology/Holistic Ontology and Positivist Ontology that occurs within each field. In the latter, a contrapuntal reading yielded an interpretation of a complex discursive dynamic between Ecological Epistemology/Holistic Ontology and Positivist Ontology that I characterize as paradoxical. Into my digital visual model, I inserted as a theoretical bridge between Ecological Epistemology/Holistic Ontology and Positivist Ontology a quotation from Said (1993) about reading for the disparate harmonies with a melody—what he characterizes as a "simultaneous awareness" (p. 51) of not only of the content of the dominant discourses and of the discourses of resistance, but also of the ways in which both discourses act "against which and together with" (p. 51) each other. In my critical historiographical analysis, I accounted for the both positivist and holistic ontologies within the conceptual nexus of the three fields. Each has its own harmony, but together they form a (conceptual) counterpoint melody. 
In addition to three primary paradigms, I also interpreted five secondary

paradigms, four of which were closely related (textually and discursively) to the primary Ecological Epistemology and Holistic Ontology paradigms: (a) social constructivism/situated cognition; (b) knowing as alignment; (c) integration; and (d) interconnection. I interpreted seven inter-textual patterns total; four were also related to the Ecological Epistemology and Holistic Ontology paradigms and the associated four secondary paradigms. The fifth secondary paradigm, empiricism, was related to the Positivist Ontology primary paradigm, and three additional inter-textual patterns.

In a subsequent round of constant-comparative analysis that involved composing memos for each inter-discursive and inter-textual pattern, I revised my re-presentation of my analysis by a further reduction of the data. As I wrote about the secondary interdiscursive patterns (e.g., knowing as alignment), I decided that it was neither helpful nor clarifying to make a distinction between primary and secondary paradigms: my interpretation of content and influence of the secondary paradigms was being expressed in my description of content and influence of the three primary paradigms. Also, conceptually I had trouble making a sharp distinction between what constituted a primary from a secondary paradigm. I came to understand that what I called the secondary paradigms were elements of the primary paradigms. So, in effect, my memos were repetitive. I revised the visual analytic model/tool for exploring the interrelationships between inter-discursive and inter-textual patterns (Figure 2). 


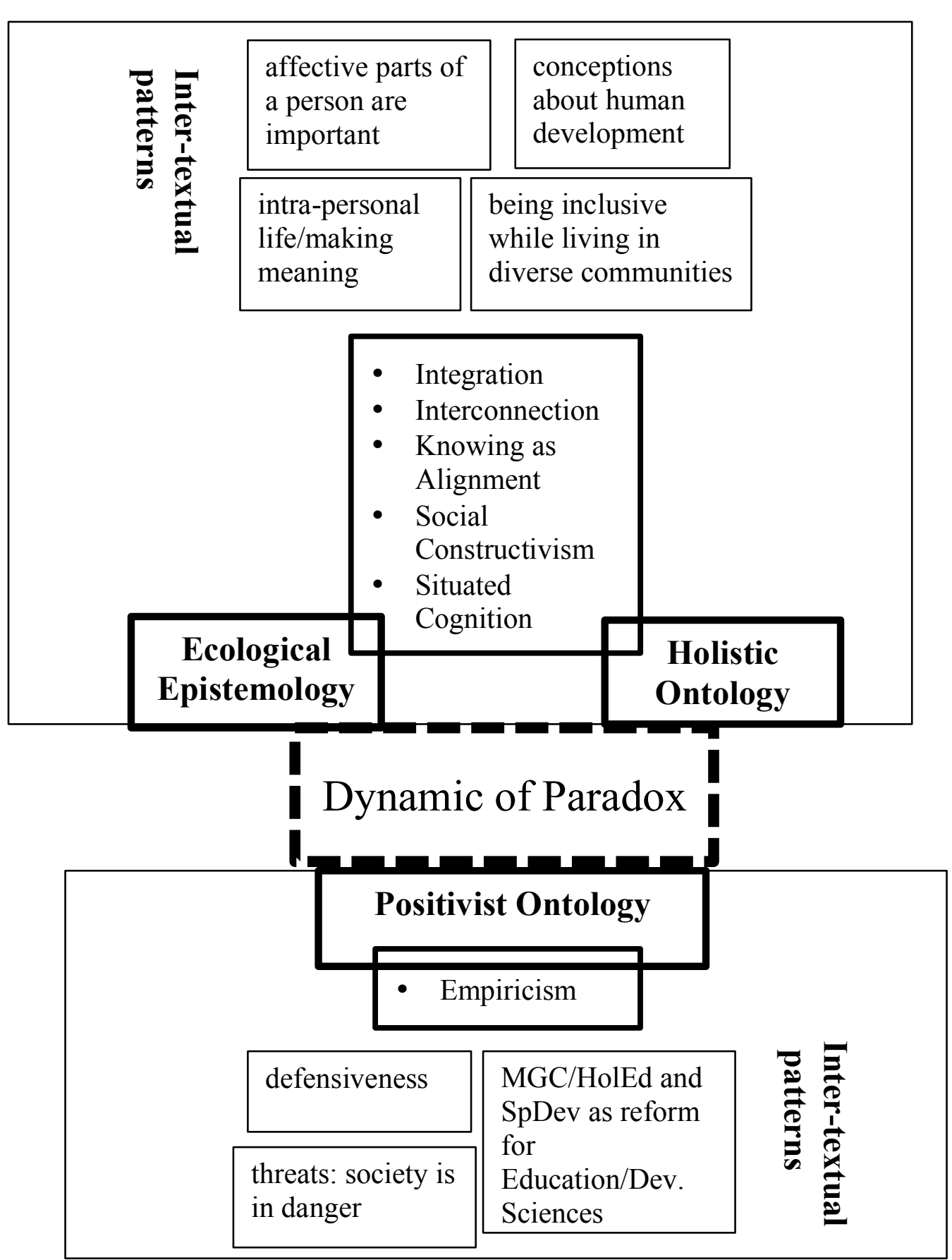

Figure 2. Revised Analytic Tool for Exploring Interrelationships between InterDiscursive and Inter-Textual Patterns.

To conclude this description of the specific procedures used to analyze the data, and begin to transition to a report of the results, it seemed fitting to return to Kincheloe's (e.g., 2005, 2008) call for a 'thick description' of the results of critical constructivist 
research. The following passage from his 2005 article illustrates his (and my) rationale for producing a thick description as part of research findings:

Complexity in the context of cultural inquiry demands that the researcher develop a thick description that avoids the reductionism of describing the 'functional role' of an individual. Such a 'literacy of complexity' understands the intersecting roles and social locations of all human beings and the multiple layers of interpretations of self, contexts, and social actors involved in rigorous research. (p. 327)

My analysis process in this research at times felt like the 'literacy of complexity' that Kincheloe described. Sorting through the many layers of interpretations, accounting for my researcher reflexivity, and navigating a unique methodology in educational research while also seeking to avoid reductionist analysis that reified emergent findings was a complex task indeed. But, as a researcher paradigm, critical constructivism proved to be strategic and useful in serving the purposes of this research, precisely in its allowance for a literacy of complexity.

\section{Research Integrity}

Discussions of limitations and my positionality as the researcher comprise this section. Each shapes the results of this study; as critical constructivist research, it would be inconsistent for me to interrogate the limitations and positionalities of the authors of the (hi)stories I analyzed without venturing into my own. In reflecting upon the limitations at various points throughout this study, three areas of weaknesses came to light: (a) the texts used as data sources, (b) my framing of certain aspects of the topic, and (c) the use of critical historiography in educational research. I conclude this final section 
of Chapter Three with a reflection on the limitations and benefits of my positionality as the researcher.

Limitations of the data sources. The first area of limitation is associated with the texts used as data sources in three ways: (a) personal bias in text selection, (b) cultural homogeneity of data sources, and (c) inconsistency in depth across the three fields. The first two ways offer some foreshadowing about my values and priorities, that is, my positionality, as a critical constructivist researcher; the third is simply an acknowledgement of the current status of the field of spirituality as a developmental domain within the developmental sciences.

In selecting foundational texts as data, I had to account for my own assumptions and researcher bias toward selecting texts that reinforced my own ideas about the relevance of spiritual development in middle grades education. My familiarity with the related literature (in the fields of applied developmental theory, spirituality as a developmental domain, holistic education, middle grades education, and the middle grades concept) strengthened my ability to select some texts over others as data that were foundational, serving as proxies for the (hi)stories of the fields. Hence, conducting a thorough review of the literature is one strategy I used to reduce the influence of my biases. In addition, I consulted with persons known to be experts in the three fields: Dr. Jack Miller, holistic education; Dr. Micki M. Caskey, middle grades education; and Dr. Robert Roeser, spirituality as a developmental domain. While each of these persons has his or her own perspectives regarding the relative influence of the potential texts, my goal as a critical constructivist researcher was to strive for trustworthiness in my data collection, not definitive validity. 
Even though I have accounted for my own researcher bias, a second way in

which this study is limited by the texts used as sources of data is that the texts included in this study overwhelmingly represent White, middle-class authorship. Some voices are still left out that could be relevant contributions to the (hi)stories of the three fields. An example of a text that met all of my criteria, and would have explicitly included nonEurocentric ideas about Holistic Education is Education for Awakening: An Eastern Approach to Holistic Education (Nakagawa, 2000). This limitation becomes even more troubling in light of the literature on a culturally responsive theory of spiritual development which suggests that the predominance of Western theoretical and research paradigms is harmful to the efforts of an educational approach that addresses student spirituality (Juang \& Syed, 2008; Lippman \& Keith, 2006; Mattis, Ahluwalia, Cowie, \& Kirkland-Harris, 2006; Nicholas \& DeSilva, 2008; Owen Wilson, 2005).

My decision to use written texts that are recognized as authoritative in the field of middle grades education as data sources is strategic given the audience for this research. But in making that strategic decision, did I reinforce the deployment of power in favor of Euro-centric values? The absence of voices directly from historically marginalized groups is a deficit in this piece of research. My selection of a critical historiographical approach, which employs criticality as an underlying principle (Villaverde, Kincheloe, \& Helyar, 2006), is an attempt to honor my positionality as a critical constructivist researcher. Criticality sees historical discourses as socially constructed interactions between individuals and societal structures that are influenced by power and privilege. The critical perspective allows the researcher to identify and interrogate the predominance of Western theoretical paradigms, creating a discourse of possibility 
(Giroux, 1981). I also tried to account for the critical historiographical principle of

multilogicality by using contrapuntal reading as one of my data analysis strategies. However, given the limitations of my interpretive abilities to hear the voices of historically marginalized people in the data, I think a more successful way to honor multilogicality would be to use texts written by “other people's children" (Delpit, 2006).

A third limitation related to the texts used as data sources has to do with the inconsistency of the breadth and depth of scholarly literature across the three fields. Based on my review of the literature, I found a substantive body of work on the middle grades concept, a slightly less substantive body of work on holistic education, and a much sparser body of work on spirituality as a developmental domain. The range in depth, breadth, and rigor within the foundational texts limited my capacity for selecting texts across the three fields that represented their fields with the same levels of authority. In other words, within the field of spiritual development, Benson and Fowler are considered authorities and advocates. But, in my review of the literature, I found a smaller number of authors who could have met that criteria than I found in the middle grades or holistic education fields. That compromise is reflected in the fact that of the three spiritual development texts, only one (Benson) refers explicitly to a theory of spiritual development only. Fowler used the term faith development, and Oser, Bucher, and Scarlett combine spiritual development with religious development in their synthesis of the field. This is a limitation of this study, as well as a limitation within the field of spiritual development in 2013.

Framing the issue. A second area of limitation is two ways I have framed central constructs related to my research question. The first way has to do with how human 
development is constructed by middle grades advocates; the second is the predominance

of literature that views spiritual development as positive. I address both of these, and how I accounted for this area of limitation in this research.

A conceptual limitation of this research is my decision to accept how middle grades advocates frame human development. The dominant message from middle grades advocates (e.g., NMSA, 2010) is that human development occurs in distinct domains; people at different life stages have distinct developmental needs. I made the decision to follow the developmental framework employed by the advocates of the middle grades concept because they are the primary audience for my research. However, in adopting the premise that human development can be known and understood through a structural model, I also adopt the limitations of that stance.

The conceptual framing of human development into distinct domains with stagedependent needs is not neutral. In my review of the literature, I found recent work that directly countered the middle grades' emphasis on developmentally appropriate education on the grounds that adolescence, and its associated claim for being a distinct period of human development, is a social construct (Vagle, 2012). Claiborne (2007) challenged the underlying assumptions of pedagogy that is based on the construct of developmental readiness. Claiborne's work raised questions about the cultural implications of pedagogy that is based on a construct of human development as natural, progressive, and focused on the individual (p. 431-432). Webster (2013) illustrated a third argument against the construct of developmentally appropriate education by contesting the notion of developmental needs. He challenged the viewpoint that education should be responsive to developmental needs because it implies that young people are 
merely "becomings" not "beings" (p. 5) with current worth and integrity. I find these

claims to be valid, persuasive, and sound, even as they fundamentally challenge the premises of this research.

My awareness of this framing limitation from an early stage of research design and problem-posing was a resource. In wrestling with the dialectical challenge presented by Vagle's (2012) work, I was careful to not reify my own constructs of human development through this research. It also helped me during the first round of data analysis, initial coding, by inserting a distance between my own assumptions and beliefs and the texts I interpreted for assumptions and beliefs. These challenges reminded me that any program, position, or policy in education is one of a "universe of alternatives" (Sarason, 1982, p. 102), not a natural given.

A second way in which my framing of central constructs limits this study is in my treatment of spiritual development as positive. In my review of the literature, I observed some, but very little, consideration of the dark side of spiritual development. In her emerging research on the dark side of human spirituality, de Souza (2012) framed her new work on aspects of youth spirituality that inhibit healthy human growth. Working with Hay and Nye's (2006) construct of spirituality as relational consciousness, de Souza explored aspects of spiritual expression that reflect a sense of separateness. Like de Souza's earlier work (2006), I also identified the absence of the spiritual domain of human development from education contexts as a problem. But in doing so, I assumed that its inclusion could only promote healthy human development and thriving. From my reading of the literature, the dark side of human spirituality is one of the edges of the field of spiritual development to which future work will have to respond. While this study 
itself does not directly account for this framing limitation, hopefully future, field-based studies will draw from the knowledge generated in this work to inform constructs of spiritual development that include its negative implications.

Critical historiography in educational research. A third area of limitation to this research was the relatively unchartered territory of critical historiography in educational research. I had few authors to rely upon for direction, especially once I began data analysis. I negotiated this challenge using strategies described below; however, at the end of the study I did not have sufficient findings to address one potential aspect of my main research question.

One strategy I used to navigate the unchartered territory was to rely on the guidance provided by the established techniques I chose for my bricolage. Laying out the specific, well-established data analysis techniques of constructivist grounded theory before beginning data analysis proved helpful and Charmaz (2006) was frequently consulted for direction. Also, I leaned heavily on the guiding principles of constructivist grounded theory, such as allowing the emergent themes to guide my analysis. My use of tables as analytic tools in focusing coding is a strategy that emerged from the process organizing my analysis as it was produced and staying faithful to the emergent findings.

A final strategy I used to compensate for this area of limitation was drawing from my background as a historian and as a classroom teacher. Because of my academic training as a historian, I felt confident in my capacities for translating historiography in a piece of educational research. Because of my professional background as an educator, I felt comfortable with employing Kincheloe's (2008) principle of bricolage as a strategy for navigating divergent conceptual waters while still keeping my interpretive eye on the 
shore of classroom practice. In many ways, this research process reminded me of the theory/practice tension that comes with being a reflective practitioner. I frequently wrestled with the dynamics of praxis: the ideas behind my research processes and the actions I carried out as part of the process.

However, while critical historiography worked as a method for interpreting for prevalent paradigms of academic fields and inter-discursive patterns amongst the fields, my execution of the method fell short in terms of more fully situating these paradigms in their socio-historical context. When I rendered the final results for the conceptual nexus of the three fields, my analysis procedures had not given me sufficient findings on the social, political, and historical context of the nexus. A consequence of this weakness is a lack of conclusions and implications about the potential for inclusion of spiritual development as a possible means of enhancing the capacity for middle grades educators to be more culturally responsive to young adolescents. To me, the question of the potential inter-discursive relationship between culturally responsive teaching and student spiritual development is still highly potent. I hope to investigate it in future research.

In reflecting upon this failure to generate sufficient findings on the socio-political contexts of the (hi)stories, I suspect that the problem rests with my decision to select text passages for initial coding that focused on the main content and ideas of the three fields. I excluded text passages that addressed socio-historical context, thinking I would apply a direct contrapuntal reading — without subjecting those passages to initial and focused coding - as an analysis technique during the third round of data analysis. However, in the transition between constructivist grounded theory techniques and contrapuntal reading, I lacked a plan for incorporating text that had not been through initial and focused coding 
processes into the third round of analysis. This is where I lost ground in terms of positioning myself to render findings that allowed me to make claims regarding culturally responsive teaching and spiritual development.

What all of these areas of limitation have in common is the discursive relationship between constructs of spirituality and spiritual development and responsive teaching that honors the dignity and integrity of all students, but especially those who come from groups whose knowledge has not been valued in public schools in the United States. In my estimation, the issue of how teaching that is responsive to young adolescent spiritual development can be informed by cultural awareness is still paramount even though this study has not provided much new knowledge with which to generate action.

Positionality as researcher. In closing, I would like to offer a personal reflection on my own positionality in designing, executing, and discussing this research. I came to this study as an educator with almost 20 years of experience in schools. I have taught middle and high school social studies in both public and private schools in urban and suburban locales. All of the secondary schools I where have worked embraced innovative pedagogy and organizational structures which fostered collegiality, creativity, and a strongly shared sense of purpose. Although my interest in and allegiance to critical pedagogy was strengthened as a result of my doctoral studies at Portland State University, my lived identity as a radical, holistic educator was first nurtured at Oberlin College in the early 1990s where liberationist theologian bell hooks and sustainability pioneer David Orr taught. As a white, upper/middle class female, I possess insider status within the field of education; as a radical political activist with an impatience for closed systems, I am an outsider. 
My background has limited and strengthened this research project. As an

educator with little experience in mainstream public schools, I have a limited ability to suggest implications for practice that might be effective in most public schools in the U.S. However, given my direct experience in schools that rewarded creative intellectuals and empowered participants, I have the capacity for divergent thinking when it comes to re-imagining middle grades education. 


\section{DESCRIPTION OF RESULTS}

\section{Paradigms and Patterns}

In Chapter Three, I described the research methodology, critical historiography, which guided the design and implementation of this dissertation research. In that chapter, I outlined the principles and techniques associated with critical historiography, offering a rationale for my choice of methods and connecting these principles and techniques to this specific research. I described in detail how I carried out the data collection and analysis processes.

In this chapter, I describe the results of my analysis of the data. The results are presented in two sections. In the first section of this chapter, I presented the narratives for each paradigm category. As with the accounting of the research methods in Chapter Three, I organized the narratives by data set, in the same order I analyzed the data. These narratives were constructed after the first two rounds of data analysis were completed for all three data sets.

The results of my contrapuntal reading of the paradigm narratives are presented in the second section of this chapter. In the third round of analysis, I interpreted for intertextual and inter-discursive patterns across the paradigm narratives. Two types of discursive patterns resulted from the contrapuntal reading across these paradigms: (a) three meta-paradigms shared by all three fields: Ecological Epistemology, Holistic Ontology and Positivist Ontology; and (b) a similar pattern of paradigmatic interaction between the three prevalent paradigms - a dynamic of paradox. 


\section{Prevalent Paradigms}

The end result of the initial and focused coding is a claim regarding the paradigms that are prevalent for each of the fields included in this research. These findings addressed my first research subquestion: What prevalent paradigms underlie the academic discourse on spirituality as a developmental domain, the middle grades concept, and holistic education? These results represent yet another level of the hermeneutic cycle, as I move deeper within the boundaries of each paradigm category, exploring edges and areas of overlap. Table 14 shows the paradigm categories for all three data sets. This set of results became a unit of historiographical analysis for the final round of data analysis, to be described in the second section of this chapter.

Table 14

Paradigm Categories

\begin{tabular}{ccc}
\hline Middle Grades Concept & $\begin{array}{c}\text { Domain of Spiritual } \\
\text { Development }\end{array}$ & Holistic Education \\
\hline $\begin{array}{c}\text { Separating and Re- } \\
\text { Integrating }\end{array}$ & $\begin{array}{c}\text { Mapping the Human } \\
\text { Journey }\end{array}$ & $\begin{array}{c}\text { Beliefs About What it Means } \\
\text { to be Human }\end{array}$ \\
Nurturing the Nature & Aligning Heart and Will & Knowing with Wholeness \\
Be-Coming Together & Allowing Paradox & $\begin{array}{c}\text { Schooling for Cultural } \\
\text { Consensus }\end{array}$ \\
Perceiving Perils & Seeing Crucibles & Re-Framing Accountability \\
Empowering Education & $\begin{array}{c}\text { Legitimizing Spiritual } \\
\text { Development }\end{array}$ & Claiming Ontological Truths \\
& C.
\end{tabular}


Epistemological and ontological issues dominate these paradigm categories, with

the field of holistic education most deeply steeped in discussions on knowledge, learning, and reality. Holism, as a perennial philosophy, stresses a particular perspective on reality and knowing that lies in contrast to the dominance of technocratic educational discourse. So, in defining holistic education, it is not surprising that epistemology and ontology are frequent topics. The (hi)story of spiritual development primarily invokes ontological issues, especially in regards to being able to define and describe the developmental processes that are spiritual. The authors' perspectives on epistemology are invoked in the descriptions of spiritual developmental processes. One of the main themes of that (hi)story is that ways of knowing are deeply connected with spiritual development. In the foundational texts on the middle grades concept, epistemological issues are referenced when describing the content of recommended practices with young adolescents. Ontological issues are referenced when middle grades advocates make claims about the nature of the stage of young adolescence.

As an artifact of critical constructivist research, the narratives address cultural, historical, and political themes as well. My critical interpretation is woven throughout the paradigm narratives; when cultural, historical, and/or political issues are particularly important to my rendering of the paradigm narratives, my interpretation is more explicit. Examples of paradigms categories that reflect explicit critical interpretation are Perceiving Perils and Empowering Education (middle grades), Legitimizing Spiritual Development (domain of spiritual development), Schooling for Cultural Consensus, and Re-Framing Accountability (holistic education). 
Because my research strategy was to interpret for paradigms, in the narratives I

emphasize the deepest layers of beliefs, values, and assumptions that influence the (hi)stories of the three fields. However, at times I also describe in detail the content that resulted from the paradigms, as a means of further explication of the ways in which the paradigms were operating. This approach is consistent with Kuhn's (1996) definition of paradigms as both maps and rules for map-making. In that analogy, a better understanding of the rules for map-making results if one can also see the maps. This analogy is particularly apt for this research, the purpose of which is to study the "maps" of the three related fields into order to find some theoretical common ground.

When I composed these narratives, I used an extensive amount of parenthetical and in-text citations to the data. An implication of this decision is the prose is frequently interrupted, detracting from the text's readability. However, I made the decision to employ frequent parenthetical and in-text citations for the following two reasons. One, I sought to link specific claims to evidence from the data to support those claims. This is in accordance with both Charmaz (2006) and Creswell (2007). Both authors recommended keeping descriptions of the results of qualitative analysis grounded in the data by quoting and citing generously from the data. The second reason for my decision to use extensive citations relates to these paradigm narratives as not only results but also as units of analysis. During the third round of data analysis, contrapuntal reading, I applied constantcomparative analysis by looping back through the spirals of the hermeneutic cycle. I often went all the way back to the texts, to ensure that I was being faithful to the data. Citations linked with specific claims served as documentation of my past analysis and facilitation for the final round of analysis. 
A final note: any use of italics within direct quotations is a representation of the

original authors' use of italics. I did not add emphasis to any of the direct quotations.

Middle grades concept. In this section on the findings from the Middle Grades Concept data set, I describe the content, boundaries, and interconnections of my interpretation of the paradigms that guide the advocates of the middle grades concept. I rendered five paradigm categories: Separating and Re-Integrating, Nurturing the Nature, Perceiving Perils, Be-Coming Together, and Empowering Education. In this section on the middle grades paradigms, I chose to present the findings by starting with paradigms that primarily address ontological issues, before moving into paradigms that encompass epistemological perspectives. This organization mirrors a main theme of the (hi)story of this field: because of certain ontological claims about the reality of human development, certain epistemological perspectives are preferable for middle grades education. I end with the paradigm categories that draw in cultural, socio-historical, and political issues. I make these distinctions within the order of the paradigm narratives with very broad strokes: none are as cut and dried as I have described in this introduction to this section.

Separating and re-integrating. Separating and Re-Integrating as a paradigm category reflects a sequence of beliefs: (1) a holistic ontology that is a priori, (2) man's separation of constructs in a way that is negative, and (3) a call for educators to reintegrate constructs. NMSA (2010) used the term holistic to characterize knowledge, human development, and implementation of the elements of the middle grades concept (e.g., "When teachers help them see the many connections...student recognize the holistic nature of all knowledge," p. 22). Constructs that have been wrongly separated are: life from school, personal from academic, and knowledge into disciplines. Re- 
integration of these constructs is believed to be best for young adolescent learning (e.g.,

Alexander, 1968, pp. 79-81). Teachers control and determine the re-integration through curriculum and instruction: "Effective middle grades schools provide experiences, studies, and units...that are specifically designed to be integrative; for that is how learning is maximized" (NMSA, 2010, p. 21).

Middle grades advocates assume characteristics of human development are domain-specific. However, middle grades advocates also believe successful middle grades education treats the developmental domains as interrelated: “...the goal of intellectual development is not pursued at the expense of the social, emotional, and physical development of the individual" (Alexander, 1968, p. 85). A connection between this category and Empowering Education is the critique of distinguishing extracurricular learning activities from other curricula in a way that privileges the core academics. In the data, learning activities categorized as extracurricular are seen as tending to developmental domains not typically targeted in academic learning activities. Erasing the privileged status of traditional academic courses over extracurricular activities by no longer treating the latter as extra, or outside of, the curriculum, is in keeping with the paradigmatic view that human development involves distinct yet unequivocally interrelated domains.

Nurturing the nature. The Nurturing the Nature paradigm category encompasses positivist beliefs about human development, as reflected by my use of the term nature, and feminist values about adult interactions with young adolescent learners in a school context, as reflected by my use of the term nurture. The title of this paradigm category is also a play off of the debate in the later part of the $20^{\text {th }}$ century over competing influences 
on human development: nature vs. nurture. Based on my analysis of the four texts,

middle grades advocates have resolved this debate by upholding stage-based, positivist theories about the primacy of nature (inherent, biologically-determined mechanisms), while simultaneously triumphing the potential of developmentally-responsive schooling (environmental, contextual factors). For middle grades advocates, early adolescence is a stage of human development with outcomes that depend upon, among other environmental factors, what happens in middle schools (e.g, Carnegie, 1989, p. 8). An irony of this paradigm is that the student-centered construct of developmentally responsive education is informed by adult-generated knowledge about young adolescent development. Students, the young adolescents themselves, were not cited as sources of authority about their experience of human development. Based on my more comprehensive review of the literature on middle grades education, it is fair to claim that the prevalent paradigm reflects a reliance on adults for knowledge about young adolescent development. However, some literature does acknowledge, and in some cases even draw from, young adolescents as sources of authority about their development as it pertains to their education (e.g., Doda \& Knowles, 2008).

Human development is essentialized in the data: development can be known (e.g., Alexander, 1968, pp. 14-17), described (e.g., NMSA, 2010, pp. 5-7), empirically studied (e.g., Lounsbury \& Vars, 1978, pp. 16-17), and intentionally responded to in ways that facilitate positive growth (e.g., Carnegie, 1989, pp. 32-33). Growth and development are used synonymously in the data, implying a tacit understanding of human development as an upward trajectory (e.g., a "path,” with "turning points," Carnegie, 1978, p. 14). Developmental characteristics are either explicitly or implicitly referred to as a 'fact' 
(e.g., “...precocity is a distinguishing characteristic of many transescents [young

adolescents] today, a fact that must be considered in designing a curriculum for this age group," Lounsbury \& Vars, 1978, p. 35).

According to middle grades advocates, given the distinct attributes of young adolescents, successful middle grades education can be and must be responsive to those attributes. Attributes are also described in the data as needs. For example, "a volatile mismatch exists between the organization and curriculum of middle grade schools, and the intellectual, emotional, and interpersonal needs of young adolescents," (Carnegie, 1989, p. 32). Caring relationships that provide support and foster hope and belonging are valued as being developmentally responsive.

Nurturing, as the paradigm category suggests, is a process not an event. In the data, the politics of caring are sometimes implied by terminology, as the use of the term advocacy in this datum: "advocacy is not a singular event or a period in the schedule, it is an attitude of caring that translates into actions, big and small, when adults respond to the needs of each young adolescent in their charge" (NMSA, 2010, p. 35).

Be-coming together. Be-Coming Together, as a paradigm category, encompasses the meeting place between learning and interpersonal relationships, where collaboration is both a means and a goal. A metaphor from the data to describe this category is the middle school as a "finding place" (NMSA, 2010, p. 20). Closely related to the feminist values introduced in Nurturing the Nature, this paradigm category also emphasizes processes of learning and human development over outcomes of learning and development. 
In the data, being known and cared for is asserted to be the best educational approach for young adolescents: "Teaching and classroom learning, for the most part, occur in relationships. The extent of learning which results is directly related to the quality of those relationships," (Lounsbury \& Vars, 1978, p. 6). Middle grades advocates analogize successful schools as being like home (e.g., Alexander, 1968, pp. 65-67) in that the students perceive that they belong: "the middle grade school proposed here...creates community of adults and young people embedded in networks of support and responsibility..." (Carnegie, 1989, p. 36).

The teacher attitude that students are human be-ings rather than human do-ings is seen as desirable and even essential for the purpose of maximizing learning potential: "since young adolescents learn best through engagement and interaction, learning strategies should involve students in dialogue with teachers and one another..." (NMSA, 2010, p. 23). This paradigm orients middle grades practitioners to prioritize process over product, a stance that is operationalized in several specific recommendations, such as the emphasis of formative over summative assessment (e.g., NMSA, 2010).

The title of this category is a play on words - becoming is in vivo: "the basic educational objective of the middle school is neither skills nor knowledge, but simply 'becoming”” (Lounsbury \&Vars, 1978, p. 4). In separating be- from -coming I seek to emphasize my finding that middle grades advocates emphasize the dual processes of coming together in community and seeing each person as a separate learner (e.g., Alexander, 1968). An irony I interpreted in the data is the stance that because of the diverse expressions and rates of young adolescent development, learning needs are 
unique to each student, and that the uniqueness of their needs is best met through collaborative learning activities.

Perceiving perils. The Perceiving Perils paradigm category captures the various ways in which the middle grades concept is justified by the authors' emphasis on threats to young adolescents and to United States society. My use of the word "perils" is deliberate: peril as a term invokes moral turpitude, and situations that are life threatening and beyond personal control. NMSA (2010) uses the term "hazards" (p. 6). People subject to perils are vulnerable; vulnerability is one of the defining characteristics of young adolescents in the data (e.g., Carnegie, 1989, p. 21). People subject to perils need protection; in the data, the protectors are the adults, not the young adolescent peers. The proactive strategy for protection is the middle grades concept.

A consistent theme across the four texts is the theme of young adolescence as a critical period given the perils or complexities of contemporary society. A variance in this theme is the source of this danger in contemporary society. For example, in Lounsbury and Vars (1978) the source of the peril is "a pluralistic society undergoing a value crisis so severe that it threatens the very foundations of our government" (p. 37). In Carnegie (1989), the "pluralism" that Lounsbury and Vars obliquely referred to is more specifically identified as "... a source of social unrest in this nation as the relative size of minority groups increases in coming years," (p. 48). I characterize this perspective as a paradigm as opposed to simply descriptive of content because the perception of perils, be they societal or developmental, is foundational to the construction and rationale for the middle grades concept. In both of the above examples, each threat was connected to an aspect of the middle grades content. For Lounsbury and Vars (1978), the antidote was 
curricular content that was responsive to young adolescent development and societal context; for Carnegie (1989), an exploration of interdisciplinary themes “...offer[ed] one way of dealing positively..." (p.48) with the social unrest.

The volume on that alarm gets turned up as the expression of the middle grades concept moves from 1968 to 2010. In the later data (i.e., Carnegie, 1989), the perils of contemporary society are linked with the concept of equity. Diversity/equity is absent from Alexander (1968), introduced in Lounsbury and Vars (1978), hammered on in Carnegie (1989), and softened (but very much present) in NMSA (2010). "Equity" as a term is not indexed in Alexander (1968) or Lounsbury and Vars (1978). The term appears six times in my initial codes for Carnegie (1989) and twice in NMSA (2010). The paradigmatic relationship between equity and the middle grade concept is further explored in the paradigm category Empowering Education.

Finally, throughout the data are claims to the critical nature of early adolescence in terms of personal growth and the health, stability, and prosperity of society in the United States in the later $21^{\text {st }}$ century (e.g., Alexander, 1968, pp. 71-73; Carnegie, 1989, pp. 22-25). These claims overlap with the positivist perspective on human development, as described in Nurturing the Nature.

A strong relationship exists between Perceiving Perils and the previous category, Be-Coming Together. The latter is described as the response to the alarm bells sounded in Perceiving Perils. There is an interesting irony in this inter-categorical relationship: the use of fear tactics to motivate trusting relationships.

Empowering education. The Empowering Education paradigm category encompasses teacher self-efficacy, learning theory, and the middle grades concept as 
educational reform. In this category, empowerment is both personal and collective, and

occurs at classroom, school, and societal levels. This category and Be-Coming Together overlap: The strongest area of overlap is the function and value of teacher intrapersonal development. Seeing one's own humanity in order to see the humanity of others is emphasized in the 1968 and 1978 data as a necessary disposition or attitude (e.g., Alexander, 1968, pp. 87-88). In the 1989 and 2010 data, teacher intrapersonal development is characterized in terms of external, observable actions of caring and wellbeing (e.g., NMSA, 2010, p. 35 and p. 39). The middle grades teacher is valued as a core element of the middle grades concept; internal, personal transformation is believed to have external benefits for teaching and learning in schools (e.g., Lounsbury \& Vars, 1978, p. 112-114).

Teachers are empowered by middle grades advocates by being seen as the primary authorities on curriculum and instruction (e.g., Carnegie, 1989, pp. 54-58). In the data, testimonials from teachers were legitimized as evidence for the validity of the middle grades concept (e.g., Alexander, 1968, p. 70). Teacher authority was also reflected in specific recommendations of the middle grades concept. For example, in the Carnegie (1989) report, one of the recommendations is: "Decisions concerning the experiences of middle grades students should be made by adults who know them best," (p. 54). In my analysis, locating a source of authority within classroom teachers reflects an epistemological, and therefore paradigmatic, belief about whose knowledge counts when crafting curriculum practice and theory.

Another area of this paradigm category is learning theory. Subjectivist epistemologies dominate the data. Social constructivist and situated learning theories 
prevail. Learning happens when (a) the learner is an active participant in authentic learning contexts (e.g., Alexander, 1968, pp. 10-12; Carnegie, 1989, pp. 58-60); (b) when the learner is perceived by the teacher and by him/herself to have worthwhile assets (e.g., NMSA, 2010, pp. 24-26); and (c) learning occurs in and through community (e.g., Lounsbury \& Vars, 1978, pp. 112-114). Beliefs and values about learning are also reflected by the learning activities that are considered legitimate. In the middle grades concept, academic curricula are not privileged over extracurricular activities: "considering, as we do, the total program of learning opportunities to be the curriculum, the term 'extracurricular' is not really an appropriate category for any learning opportunities" (Alexander, 1968, p. 65).

The middle grades are believed to be a potent site for reform of education in the United States, beyond just the middle grades. I interpreted a difference over time regarding the purpose of the reform. In the earlier two texts (i.e., Alexander, 1968; Lounsbury \& Vars, 1978), the purpose of the middle grades concept as reform was to innovate education in the United States. In the latter two texts (i.e., Carnegie, 1989; NMSA, 2010), the purpose of the reform was to increase equity in education. For either purpose, I interpreted an explicit critique of the factory models of education in $21^{\text {st }}$ century schools: '[Middle school] ought not to be an 'institution,' a teaching factory, but rather a center for learning and growing, a place especially designed for young adolescents where they are 'at home..." (Lounsbury \& Vars, p. xii).

Understanding metaphors to be signposts for paradigms, the distinction between school as factory and school as home is significant to the task of articulating the prevalent paradigms of the middle grades concept. The significance lies in how the epistemological 
and ontological perspectives guiding the middle grades concept, which value caring

relations and constructivist learning theories, are related with the paradigms guiding the next (hi)story, spirituality as a developmental domain.

Spirituality as a domain of human development. In this section on the findings from the Spirituality as a Domain of Human Development data set, I will describe the content, boundaries, and interconnections of my interpretation of the paradigms that guide the advocates of this field. The five paradigm categories for this data set are: Mapping the Human Journey, Aligning Heart and Will, Allowing Paradox, Seeing Crucibles, and Legitimizing Spiritual Development. I begin the narratives with the paradigm that influences how the authors conceive of human developmental theory in general before then turning to the paradigm that influences the contents of spiritual development theory in particular. As a continued exploration of the contents of spiritual development, I describe two paradigms, Allowing Paradox and Seeing Crucibles, which depict the authors' lenses through which the (hi)story of spiritual development is constructed and explained. Finally, I situate the (hi)story within its cultural, social, and political context of the developmental sciences by describing the paradigm guiding the authors' argument for the addition of a domain of spiritual development.

Mapping the human journey. The paradigm category Mapping the Human Journey reflects a major theme in the data: theorizing about human development. An important part of the (hi)story of the domain of spiritual development is how the storytellers explain human developmental processes and outcomes: "Central, then, to a theory of spiritual development are conceptions of the developing person" (Benson, 2006, p. 487). Human development is allegorized in the data as a road that all persons 
travel, reflecting the perspective that human development is a universal phenomenon (e.g., Oser, Scarlett, \& Bucher, 2006, p. 967). Empiricism is highly valued as a tool for knowing more about human developmental processes and outcomes, reflecting positivist ontology. In some data the value placed on empiricism is reflected in specific datum, for example, Oser, Scarlett, and Bucher's (2006) reference to "the results of careful and thoughtful studies" (p. 976); in some data the value is inferred, such as Fowler's (1981) use of a large body of mixed-methods research upon which his theory of faith development is based.

Two approaches to explaining human development are cited: stage-structural theory and developmental systems theory. In the data, stage-structural theory and developmental systems theory are valued when used in conjunction with each other. For example, Oser, Scarlett, \& Bucher (2006) refer to these two frameworks as "paradigms" that are "theoretically compatible" (p. 943). In the data, each approach is believed to be necessary, but not sufficient without the use of the other (e.g., Fowler, 1981, p. 90: "the stages tell only part of the story"). Benson (2006) encapsulated the two frameworks as "three dynamics of human development," (p. 485): core processes (stage-structural theory), context (developmental systems theory), and goals (addressed in both approaches). Throughout the data, the role of context in human development, as an influence on outcomes and an impetus for developmental processes, is believed to be significant (e.g., Oser, Scarlett, \& Bucher, 2006, p. 971-972). My analysis of the role of context and environment on spiritual development will be further explicated in the narrative on the paradigm category, Seeing Crucibles. 
Mapping the Human Journey includes the authors' humanistic perspective that

human development occurs from a strength-based orientation, rather than a deficit-based orientation (e.g., Benson, 2006, p. 489). In other words, human development is not viewed as incomplete people getting better through more development. An example of this perspective is found in a datum from Fowler (1981): "Each stage has the potential for wholeness, grace and integrity and for strengths sufficient for either life's blows or blessings" (p. 274).

The data reflect a willingness to accommodate cultural variations in how people develop (e.g., Benson, 2006, p. 498; Fowler, 1981, p. 273). However, the dominant paradigm is human development theory as normative, with distinct patterns or stages that can be identified using empirical methods:

Our empirical studies have aimed at testing whether there is a predictable sequence of formally describable stages in the life of faith. The hypothesized stages with which we began, however, and the versions of them that have withstood empirical scrutiny exhibit an indisputably normative tendency. (Fowler, 1981, p. 199)

Within the normative framework the function of each domain of human development is privileged as a criterion for determining the legitimacy of a phenomenon as developmental (e.g., Oser, Scarlett, \& Bucher, 2006, p. 943). How the function of spiritual development is described by the data will be addressed in the narrative on the paradigm category, Legitimizing Spiritual Development.

Aligning heart and will. The name for the final paradigm category, Aligning Heart and Will, is also in vivo. The phrase originates from Fowler (1981), who 
characterized faith development as "an alignment of heart and will" (p. 11). This

paradigm category illustrates the contents of spiritual development, as distinguished from the Legitimizing Spiritual Development category, which captures how the data reflect a focus on constructing a theory of spiritual development more than the contents of such a theory. The category name refers to my analysis of how spiritual development is conceptualized in the data: what develops (goals, functions) and how it develops (processes). In this narrative, I first explore the paradigm category's title. Then, I divided my description of the related results into those two ways in which spiritual development is conceptualized, what develops and how it develops.

Aligning captures the joint influence of the two prevailing developmental frameworks: (a) human development as adaptation (from developmental systems theory) and (b) human development as restoring equilibrium (from state-structural theory). Heart and will capture the aspects of being human that I interpret as central to the story of spiritual development theory—in terms of the what and the how. Finally, the category Aligning Heart and Will also captures the data that reflect a holistic paradigm. In a holistic paradigm, alignment is a dynamic, on-going process in which healthy human developmental systems are distinguished from each other but seen as deeply interconnected to each other, to ecologies, to transcendence. A datum that illustrates the emphasis on alignment of heart and will is Oser, Scarlett, and Bucher's (2006) assessment of Fowler's (1981) theory of spiritual development: “[Fowler's] stages take into consideration an individual's development with respect to major developmental tasks including identity achievement, cognitive development, moral judgment, symbol formation, social 
perspective taking, and locus of control. For Fowler, the development of

faith and the development of persons are so intertwined as to be, to a large

extent, one in the same.” (p. 959)

In this datum, the authors' use of the phrase "one in the same" speaks most clearly to me of the holistic perspective. Seeing the parts and the whole simultaneously is a holistic lens by which to understand, explain, and explore phenomena. As a lens, holism echoes the use of paradox as a heuristic that also requires holding apparent binaries as mutually co-influencing.

I continue my explication of this paradigm by first exploring how the texts convey what is developing as part of the domain of spiritual development. Then, I turn to how the authors conceptualize how spiritual development happens.

The act of clarifying the contents of spiritual development is reflected in the data as a task that is complex but possible, using empirical methods of inquiry and scholarship (see Legitimizing Spiritual Development). In the data, the contents (the 'what' that is developing) of spiritual development are characterized as qualitative growth in the capacities for making meaning, creating order, constructing myths or narratives, and creating or applying an interpretive framework/orientation. Two data that illustrate these characteristics of spiritual development include:

- "Prior to our being religious or nonreligious...we are concerned with how to put our lives together and with what will make life worth living." (Fowler, 1981, p. 5) 
- “...spiritual development as a process of actively constructing a view of the self in the context of self-transcending myths and frames." (Benson, 2006, p. 489)

In Fowler's (1981) description of the stages of faith development, a central theme is the process of using stories (received and self-told) as a means of organizing a personal sense of meaning and purpose. The different ways in which stories are used is a main element in Fowler's theory of what happens in the domain of spiritual development. In Fowler's Mythic-Literal Stage (approximately ages 8-11), “...the meaning is both carried and 'trapped' in the narrative," (p. 149). In a later stage, the Conjunctive Stage, which not all adults reach, according to Fowler's theory, the capacity for using narratives as a source of personal meaning and purpose looks qualitatively different: “...the rise of the ironic imagination - a capacity to see and be in one's or one's group's most powerful meanings, while simultaneously recognizing that they are relative, partial and inevitably distorting apprehensions of transcendent reality," (p. 198). Here, the capacity for tolerating and appreciating paradox is defined as a key outcome of spiritual development.

One datum makes an explicit cultural distinction when referring to the types of interpretive frameworks created as a part of a person's spiritual development. Benson (2006) distinguished between the personal interpretive frameworks, associated with European or United States' cultural paradigm, and the collective interpretive frameworks, associated with “...other social and cultural locations...” (p. 487).

Spiritual development is also described as the ways in which people of different ages (a) cope with challenges and successes (e.g., Oser, Scarlett, \& Bucher, 2006, p. 991), (b) value and commit to beliefs about what is sacred (e.g., Fowler, 1981, pp. 10- 
14), and (c) experience connection within themselves, with others, with the

environment, and with a sense of transcendence (e.g., Benson, 2006, p. 485). A lengthy and complex datum from Fowler (1981) illustrated the complex expressions in which advocates of a theory for the domain of spiritual development try to sum up these three aspects of spiritual development:

...faith is: people's evolved and evolving ways of experiencing self, others and world (as they construct them) as related to and affected by the ultimate conditions of existence (as they construct them) and of shaping their lives' purposes and meanings, trusts and loyalties, in light of the character of being, value and power determining the ultimate condition of existence (as grasped in their operative images - conscious and unconscious - of them). (pp. 92-93)

In this datum, aspects of the prevalent paradigms of this (hi)story are addressed: human development as an on-going journey, the use of secular constructs as a strategy for legitimizing spiritual development theory, the use of paradox heuristics as a device for understanding developmental processes, and spiritual development occurring within crucibles.

Fowler (1981) characterized spiritual development as a process of re-integrating the capacities and strengths of previous stages of development: "Try to imagine the whole process as dynamically connected, each successive spiral stage linked to and adding to the previous ones. Each stage...marks the rise of a new set of capacities or strengths in faith. These add to or recontextualize previous patterns of strength without negating or supplanting them" (p. 274). Spiritual development as a process of deeper 
levels of integration echoes the strength-based humanistic perspective on human

development referred to in the narrative on Mapping the Human Journey. The (hi)story of this field characterizes the domain of spiritual development as a critical component of the process of intrapersonal integration, again reflecting a holistic paradigm.

In addition to these aspects of what develops, spiritual development was characterized as a "perfecting" (Oser, Scarlett, \& Bucher, 2006, p. 947) process over the course of a lifetime, although I interpreted variations in the criteria for perfection. These variations range from Fowler's (1981) criteria for the final stage of faith development: “...inclusiveness of community, of radical commitment to justice and love and of selfless passion for a transformed world, a world made over not in their images, but in accordance with an intentionality both divine and transcendent," (p. 201), to Benson's (2006) notion of developing persons being able to know and explain “... what is good, important, and real..." (p. 487), to Oser, Scarlett, and Bucher's (2006) argument that perfecting is a process of moving from "narrow-minded...behavior and thinking into open, fully integrated...spirituality," (p. 943). While the data on perfecting reinforce my claim that a normative paradigm outweighs the call for embracing diversity of developmental expression and patterns (see Mapping the Human Journey), the variations I interpreted in the data belie a more subjectivist epistemology than a normative paradigm might otherwise suggest.

In addition to conceptualizing what is developing in the domain of spiritual development, the authors address a second component of the contents of a theory of spiritual development: how development is stimulated, sustained, and expressed. Like the data referred to in the narrative on Mapping the Human Journey, advocates of the field of 
spiritual development wrestle with fundamental notions of how human development

occurs. The results of my analysis show significant conceptual overlap between this paradigm category and the category Seeing Crucibles in this area.

One example of this overlap is the relationship between the processes of spiritual development and a developing subject's cultural context. Benson (2006) identified the joint processes of creating and inheriting as of paramount significance in determining the outcome and process of spiritual development: "Culture informs the texts that are inherited; the language that shapes one's thinking; the symbols that are accessible; the rituals that command attention and focus the person on culturally sanctioned definitions of person, cosmos, and transcendence; and the degree of normative permission there is for one to consciously and actively engage one's spiritual development.” (p. 492). From this datum, and others, I interpret that advocates of a field of spiritual development believe that the domain of spiritual development can be stimulated by specific elements of a person's environment. The discursive effect of cultural context on spiritual development is vividly illustrated in the Benson datum in his mention, for instance, of how language shapes thinking.

The category label Aligning Heart and Will suggests a previous period of misalignment. In my analysis, the data address multiple causes of the misalignment and multiple explanations for the ways in which a developing subject responds to that experience. Periods of misalignment are described in the data as disequilibrium between person and context (e.g., Oser, Scarlett, and Bucher, 2006, p. 971), as well as between different domains of development such as cognitive and moral (e.g., Fowler, 1981, pp. 172-173). Fowler suggested that without disequilibrium, a developing subject may not 
transition to another stage of faith development. One of his research findings was that it is not uncommon for persons to reach equilibrium (alignment) at his third stage of faith development, the Synthetic-Conventional Stage. This finding supports his claim that not all persons move beyond what he theorizes as a third stage of faith development.

Finally, the authors cite, in one form or another, the existence of an innate drive as a motivating force for human development (e.g., Fowler, 1981, pp. 149-150). This drive is connected to what is developing in the spiritual domain: an evolving sense of personal meaning and purpose. One datum from Benson (2006) described the how in relation to the what: “...meaning, purpose, obligation... and contribution (knowing and affirming why one matters) pull persons into spiritual development... and the animating forces within the person...push the person forward. Hence, spiritual development is energized by both push and pull..." (p. 492). What exactly these animating forces are is addressed indirectly in the data; in another datum, Benson (2006) used the metaphor of an "engine" (p. 485) to describe "developmental press" (p. 488). Fowler (1981) attributes the innate drive to critical self-reflection and creative imagination: "Disillusionment with one's compromises and recognition that life is more complex than Stage 4's logic of clear distinctions and abstract concepts can comprehend, press one toward a more dialectical and multileveled approach to life truth," (p. 183). In this datum, I interpreted a developmental perspective that places importance on disequilibrium, and values integration.

Allowing paradox. The third paradigm category, Allowing Paradox, captures my analysis of how paradox is used and valued as a heuristic by advocates for the field of spiritual development. As a paradigm, paradox heuristics challenge binary thinking by 
suggesting that clarity comes from allowing two things to be true, not from adherence of

one or the other. For this paradigm and others in the Spiritual Development data set, I interpreted evidence that suggests a paradigm shift, with some aspects of the traditional scientific paradigm upheld (e.g., thinking in binaries) while aspects of a different paradigm arise (e.g., embracing paradox). In the data, paradox is offered as a heuristic, or conceptual model, for clarifying a theory of spiritual development. This paradigm category differs from Seeing Crucibles (below) in that the emphasis is less on the interaction between two constructs and more on the conceptual act of holding as true two seemingly opposite or contradictory constructs.

I interpreted many examples of paradoxes used in the data as a device either for explaining the contents of spiritual development theory or for directing how to theorize about spiritual development. Scholarly and personal writing is offered by Fowler (1981) as a means of adhering to the criteria of academic research and writing while simultaneously honoring the intimacy of spiritual development: "I am committed to rigorous examination and clarification of the meanings we share. This intends to be a book of responsible scholarship and research. But to communicate and to bring its truths to expression we will have to write and read in personal ways," (p. xii). In this datum, Fowler reinforced the binary of scholarly and personal by drawing attention to them as disparate types of formal communication. But at the same time, Fowler critiqued the privileged status of what is considered scholarly by insisting that a complete understanding of spiritual development theory is incomplete without a personal voice.

Two paradoxes are invoked frequently in the data: (a) the explanatory power of a formal theory that maintains fidelity to the peculiarities of personal experiences, and (b) 
universal patterns with diverse manifestations. A datum from Oser, Scarlett, and Bucher (2006) illustrated these similar paradoxes: “...there are meaningful ways to attend to individual and cultural differences while still attending to what is universal and normative. We need to find ways to attend integratively to both diversity and general principles," (p. 990). The two prevailing frameworks of human development, stagestructural theory and developmental systems theory, are also presented as a paradox heuristic. In my analysis, the advocates treat both frameworks as necessary, but insufficient without the other (e.g. Oser, Scarlett, \& Bucher, 2006, p. 943). This claim about a theory's completeness echoes Fowler's (1981) claim that spiritual development theory is incomplete without both scholarly and personal writing.

Other paradoxes presented as heuristics are: serious play (e.g., Fowler, 1981, p. xiii-xiv), intuitive and counterintuitive ontologies (e.g., Oser, Scarlett, \& Bucher, 2006, pp. 972-976), rationality and passion (e.g., Fowler, 1981, pp. 270-273), and knowing self through transcendence of self (e.g., Benson, 2006, pp. 487-489). In a datum from Oser, Scarlett, and Bucher's (2006), there is a reference to the use of heuristics in understanding spiritual development theory: "Whatever the ways, the effort is the same, explaining not only the development of acts, thoughts, and feelings, but also explaining the development of persons. In general, critics forget that stages and structures are heuristic instruments for understanding this development," (p. 957). This datum reflects a tone of defensiveness in the authors' rationale for the use of heuristic devices in this field, connecting this paradigm category to Legitimizing Spiritual Development.

Allowing Paradox, like the category Seeing Crucibles, reflects a deeply constructivist perspective of learning in two ways. First, the learner (i.e., the developing 
subject) is viewed as an active agent, not a passive recipient of transferable information

(e.g., Benson, 2006, p. 486). Secondly, the student of spiritual development theory is asked to actively hold two binaries as a means of understanding the processes and contents of the domain of spiritual development. This latter point reflects the constructivist perspective (Dewey, 1902, 1916) on using inquiry to formulate adaptable dispositions with which to solve current and future problems.

Seeing crucibles. Seeing Crucibles is closely related to, but distinct from, the use of paradox as a heuristic. The name of this paradigm category is in vivo, reflecting the authors' claims that spiritual development occurs within and as a result of interactions between separate entities. Captured in this category are ontological and epistemological perspectives that are subjectivist. The term crucible appeared in Benson (2006): “...it [spiritual development] also includes the myths learned on Grampa's or Grandma's lap and in the crucible of peer relationships, family, and community," (p. 490). Benson went on to claim that spiritual development occurs because of and is influenced by, “...the ecologies one chooses to be the primary crucibles for development," (p. 490). In the field of chemistry, substances in a crucible are subjected to strong forces (e.g., high heat) resulting in the melting and re-forming process of alchemy. As a metaphorical term in the data and in this analysis, a crucible conceptually symbolizes the space of interaction between two or more forces in which the participating entities are irrevocably altered or transformed.

Crucibles are places of alchemy, a combination of the contents of the interaction and the resulting outcome(s) of the interaction. Throughout the data, the significance of a developing person's interaction with cultural and social context is explored in multiple 
ways. Crucibles are viewed as bidirectional influences (e.g., Benson, 2006, p. 490;

Fowler, 1981, p. 100), adaptations (e.g., Oser, Scarlett, \& Bucher, 2006, pp. 271-272), and "interplays" (Benson, 2006, p. 490). One datum refers to the bidirectional interplay between person and environment as a process of creating and inheriting: "the myths and narratives that organize and give direction to our lives involve a lifelong creative process in which persons actively create (whether the activity is conscious or not) a story, using source material that can come from many institutions and relationships," (Benson, 2006, p. 490). Oser, Scarlett, and Bucher (2006) refered to the crucible between parent and child as a process of “...co-constructing their spiritual identities,” (p. 978). In these ways, spiritual development is framed as a type of social constructivist learning theory.

Another way in which spiritual development is seen as both a process and product of interactive transformation is in its relationship with other domains of human development. Human development is viewed as having separate domains whose growth and maturation are interrelated not only in terms of overlapping focus areas, but also in terms of stimulating further development. For example, all three data sources cite how shifts in cognitive capacities influence and are caused or accompanied by shifts in spiritual capacities (e.g., Benson, 2006, pp. 490-492; Fowler, 1981, pp. 149-150; Oser, Scarlett, \& Bucher, 2006, pp. 972-976).

Other important though less frequent interactions that reflect the paradigm Seeing Crucibles are: (a) academics and practitioners in the field of spiritual development (e.g., Benson, 2006, p. 943), (b) structures and contents of spiritual development (e.g., Fowler, 1981, pp. 272-273; Oser, Scarlett, \& Bucher, 2006, pp. 955-956), and (c) spiritual development theory and theories for other domains of human development (e.g., Fowler, 
1981, pp. 275-276). For example, through intentionally created interactions between

academics/researchers and practitioners/clinicians, a more useful theory for and applications of spiritual development can result (Benson, 2006).

In sum, this analytic category is intended to capture the conceptual tools employed by advocates of the field of spiritual development as a means of articulating the paradigm. Seeing Crucibles captures the fundamental valuing of interaction, the assumption that something of substance happens in the 'in-between' space, and the belief that human development occurs because of and within these crucibles.

Legitimizing spiritual development. The influence of positivist ontologies interpreted in the first paradigm category Mapping the Human Journey was also interpreted in the data supporting the final category, Legitimizing Spiritual Development. The authors of the (hi)story defended theorizing about spiritual development within and in response to the parameters of empirical criteria rooted in the social sciences. In my rendering of this paradigm, I analogized the authors' arguments for a scientific theory on the domain of spiritual development as five defensive walls. These walls, each of which I explicate in this narrative, are the conceptual scaffolding for this paradigm category. I used the metaphor of defensive walls (from the medieval castles) to illustrate my interpretation of the defensive tone of the texts, and the complex layers of the building blocks of logic, discourse analysis, empiricism used to erect a formidable argument for spiritual development as a field in psychology.

Within these walls, a theory of the development of spirituality is described. I have already described what happens in the domain of spiritual development and how it happens in Aligning Heart and Will; here I will only revisit a few aspects of spiritual 
development that are protected by the defensive walls. Spiritual development is

described as involving the whole person (e.g., Oser, Scarlett, \& Bucher, 2006, pp. 967968), experienced in multilayered interactions (e.g., Benson, 2006, pp. 484-486; Oser, Scarlett, \& Bucher, 2006, pp. 971-972), and occurring across the lifespan (e.g., Fowler, 1981, p. 274).

On the first defensive wall, a distinction is made between spirituality and religiosity: “...spiritual development is a universal domain of development that can be dramatically informed by ideas and practices that are theological and/or religious. But, explicit in the definition is the possibility that spiritual development also occurs independent of religion and/or conceptions of sacred, ultimate, or alternative forms of reality," (Benson, 2006, p. 486). Fowler (1981) also made this distinction in his theory by referring to the structure of faith development versus the contents of faith development, the latter being more potentially related to specific religious beliefs. The distinction between spiritualty and religion implies, in my interpretation of the data, a positivist ontology. Spiritual development is privileged as an essentialized human developmental process, whereas religion is viewed as a social construct that is, therefore, excluded as a developmental process. By holding spiritual development apart from religiosity, even while acknowledging that the latter may overlap with the former, advocates of a theory of the domain of spiritual development are playing by the same map-making rules (i.e., empiricism) as those who have historically discounted spirituality as ineligible for inclusion in the social sciences. Therefore, in my analysis, the paradigm shift illustrated by this defensive wall is paradoxical — the traditional paradigms of the developmental 
sciences are being both challenged and reaffirmed by (hi)story of the field of spiritual development.

A significant exception in the data to this distinction between religiosity and spirituality is Oser, Scarlett, and Bucher (2006), whose review of the prevailing theories on spiritual development includes theories on religious development as well. In my more comprehensive review of the literature on the field of spiritual development, however, I found this synonymous treatment of spiritual and religious development to be an exception. Oser, the lead author, has written a large body of work on the development of religious judgment; it is possible that he was more inclined to collapse spiritual and religious judgment because of his pre-existing record of scholarship. In their justification of this categorization, Oser, Scarlett, and Bucher (2006) offered the following perspective:

...if separated from religious development, the contents of spiritual development seem less fixed, and the steps toward higher, more complex levels seem less evident. There is today no theory of pure spiritual development. That is why in this chapter...we use religious and spiritual as highly overlapping entities, which can be taken mostly together." (p. 943)

The authors identify experiences of/relationship with transcendence as the main area of overlap (p. 953). Based on my review of the literature on spirituality as a developmental domain, as well as the literature on spirituality and education, Oser, Scarlett, and Bucher's (2006) strategy of collapsing religious and spiritual development is not representative of the strategy employed for the purpose of legitimizing the field of 
spiritual development in the developmental or social sciences. I noted, in my interpretation for beliefs, values, and assumptions, that the authors' criteria of a pure theory of development also reaffirms a positivist ontology by implying that theories can be pure, i.e., uncontaminated by subjective epistemologies.

The second defensive wall constructed to legitimize a theory of spiritual development is a call for additional empirical scholarship. The perspective that there is a dearth of empirical literature was confirmed during my review of the literature. What is significant, as part of an analysis for prevalent paradigms, is not the actual lack of empirical scholarship in this field, but the perception that there is a lack, as well as the argument that more empirical literature would legitimize a theory of spiritual development: "Another potential criterion for effective field building is...growing the rigor of theory, measurement, and research,” (Benson, 2006, p. 493). This defensive wall affirms empiricism as an influence on the (hi)story of this field.

The third defensive wall is a clarification of the differences between faith and belief, interpreted most strongly in the Fowler (1981) data. Fowler introduces his theory with an explanation of the historical evolution of the linguistic conceptions of the two terms. In this evolution, faith becomes linguistically synonymous with belief. Fowler claimed that the significance of this evolution lies in noting the discursive ways in which faith has come to be understood as a cognitive, voluntary action: “... so pervasive is the impact of secularizing consciousness that even religionists and persons of faith have tended to accept the culture's truncation of belief into assent to a set of propositions or commitment to a 'belief system,'” (p. 13). Oser, Scarlett, and Bucher (2006) made a similar argument regarding the relationship between power and knowledge: "The 
consequences of conflating faith and belief have been to marginalize religion and to dismiss spirituality as something less than rational,” (p. 956). Fowler (1981) argued that the linguistic meaning of faith has a historical precedent to its post-Enlightenment meaning, whereas faith is understood not as a concept, but as an affective orientation: "faith involves an alignment of the heart and will, a commitment of loyalty and trust" (p. 11). Other data (e.g., Benson, 2006, pp. 487-489; Oser, Scarlett, \& Bucher, 2006, p. 991) affirmed the strategy of distinguishing between faith and belief by seeing them as culturally bound discursive constructs in order to legitimize the field of spirituality as a developmental domain.

The fourth defensive wall is a claim that spiritual development is a universal phenomenon: "Spiritual capacity is inherited capacity, a product of brain development," (Oser, Scarlett, \& Bucher, 2006, p. 969). Universality is reflected in the data as an accepted criterion for determining whether or not spirituality, like cognition, is something that develops. Benson (2006), while distinguishing between spirituality and spiritual development, made the analogy with cognition explicit: "[Spiritual development] is not isomorphic with the term spirituality. There are linkages, of course, but they are also as different as cognition is from cognitive development," (p. 485). Fowler (1981) describes the capacity for spirituality (faith) as something with which “...we are endowed at birth," (p. xiii). This claim of universality in the data as a source of legitimacy is presented alongside concerns about constructing a theory of spiritual development that addresses issues related to cultural diversity (e.g., Oser, Scarlett, \& Bucher, 2006, p. 990). I accounted for this data in my narratives on the paradigms Allowing Paradox and Seeing Crucibles. 
Finally, the role of spiritual development for the individual subject is addressed,

as the fifth defensive wall, reflecting the use of function as a criterion for developmental theories in the social sciences (as introduced in the narrative on Mapping the Human Journey). The emphasis in the data on the function(s) of spiritual development illustrates the authors' strategy for legitimizing theories on the domain of spiritual development in a Western context that wants to account for the functionality of phenomena. In the data, the function of spiritual development is viewed in different ways: as a process of holistic intrapersonal integration (e.g., Fowler, 1981, p. 274), as a foundational orienting framework for one's life (e.g., Fowler, 1981, p. 14), and as a basis for thriving (e.g., Benson, 2006, pp. 493-494). My analysis of these data was more fully described in the narrative on the paradigm category Aligning Heart and Will.

The paradigms guiding the Spiritual Development data set are suggestive of a potential paradigm shift away from Enlightenment criteria for what is counted, or legitimized, as scientific knowledge (e.g., Benson, 2006, p. 484; Oser, Scarlett, \& Bucher, 2006, pp. 944-946). A subjectivist epistemology is reflected in the data: spirituality and religion are identified as social constructs that have discursively affected how spiritual development has historically been treated in the social sciences. The discursive nature of the language of spirituality is reflected by the authors' attention to the fluidity of spirituality as a linguistic term. The context of an action (e.g., ringing a bell) can determine whether or not the action is labeled by the participant(s) or the observer(s) as spiritual (e.g., Fowler, 1981, pp. 272-273; Oser, Scarlett, \& Bucher, 2006, p. 972). However, as described in the narrative Mapping the Human Journey, I found evidence of reaffirmation of the same positivist paradigms that have historically been 
used to discount academic study of human spirituality, i.e., a reliance on empiricism.

The potential importance of the paradoxical discourse represented by these narratives are further explored in my analysis of the contents of the convergence of the paradigms of the three data sets.

Holistic education. In this section on the findings from the Holistic Education data set, I describe the content, boundaries, and interconnections of my interpretation of the paradigms that guide the advocates of holistic education. I rendered five paradigm categories: Beliefs About What it Means to be Human, Knowing with Wholeness, Schooling for Cultural Consensus, Re-Framing Accountability, and Claiming Ontological Truths. For this data set, I begin with what I perceived to be the grounding paradigm, Beliefs About What it Means to be Human, and the only paradigm label in this section for which I did not use a gerund. Epistemological issues are the focus of the next paradigm, Knowing with Wholeness. Although for the previous two data sets I concluded with the paradigm categories that were explicitly situated within a cultural, social, and political context, for this data set cultural-political issues were paramount. Therefore, Schooling for Cultural Consensus and Re-Framing Accountability are presented in the middle. I conclude with one of the surprise findings, the strong influence of positivist ontology in the (hi)story of holistic education, as represented in Claiming Ontological Truths.

Beliefs about what it means to be human. The first paradigm category, Beliefs About What it Means to be Human, has multiple areas of overlap with the four other paradigms in the Holistic Education data set. This paradigm strikes me as both a beginning point and an ending point, suggesting the same spiral model of human development that was reflected in the data. The Spiritual Development data set included a 
paradigm on theorizing about human development; these data from the Holistic

Education data set show theorizing about being human. These data reflect the perspective that one can be fully human, with the opposite also being true - that one can be incomplete. For the holistic educators represented in this data, any belief about what it means to be human that does not include spirituality and spiritual development is incomplete.

In my analysis, the main metaphor/imagery regarding what it means to be human is wholeness, which is viewed as the human ideal. Wholeness is seen as both a means for human happiness and fulfillment (e.g., Miller, 1997, pp. 7-8) and as the natural state of being human (e.g., Miller, 2007, pp. 8-9). Human development is presented as a process of integration and "unfolding" (Miller, 1997, p. 197), with developmental domains described as highly interactive with each other. These data reflect humanistic psychology in its emphasis on the appearance of human assets and strengths during growth instead of the Freudian emphasis on moving beyond human deficiencies:

American education is built on the premise that children's development must be controlled to ensure an orderly society. Rodgers, and humanistic psychology in general, dissented on just this point: Their central claim was that the natural unfolding of the human being can and should be trusted. (Miller, 1997, p. 197)

Data that overlap with this paradigm category and the category Schooling for Cultural Consensus include an argument that the purpose of schooling should be to promote healthy human development (e.g., Miller, 1997, pp. 206-207), including spiritual development (e.g., Kessler, 2000, p. x). 
One significant consequence of believing humans to be complete as they are at any given point in time is a valuing of stakeholder voices as part of schooling. Kessler (2000) expressed this perspective most frequently (e.g., p. xv-xvi). Accordingly, the holistic beliefs about what it means to be human overlap strongly with the paradigm category for Re-Framing Accountability. In that paradigm category, students are described as active agents in their learning (Miller, 1997, p. 206-207), capable of knowing what they need (Kessler, 2000, p. 6-8), and deserving of care and trust (Miller, 2000, p. 192-193). An implication of this paradigm category overlap is that holistic beliefs about being human are much different from the beliefs about being human suggested by the dominant notions of accountability in education (e.g., NCLB).

I also found overlap in the data around beliefs about what it means to be human with knowing and knowledge (Knowing with Wholeness). The strongest topic of overlap concerned learning in genuine community. Miller (2007) advocated deep listening (p. 193-195) among members of the school community to facilitate learning. Kessler (2000) offers specific strategies for sharing sacred questions in peer groups to foster knowledge of self and others.

In the (hi)story, an implication of the holistic beliefs about what it means to be human is that education should look different than it does now. Miller (2007) explicitly distinguished holistic education from present day schooling as an approach that addresses spiritual issues in the classroom (p. 6). Miller (1997) expressed this point in the following datum: "Acknowledging the spiritual dimension of human existence places education in an entirely different light," (p. 87). Kessler (2000) took this point to its ultimate conclusion: “...even in our secular, high-tech world, our spirits hunger for answers. To 
me, the most important challenge has always been not whether we can address spiritual development in secular schools but how," (p. ix).

Knowing with wholeness. In the data, schools were described as places where learning happens, among other things, but learning was clearly expressed as one of the main activities in schools. In taking the position that one major purpose of school is to promote holistic human development (i.e., inclusive of spirituality), a spiritual epistemology is reflected in the data as the second of the five paradigm categories, Knowing with Wholeness. Epistemological beliefs are paradigmatic - beliefs about knowing and knowledge form the "map" as well as the "directions essential for map making" (Kuhn, 1996, p. 109). So, in describing my analysis of these data, I argue that spiritual epistemology guides not only the specific vision of holistic education, but also provides the criteria by which education is evaluated and critiqued. This is significant in this research project because a major content theme of holistic education is a strong critique of hegemonic practices in education in the United States and elsewhere.

The spiritual epistemology of holistic educators is captured by the name for this paradigm category: Knowing with Wholeness. In the (hi)story of holistic education, the construct of human wholeness is defined by its contrast with current educational practices. The authors claim that current practices treat knowledge and knowing as fragmented, with rationality privileged over intuition (e.g., Kessler, 2000, pp. xiv-xv). A datum from Miller (1997) illustrates the way in which wholeness is contrasted with fragmentation:

As the well-known saying goes, a whole (a phenomenon-in-context) is always greater (more complex, more integrated, more meaningful) than 
the sum of its parts. This...flies directly in the face of the dominant

epistemology of the modern age. Reductionism is atomistic and

fragmenting; it argues that we know what is fundamentally real by

dissecting things into component parts. (p. 81)

How advocates of holistic education view the consequences of the influence of reductionist epistemology on schooling will be further explored in the narrative on Schooling for Cultural Consensus.

From the holistic perspective, knowing involves integration —of self and of domains of knowledge (e.g., Miller, 2007, p. 8) and with nature and within relationships (e.g., Miller, 2007, pp. 3-6). Knowing is described as subjective, multidimensional, and interconnected (e.g., Miller, 1997, pp. 199-201; Miller, 2007, pp. 190-192). Processes of learning are privileged over products of learning, as vividly illustrated by a datum from Kessler (2000, pp. 1-5) describing how a group of adolescent students dealt with critically ill peer while on retreat. Knowledge is described in the data as fluid, dynamic, and highly context-dependent. Situated cognition, constructivist, specifically social constructivist learning theories, are represented in the data: “...knowledge is co-created as students construct their own meaning and ways of knowing" (Miller, 2007, p. 6).

While knowing is primarily construed in the data as an inner process, many data describe the influence of external forces such as institutions, teachers, and peers (e.g., Miller, 1997, p. 220). These data suggested a spiritual epistemology that includes the belief that processes of knowing and knowledge can be taught as a result of processes that occur outside of a person. Holistic educators view inner and outer processes of knowing as two sides of the same coin, not as opposing binaries. The data from Kessler 
(2000) is particularly strong in this regards; the entire premise of her work is that teachers can promote healthy human development as part of learning in schools through seven gateways or entry points to students' inner lives. In addition to the interactions between teacher and students, this paradigm category is closely related to the paradigm Re-Framing Accountability, which captures the perspective that knowing occurs through the crucible of relationships in genuine communities.

The significance of including an epistemological perspective in the (hi)story of holistic education is raised by Kessler (2000), Miller (1997), and Miller (2007): how one knows and what one knows guides one's responses to the world. For example, in one datum Miller (1997) explicitly characterizes knowing as “a spiritual endeavor” (p. 220) because it involves meaning-making in relationship to self and others. For advocates for the field of holistic education, epistemological issues are central to their vision and critique of education in the United States: "Holistic education appears anti-intellectualindeed, thoroughly nonsensical—from within the 'transmission' position, but from the viewpoint of 'transformation,' modern society's way of understanding and measuring intellect is a shriveled and inadequate caricature of the human mind's capacities," (Miller, 1997, p. 200).

Schooling for cultural consensus. The third paradigm category, Schooling for Cultural Consensus, captured how advocates of holistic education view the relationship between power and knowledge in schools. The first term of this paradigm category (schooling instead of education) is intentional: in the data, the authors wrote more on what happens in schools than on the universal practice of education. The distinction is 
subtle, but I hope to convey the focus on the particular (schools) over the universal (education).

Part of the strategy used by holistic advocates is to make explicit the ways in which constructs of knowledge are influenced by people and institutions that hold power. The latter part of the category label, cultural consensus, is a partial in vivo code from Miller (1997). Miller used a construct of "cultural consciousness" (Tart, 1986) to frame his exploration of the dominant cultural values that are highly influential in schooling, yet remain largely tacit (Miller, 1997, p. 2). What Miller (1997), Miller (2007), and Kessler (2000) argued is that schooling builds, reinforces, and replicates certain values and beliefs. In this narrative, I describe the various ways in which the authors of the (hi)story of holistic education make their case.

This critical argument is paradigmatic because it is a starting point for the remainder of the holistic treatise. Consistent with both critical theory and postmodernism, a cultural consensus is an agreement by most or all participants in a society about what is good, true, and real; the power of this agreement, or consensus, is purposively sustained though various actors, including institutions such as schools. The authors in this data set echoed the critical perspective that education is not neutral: “...school reflect[s] the prevailing worldview of American society — the basic, and largely implicit, epistemological and moral assumptions that guide the formation of social practices and institutions," (Miller, 1997, p. 2). This perspective is a significant piece of how the story of holistic education is told. For advocates of holistic education, dominant cultural assumptions in the U.S. about epistemology and ontology threaten the dignity and 
integrity of society (e.g., Miller, 1997, pp. 221-225), as well as the dignity and integrity

of individuals (e.g., Kessler, 2000, p. xiii).

In bringing the first and second parts of the category together, Schooling for Cultural Consensus captured the data on the possibility of being able to define and articulate dominant cultural values, especially as they relate to the purpose(s) of schooling. I interpreted a strong critique of the ways schooling in the United States (and Canada) is negatively affected by dominant cultural values. In the (hi)story, schooling was criticized for overemphasizing economic outcomes (e.g., Miller, 1997, pp. 1-4) and emphasizing individual achievement over collaborative processes (e.g. Miller, 2007, p. 6). Fragmentation of knowledge and coercive social control were critiqued on the grounds that those practices alienated teachers and students (e.g., Miller, 2007, pp. 3-6). Finally, holistic advocates accused schools of intentionally ignoring human spirituality: "Many communities decided years ago that the inner life of our children was simply not the business of public schools. Many classrooms are 'spiritually empty' not by accident, but by design," (Kessler, 2000, p. xi).

The critique of the ways in which dominant culture values harm schooling is supplemented by alternative cultural values that could be sustained through schooling. The (hi)story reflects a vision of schooling that draws on humanistic psychology (e.g., Miller, 1997, pp. 195-198), balances rationality with intuition (e.g., Miller, 2007, p. 8), and nourishes all domains of human development (e.g., Kessler, 2000, p. x). In response to the ways in which the dominant epistemology fragments knowledge and alienates teachers and students, the storytellers of holistic education emphasize schooling that cultivates an awareness of interconnection: "We hope to foster in our students a deep 
sense of connectedness within themselves and to other beings on the planet" (Miller, 2007, p. 199).

Within the data is a bridge between this paradigm category and the following one, Re-Framing Accountability. This theoretical bridge is that if schooling has the power to indoctrinate certain cultural values and beliefs that shape perceptions of reality, it is in schools that hope for a better future lies. One datum captures this point well, in articulating education as a means of transforming individual perception and social integrity: “A 'revolution of the sensibilities' - that is, a transformation of consciousness, a fundamental shift in the cultural epistemology that defines reality-is considered primary. And this is an 'inward' revolution, requiring the active effort of individual persons throughout society" (Miller, 1997, p. 199).

Re-framing accountability. A telling aspect of the fourth paradigm category, ReFraming Accountability, is the tacit acceptance of accountability as legitimate criteria for evaluating educational endeavors. Like the reliance on positivistic ontology for critiquing current hegemonic practices in schools (see Claiming Ontological Truths), using accountability, even in its reframing, suggests a continuity with the paradigms held by those who support what the authors refer to as traditional education in the United States.

That said, I interpreted a conception of accountability quite distinct from the more common understanding and application of accountability in the United States (i.e., the standards movement of the 1990's, NLCB of the 2000's, the Core Curriculum of the 2010's). In my analysis of the data, accountability has been co-opted from empiricized products taken from single-point evaluations of recipients of information to an engaged sensibility, an orientation of interconnectedness, and a deep sense of presence in the 
classroom communities. In one datum, Miller (2007) called this collection of attributes "organic accountability" (p. 193), reflecting the ways in which advocates of holistic education reject the factory/machine metaphors of teaching and learning in favor of metaphors that emphasize biology, nature, and ecology. The complete datum from Miller (2007) illustrated how holistic advocates use ecological metaphors: "Genuine community creates what we might call an organic accountability. Because people are communicating with one another in an open and transparent manner, problems regarding student behavior and performance can be dealt with directly..." (pp. 193-194).

From a critical constructivist lens, the holistic re-framing of accountability shifts the source of power and empowerment away from policy-makers who may or may not be intimately connected to classroom realities, and towards the students, teachers, and building-level administrators who cultivate and are nurtured by quality relationships. Therefore, student and teacher efficacy and autonomy is addressed as an accountability issue in several ways. For example, students are characterized as active agents in their learning (e.g., Miller, 1997, pp. 206-207). A critical need for teacher intrapersonal growth is identified (e.g., Miller, 2007, pp. 197-199) as a means of increasing efficacy. Teachers and students are characterized as authorities in schooling (e.g., Kessler, 2000, pp. xvixvii). Schools are also described as needing to be held accountable through a shared sense of purpose and large vision: "The deeper the integration between thought and action, the more powerful effect on the teachers. The vision should provide a sense of direction for the school and be open enough so that the teachers can share in its vision and development," (Miller, 2007, p. 198). In sum, in the (hi)story of holistic education, 
accountability is co-constructed in multiple layers of relationships and roles grounded in mutual trust.

It follows then, that a main theme in this data was accountability through the authors' vision of a genuine community. In the (hi)story of holistic education, teachers and administrators should be responsive to students' needs for experiencing belonging; in several datum, responsiveness was defined as deep listening to student interests, questions, and hopes: "To listen completely and fully is a difficult challenge in a culture that values multitasking and speed; yet it is the beginning of being accountable to our students" (Miller, 2007, p. 193). Kessler (2007) included students listening to each other in intentionally sacred spaces as part of accountability through community (e.g., p. 14). Relationships should be seen as relevant to learning (e.g., Kessler, 200, p. 17; Miller, 1997, pp. 82-84), and student privacy should be acknowledged and honored (e.g., Kessler, 2000, pp. 8-10) in the holistic re-framing of accountability in schooling. In my analysis of the data, schools are not analogized as factories with products, but as living, dynamic organisms in need of flexible care and co-existing within a larger context. Change, in the re-framed notion of accountability, is natural, and should be embraced as an opportunity (e.g., Miller, 2007, pp. 195-198). The content of curriculum should be integrated with student experiences and interests: "Transformational learning acknowledges the wholeness of the child. The curriculum and the child are no longer seen as separate but connected," (Miller, 2000, p. 11). Instruction should build from democratic collaboration in authentic contexts (e.g., Miller, 1997, pp. 206-207), as a means of providing on-going support for an organic accountability. 
Finally, in articulating criteria for success, outcomes to which school should be held accountable, currently realized as scores on standardized achievement tests, are replaced by a commitment to fullest human potential. A holistic understanding of what it means to be human that includes intuition, artistic sensibilities, and transcendence prevails throughout the data (e.g., Kessler, 2007, p 17; Miller, 1997, p. 223-225; Miller, 2007, pp. 6-7). Notions of fullest human potential are also captured in the paradigm category Beliefs About What it Means to be Human.

Claiming ontological truths. The final paradigm category, Claiming Ontological Truths was a surprise finding in my analysis. I held the impression that the adherents to holistic education claimed a subjectivist ontological orientation, that there are multiple truths that various individuals hold, depending on social contexts, such as culture and history, as well as individual traits. However, throughout the data, there were claims to the existence of a single Truth, reflecting a more positivist viewpoint than I had anticipated. For example, Miller (2007, p. 193-194) and Kessler (2000, p. 6-8) distinguish between community and communication that is genuine and that which is not. My finding is less focused on the criteria they suggest about determining whether or something is genuine, and more the claim that it is possible to evaluate - and therefore critiquecommunities and communication on the basis of genuineness. In this example, I am framing genuine as a synonym for real. Miller (1997) also used dichotomous rhetoric in his characterization of some types of human interactions as more "natural" and "normal" than others (p. 220). Again, what types of interactions he classifies as more natural and normal (e.g., cooperation) is less my focus in this paradigm category than his claim there is a natural type of human interaction. Other examples from the data include explicit 
references to "complete" and "incomplete" ways of knowing (Miller, 1997, p. 197-201)

and a "fundamental reality" to nature that can be known (Miller, 2007, p. 3-6). It is worth noting that I also interpreted expressions of subjectivist ontology in the data (see Schooling for Cultural Consensus), but in my overall analysis positivist ontology was the more prevalent paradigm.

The positivist ontological stance is significant to this critical constructivist research. Positivist ontology seems to contradict the plea of holistic educators for a broader ontological perspective when considering the relevance of spirituality in the social sciences. The potential contradiction lies in my observation that scholars (in education and the developmental sciences) have historically ignored spirituality/spiritual development on the grounds that spirituality cannot be studied/known using empirical tools. Accordingly, it is worth noting, as a piece of analysis for prevalent paradigms, that these attempts to challenge dominant cultural agreements fall back on the very same grounds for claims of reality that those who sustain hegemonic beliefs and values draw from: positivist ontology.

The significance of the thread of positivism alongside ontological and epistemological perspectives that appear dichotomous to positivist ontology is explored in more detail in the following section. These paradigm narratives represent findings that have significance on their own, but they also were used as a unit of further historiographical analysis. The paradigms were rendered in order to provide material with which to identify ideas and/or perspectives commonly held by advocates of the middle grades concept, spirituality as a developmental domain, and holistic education. 


\section{Results of Contrapuntal Reading - The Nexus}

In the final section of this description of the results, I explore my rendering of the contents of the nexus between the fields of the middle grades concept, spirituality as a developmental domain, and holistic education. I used contrapuntal reading as a strategy for analyzing the three sets of paradigm narratives for evidence of inter-textual and interdiscursive patterns.

The conceptual framework for this research project emerged for me after my review of the literature of the academic fields I saw as related to my research topic, the relevance of the domain of spiritual development in a developmentally responsive model of middle grades education. I drew three overlapping circles in a Venn Diagram, with each circle representing the ideas, positions, beliefs, values, and assumptions of each of the three related fields: the middle grades concept, spiritual development, and holistic education. The goal of this critical historiographical study was to use data collection and analysis strategies that enabled me to make a claim regarding the conceptual contents of the nexus of the three fields, the space in the middle of the Venn Diagram created by the overlapping circles. This final section of this chapter describes what I rendered in the nexus.

In my description of how the paradigms share space in my conceptual framework or, the nexus, I distinguish between two types of discursive patterns: (a) the types of paradigms and (b) the dynamic amongst the paradigms shared by all three fields. What I found, in other words, is that not only were specific types of paradigms common to all three fields (ecological epistemology, holistic ontology, and positivist ontology), but also a pattern of paradigmatic interactions that was common to all three fields - a dynamic of 
paradox. These paradigms interacted with (and against) each other within their

respective academic fields as part of how practitioners and advocates in the three fields

decided what was important, valued, and sustained. My interpretation of a pattern of

interaction that was also part of the conceptual nexus was an unanticipated finding is this

research. I had expected and hoped to make claims about shared paradigm types; I had

not anticipated being able to make claims about patterns of interaction amongst the

paradigm types. Figure 3 is a visual illustration of these findings.

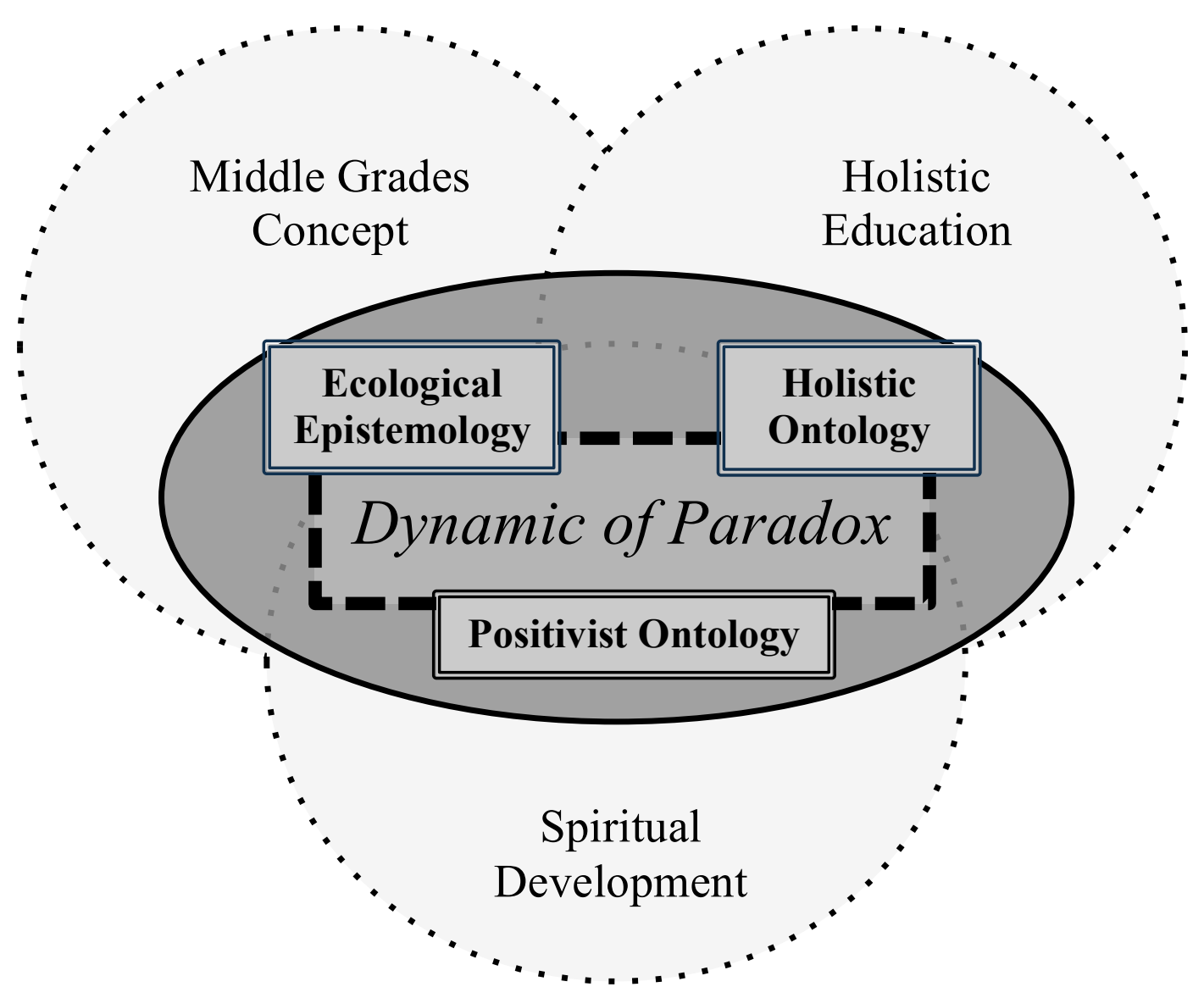

Figure 3: Visual illustration of the conceptual contents of the nexus. Three metaparadigms were interpreted in the area of overlap amongst the paradigm narratives for the three fields. A discursive interrelationship within each field between Positivist Ontology and Ecological Epistemology/Holistic Ontology was also found; this pattern was labeled as a Dynamic of Paradox. 
This second section of results, therefore, is described in two sub-sections: I first

identify and describe, using supporting evidence from all levels of data analysis, the three paradigms I interpreted as being common to all three fields. To distinguish these findings from those of the previous section and capture their foundational qualities, I refer to them as meta-paradigms. Second, I identify and describe (using supporting evidence from all level of data analysis) the dynamic of paradigm interaction that was common to all three fields.

Common meta-paradigms across the three fields. In this sub-section, I describe the meta-paradigms common to the three fields. Two paradigms, Ecological Epistemology and Holistic Ontology, expressed influence over the main ideas, positions, and beliefs of the three academic fields. These two meta-paradigms determined the "story" of the fields: the problems that were identified, the knowledge that was privileged, the claims for reality that were legitimized, and the sources of authority that were acknowledged.

Alongside Ecological Epistemology and Holistic Ontology was a third metaparadigm, Positivist Ontology. Although the characteristics of Positivist Ontology are dichotomous to the characteristics of Ecological Epistemology and Holistic Ontology, I interpreted an equally strong influence of Positivist Ontology over how the "stories" of the middle grades concept, spirituality as a developmental domain, and holistic education were conceived, framed, expressed, and argued.

The influence of these apparent contradictions in paradigms was expressed through a dynamic of paradox. That is, both were "true" and "valid" for the advocates of the three fields, and presented not as an argument to be resolved but as a complex 
scaffolding by which to challenge old rules and offer new visions within a discourse that would be acceptable within the socio-historical context of the United States in the late $20^{\text {th }} /$ early $21^{\text {st }}$ century.

For each meta-paradigm, I begin by summarizing its main elements and tacit rules before providing more detailed evidence in support of my analysis. The evidence is organized around my interpretation of the paradigm narratives for inter-textual and interdiscursive patterns. In my description, I characterize the inter-discursive patterns as the main components of the meta-paradigms; the inter-textual patterns are referred to as inter-textual patterns.

Ecological epistemology and holistic ontology. Ecological Epistemology as a meta-paradigm category encompasses a perspective on knowledge, knowing, and learning that emphasizes interconnection and integration, draws from the natural world when using metaphoric language, and privileges transformational and transactional models of learning over transmission models. While the label I am using for this metaparadigm is in vivo (e.g., Benson, 2006, p. 490), the term was employed by Bateson (1972, 1979), and others (e.g., Cajete, 1994; Orr, 1990, 1992) as well. I am familiar with some of this work and the authors' construct of an ecological epistemology. However my description of the paradigm category I interpreted as Ecological Epistemology is grounded in the data and data analysis from this research. Had I knowingly borrow constructs and language from Bateson or others I would have given proper attribution to their work.

Acting in tandem with Ecological Epistemology is the meta-paradigm Holistic Ontology. As a meta-paradigm category, Holistic Ontology embodies an interconnected 
view of reality, a view that sees truths about the world as essentially interdependent with each other. A holistic ontology embraces a reality of wholeness that is a priori to the Enlightenment illusion of fragmented knowledge and separate selves. Accordingly, the present is imbued with integrity, on-going processes are privileged over single-point products, and wholes are foregrounded from parts.

Applying Kincheloe's (2008) definition of discursive practices, here are the ways Ecological Epistemology and Holistic Ontology share "tacit rules that regulate..." (p. 36):

- What can and cannot be said: What can be said is that human beings are interconnected with each other, the natural world, and the cosmos; this interconnection implies a leveling of authority; and something of import and value occurs within and as a result of interactions. What cannot be said is that people are essentially separate entities whose individual actions are isolated; that the natural world is distinct from and subjugated to human existence; and knowledge can be reduced into fragments that can be transmitted from one entity to another.

- Who can speak with authority and who must listen: Authority emanates from participants, intuition, experience, and collaboration. Those who must listen are proponents of hegemonic scientific and educational practices that alienate, demoralize, and oppress human dignity and integrity.

- Whose socio-educational constructions are scientific and valid: Humanist psychologists/educators, teachers/practitioners (and sometimes students), people who are critically self-reflective, and voices that integrate personal and 
professional/academic experiences have scientific and valid socio-educational constructions.

- Whose socio-educational constructions are unlearned and unimportant: People who insist on treating human development and teaching as endeavors that happen in silos, reduce human learning to cognition, and compartmentalize human experiences have unlearned and unimportant socio-educational constructions. Ecological Epistemology and Holistic Ontology were comprised of four components, which I had initially interpreted as inter-discursive patterns. The four components are: (a) social constructivism/situated cognition, (b) knowing as alignment, (c) integration, and (d) interconnection. In my analysis of the paradigm narratives, as well as the focused content codes and BVA interpretations, the four components are themselves deeply interrelated with each other. For example, social constructivism/situated cognition and knowing as alignment (in my analysis) are closely related. The former addresses learning theory while the later emphasizes processes of knowing. I made this distinction in my analysis because I interpreted the texts as making that semantic and conceptual distinction.

In my analysis, learning is characterized as resulting from and occurring within formal and informal collaboration and interactions (e.g., stories heard on Grandma's lap), constructed by active participants (e.g., democratic collaboration in authentic contexts), and dependent upon a dynamic of mutuality (e.g., integrative curriculum). A "learner" in the context of this data included students, teachers, and developing subjects.

Knowing as alignment was closely related to social constructivism/situated cognition, as well as a third component, integration. Across the paradigm narratives, 
knowing was positively characterized as an on-going process of alignment, also referred to as integration in ways that I interpreted as synonymous with alignment. The aligned and/or integrated entities identified in the data were: domains of self (identity, affect, spirituality), curricular content with disciplinary subjects as well as with the knowers, humans and nature, relationships with others (e.g., Miller, 2007, p. 8). As a component of Ecological Epistemology and Holistic Ontology, alignment reflects fluidity and movement rather than a state of stasis. The processes of human growth, learning, and knowing are emphasized over the outcomes or products.

The fourth component I interpreted from the paradigm narratives was interconnection. The influence of interconnection as a discursive practice was seen in how the stories of the middle grades concept, spiritual development, and holistic education privileged unified wholes (e.g., "the holistic nature of all knowledge" NMSA, 2010, p. 22) over "the dominant epistemology of the modern age[:] Reductionism [that] is atomistic and fragmenting..." (Miller, 1997, p. 81). Learning and human growth occur because of and within multiple points and types of interconnections, also referred to as crucibles. In all three of the data sets, fostering a strong awareness of interconnection was portrayed as desirable because, as claimed by the authors, it allowed for a genuine awareness of how things really are.

The tacit rules imposed by Ecological Epistemology and Holistic Ontology and their four specific components as described above are reflected in the four inter-textual patterns I interpreted as associated with these two meta-paradigms. The first inter-textual pattern is 'conceptions of human development.' Each of the (hi)stories of the academic fields include a theory of human development that: (a) sees domains as interactive (e.g., 
cognitive growth stimulating spiritual growth in adolescence); (b) sees healthy

development as a process of deeper integration of these domains (e.g., applying an interpretive framework for making meaning that draws from cognition, spirituality, emotion, and morality); and (c) favors a development theory that integrates stagestructural theory with developmental-systems theory (e.g., the promise of developmentally responsive middle grades education).

A second inter-textual pattern, 'affective parts of a person are important,' reflects the holistic ontological paradigm that affirms a vision of humanity including emotional, moral, psychological, and spiritual aspects. I interpreted this inter-textual pattern as an explicitly stated challenge to the ways in which the authors perceived the privileging of the cognitive and physical aspects of being human. In addition to positioning affective aspects as equal to cognitive/physical aspects, the advocates of the three fields described healthy development and effective learning as dependent on caring relationships.

A third inter-textual pattern I interpreted across the three sets of paradigm narratives was the 'valuing of a person's inner life,' in terms of how a person makes meaning of their life and the degree of connection to one's deepest self. I interpreted this inter-textual pattern in two ways. First, the advocates of a theory of spiritual development, by connecting the domain of spirituality with the domains of cognition and emotion, call for increased recognition of spiritual development on the grounds that ignoring it jeopardizes the healthy development of other domains. This textual pattern is reflected in the other two data sets with claims that the intentional neglect of student/teacher inner life is harmful to academic (i.e., cognitive) growth. The second way this inter-textual pattern is manifest is in a characterization of the life-long process of 
making meaning of one's life as critical to healthy development and learning. One holistic education datum (Miller, 1997, p. 220) textually links meaning-making as a spiritual practice, as a means of situating spiritual development as relevant to schooling practices. I decided to join the two ways in which I categorized this inter-textual pattern because conceptually they are closely related; but the precise textual references to intrapersonal integrity and making meaning in a personal and collective narrative were distinct enough to warrant differentiation in my description of this pattern.

The fourth and final inter-textual pattern is 'being inclusive while living in diverse communities,' as a desirable outcome and guiding principle for on-going processes. As reflective of Ecological Epistemology, this inter-textual pattern describes individuals as living (and thriving or ailing) in larger, complex interrelated systems. In analyzing the ways in which the (hi)stories of the three fields were told, I interpreted a comfort with shifting back and forth between focusing on individual and diverse expressions of learning and development. In the middle grades concept texts, this ease manifested in repeated recommendations for academic benefits for individual achievement through learning in diverse communities. In the holistic education texts, individual integrity was made possible through shared communal vulnerability and openness. In the Spiritual Development texts, the "best" theories of spiritual development drew from frameworks that emphasized internal structural growth and frameworks that emphasized growth that happens because of and within external factors. I also interpreted a valuing of cultural diversity when it came to expressions of spiritual development (e.g., a Euro-centric personal narrative vs. a non-Eurocentric collective narrative), as well as in the 
establishment of a rationale for the middle grades concept and holistic education (as pedagogical approaches).

Positivist ontology. In my contrapuntal reading of the paradigm narratives, I interpreted the influence of a third meta-paradigm, Positivist Ontology. This metaparadigm category captures a perspective that is firmly steeped in the principles of empiricism: quantifiable truths about reality can be studied and verified through scientific methods of objective inquiry and systematic experimentation. In Positivist Ontology, claims can be made for truths that are 'right' and 'wrong' because it is possible to come to unambiguous answers using empirical methods of inquiry.

The discursive practices of Positivist Ontology are quite different from the discursive practices of Ecological Epistemology and Holistic Ontology. I again use Kincheloe's (2008) definition of discursive practices to frame my description of the "tacit rules" (p. 36) of the Positivist Ontology meta-paradigm for this data:

- What can and cannot be said: What can be said is that it is possible to know, define, study, and make claims about reality in the natural world and in human processes such as development and learning. Because of this, there are things that are true, genuine, and natural. It is possible to study phenomena in nature and human beings because it is possible for the investigator to be rational, objective, and neutral about the subject and methods used for investigation. What cannot be said is that truths about reality are subjective, or dependent upon the person making the claim; phenomena from the human or natural world are contextually dependent; and there are truths about reality that cannot be known through empirical study. 
- Who can speak with authority and who must listen: Authority emanates from a credentialed few, whose credentials are determined by their successful completion of a quantifiable program of legitimized study. Those who must listen are the majority of people, who live in the lower rungs of a highly stratified society and who, lacking intellectual resources, will benefit from the specialized expertise of the credentialed few.

- Whose socio-educational constructions are scientific and valid: Scholars who write and speak in neutral, objective language, adults (because of their superior cognitive abilities), and members of highly selective academic and political societies have socio-educational constructions that are scientific and valid.

- Whose socio-educational constructions are unlearned and unimportant: People who claim experience and/or intuition as valid sources of authority, and who believe truths to be partial, culturally determined, and/or subjective, and people who lack the valid academic credentials have socio-educational constructions that are unlearned and unimportant.

The primary component of Positivist Ontology, in my analysis of this data, is empiricism. In some data empiricism is explicitly called for, for example Benson (2006), who used it as a rationale for legitimizing a field of spiritual development theory. In other data, empiricism is strongly implied through claims of unambiguous truths, e.g, Miller (2007), who stated that there are "fundamental realities of nature" to which "education [must be brought] into alignment" (p. 3).

In addition to the categorical differences between Ecological Epistemology/Holistic Ontology and Positivist Ontology, I also interpreted a difference 
in the way the two sets of meta-paradigms were expressed in the (hi)stories of the three

fields. In the former set, I interpreted that Ecological Epistemology and Holistic Ontology influenced the content of the (hi)stories. For example, one of the specific recommendations of middle grades advocates, the use of advisory groups, is explicitly related to the interconnection component of both meta-paradigms. However, in my interpretation of the way Positivist Ontology was expressed, I found that the connection was not in the content but in the rationale used to defend the content. The influence of Positivist Ontology was much more subtle. Yet, its influence ran just as deeply as the influence of Ecological Epistemology and Holistic Ontology.

I interpreted three inter-textual patterns that were associated with Positivist Ontology: 'threats,' 'Middle Grades Concept/Holistic Education and Spiritual Development as reform for the fields of Education/Developmental Sciences,' and 'defensiveness.' The common denominator in all three inter-textual patterns is an assertion that there is a "right" and a "wrong" way to educate students and conceptualize human development. While obviously any advocacy position may lay claim to a higher ground of authority, in all of the levels of my analysis of the data, from initial coding up through contrapuntal reading of the paradigm narratives, I was struck by the tone of vehemence in the authors' claim not just for authority, but also by their claim that their position was closer to a real truth than the practices they argued against.

In the (hi)stories, two of the inter-textual patterns function as warnings about (a) potential and actual dangers facing society because of (b) the incompleteness of the culturally-dominant education/human developmental theory that only addresses certain domains/aspects of being human, and compartmentalizes knowledge, learning, and 
growth. Both of these patterns, 'threats' and 'Middle Grades Concept/Holistic Education

and Spiritual Development as reform for the fields of Education/Developmental

Sciences,' are written in a tone that I interpreted as the third inter-textual pattern associated with Positivist Ontology, 'defensiveness.'

The authors of the three fields positioned their respective field of study as a potential reform for the greater fields under which they operate. For example, especially in the earlier middle grades concept texts (e.g., Lounsbury \& Vars, 1978), the recommended principles that would guide practices for the education of young adolescents are offered not only as good for that population, but also for other grade levels. While the exact practice of integrated curriculum should look different for 14-year olds vs. 8-year olds, the principles guiding that practice - that is, connecting students with teachers, each other, their communities, and their inner lives through curriculumare viewed by middle grades advocates as a potent reform for alienating curricular practices throughout K-12 education. In the spiritual development data set, a similar rationale is offered: "[it is] ... a field...that is both rigorous and generates knowledge that becomes central to how the academic establishment thinks about human development," (Benson, 2006, pp. 492-493). The advocates of a theory on the domain of spiritual development reflect what both middle grades advocates and holistic education advocates argue: further refinement and implementation of the principles and practices suggested in their field will rectify fundamental errors in the larger fields of education and the developmental sciences.

A datum from Miller (1997) illustrates the previous point, and serves as an example of the defensiveness that I interpreted as one of the three inter-textual patterns 
associated with Positivist Ontology. In this datum, Miller linked individual and cultural

transformation that could occur, and needs to occur, with the implementation of the principles (paradigms) of holistic education: "A 'revolution of the sensibilities'-that is, a transformation of consciousness, a fundamental shift in the cultural epistemology that defines reality—is considered primary," (p. 199). Another example of the data in which I interpreted a defensive tone is from the spiritual development data set. This statement from Oser, Scarlett, and Bucher (2006) was made in the context of explaining why spiritual development theorists draw from the stage-structural framework in their work, despite late $20^{\text {th }}$ century critique of that framework as inadequate: "In general, critics forget that stages and structures are heuristic instruments for understanding this development," (p. 957). This datum in particular is also interesting, as an example of the influence of Positivist Ontology, because the stage-structural framework carries an implication of universal, verifiable truths about human development. From my review of the literature on spiritual development theory, I concluded that one of the main criticisms of any theory of spiritual development was that trying to study spirituality using empirical principles was not possible. In other words, claims for a stage-based theory of spiritual development were desirable in order to be compliant with acceptable standards of scientific practice, but challenged by (a) the diverse manifestations of spiritual expression and (b) the lack of a universal definition of spirituality as a human phenomenon.

The third and final inter-textual pattern I interpreted during my contrapuntal reading across the paradigm narratives is the use of threats and invocation of current and/or future dangers as rationale for the positions advocated by the authors. The 
(hi)stories, in other words, were cloaked under an ominous cloud of peril, with looming

disaster for the dignity and integrity of individuals and Western society. For example, Lounsbury and Vars (1978) indicated that they see the U.S. in the late 1970s as “...a pluralistic society undergoing a value crisis so severe that it threatens the very foundations of our government," (p. 37). When I first encountered this textual pattern during initial coding of the Middle Grades Concept data set, I was struck by the contrast between the use of fear tactics to promote a vision of education explicitly grounded in trust, caring, and mutuality. In my analysis, this inter-textual pattern reflects the discursive practices of Positivistic Ontology because across all three data sets, the threats are grounded in claims about what is essential about what it means to be human, in terms of development, learning, and knowing, as well as claims about what is best for human societies. In my analysis, these are positivist ontological claims.

Dynamic of paradox. As a result of a contrapuntal reading across the paradigm narratives, I interpreted a similar pattern of interaction between the three meta-paradigms. Within each respective field, Positivist Ontology acted discursively alongside and against Ecological Epistemology and Holistic Ontology. I characterized this pattern of interaction as a dynamic of paradox. In this dynamic, dichotomous paradigms are equally privileged by seminal authors of the (hi)stories of the middle grades concept, spirituality as a development domain, and holistic education. As a historiographical finding, this pattern of paradigmatic interaction might illustrate what $\operatorname{Kuhn}(1996,2000)$ characterized as an initial stage of a paradigm shift: a time when questions and problems requires new tools and rules for investigation, but the problem-solvers are still trying to use the old tools and rules because they are neither ready to let go nor able to envision what the new tools and 
rules might look like. In this last round of data analysis, I found evidence of some of

Kuhn's hallmarks of a paradigm revolution, such as a qualitative change in how concepts/phenomena are labeled (e.g., personal meaning making as a spiritual act; caring as advocacy) and the criteria by which the concepts/phenomena are categorized (adding a spiritual domain of human development). Taking Kuhn's logic a step further, during a paradigm shift advocates of new paradigms (in this data, Ecological Epistemology and Holistic Ontology) would logically apply old paradigms (Positivist Ontology) in a society that might be more likely to pay attention if the dominant (old) discursive practices, or tacit rules, were being followed. Hence, during the multi-stage process of a paradigm shift, the discourse would be rife with paradox.

In my analysis of this data, I distinguished between a dynamic of paradox as a discursive interrelationship amongst the prevalent paradigms and a paradox in the content (ideas, positions, recommendations) of the fields. For example, in the Middle Grades Concept data set, a paradox in the content was the position that diverse individual student needs, due to the variance in rate of development, were best met through collaborative learning activities. This example is different from a dynamic of paradox as a discursive interrelationship.

In my analysis, the dynamic of paradox involves the dichotomous tacit rules espoused by the meta-paradigms in ways that influence the content of the (hi)stories, simultaneously and without cancelling out the other meta-paradigm(s). This finding is illustrated by a datum from the Holistic Education data set, in which positivist notions of accountability, as expressed in the context of U.S. education in the late $20^{\text {th }}$ and early $21^{\text {st }}$ century, are simultaneously affirmed and challenged by the authors' reframing of an 
“organic accountability” (Miller, 2007, p. 193). The concept of organic accountability,

as presented by the authors of the (hi)story of holistic education (especially Miller, 1997 and Miller, 2007) adhered to the tacit rules of Ecological Epistemology (e.g., learning through relationships) and Holistic Ontology (e.g., people are deeply interconnected with each other and with nature). Yet, their vision of new paradigms is explicitly framed within a Positivist-influenced construct (e.g., that it is possible and desirable to articulate and evaluate the products/outcomes of schooling).

Another example of my interpretation of a dynamic of paradox is how the advocates for a theory of spiritual development critique limitations imposed on the inclusion of spiritualty. The grounds on which advocates offered their critique are rooted in a subjectivist epistemology positing that scientific claims are reflections of culturally bound representations of truth, not essential or ahistorical Truths. The domain of spiritual development, so the (hi)story goes, has been excluded not because it has some essential qualities that violate rules of scientific scholarship, but because of “...a prevailing but outdated philosophy of science grounded in positivism," (Benson, 2006, p. 484). Yet, even as positivist is proclaimed outdated by Benson, in the same text he calls for more empirical work on spiritual development theory as a "criterion for effective field building..." (p. 493).

Invoking the 'myth' of neutrality, as illustrated above in the developmental sciences, is also invoked in the Holistic Education data set as a strategy for creating space for the inclusion of spirituality in an educational context. However, the grounds for claiming the importance of spiritualty are as ontologically positivist as they are ontologically holistic. In my analysis of the data, seeing the world as interconnected is 
not presented as one possible perspective; it is presented as the way things are.

Development happens as a result of "natural unfolding" (Miller, 1997, p. 197) and because this is the way things are, a better education is one that prioritizes trust and mutuality (i.e., a holistic education) over social control and domination.

My analysis of the Middle Grades Concept data set revealed a similar line of logic: problems are legitimized using positivist rules (this is they way things are), solutions are influenced by different paradigms. For example, because of the "fact" of the characteristics of young adolescents (Lounsbury \& Vars, 1978, p. 35), middle grades education must be developmentally responsive to their unique and knowable needs, an assertion of a Positivist Ontological Truth. In identifying instructional strategies that are properly responsive, however, I interpreted the dual influence of Ecological Epistemology and Holistic Ontology: "When teachers help them see the many connections...students recognize the holistic nature of all knowledge," (NMSA, 2010, p. 22). This is an excellent example of the dynamic of paradox: Positivist Ontology directs descriptions of reality that can only be adequately addressed by solutions that embody Ecological Epistemology and Holistic Ontology.

Before concluding this section, I address one potential critique of my analytical logic. Perhaps, one might argue, a component of Holistic Ontology is positivism. Perhaps the data represented here is not simply trying to have it both ways, perhaps you have simply mischaracterized the elements of Holistic Ontology by not including positivist principles. To this criticism I respond: The positivist paradigm emphasizes a reality that can be known, studied, and described. The holistic paradigm emphasizes a reality that is interrelated at multiple points of connection between people, nature, and the cosmos. The 
presence of one paradigm does not necessarily negate or cancel out the other, but they are still dichotomous. They are still qualitatively different ways of seeing reality.

As I further discuss in the next chapter, my finding of paradoxical ontological paradigms and their accompanying epistemology is no small matter when it comes to articulating the educational relevance of the spiritual domain of human development in middle grades education. It is perhaps the lack of collective imagination around addressing spiritual needs in public schools in the United States that has limited its explicit inclusion in the middle grades literature on developmentally responsive education for young adolescents. I would argue that embracing paradoxes, especially ontological ones, requires significant individual and collective imagination. So far, the track record in U.S. education has leaned more towards reductionist dualism (Miller, 1997). 


\section{DISCUSSION OF RESULTS}

\section{Relevance and Recommendations}

In this chapter, I discuss the conclusions I reached based on the results of the research and offer implications for practice in middle grades education. Drawing from the findings for both research subquestions, I address the main research question: What is the educational relevance of spiritual development in middle grades education? Because this was a study conducted with a critical constructivist lens, attempts to answer the research question are framed within a certain set of assumptions: knowledge production is influenced by the values of the producers and the context within which knowledge is produced; there is a symbiotic relationship between knowledge production and the deployment of power within a society; and education, as an institutional agent of knowledge transmission, is not neutral.

In this chapter I also situate this study within the larger context of the fields of middle grades education and educational research. In developing this chapter, I referred back to my review of the related literature, to explain how this work fills gaps in the knowledge base and what gaps remain after this study.

This chapter is organized into three sections. I introduce the discussion with a brief summary of the main findings. Then, I offer the conclusions based on the findings, focusing on situating spiritual development within the context of public education in the United States. Finally, I identify implications for establishing the relevance of spiritual development in the field of middle grades education. Because of the unique nature of this 
research design for an Ed.D dissertation, I will also identify methodological implications for the field of educational research.

\section{Summary of Results}

In this study, I used critical historiography to interpret for the prevalent paradigms guiding the (hi)stories of the fields of the middle grades concept, spirituality as a developmental domain, and holistic education. For each field, I rendered five prevalent paradigms from my analysis of three to four foundational texts from the three fields.

Figure 4 shows the paradigms for each field.

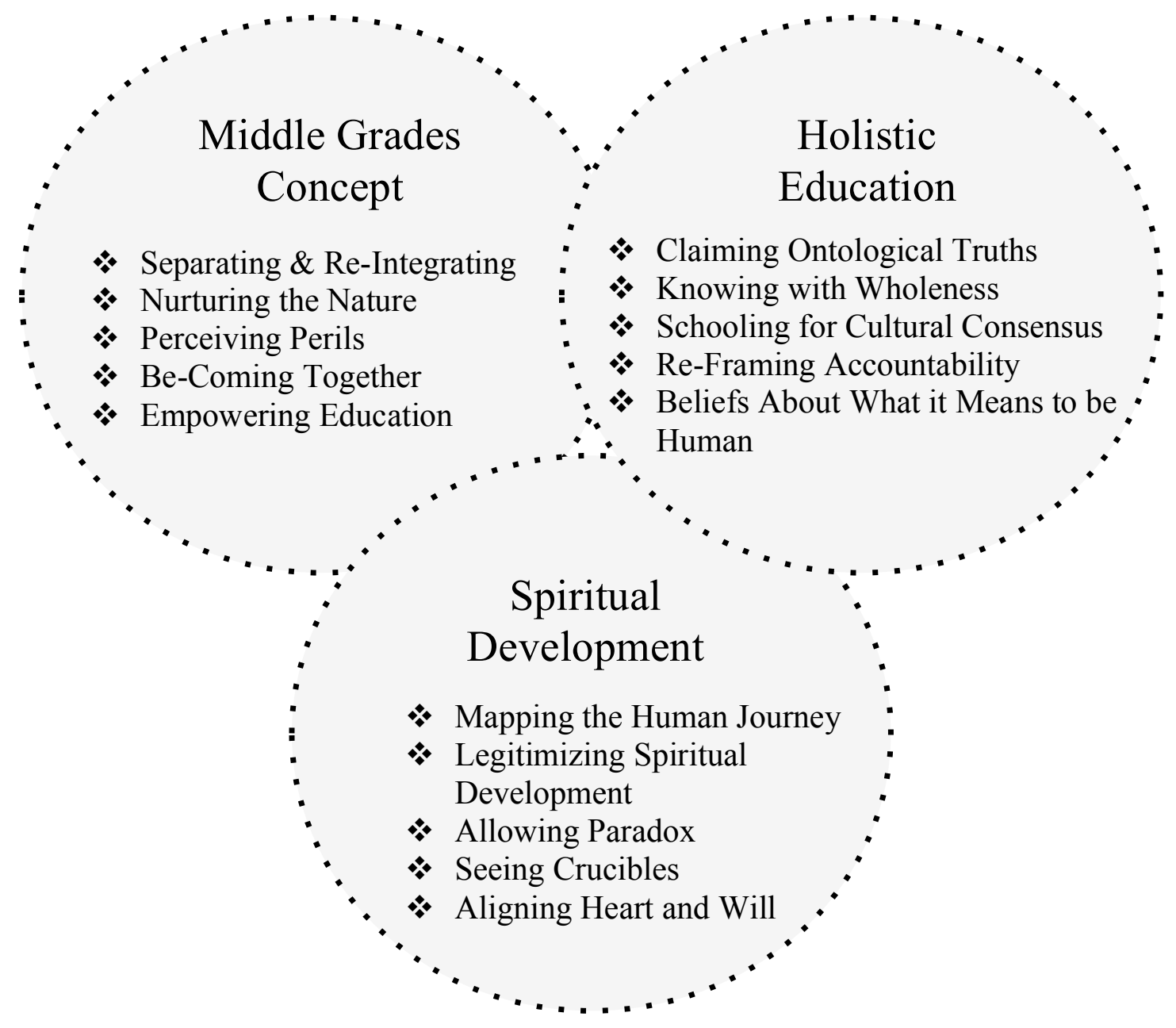

Figure 4. Prevalent paradigms for each of the three (hi)stories. 
After articulating the prevalent paradigms for the three fields, I read across the narratives contrapuntally to interpret for inter-textual and inter-discursive patterns. In initially conceptualizing this research, I sought to describe the area of paradigmatic convergence amongst the three fields, to be able to express what was common or shared as a strategy for making a case for the relevance of spiritual development in the middle grades concept of developmentally-responsive education. As a result of my analysis of the paradigm narratives, I found three shared meta-paradigms as well as a shared pattern of discursive interaction. The three meta-paradigms within the nexus of the three fields are Ecological Epistemology, Holistic Ontology, and Positivist Ontology. Within each field, these three meta-paradigms had a pattern of interaction, a dynamic of paradox, that was similar. In other words, I found a discursive interrelationship within each field that was the same for all three (hi)stories. Figure 3 (presented again here for clarity) represents the conceptual contents of the nexus and the pattern of interaction within each field that was the same for all three. 


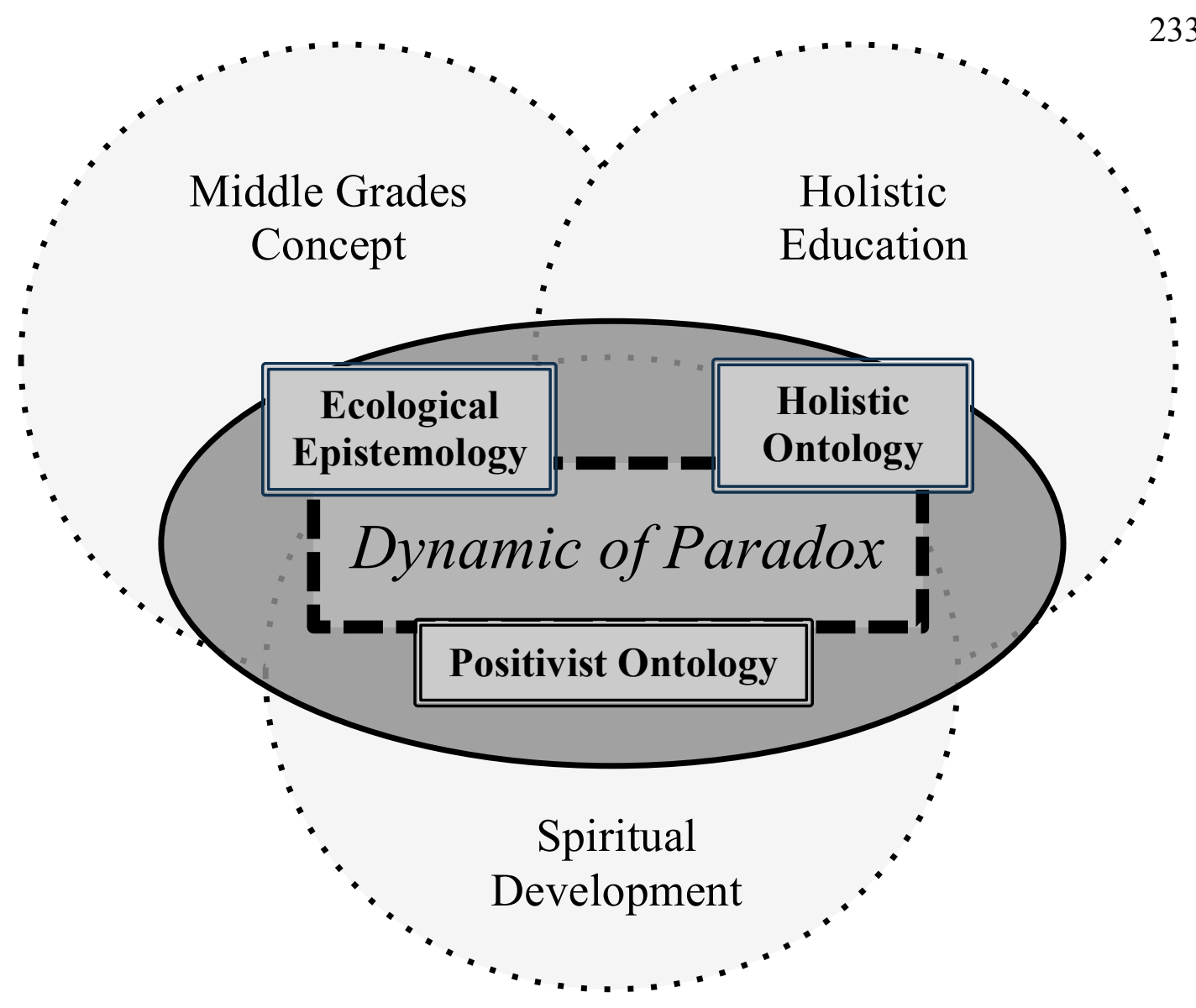

Figure 3. Visual illustration of the conceptual contents of the nexus. Three metaparadigms were interpreted in the area of overlap amongst the paradigm narratives for the three fields. A discursive interrelationship within each field between Positivist Ontology and Ecological Epistemology/Holistic Ontology was also found; this pattern was labeled as a dynamic of paradox.

\section{Conclusions}

In my discussion of the conclusions I drew from these findings, I focus on addressing my main research question: What is the educational relevance of the spiritual development in the middle grades concept? There are several reasons, as raised in Chapter One, for middle grades educators to question the relevance of the spiritual domain of development. These reasons are connected to the cultural context within which they reside: late $20^{\text {th }} /$ early $21^{\text {st }}$ century public education in the United States of America. 
However, in designing this research, I saw it as a problem that the middle grades concept was not explicitly incorporating the spiritual domain. In framing the problem, I linked the phenomenon of alienation to the relevance of spiritual development. I saw inclusion of spiritual development as a potential strategy for increasing belonging.

Before offering my conclusions, I revisit what I mean by relevance. Relevance implies that a construct or idea is germane to the context. Relevance is subjective, although groups can have strong consensus on relevance that appears on the surface to be objective, neutral, and/or empirically based. This consensus is based on the group's values, shared history, and purpose. Relevance, as a subjective construct, can shift over time and when individuals from a group find themselves in new contexts. While relevance, like paradigms, can appear so tacit as to be essentialized, at its core relevance is a social construction and therefore subject to debate. However, to claim that an idea or a construct has relevance is to grant it legitimacy. Therefore, while relevance is a subjective designation, because of its potential for authority, it is desirable to possess.

Seen in this light, my research question about the educational relevance of spiritual development is actually a critical interrogation of the tacit understandings that guide education in general and the middle grades concept in particular. As such, it is also a critical interrogation of which knowledge and cultural values are privileged.

I have organized the discussion of my conclusions around three areas of relevance: educational, cultural-historical, and methodological. The first two conclusions address my main research question directly. In reviewing the findings, I identified the way in which spiritual development is relevant in middle grades education: as a source of enrichment for two components of the middle grades concept—caring relationships and 
constructivist learning theory. The educational relevance conclusion is nested within a

third conclusion on the cultural-historical relevance of spiritual development in an educational context: evidence that suggests a paradigm shift in U.S. academia. Finally, my conclusions about educational and cultural-historical relevance are made possible by the strength of these historiographical findings, and so I close my discussion on conclusions with a brief note on methodological relevance of this study to the topic of spiritual development in education. By using a critical historiographical approach with my research question, I was able to generate reliable findings that supported a clear articulation of how spiritual development is theoretically relevant to the middle grades concept.

Educational relevance. At its roots, the field of middle grades education revisioned what was relevant for the education of young adolescents. While Hall (1904) introduced the concept of a pedagogical relationship between stage of development and education in the early 20th century, it was not until the 1960s that educators of young adolescents called for a systemic reorganization of K-12 education that acknowledged the distinctness of the middle grades. As I found in my interpretation of the prevalent paradigms of the middle grades concept, one of the main criteria for establishing relevance for a middle grades education was knowledge of young adolescent development. The paradigm category Nurturing the Nature captures how human development is viewed as an essentialized construct, a view consistent with development theory throughout most of the 20th century. The cited middle grades advocates use this perceived objective reality of human development as a source for their claim that middle grades education needs to do a better job being responsive to the students' developmental 
needs. In my analysis of the data from the middle grades concept, the passion for an

educational model that tends to the needs, interests, and abilities of young adolescents is fueled by this allegiance to the Truth of the stage-based developmental distinction. I found this passion whether the authors were curriculum theorists, members of the only organization dedicated to middle grades education, or representatives from the highest levels of government and education.

For middle grades advocates, the certainty about conceptions about human development meant that the distinct needs of middle grades students could be known and translated into the middle grades concept of developmentally responsive education. Two main components of the middle grades concept, caring relationships and constructivist learning theory, show the strongest potential for being enriched by teacher knowledge of adolescent spiritual development processes.

Need for caring relationships. The results of this research suggested that the primary developmental needs of young adolescents are identified as relation-based, reflecting the cumulative influence of the paradigms Nurturing the Nature, Be-Coming Together, and Empowering Education. For example, a common recommendation for practice is collaborative learning activities, which are described as best for middle grades students because their developmental need for social interaction with peers is addressed.

My identification of the primacy of the relation-based needs of young adolescents is also reflected through metaphor. The metaphor of school as home dominates the discourse on the middle grades concept. In a home, parents hold the responsibility of making their children feel wanted, loved, and understood. The home metaphor contrasts sharply with the factory metaphor, which has dominated U.S. education for the past 100 
years. In a factory, managers hold the responsibility of making their workers be

productive, compliant, and skilled. When considering all five of the prevalent paradigms of the (hi)story of the middle grades concept, and the distinction between homes and factories, I note the value placed on care, as conceived of and described by Noddings (2005). In her seminal work on care as an educational approach in public schools in the United States, Noddings made the case that "...the basic caring relation is an encounter" (p. 16). As such, caring relations between teachers and students have mutuality; in each encounter, one participant gives care, but there is an equally important participant who receives the care. Middle grades advocates, in my analysis, see the world through a similar lens of mutuality, grounded in a deep and abiding love for the participants in education, the process of learning, and promise of youth. A datum from Lounsbury and Vars (1978), whose own compassion, generosity, and grace as leaders in the middle grades movement has been well-documented, illustrates my summative claim: "Core ${ }^{3}$ requires that the teacher treat each pupil with humaneness and respect. In turn, the student becomes aware of his own humanity and of his relationships and responsibilities to other human beings" (p. 59).

If caring relationships are a central developmental need for middle grades students, then a relevant educational experience for young adolescents is awareness of that dynamic of mutual caring and responsibility for each other. If teachers' role is to create conditions in which learning happens, and learning for young adolescents is dependent upon their perception that they are caring people who are also cared for, it is

${ }^{3}$ curriculum, specific to the middle grades concept and entirely different from the current usage of core curriculum 
relevant for teachers to create conditions in which students can cultivate awareness of

that perception. In drawing these conclusions, I am not discounting other adult-generated conditions related to the need for caring relationships, such as class schedules and team grouping that facilitate each student being well known by at least one adult.

Cultivating awareness of one's interconnection to others is one of the primary activities privileged in the foundational literature on the domain of spiritual development and holistic education. In both of these fields, this awareness is characterized as a spiritual experience. The literature on spiritual development and holistic education offer strong rationale for the importance of awareness of interconnection: healthy development, thriving, and integrity are examples of desirable outcomes. Middle grades advocates do not use the term spiritual when addressing the students' relational need for experiencing belonging and care within their school communities. However, drawing from the shared Ecological Epistemology paradigm that values learning as dependent upon interconnection could be a entry point for middle grades educators seeking to integrate a more holistic knowledge of young adolescent development.

In my analysis of the results, holistic educators, middle grades advocates, and proponents of a theory of spiritual development share a strong commitment to supporting human growth and learning that is grounded in caring relationships. When establishing the educational relevance of spiritual development, the challenge is not finding agreement on the importance of student intra- and interpersonal relationships and the students' sense of place within something greater than themselves. What I conclude, based on my historiographical findings, is that the challenge lies in finding a culturally shared 
conception of students' inner lives that is honored in systemic ways in public schools in the United States.

This conclusion leads to the next topic in my discussion: learning. The shared Ecological Epistemology paradigm that privileges awareness of interconnection also provides the three fields a sense of convergence around learning theories. A second conclusion I reached from the results of this research is that there are both opportunities and limitations for seeing spiritual development as relevant for the middle grades concept, when learning theory is the shared focal point.

Constructivist learning theory. A shared Ecological Epistemology suggests educational relevance through a common perspective on learning theory. From my analysis of the findings, I characterize this shared perspective in even stronger terms: as a commitment. This conclusion is construed as both an opportunity for integration of the spiritual domain with the middle grades concept, as well as a challenge for its inclusion in public education in the United States.

The common commitment is to constructivist learning theory, and its subcategory, social constructivist learning theory. The paradigms from the data sets that demonstrate this commitment are: (a) Be-Coming Together and Empowering Education, from the middle grades concept; (b) Seeing Crucibles and Aligning Heart and Will, from spirituality as a developmental domain; and (c) Knowing with Wholeness and Beliefs About What it Means to be Human, from holistic education. Two aspects of constructivist learning theory are important to articulating the educational relevance of spiritual development: the role of the learning environment and the primacy of inquiry, as a learning activity and as an acquired disposition. 
The significance of the role of the learning environment, especially with pedagogy influenced by constructivism/social constructivism, is part of the parallel that suggests how spiritual development is relevant for middle grades education. Spiritual development theory emphasizes that factors external to the developing person, such as the stories told by caregivers, are a significant influence on the process and outcome of human growth. For example, Fowler (1981) stipulated "How these capacities [for faith] are activated and grow depends to a large extent on how we are welcomed into the world and what kinds of environments we grow in," (p. xiii). Likewise, theorists from the middle grades and holistic education are adamant about the importance of the role of the environment for students (e.g., middle grades advocates citing non-developmentally responsive classrooms as hazardous). The conclusion I draw from these findings is that an opportunity for integration of knowledge about adolescent spiritual development may come from the fields' shared understanding (as influenced by both Ecological Epistemology and Holistic Ontology) around the interrelationship amongst student learning, human growth, and the design of the environment within which learning and development occur.

The second element of constructivist learning theory that is valued by all three fields is the primacy of inquiry. As a learning activity, inquiry is recommended as a main element of a successful middle grades curriculum. For example, Alexander (1968) emphasized "...the importance of the student's own investigation," (p. 78) in his summary of four essential components of a developmentally responsive middle grades curriculum. NMSA (2010) echoed Alexander (1968): “An integrative curriculum revolves around important questions students ask, rather than around a predetermined 
body of content" (p. 21). Learner-centered inquiry is advocated as a means of

responding to young adolescent cognitive, moral, and socio-emotional developmental characteristics.

The distinction between learner-centered inquiry and adult-chosen curricular content mirrors the distinction between religion, as acceptance of and belief in specific doctrine, and spiritual development, as a process of evolving reflection about meaning. In that distinction made by advocates of a domain of spiritual development, inquiry is one of the main features that sets spirituality apart from religiosity as a scholarly construct. Spiritual developmental processes of searching, posing questions, and making meaning sound very similar to the types of learner-centered inquiry activities recommended by middle grades advocates. Therefore, one conclusion I draw about the educational relevance is that there is theoretical potential for increased teacher knowledge of the domain of spiritual development to support design of classroom inquiry-based projects.

In addition to inquiry as a learning activity, inquiry is also privileged as a disposition. I refer to disposition in the same way that Dewey (1916) characterized disposition in a learning context ${ }^{4}$. Dewey wrote about dispositions as resources for adaption; learning is a change in disposition. Through "educative teaching" (p. 13), as opposed to mere training, a learner acquires certain mental-emotional dispositions. Held in highest regards of all dispositions is “...a habit of learning. He learns to learn," (p. 45). In the findings from this study, the meta-paradigms of Ecological Epistemology and Holistic Ontology guide an educational approach that views learners as active agents in

\footnotetext{
${ }^{4}$ I am indebted to Webster (2013) for the idea to pair Dewey's definition of inquiry with spiritual developmental processes.
} 
their own life-long learning who possess integrity and competence in their current stage

of growth. The disposition of inquiry may be cultivated and stimulated in schools, but the purpose of education is not simply to train students to mimic questioning and curiosity in a classroom; the purpose of education is to develop full human potential, in all contexts, by nurturing the whole child/adolescent. This purpose is seen most explicitly in the following paradigm categories: Empowering Education (middle grades), Aligning Heart and Will (spiritual development), and Re-Framing Accountability (holistic education).

Through the shared commitment to the principles of constructivist learning theory, I see an opportunity for legitimizing teacher knowledge of adolescent spiritual developmental processes. An explicit description of what happens in the domain of spiritual development could deepen and expand a developmentally responsive middle grades teacher's application of constructivist learning principles. For example, one of the processes of spiritual development is formulating an interpretive narrative as a source of making meaning and knowing purpose. An example of the language from the spiritual development literature is “...spiritual development [is] a process of actively constructing a view of the self in the context of self-transcending myths and frames," (Benson, 2006, p. 489). My conclusion, the implications of which I address in the next section, is that it is possible to extract characteristics of the processes of human growth categorized as spiritual development and apply them within the relational, constructivist-based framework of the middle grades concept. This opportunity is made possible by the paradigmatic level of shared commitment to a particular theory on human learning.

However, a related conclusion I draw from these results suggests a challenge to the integration of knowledge about the spiritual domain of development in public 
education in the United States today. The challenge comes from the dissonance between ideas about how learning happens, as expressed by the foundational literature of these three fields, and culturally dominant assumptions about how learning happens.

For example, one of the findings was a shared value for humanist perspectives on learning and development, as seen in the narratives on the paradigms Ecological Epistemology and Holistic Ontology. The humanist perspective views learners and developing subjects as active agents, not as passive recipients of transferable information. Expressed most clearly in the holistic education data set as the paradigm category Beliefs About What it Means to be Human, my finding was that a belief about the nature of being human, radically different from the one held by proponents of public education in the U.S. was an energizing force within the field of holistic education. That is to say, one of the ways in which holistic education is defined is in its critique of dominant epistemological values that are sustained through the practice of schooling.

The theme of cultural critique was found in the middle grades literature as well, through the paradigm categories Separating and Re-Integrating and Empowering Education. Within the spiritual development literature, Legitimizing Spiritual Development is a category I interpreted as sustained by defensive walls against dominant epistemological and ontological values in the field of developmental sciences.

The fields' embrace of constructivist learning theory is a clue to the challenges facing the incorporation of spiritual development theory in public education in the United States today. I perceive that, as a learning theory, constructivism and social constructivism have not fully penetrated models of teacher or student learning in public education. Because of this, developmental theories that rely on constructivist learning 
principles will be harder to address in meaningful ways in teacher/student education. So, taking the opportunity to use constructivist learning theory as a culturally acceptable bridge between the middle grades concept and adolescent spiritual development is limited by the dissonance between constructivist principles/assumptions/values and the culturally dominant technocratic epistemologies that influence the factory and banking models of public education in the United States today.

However, this contrast between opportunity and challenge in regard to constructivist learning theory is related to my third conclusion, that I found evidence of a paradigm shift.

Cultural-historical relevance: Paradigm shift. I conclude that the paradigm narratives and dynamic of paradox suggest a paradigm shift in the developmental and social sciences in the United States. This shift is most clearly seen in the field of spiritual development. In Kuhn's (1996) definition of a paradigm shift, the move occurs when new questions cannot be answered with old tools. Questions about meaning, purpose, connection, and transcendence are not new questions; placing them in a developmental framework is.

The shared discursive interrelationship of a dynamic of paradox suggests a paradigm shift. Positivist principles are applied to make claims about the objective reality of young adolescent development, knowledge, and learning. But while the claims are grounded in positivism ontology, the content of the claims - ecological epistemology and holistic ontology — challenge the content of the dominant discourse on knowledge and learning as manifest in public school in the U.S. 
The clearest illustration of a potential paradigm shift, or at least of the paradigm

confusion that Kuhn (1996) postulated, is the findings from the paradigm category Legitimizing Spiritual Development. In my rendering of that paradigm's influence, I found that the advocates for a developmental categorization of spirituality affirmed the same empiricist principles that they also critique for excluding spirituality as a legitimate domain of human development. This irony suggests Kuhn's (1996) theory of scientific revolution, which he characterized as the result of a crisis of competing paradigms.

Kuhn used the analogy of a political revolution when describing his theory on scientific revolutions. One of the ways in which he found the two types of revolutions analogous is in the questioning of an established authority, as well as the institutions representing that authority. I think the findings from this study suggest a similarly foundational (paradigmatic) questioning of the authority represented in schools. The locus of learning and knowledge moves from external sources, such as organized disciplines of knowledge, teacher lectures, and implementation of state standards, to internal sources of authority. Examples of what I consider to be internal sources of authority are students' previous knowledge and cultural background, students sharing ideas collaboratively and problem-solving in authentic situations, and the middle grades concept of core, or integrative curriculum, which privileges student academic interests.

While my interpretation of the co-existence of dichotomous paradigms suggests a potential paradigm revolution, I also conclude that the shared pattern of discursive interrelationships between Positivist Ontology and Ecological Epistemology/Holistic Ontology has a variant that implies a difference in how far along the paradigm shift process the three fields are, compared with one another. The results from this study 
suggest that the field of middle grades education is at the edge of a paradigm shift, but is not as fully immersed as the field of spiritual developmental theory or holistic education in a paradigm shift.

The ecological epistemology and holistic ontology embraced by middle grades advocates does not extend its influence to allow for explicit inclusion of student spiritual development, despite the findings from this study which suggest the field's deep congruence with the same commitment to the inner life expressed in the (hi)stories of holistic education and spirituality as a developmental domain. Based on the results of this study, I conclude that the foundational literature of the middle grades concept lacks a critical (i.e., critical theory) pedagogical or theoretical perspective. I did find that perspective in the foundational literature of the other two fields, holistic education and spirituality as a developmental domain (e.g., Schooling for Cultural Consensus and Legitimizing Spiritual Development). In those (hi)stories, there was a willingness to see the fields of developmental sciences and education as social constructions that replicated certain political and cultural values. The critical perspective opened up a conceptual space for re-evaluating the relevance of spiritual development in the developmental sciences and in education. Lacking the influence of a critical perspective, the field of middle grades education is not yet well positioned to entertain the explicit inclusion of a developmental domain that is not seen as relevant by the dominant discourse in the U.S. public education.

Methodological relevance: On the nature of findings. The last conclusion I will address in this section relates to the research methodology that made these conclusions possible. Historiographical findings are distinct from traditional quantitative 
or qualitative findings in that the new knowledge generated comes from systematic

conceptual analysis of extant texts. In this sense, historiography is more similar to philosophy, although hermeneutics can also be part of a qualitative study. For this work, in the context of educational research, how are the findings substantially distinct from a well-conducted review of the related literature? What delineates historiography from a literature review, given the many similarities in terms of purpose, procedures, and results?

In considering where this study and its findings fit in with the larger context of educational research, I chose to include a conclusion that addressed this challenge to the use of historiography as a legitimate research method in the field of education. Doing so led me to the question, in a historiographical study, what are the criteria for establishing that the results are sufficiently distinct from the conclusions reached from a review of the related literature? In other words, can I conclude that historiography worked as a research method?

To address this question, I compared conclusions that I reached as a result of the literature review with findings from the research that were related to the literature review conclusions. For example, one observation I made early on my review of the literature was that some phenomena, such as having a greater sense of purpose, were described in the middle grades literature as part of social and/or emotional development (e.g., Van Hoose, Strahan, \& L'Esperance, 2001) whereas in the spiritual development and holistic education literature, the same phenomena were categorized as spiritual (e.g., Fowler, 1981; Kessler, 2000). This observation challenged my initial problem statement: that developmental needs related to the spiritual domain of human development were 
excluded from the middle grades concept. Perhaps those issues were being addressed in

the foundational literature, but just under a different name in order to honor cultural and legal expectations in U.S. public education.

The findings from this research suggest that the prevalent paradigms influencing the middle grades concept are resonant with an explicit inclusion of spiritual developmental needs and interests. Also, the inter-textual pattern on 'the valuing of a person's inner life' shared by all three data sets affirms the hypothesis that whether or not the term spiritual is being used as a designation, some developmental needs and interests otherwise categorized as spiritual are being privileged in the foundational literature on the middle grades concept.

In this example, the findings from the research are complementary to the initial conclusions drawn from a review of the literature. For my research purposes, these findings are encouraging, in terms of establishing the educational relevance of spiritual development in middle grades education.

However, the presence of complementary conclusions does not confirm that there is no qualitative difference between a literature review and historiographical study. Based on the experience of conducting this research and its results, I conclude that the method of historiography is distinct from a literature review. The inter-textual and interdiscursive findings from this research were subjected to far more rigorous and lengthy processes of systematic analysis than the conclusions I reached from conducting a review of the related literature. In addition, the texts that I cited as foundational were only included in the data sets after a more substantive series of tests than any applied during the literature review. 
An analogy to illustrate my claim is substituting the data sources in this study

with human subjects. If I were investigating the educational relevance of the spiritual domain of development in middle grades education using middle grades teachers as sources of data, I might inform my research design and problem statement by having a series of conversations with licensed, experienced teachers. Conclusions drawn from these conversations, even if I strategically selected which teachers I was going to talk to, would be qualitatively distinct from conclusions drawn from a systematic and trustworthy analysis of written transcripts of interviews with participants who became part of the study after being subjected to a series of criteria for inclusion.

As I discuss in the next section, the results of a historiographical study might have substantial implications for further field-based qualitative and quantitative research. Indeed, my hope in designing this research, as with any research project, was that the results would inform further research on the relevance of spirituality in public education in the United States. Part of my rationale for conducting a study that would produce new knowledge came from my observation about the lack of definitional clarity around spiritual development within academic literature and educational practice. The findings from this study stand on their own as trustworthy, substantive, and of value in their own right.

\section{Implications}

In this section, I address implications for practice within the fields of middle grades education and educational research. In considering potential implications, I drew from my professional background as a middle and high school teacher in public and private schools as well as my service and teaching as an emerging scholar in higher 
education. The first two implications - - leveraging spiritual development knowledge

within the accountability-based framework and using empowering and clarifying language in spiritual development teacher education — are intended for a middle grades audience. I include in that audience classroom teachers, administrators, and universitylevel teacher educators. The last two implications are intended for a university-level audience, as they pertain to (a) recommendations for future research on how to integrate knowledge of adolescent spiritual development in middle grades curriculum and instruction and (b) the merits of critical historiography for research that influences educational policy.

Middle grades education. In considering implications of this research, I negotiated a tension: Is my goal to revolutionize middle grades education through a radical reconceptualization of what it means to be developmentally responsive? Or, is my goal to give teachers a conceptual and linguistic framework for tending to their students' spiritual development that does not jeopardize how they are perceived to be in compliance with the Establishment Clause? In my discussion of implications for practice in middle grades education, I address both aspects of this tension.

Facilitating outcomes in an accountability-based system. An entry point for legitimizing teacher knowledge of adolescent spiritual development within the educational discourse is to position such knowledge as there to facilitate academic achievement in the middle grades. The conclusions I reached regarding the ways in which spiritual developmental processes (i.e., awareness of interconnection) have the potential to enrich elements of the middle grades concept (i.e., caring relationships) suggest that even within the context of secularized discourse, teacher knowledge of spiritual 
development can theoretically influence academic achievement. In this section, I make

the case that knowledge of two aspects of spiritual development processes, interplay with other domains of development and integration, can be drawn upon to facilitate positive academic outcomes in today's accountability-based system of public education.

The reality for most public educators at this time is a particular pedagogical model of accountability and outcomes. Therefore, a potentially realistic strategy for integrating spiritual development in the middle grades concept is to use the same behaviorist concepts that influence the accountability framework. This is a deeply ironic pairing, behaviorism with spiritual development, as the former discounts the significance of a person's inner life as it relates to changes in behavior (i.e., learning) and the latter prioritizes a person's inner life. However, given my conclusion that a paradigm shift is only suggested but not assured by the findings, and that such a revolution is hampered in the field of middle grades education by the lack of a demonstrated critical perspective, imagining an implication that honors the current cultural-historical consensus is strategic.

In the holistic education paradigm category Re-Framing Accountability, the influence of the behaviorist philosophy in the dominant educational discourse is not challenged. What it means to be accountable is reframed, but the underlying principle of accountability is not questioned. In a behaviorist model, education has inputs and outputs, both of which can be measured and manipulated by the teacher (Skinner, 1987). This model has been affirmed in the past 25 years in the United States through policies such as state and local district establishment of learning outcomes and standards in the 1990s, the federal accountability policy NCLB in the 2000s, and nation-wide adoption of the Common Core Curriculum in the 2010s. I suggest that teacher knowledge of adolescent 
spiritual development could be considered one input into curricular design and instructional strategies.

The interrelationship between developmental domains is a way in which inclusion of knowledge about adolescent spiritual development fits within the accountability framework. In the results of this study, spiritual development is presented as a developmental process that involves other domains of human development, such as cognition and social/emotional development. For example, the shared paradigm of holistic ontology came from several data that characterized the relationship between spiritual and cognitive growth being symbiotic. So, in an educational discourse that strongly privileges cognitive growth (which was a position of holistic educators, i.e., Schooling for Cultural Consensus), what is good for the cognitive domain is relevant as an educational concern. From my review of the literature on social-emotional education, this line of logic is used in that field as well (e.g., Durlak, Weissberg, Dymnicki, Taylor, \& Schellinger, 2011). Durlak and associates, who found statistically significant academic achievement gains for students participating in social/emotional, also situated the potential relevance of social-emotional education within an NCLB educational context.

From my historiographical analysis, as well as my initial review of the literature, I encountered a common challenge to any discussion of the relevance of affective qualities of students; that challenge argues that tending to the inner lives of students compromises the opportunities to engage in the "real work" of public education, i.e., academic achievement (Juvoven, 2007; Kessler, 2000; Woolley \& Bowen, 2007). The present research suggests that teachers could be better equipped to engage in what the dominant educational discourse characterizes as the real work by leveraging knowledge of 
adolescent spiritual developmental processes. However, this research can only clarify

the potential of incorporating knowledge about spiritual development; further work, such as the research conducted on the correlation between social-emotional education programs and academic achievement (e.g., Durlak et al., 2011), is still needed to be able to provide empirical evidence to support my claim.

Another strategy for leveraging knowledge of spiritual development to improve academic outcomes is the pairing of a main component of the middle grades concept with a central element of spiritual development: integration. One of the central tenets of the middle grades concept, as affirmed in this research, is school organization and learning activities that promote integration, of one's life in and out of school, of a sense of place in one's intellectual community, and of culturally sanctioned knowledge. As a developmentally appropriate principle of middle grades education, integration is promoted as a means of increasing academic achievement (e.g., NMSA, 2010). In the findings from this study, spiritual development is conceptualized as a process of integration; the meta-paradigms of ecological epistemology and holistic ontology privilege integration as a core principle. Teacher knowledge of what the process of integration looks like for 10- to 15-year-olds from the perspective of their spiritual development can be used to further inform the principle of integration as part of middle grades curriculum and instruction. Thus, this research implies that teacher knowledge of adolescent spiritual development could be considered an asset, not an intrusion, in the work of implementing a developmentally responsive education that promotes academic achievement in an accountability era. 
In rendering these suggested implications, I have leaned more towards the

pragmatist approach of offering strategies that do not jeopardize teachers' standing vis-àvis dominant cultural and legal consensus about the educational relevance of spiritual development. Implicitly though, situating spiritual development as a means of promoting academic achievement perhaps opens the door to an explicit radical reconception of what it means to be developmentally responsive in middle grades education.

Unpacking the contents of spirituality. The results of this study affirm what I had learned from the literature review and through my personal communications over the past two years with people inquiring about my dissertation subject: the power of the term spirituality when it is used as a descriptor for a domain of human development. For some, framing spirituality as a scientifically accepted domain of human development - that is, use of the phrase spiritual development — empowers teachers to include the inner lives of students when planning curriculum and instruction (e.g., de Souza, 2006). For others, the phrase immediately conjures up an intractable association with religion; this association, in the context of public education in the United States, is an instant challenge to the legitimacy of leveraging knowledge of students' inner lives when planning curriculum and instruction.

Therefore, a strategy for incorporation of spiritual development in the middle grades concept is to articulate the contents of that domain using language that empowers and clarifies, rather than discourages and confuses. Empowering and clarifying language might look like this: spiritual development is identified as a process of making meaning of one's life, experiencing connection with someone or something greater than oneself, constructing an interpretive framework or lens through which life experiences are 
unraveled, cultivating compassion and empathy, strengthening resilience, and making commitments to certain values and/or beliefs. An implication of this research is the addition of new knowledge with which to skillfully introduce constructs from spiritual development theory and research into the professional development of teachers and administrators who work in secular, public schools. In this way, the results of this research complement the work done for Australian schools by de Souza (2006), who also advocated for a model inclusive of spiritual development when designing learning environments that meet the needs of all learners.

In addition to employing empowering and clarifying language, another implication of this research is development of professional development curriculum that teaches educators about young adolescent spiritual development which draws from multiple literatures. Informed by the historiographical findings from this research, such a professional development curriculum would utilize literature from holistic education and the developmental sciences, while staying firmly grounded in literature that describes the middle grades concept. A source from the developmental sciences that could be useful is King and Roeser's (2009) chapter on adolescent spiritual development in The Handbook of Adolescent Psychology. Recall that King and Roeser (2009) reported six ways in which adolescent spiritual development was conceptualized: (a) as a relational system; (b) as a meaning system; (c) as the creation of cognitive-conceptual schema; (d) as an identitymotivation system; (e) as the experience of various states of transcendent awareness; and (f) as a "dynamic developmental systems perspective in which [spiritual development] is seen in relation to multiple contexts, people, symbol systems, and opportunities and risks" (p. 440). Their framework, rooted in the language and constructs from psychology, 
could be useful for clarifying how spiritual development supports and is supported by

other domains of human development within particular cultural contexts.

King and Roeser's (2009) work an adolescent spiritual development could be used in conjunction with my findings on the contents and processes of spiritual development from the paradigm category Aligning Heart and Will. For example, the developmental process of making commitments to certain values and/or beliefs could be explained within several of King and Roeser's (2009) frameworks: as a relational system, as a meaning system, and as an identity-motivation system. While I decided that King and Roeser's (2009) text did not fit within the parameters of this research, I do think that text is important for helping to transfer these findings into practice.

Finally, in an effort to use empowering and clarifying language that also utilized multiple fields of literature, I could conduct further analysis of the data from the middle grades texts. The purpose of this analysis would be to interpret for recommendations that might correspond to aspects of young adolescent development as also characterized in the holistic education and spiritual development texts as elements of spiritual development. Also, it would honor the recommendations that already integrate developmental attributes directly related to the inner lives of middle grades students.

Closely related to the implications identified in this section are those of the next section. Now, I turn to a more focused consideration of the implications of this research for the field of educational research, in the middle grades and at other levels.

Educational research. I recommend two related areas for future research. The first focuses on how to integrate knowledge of adolescent spiritual development in public 
schools in the United States. The second concerns legitimizing historiography within the field of educational research, particularly for policy makers.

Stepping stone for future work on spiritual development. I intend for this work to be one small contribution to a much greater project of situating spiritual development within the middle grades concept to more fully realize the promise of developmentally responsive education. Instead of "making final pronouncements on the way things are," the findings from this research are part of "a larger interdisciplinary and intercultural conversation" (Kincheloe, 2008, p. 132). This research could be extended with fieldbased inquiry that compares and refines ideas about how middle grades teachers can leverage a more holistic knowledge of the development of young adolescents. For example, a potential future research question informed by the results of this research is: How do middle grades teachers perceive the educational relevance, if at all, of the inner lives of their students?

Drawing from the findings of the present research, I envision being better positioned to design quantitative or qualitative research with middle grades teachers as sources of data. For example, using the combined results from the prevalent paradigm narratives, I could design a quasi-experimental study using a survey instrument that asks teacher participants to categorize adolescent developmental characteristics by domain. One group would get a survey that offers spiritual as one domain category among the more typical options (e.g., cognitive, social); the other group would have the same domain options except for the spiritual category. Results would be analyzed for a comparison of developmental characteristics that are categorized as spiritual when offered the option and how those same characteristics are categorized when spiritual is 
not an option. These results could be combined with another study using qualitative

coding techniques to conduct further analysis of extant texts. That study would focus on identifying recommendations from the literature on the middle grades concept that address aspects of young adolescent development characterized in other literature as spiritual development. That type of analysis was only begun here; it could be deepened to produce results more focused on translating theory into practice.

If I conducted the study described above, the research purpose would shift away from generating new knowledge about the educational relevance of spiritual development, which was the purpose of this dissertation research. The new research purpose would be to generate culturally respectful professional development curriculum that deepens the holistic aspects of the middle grades concept and empowers middle grades teachers with the competencies and dispositions to leverage knowledge of adolescent spiritual development. This dissertation research would serve as a stepping stone for further research that is less on whether spiritual development is relevant, but more focused on how to integrate knowledge of adolescent spiritual development in public schools in the United States.

Legitimizing historiography. The American Educational Research Association (AERA) dedicates a division to historiography and the history of education. However from my own experience in an Ed.D program and my reading of the educational research literature, my impression is that historiographical research is an outlier in educational research. Historiographical research uses techniques that are both quantitative and qualitative, as an approach, but it doesn't fall neatly into either category of educational research. Even forming my dissertation committee was challenging in terms of finding a 
tenure-track faculty member in the Graduate School of Education who has expertise

with historiographical research. As Thayer-Bacon and Moyer (2006) found in their own work as philosophical/historiographical teacher-researchers in the field of education, "in the absence of more familiar and tangible products such as taped interviews, field sites, or chi-squares, alternative forms of research can appear abstract and disconnected from educational practice" (p. 139). Kincheloe (2001, 2005, 2008), whose work on critical constructivism shaped many of my ideas, also expressed this perspective. This challenge was a potential limitation to my selection of historiography as a method for my dissertation research. However, after conducting this research, and becoming increasingly familiar with the literature on historiography in education, I am convinced of both its merits and applicability in the field of education.

As a method, historiography is especially applicable for my area of specialization, curriculum and instruction. The content of curriculum and the strategies of instruction are not neutral (Kincheloe, 2008). Educational historians Novoa and Mashal (2003) argued:

The formation of educational knowledge - what is important to know and what should or should not be reflected in the study and practice of education - has historically been a consequence of social and political as well as academic developments. More than epistemological discussion, these developments entail a process that is historically contingent, vulnerable, and reflective of the political mood and intellectual space that they express. (p. 423)

Historiography reflects poststructural arguments against language as a "closed structure" (Bentley, 1999, p. 141). Through the hermeneutical approach of historiography, 
foundational texts are interpreted for the epistemological and ontological worldviews

that influence the content. By shining a light on those worldviews, what is considered legitimate educational knowledge is seen as products of social and historical processes. Critical historiography is a research method that opens up space for alternative ways for middle grades teachers to consider the domain of spiritual development as they work with curricular content and select instructional strategies.

My research design was facilitated by an approach that emphasized written texts as data and a research paradigm, critical constructivism, that emphasized "the deep social assumptions and power relations embedded in everyday language....the ways unexamined language shapes education, the research about it and the narrative format that transmits it to the reader" (Kincheloe, 2008, p. 122). My purpose for doing this research was to bring more clarity to the developmental processes characterized as spiritual and to be able to articulate how these processes could be considered relevant within a secular educational context. Critical historiography suited that purpose, as it allowed me to draw heavily upon the foundational literature that influences educational practice in the middle grades, while at the same time interrogating the tacit rules guiding those (hi)stories.

Finally, as Kaestle (1997) argued in his rationale for educational research that is historiographical, many of today's major decisions about practice and policy in public education are driven by a belief in how things have always been done. I do not propose that this is a phenomenon unique to education. However, if educators are going to draw from historical accounts for their decisions, a more nuanced understanding of the 
assumptions and agendas that are behind the foundational literature could better serve all ${ }^{261}$ students.

Hopefully, by nesting my conclusions regarding the educational relevance of spiritual development within their cultural-historical and methodological contexts, I have strengthened my vision of a new conceptual landscape of middle grades education in the United States. As I had suspected when I began this research project, issues of discourse and cultural context weigh heavily on any exploration of spirituality and public education. However, through these conceptual conclusions about the ways in which knowledge of spiritual development enriches the central tenets of the middle grades concept, I see great promise for increasing a sense of belonging for young adolescents in schools, empowering teachers who are inclined towards a holistic pedagogy, and positively influencing academic achievement. 
CHAPTER VI

\section{CONCLUSION}

\section{Final Reflections}

In this final chapter, I will reflect upon my transformation during this critical constructivist research process, identify who might be most interested in the results of this research, and offer some final thoughts on the purpose of education.

\section{My Transformation as an Educator}

“....critical constructivist research changes not only what one knows but who one actually is" (Kincheloe, 2008, p. 132). As a result of my work on this project, my identity as a purely radical educator has been expanded to incorporate the principles of holistic education more explicitly. My internal rearrangement reminds me of the transformation of Buddhist teacher Thich Nhat Hahn during the U.S. war in his homeland of Vietnam (Malkin, 2003). In his transformation, he integrated his deep spiritual practices with his political endeavors. Being a Buddhist political activist is challenging, given the Buddhism principle that people's rigid notions about institutions, identities, and relationships are delusions that mask a spacious, loving, and intelligent reality. Thich Nhat Hahn was compelled to address this challenge as he sat in the meditation hall while violence against his people raged outside. The integration of spiritual practice in the Buddhist context with social justice action is often described in Western culture as "Engaged Buddhism" (e.g., Macy, 1991). In my transformation through this critical constructivist research, my rearrangement went the opposite direction: I developed a deeper awareness of how to integrate my radical political pedagogy with my spiritual commitments. Although the work of bell hooks, who writes often of the spirituality of 
critical pedagogy, has been a powerful influence for the past 20 years, it was not until

my work on this dissertation that my conceptual understanding of critical spiritual pedagogy became an embodied understanding.

I was led to this transformation through my deep engagement with the foundational literature of holistic education. Advocates of holistic education make explicit the relationship between societal values and what types of knowledge and learning are privileged in public education in the United States. In the holistic critique, knowledge is viewed as a reflection of whose perspective is most valued and which conceptions of reality are considered to be legitimate. This strategy de-naturalizes a tacit understanding of knowledge as a neutral construct. In contemplating this finding, I saw the consistency between the holistic strategy of challenging the inevitability of current practices and my own strategy for designing a critical constructivist research project. I chose a research design that would enable to me interrogate the ways in which power and knowledge played a role in the absence of the spiritual domain of development in the middle grades concept.

This connection between the perspective of holistic advocates and my research design has led me to re-think how I describe my pedagogical stance as an educator. Although I have not previously self-identified as a holistic educator, that identity has been transformed as a result of my work on this research project. For instance, in the past several months when people ask me what I think of my daughters' education in their public neighborhood school, I express my dissatisfaction with the disclaimer, "But, I am a holistic educator.” The words have been coming out easily, with little forethought. I align my critique of the technocratic pedagogy I see at my children's public school with 
the field of holistic education. Before my work on this research project, I aligned such a

critique only with the work of radical educators such as hooks and Freire. My

transformation involved a deeper understanding of the principles of holistic education, and how those principles are consonant with my identification as a radical educator.

In exploring the relevance of spiritual development in middle grades education, I am convinced that the problem is rooted in the current dominant consensus about learning, human development, and the purpose of education. In that consensus, learning is viewed as a passive activity, children and adolescents are believed to be immature and unreliable, and education is preparation for an industrial workforce. Within such a consensus, educational priorities are (a) social control, (b) adult domination, and (c) a one-size-fits-all pedagogical model.

If we are, as has been suggested (e.g., Wilber, 2000), on the precipice of an ecological revolution in U.S. society, then I feel hopeful about the likelihood of the field of middle grades education enriching their emphasis of caring relations and constructivist learning theory with explicit inclusion of adolescent spiritual developmental characteristics. But the field will first need to be willing to adopt a more critical stance on the implementation of public education in the U.S., to be willing to have consensus on the perspective that education is not neutral.

\section{Application in the Field of Middle Grades Education}

In the fall of 2012, I had the opportunity to be a guest speaker in a graduate learning theory class at a private college in the Portland metro area. I was asked to present some of my work on developmentally responsive instruction that includes the domain of spiritual development. After presenting this work, the group discussed the 
implications of it, as well as their own personal responses in the context of their work as

educators at various stages of their career. I took notes on the conversation and analyzed them later for themes.

I noticed two patterns of responses to the topic of explicit inclusion of the term spiritual: one group of students expressed a sense of what I describe as relief and empowerment. These students said they were grateful to be offered a language and framework for addressing the inner lives of their students, something they believed was relevant in a learning context. Another group of students expressed confusion and skepticism. Their skepticism was not in regard to the characteristics of adolescent spiritual development; they linked their skepticism and confusion to the application of the word spiritual as a descriptor. As one student said, "I was thrown off by the word spiritual because I immediately conjured up associations that did not seem legitimate for a public school."

I think my work is for the teachers in the first group, who express a thirst for tools that enable them to respectfully but intentionally tend to the spiritual needs, interests, and abilities of their students. These teachers see, as I do, spiritual development as a developmental resource for growth in all other domains of human development. They see, as I do, the need for professional development curriculum that expands their knowledge of young adolescent development to increase their capacity for being developmentally responsive educators.

\section{Final Thoughts on The Purpose of Education}

In my explanation of how I use the term relevance in this research, I characterized relevance as a topic or idea that was germane to the context. Germane is an intentional 
word choice; its origins are the Latin germanus, which means genuine or having the same parents (Oxford Dictionary of English, 2010). Knowing its etymological origins led me to consider the parents of education, and I thought of the purpose of education. Relevance is connected to purpose, and so the absence of explicit consideration of the spiritual domain of human development could be related back to questions about the purpose of education in the United States. If the purpose of education is limited to the transmission of certain knowledge or skills, I can see how the relevance of spiritual development might be called into question. As the findings and conclusions from this study show, spiritual development is conceived of as a process of making personal meaning, being aware of interconnection, and exploring commitments to values and beliefs. The spiritual development processes are not consonant with an educational purpose focused on transmission of pre-determined knowledge and skills. While participation in religious affiliations may involve transmission of doctrine as knowledge, in the (hi)stories of spiritual development and holistic education, spiritual development is not synonymous with religiosity. So, spiritual development is not relevant in an educational endeavor with the purpose of knowledge transmission only.

But what if the purpose of education is not "to deliver the answers" but rather "enable students to live with...questions," (Webster, 2013)? In that educational endeavor, teacher knowledge of adolescent spiritual developmental processes becomes highly relevant.

And so, the questions I am left with are: What is the power of the term spiritual when used as a descriptor for human attributes or activities that could be categorized with other terms? Is there something to be gained in the field of education by integrating 
spiritual into our pedagogical lexicon? Or, is the purpose of public education in the

United States too radically challenged by using the term spiritual? Are other terms, such as inner life, more palatable simply because they do not produce the same deep level of challenge to the adults who are more comfortable with a learning theory that privileges adult control and requires student submission in the classrooms? These questions reflect the ontological and epistemological levels of inquiry that characterizes this research and the cultural depths of my research question.

What I conclude from this research is that there are deep, paradigmatic connections amongst the fields of the middle grades concept, spirituality as a developmental domain, and holistic education. The foundation is there for integrating a more holistic middle grades concept. It is possible to develop valid professional development curriculum that addresses the spiritual development of middle grades students without frequently using the term spiritual. The term inner lives might capture and communicate similar human attributes as those from adolescent spiritual development without being too threatening to the assumptions and beliefs about the purpose of education in the United States. I recognize that even the limited acceptance of a relatively innocuous term like inner lives is an accomplishment given the dominance of technocratic and behaviorist influences on curriculum and instruction for most of the $20^{\text {th }}$ century.

This dissertation research offers direction for field-based methods to explore these final questions. It addresses a gap in the literature of the middle grades concept by providing a sound theoretical basis for pursuing a more holistic implementation of developmentally responsive education for young adolescents. It is hoped that this 
theoretical basis will guide and inspire future middle grades educators and others who care about young adolescents. 
Adarkar, A., \& Keiser, D. L. (2007). The Buddha in the classroom: Toward a critical spiritual pedagogy. Journal of Transformative Education, 5(3), 246-261.

Alcalay, A. (1993). After Jews and Arabs. Minneapolis, MN: University of Minnesota Press.

Alexander, W. (1963, July). The junior high school: A changing view. Paper presented at the Tenth Annual Conference for School Administrators: A National Conference on the Junior High School, Ithaca, NY. In T. W. Smith, \& C. K. McEwin (Eds.), The legacy of middle school leaders: In their own words (pp. 6-15). Charlotte, NC: Information Age.

Alexander, W. M., Williams, E. L., Compton, M., Hines, V. A., \& Prescott, D. (1968). The emergent middle school. New York, NY: Holt, Rinehart, \& Winston. Azevedo, M. da C., \& Gil da Costa, H. (2006). Creative and spiritual education through the human development process. In M. de Souza, G. Durka, K. Engebretson, R. Jackson, \& A. McGrady (Eds.), International handbook of the religious, moral and spiritual dimensions in education (pp. 1321-1341). Dordrecht, The Netherlands: Springer.

Balfanz, R. (2009). Executive summary: Putting middle grades students on the graduation path. Westerville, OH: National Middle School Association. Bateson, G. (1972). Steps to an ecology of the mind. New York, NY: Ballantine Books. Bateson, G. (1979). Mind and nature: A necessary unity. New York, NY: Dutton. 
Bateson, M. C. (1994). Peripheral visions: Learning along the way. New York, NY: Harper Collins.

Bauman, Z. (1978). Hermeneutics and social science. New York, NY: Columbia University Press.

Beachum, F., Dentith, A., McCray, C., \& Boyle, T. (2008). Havens of hope or the killing fields: The paradox of leadership, pedagogy, and relationships in an urban middle school. Urban Education, 43(2), 189-215.

Belousa, I. (2006). Defining spirituality in education: A post-Soviet perspective. In M. de Souza, G. Durka, K. Engebretson, R. Jackson, \& A. McGrady (Eds.), International handbook of the religious, moral and spiritual dimensions in education (pp. 215-230). Dordrecht, The Netherlands: Springer.

Benami, A. (2006). The spiritual dimension of education. (Doctoral dissertation). Retrieved from ProQuest. (AAT 3211000)

Benson, P. L. (2004). Emerging themes in research on adolescent spiritual and religious development. Applied Developmental Science, 8(1), 47-50.

Benson, P. L. (2006). The science of child and adolescent spiritual development: Definitional, theoretical, and field-building challenges. In E. C. Roehlkepartain, P. E. King, L. Wagener, \& P. L. Benson (Eds.), Handbook of spiritual development in childhood and adolescence (pp. 484-497). Thousand Oaks, CA: Sage.

Benson, P.L., Roehlkepartain, E. C., \& Rude, S. P. (2003). Spiritual development in childhood and adolescence: Toward a field of inquiry. Applied Developmental Science, 7(3), 205-213.

Bentley, M. (1999). Modern historiography. New York, NY: Routledge. 
Bondy, E., \& Ross, D. (2008) The teacher as warm demander. Educational Leadership, 66(1), 54-58.

Borgman, D. (2006). Bridging the gap: From social science to congregations, researchers to practitioners. In E. C. Roehlkepartain, P. E. King, L. Wagener, \& P. L. Benson (Eds.), Handbook of spiritual development in childhood and adolescence (pp. 435-444). Thousand Oaks, CA: Sage.

Bradley, C. (2011). An inquiry into the relationships between spirituality and language pedagogy. (Unpublished doctoral dissertation). Temple University, Philadelphia, PA.

Bruce, M. A., \& Cockerham, D. (2004). Enhancing the spiritual development of adolescent girls. Professional School Counseling, 7, 334-342.

Brown, D. F., \& Leaman, H. L. (2007). Recognizing and responding to young adolescents' ethnic identity development. In S. B. Mertens, V. A. Anfara, Jr., \& Caskey, M.M. (Eds.), The young adolescent and the middle school (pp. 219-236). Westerville, OH \& Charlotte, NC: National Middle School Association and Information Age.

Buchanan, I. (2010). "historiography" A Dictionary of Critical Theory. Oxford Reference Online. Oxford University Press. Retrieved from: $<$ http://www.oxfordreference.com/views/ENTRY.html?subview=Main\&entry=t3 06.e324>

Burke, P. (2001). Overture. The new history: Its past and its future. In P. Burke (Ed.), New perspectives on historical writing ( $2^{\text {nd }}$ Ed., pp. 1-24). University Park, PA: The Pennsylvania State University Press. 
Cajete, G. (1994). Look to the mountain: An ecology of indigenous education. Durango, CO: Kivaki Press.

Carnegie Council on Adolescent Development's Task Force on Education of Young Adolescents (1989). Turning points: Preparing American youth for the $21^{\text {st }}$ Century. Washington, DC: Carnegie Council on Adolescent Development. Carney, S., \& Bista, M. B. (2009). Community schooling in Nepal: A genealogy of education reform since 1990. Comparative Education Review, 53(2), 189-211.

Caskey, M. M. (2003). Preparing middle level teachers in field based cohorts. In P. G. Andrews \& V. A. Anfara (Eds.) Leaders for a movement: Professional preparation and development of middle level teachers and administrators (pp. 5376). Greenwich, CT: Information Age.

Caskey, M. M., \& Anfara, V.A., Jr. (2007). Research summary: Young adolescents’ developmental characteristics. In M.M. Caskey (Ed.), Middle level education: Research annual (pp. 1-5). Westerville, OH: National Middle School Association.

Charmaz, K. (2006). Constructing grounded theory: A practical guide through qualitative anaylsis. Thousand Oaks, CA: Sage.

Claiborne, L. B. (2007). Beyond readiness: New questions about cultural understandings and developmental appropriateness. In J. L. Kincheloe \& R. A. Horn, Jr. (Eds.), The praeger handbook of education and psychology (pp. 428-438). Westport, CT: Praeger.

Cohen, J. (2008). Social, emotional, ethical, and academic education: Creating a climate for learning, participation in democracy, and well-being. Harvard Educational Review, 76(2), 201-237. 
Cohen, R. (2005). Journal writing in mathematics education: Communicating the affective dimensions of mathematics learning. In J. P. Miller, S. Karsten, D. Denton, D. Orr, \& I. Colalillo Kates (Eds.), Holistic learning and spirituality in education (pp. 145-152). Albany, NY: SUNY Press.

Colalillo Kates, I. (2005). The creative journey: Personal creativity as soul work. In J. P. Miller, S. Karsten, D. Denton, D. Orr, \& I. Colalillo Kates (Eds.), Holistic learning and spirituality on education (pp. 193-205). Albany, NY: SUNY Press.

Conti, S. D. P. (2002). The spiritual life of teachers: A study of holistic education and the holistic perspective. Unpublished doctoral dissertation, Teachers College, Columbia University, New York.

Cottingham, M. (2005). Developing spirituality through the use of literature in history education. International Journal of Children's Spirituality, 10(1), 45-60.

Creswell, J. W. (2007). Qualitative inquiry and research design: Choosing among five approaches. Thousand Oaks, CA: Sage.

Daniels, E. (2005). On the minds of middle schoolers. Educational Leadership, 62(7), 5254.

de Jager Meezenbroek, E., Garssen, B., van den Berg, M., Tuytel, G., van Dierendonck, D., Visser, A., \& Schaufeli, W. B. (2012). Measuring spirituality as a universal human experience: Development of the spiritual attitude and involvement list (SAIL). Journal of Psychosocial Oncology, 30 (2). 141-167.

de Souza, M. (2006). Rediscovering the spiritual dimension in education: Promoting a sense of self and place, meaning and purpose in learning. In M. de Souza, G. Durka, K. Engebretson, R. Jackson, \& A. McGrady (Eds.) International 
handbook of the religious, moral and spiritual dimensions in education (pp.

1127-1139). New York: Springer.

de Souza, M. (2012). Connectedness and connectedness: The dark side of spirituality implications for education. International Journal of Children's Spirituality, 17(4), 291-303.

Deakin Crick, R., \& Jelfs, H. (2011). Spirituality, learning, and personalization: Exploring the relationship between spiritual development and learning to learn in a faith-based secondary school. International Journal of Children's Spirituality, 16(3), 197-217.

DeBlasio, G. (2011). The effect of spiritual intelligence in the classroom: God only knows. International Journal of Children's Spirituality, 16(2), 143-150.

Delpit, L. (2006). Other people's children: Cultural conflict in the classroom. New York, NY: The New Press.

Dewey, J. (1902). The child and the curriculum. Chicago, IL: The University of Chicago Press.

Dewey, J. (1916). Democracy and education. New York, NY: The Free Press.

Doda, N., \& Knowles, T. (2008). Listening to the voices of young adolescents. Middle School Journal, 39(3), 26-33.

Durlak, J. A., Weissberg, R. P., Dymnicki, A. B., Taylor, R.D., \& Schellinger, K. B. (2011). The impact of enhancing students' social and emotional learning: A metaanalysis of school-based universal interventions. Child Development, 82(1), 405432. 
Eccles, J. S., \& Midgley, C. (1989). Stage-environment fit: Developmentally appropriate classrooms for young adolescents. In C. Ames \& R. Ames (Eds.), Research on motivation in education: Vol. 3. Goals and cognitions (pp. 13-44). New York, NY: Academic Press.

Eccles, J. S., Midgley, C., Wigfield, A., Buchanan, C. M., Reuman, D., Flanagan, C., \& MacIver, D. (1993). Development during adolescence: The impact of stageenvironment fit on adolescents' experiences in schools and families. American Psychologist, 48(2), 90-101.

Eccles, J., \& Roeser, R. (2009). Schools, academic motivation, and stage-environment fit. In R. M. Lerner \& L. Steinberg (Eds.), Handbook of adolescent psychology $\left(3^{\text {rd }}\right.$ ed, pp. 404-434). Hoboken, NJ: Wiley.

Erb T. O. (2000). Do middle school reforms really make a difference? The Clearing House, 73(4). 194-200.

Erb, T. O. (2006). Middle school models are working in many grade configurations to boost student performance. American Secondary Education, 34(3), 4-13.

Erikson, E. H. (1968). Identity: Youth and crisis. New York, NY: Norton. Everson v. Board of Education. 330 U.S. 1 (1947).

Feldman, D. H. (2008). The role of developmental change in spiritual development. In R. M. Lerner, R. W. Roeser, \& E. Phelps (Eds.), Positive youth development and spirituality (pp. 167-198). West Conshohocken, PA: Templeton Foundation Press.

Felner, R. D., Seitsinger, A., Brand, S., Burns, A., \& Bolton, N. (2007). Creating small learning communities: Lessons from the project on high-performing learning 
communities about "what works" in creating productive, developmentally

enhancing, learning contexts. Educational Psychologist, 42(4). 209-221.

Foucault, M. (1973). The order of things: An archaeology of the human sciences. New York, NY: Vintage.

Fowler, J. (1981). Stages of faith: The psychology of human development and the quest for meaning. New York, NY: Harper.

Fowler, J. W., \& Dell, M. L. (2006). Stages of faith from infancy through adolescence: Reflections on three decades of faith development theory. In E. C. Roehlkepartain, P. E. King, L. Wagener, \& P. L. Benson (Eds.), Handbook of spiritual development in childhood and adolescence (pp. 34-45). Thousand Oaks, CA: Sage.

Fraser, D. (2007). State education, spirituality, and culture: Teachers' personal and professional stories of negotiating the nexus. International Journal of Children's Spirituality, 12(3), 289-305.

Freire, P. (1993). Pedagogy of the oppressed. (M. Bergman Ramos, Trans.). New York, NY: Continuum. (Original work published in 1970).

Gandhi, M. K. (1953). Towards new education. Ahmedabad, India: Navijivan.

Gatto, J. T. (1999). Education and the Western spiritual tradition. In S. Glazer (Ed.) The heart of learning: Spirituality in education (pp. 151-172). New York, NY: Penguin Putnam.

Gentilucci, J., \& Muto, C. (2007). Principals' influence on academic achievement: The student perspective. NASSP Bulletin, 91(3), 219-236. 
George, P. (2009). Renewing the middle school: The early success of middle school education. Middle School Journal, 41(1), 4-9.

German (2010). In A. Stevenson (Ed.), Oxford Dictionary of English. Retrieved from http://www.oxfordreference.com/view/10.1093/acref/9780199571123.001.0001/ m_en_gb0333000.

Giroux, H. A. (1981). Ideology, culture, and the process of schooling. Philadelphia, PA: Temple University Press.

Glaser, B. G. (1978). Theoretical sensitivity. Mill Valley, CA: The Sociology Press. Good, M., \& Willoughby, T. (2008). Adolescence as a sensitive period for spiritual development. Child Development Perspectives, 2(1), 32-37.

Greenblatt, S. (1998). Culture. In D. Keesey (Ed.) Contexts for criticism ( $3^{\text {rd }}$ Ed.). Mountain View, CA: Mayfield.

Greene, W. L., Musser, P. M., Casbon, J., Caskey, M.M., Samek, L. L., \& Olson, M. (2008). Caught in the middle again: Accountability and the changing practice of middle school teachers. Middle Grades Research Journal 3(4), 41-72.

Guba, E. G. (1990). The alternative paradigm dialog. In E. G. Guba (Ed.) The paradigm dialog (pp. 17-27). Newbury Park, CA: Sage.

Guba, E. G., \& Lincoln, Y. S. (2005). Paradigmatic controversies, contradictions, and emerging confluences. In N. K. Denzin \& Y. S. Lincoln (Eds.), The Sage handbook of qualitative research (pp. 191-215). Thousand Oaks, CA: Sage.

Gutman, L. M., \& Eccles, J. S. (2007). Stage-environment fit during adolescence: Trajectories of family relations and adolescent outcomes. Developmental Psychology, 43(2), 522-537. 
Hall, G. S. (1904). Adolescence: Its psychology and its relations to physiology, anthropology, sociology, sex, crime, religion and education. New York, NY: D. Appleton and Company.

Hamm, J. V., Farmer, T. W., Robertson, D., Dadisman, K. A., Murray, A., Meece, J. L., \& Song, S. Y. (2010). Effects of a developmentally based intervention with teachers on Native American and White early adolescents' schooling adjustment in rural settings. The Journal of Experimental Education, 78(3), 343-377.

Hamilton, D. M., \& Jackson, M. H. (1998). Spiritual development: Paths and processes. Journal of Instructional Psychology, 25(4), 262-271.

Hart, T. (2004). Opening the contemplative mind in the classroom. Journal of Transformative Education, 2(1), 28-46.

Hay, D., \& Nye, R. (2006). The spirit of the child. Philadelphia, PA: Jessica Kingsley Publishers.

Hay, D., Reich, K. H., \& Utsch, M. (2006). Spiritual development: Intersections and divergence with religious development. In E. C. Roehlkepartain, P. E. King, L. Wagener, \& P. L. Benson (Eds.), Handbook of spiritual development in childhood and adolescence (pp. 46-59). Thousand Oaks, CA: Sage.

Henry, A. (2006). Historical studies: Groups/Institutions. In J. L. Greene, G. Camilli, \& P. B. Elmore (Eds.), Handbook of complementary methods in educational research (pp. 333-355). Mahwah, NJ: Erlbaum.

Hill, C., Herndon, A. A., \& Karpinska, Z. (2006). Contemplative practices: Educating for peace and tolerance. Teachers College Record, 108(9), 1915-1935.

Hill, P., Jr. (1992). Coming of age: African-American male rites-of-passage. Chicago, IL: 
African American Images.

"historiography noun" (2010). Oxford Dictionary of English. A. Stevenson (Ed.). Oxford Reference Online. Oxford University Press. Retrieved from: http://www.oxfordreference.com/views/ENTRY.html?subview=Main\&entry=t14 $0 . \mathrm{e} 0380360$

hooks, b. (1994). Teaching to transgress: Education as the practice of freedom. New York, NY: Routledge.

hooks, b. (2003). Teaching community: A pedagogy of hope. New York, NY: Routledge. Huebner, D. E. (1999). Education and spirituality. In V. Hillis \& W. Pinar (Eds.), The lure of the transcendent: Collected essays by Dwayne E. Huebner (pp. 401-416). Mahwah, NJ: Erlbaum.

Hunter, J., \& Solomon, J. (2002). A psychological view of spirituality and leadership: Finding meaning through Howard Gardner's notion of existential intelligence. School Administrator, 59(8), 38-41.

Husen, T. (1999). Research paradigms in education. In J.P. Keeves \& G. Lakomski (Eds.) Issues in Educational Research (pp. 31-39). New York, NY: Pergamon.

Jackson, A., \& Davis, G. (2000). Turning Points 2000: Educating adolescents in the $21^{\text {st }}$ century. New York, NY: Teachers College Press.

Janesick, V. J. (2011). "Stretching” exercises for qualitative researchers. Los Angeles, CA: Sage.

Jewett, S. (2009). "You feel like you're in your second family": Spinning a relational web in middle school. Urban Review, 41(3), 201-221. 
Johnson, C. N. (2008). The spirit of spiritual development. In R. M. Lerner, R. W.

Roeser, \& E. Phelps (Eds.), Positive youth development and spirituality (pp. 2541). West Conshohocken, PA: Templeton Foundation Press.

Juang, L., \& Syed, M. (2008). Ethnic identity and spirituality. In R. M. Lerner, R. W. Roeser, \& E. Phelps (Eds.) Positive youth development and spirituality (pp. 262284). West Conshohocken, PA: Templeton Foundation Press.

Juvoven, J. (2007). Reforming middle schools: Focus on continuity, social connectedness, and engagement. Educational Psychologist, 42(4). 197-208.

Kaestle, C. F. (1997). Historical methods in education. In J. P. Keeves (Ed.) Educational research, methodology and measurement: An international handbook. $\left(2^{\text {nd }}\right.$ ed. $)$ (pp. 75-81). New York, NY: Pergamon.

Kessler, R. (2000). The soul of education: Helping students find connection, compassion, and character at school. Alexandria, VA: Association for Supervision and Curriculum Development.

Kincheloe, J. L. (2001). Describing the bricolage: Conceptualizing a new rigor in qualitative research. Qualitative Inquiry, 7(6), 679-692.

Kincheloe, J. L. (2005). On to the next level: Continuing the conceptualization of the bricolage. Qualitative Inquiry, 11(3), 323-350.

Kincheloe, J. L. (2008). Critical constructivism. New York, NY: Peter Lang.

King, P. E., \& Benson, P. L. (2006) Spiritual development and adolescent well-being and thriving. In E. C. Roehlkepartain, P. E. King, L. Wagener, \& P. L. Benson (Eds.), Handbook of spiritual development in childhood and adolescence (pp. 384-398). Thousand Oaks, CA: Sage. 
King, P. E., \& Roeser, R. W. (2009). Religion and spirituality in adolescent development. In R. M. Lerner \& L. Steinberg (Eds.), Handbook of adolescent psychology ( $3^{\text {rd }}$ ed.) (pp. 435-478). Hoboken, NJ: Wiley.

Koenig, H. G., McCullough, M. E., \& Larson, D. B. (2001). Handbook of religion and health. New York, NY: Oxford University Press.

Kohlberg, L. (1981). Essays on moral development. San Francisco, CA: Harper \& Row. Kuhn, T. S. (1996). The structure of scientific revolutions ( $3^{\text {rd }}$ ed.). Chicago, IL: The University of Chicago Press.

Leavy, P. (2009). Method meets art: Arts-based research practice. New York, NY: Guilford Press.

Lee, V., \& Smith, J. (1993). Effects of school restructuring on the achievement and engagement of middle-grade students. Sociology of Education, 66(3), 164-187.

Leithwood, K., Louis, K.S., Anderson, S., \& Wahlstrom, K. (2004). Executive summary: How leadership influences student learning. Minneapolis, MN: University of Minnesota, Center for Applied Research and Educational Improvement.

Leopold, D., \& Juniu, S. (2008). Incorporating a spiritual component into the health education aspects of a physical (activity) education program. Physical Educator, 65(4), 208-221.

Lerner, R. M. (2006). Developmental science, developmental systems, and contemporary theories of human development. In W. Damon (Series Ed.) \& R. M. Lerner (Vol. Ed.), Handbook of child psychology: Vol. 1. Theoretical Models of Human Development ( $6^{\text {th }}$ ed., pp. 1-17). Hoboken, NJ: Wiley. 
Lerner, R. M., Roeser, R. W., Phelps, E. (2008). Positive development, spirituality, and generosity in youth. In R. M. Lerner, R. W. Roeser, \& E. Phelps (Eds.), Positive youth development and spirituality (pp. 3-24). West Conshohocken, PA: Templeton Foundation Press.

Lippman, L. H., \& Keith, J. D. (2006). The demographics of spirituality among youth: International perspectives. In E. C. Roehlkepartain, P. E. King, L. Wagener, \& P. L. Benson (Eds.), Handbook of spiritual development in childhood and adolescence (pp. 137-149). Thousand Oaks, CA: Sage.

Lohani, S., Singh, R. B., \& Lohani, J. (2010). Universal primary education in Nepal: Fulfilling the right to education. Prospects, 40(3), 355-374.

Long, L. (2008). Narrative autoethnography and the promotion of spiritual well-being in teacher research and practice. Pastoral Care in Education, 26(3), 187-196.

Loukas, A., \& Murphy, J. L. (2007). Middle school student perceptions of school climate: Examining protective functions on subsequent adjustment problems. Journal of School Psychology, 45(3), 293-309.

Lounsbury, J. H., \& Vars, G. (1978). A curriculum for the middle school years. New York, NY: Harper \& Row.

Lounsbury, J. H., \& Vars, G. (2003). The future of middle level education: Optimistic and pessimistic views. Middle School Journal, 35(2), 6-14.

Maclean, M. J. (1982). Johann Gustav Droysen and the development of historical hermeneutics. History and Theory, 21(3), 347-365.

Macy, J. (1991). Mutual causality in Buddhism and general systems theory: The dharma of natural systems. Albany, NY: State University of New York Press. 
Malkin, J. (2003). In engaged Buddhism, peace begins with you. Shambhala Sun.

Retrieved from:

http://www.shambhalasun.com/index.php?option=content\&task=view\&id=1579.

Masterman, M. (1970). The nature of a paradigm. In I. Lakatos \& A. Musgrave (Eds.), Criticism and the growth of knowledge (p. 59-89). Cambridge, UK: Cambridge University Press.

Mattis, J. S., Ahluwalia, M. K., Cowie, S. E., \& Kirkland-Harris, A. M. (2006). Ethnicity, culture, and spiritual development. In E. C. Roehlkepartain, P. E. King, L. Wagener, \& P. L. Benson (Eds.), Handbook of spiritual development in childhood and adolescence (pp. 283-296). Thousand Oaks, CA: Sage.

McCullom v. Board of Education. 333 U.S. 203 (1948).

McEwin, C. K. (2007). Certification/licensure by state. In National Middle School Association: Professional Preparation. Retrieved from: http://www.nmsa.org/ProfessionalPreparation/CertificationLicensurebyState/tabid /1235/Default.aspx

McLaren, P. (2009) Critical pedagogy: A look at the major concepts. In A. Darder, M.P. Baltodano, \& R. Torres (Eds.), The critical pedagogy reader (61-83). New York, NY: Routledge.

Mertens, S. B., \& Flowers, N. (2003) Middle school practices improve student achievement in high poverty schools. Middle School Journal, 35(1), 33-43.

Mezirow, J. (2000). Learning as transformation. San Francisco, CA: Jossey-Bass.

Miller, J. P. (2005). Introduction: Holistic learning. In J. P. Miller, S. Karsten, D. Denton, D. Orr, \& I. Colalillo Kates (Eds.), Holistic learning and spirituality on education 
(pp. 1-6). Albany, NY: SUNY Press.

Miller, J. P. (2007). The holistic curriculum ( $2^{\text {nd }}$ ed.). Toronto, ON: University of Toronto Press.

Miller, R. (1990). What are schools for: Holistic education in American culture. Brandon, VT: Holistic Education Press.

Miller, R. (1999). Holistic education for an emerging culture. In S. Glazer (Ed.) The heart of learning: Spirituality in education (pp. 189-202). New York, NY: Penguin Putnam.

Milojevic, I. (2005). Critical spirituality as a resource for fostering critical pedagogy. Journal of Future Studies, 9(3), 1-16.

Muijs, D. (2011). Doing quantitative research in education with SPSS. Los Angeles, CA: Sage.

Mulhall, P. F. (2007). Health promoting, high performing middle level schools: The interrelationships and integration of health and education for young adolescent success and well-being. In S. B. Mertens, V. A. Anfara, Jr., \& Caskey, M.M. (Eds.), The young adolescent and the middle school (pp. 1-26). Westerville, $\mathrm{OH}$ \& Charlotte, NC: National Middle School Association and Information Age. Nakagawa, Y. (2000). Education for awakening: An eastern approach to holistic education. Volume Two of the Foundations of Holistic Education Series. Brandon, VT: Foundation for Educational Renewal.

Nakkula, M. J., \& Ravich, S. M. (1998). Matters of interpretation: Reciprocal transformation in therapeutic and developmental relationships with youth. San Francisco, CA: Jossey-Bass. 
Nakkula, M. J., \& Toshalis, E. (2006). Understanding youth: Adolescent development for educators. Cambridge, MA: Harvard Education Press.

National Association of Secondary School Principals. (2006). Breaking ranks in the middle: Strategies for leading middle level reform. Reston, VA: Author.

National Forum to Accelerate Middle Grades Reform (n.d.). Vision and mission.

Retrieved from: http://www.middlegradesforum.org/index.php/about/visionmission.

National Middle School Association. (2010). This we believe: Keys to educating young adolescents. Westerville, $\mathrm{OH}$. Author.

Nicholas, G., \& DeSilva, A. M. (2008). Application of the ecological model: Spirituality research with ethnically diverse youth. In R. M. Lerner, R. W. Roeser, \& E. Phelps (Eds.) Positive youth development and spirituality (pp. 305-321). West Conshohocken, PA: Templeton Foundation Press.

Nichols, S. (2008). An exploration of students' belongingness beliefs in one middle school. The Journal of Experimental Education, 76(2), 145-169.

Niederman, R. (1999). The conceptualization of a model of spirituality. Unpublished doctoral dissertation, University of Georgia, Athens, GA.

Noddings, N. (1988). An ethics of caring and its implications for instructional arrangements. Stanford, CA: CERAS, School of Education, Stanford University Press.

Noddings, N. (2005). The challenge to care in schools: An alternative approach to education. New York, N.Y.: Teachers College Press. 
Novoa, A. \& Yariv-Mashal, T. (2003). Comparative research in education: A mode of governance or a historical journey? Comparative Education, 39(4), 423-438.

Orr, D. W. (1990). The liberal arts, the campus, and the biosphere. Harvard Education Review, 60(2), 205-216.

Orr, D. W. (1992). Ecological literacy: Education and the transition to the postmodern world. Albany, NY: State University of New York Press.

Orr, D. J. (2005). Minding the soul in education: Conceptualizing and teaching the whole person. In J. P. Miller, S. Karsten, D. Denton, D. Orr, \& I. Colalillo Kates (Eds.), Holistic learning and spirituality on education (pp. 87-99). Albany, NY: SUNY Press.

Oser, F. (1991). The development of religious judgment. In F. K. Oser \& W. G. Scarlett (Eds.), Religious Development in Childhood and Adolescence (pp. 5-25). San Francisco, CA: Jossey-Bass.

Oser, F. W., Scarlett, W. G., \& Bucher, A. (2006). Religion and spiritual development throughout the lifespan. In W. Damon \& R. M. Lerner (Series Eds.) \& R. M. Lerner (Volume Ed.), Handbook of Child Psychology (6 ${ }^{\text {th }}$ ed.), vol. 1: Theoretical models of human development (pp. 942-998). Hoboken, NJ: Wiley.

Osterman, K. F. (2000). Students' need for belonging in the school community. Review of Educational Research, 70, 323-367.

Owen Wilson, L. (2005). Listening to ancient voices: Reaching hearts and souls through benchmarks and rites of passage experiences in schools. In J. P. Miller, S. Karsten, D. Denton, D. Orr, \& I. Colalillo Kates (Eds.), Holistic learning and spirituality on education (pp. 167-177). Albany, NY: SUNY Press. 
Palmer, P. (1997). The grace of great things: Reclaiming the sacred in knowing, teaching, and learning. In S. Glazer (Ed.), The heart of learning: Spirituality in education (pp. 15-32). New York, NY: Penguin Putnam.

Palmer, P. (1998). Courage to teach: Exploring the inner lives of teachers. San Francisco, CA: Jossey Bass.

Parker, A., Allen, D., Alvarez McHatton, P., \& Rosa, L. (2010). Dance lessons: Preparing preservice teachers for coteaching partnerships. Action in Teacher Education, 32(1), 26-38.

Pearmain, R. (2005). Transformational experiences in young people: The meaning of a safe haven. International Journal of Children's Spirituality, 10(3), 277-290.

Pew Forum on Religion and Public Life. (2008). U.S. religious landscape survey. Washington, DC: Pew Research Center.

Piaget, J. (1967). Six psychological studies. New York, NY: Random House.

Popkewitz, T. (1991). A political sociology of educational reform: Power/knowledge in teaching, teacher education, and research. New York, NY: Teachers College Press.

Popkewitz, T. S. (1997). A changing terrain of knowledge and power: A social epistemology of educational research. Educational Researcher, 26(9), 18-29.

Popkewitz, T. S., \& Brennan, M. (1998). Restructuring of social and political theory in education: Foucault and a social epistemology of school practices. In T. S. Popkewitz \& M. Brennan (Eds.), Foucault's challenge: Discourse, knowledge, and power in education (pp. 3-35). New York, NY: Teachers College Press. 
Purpel, D. E. (1999). Moral Outrage and Education. In T. Kane (Ed.), Education, transformation, and transformation (pp. 57-75). Columbus, OH: Merrill.

Revell, L. (2008). Spiritual development in public and religious schools: A case study. Religious Education, 103(1), 102-118.

Roehlkepartain, E. C., Benson, P. L., King, P. E., \& Wagener, L. (2006). Spiritual development in childhood and adolescence: Moving to the scientific mainstream. In E. C. Roehlkepartain, P. E. King, L. Wagener, \& P. L. Benson (Eds.), Handbook of spiritual development in childhood and adolescence (pp. 1-15). Thousand Oaks, CA: Sage.

Roeser, R., Eccles, J., \& Sameroff, A. (2000). School as a context of early adolescents' academic and socio-emotional development: A summary of research findings. The Elementary School Journal, 100(5), 443-471.

Roeser, R. W., \& Peck, S. C. (2009). An Education in Awareness: Self, Motivation, and Self- Regulated Learning in Contemplative Perspective, Educational Psychologist, $44(2), 119-136$.

Roney, K., Coleman, H., \& Schlichting, K. (2007). Linking the organizational health of middle grades schools to student achievement. NASSP Bulletin, 91(4), 289-321.

Rury, J. L. (2006). Historical research in education. In J. L. Greene, G. Camilli, \& P. B. Elmore (Eds.), Handbook of complementary methods in educational research (pp. 323-332). Mahwah, NJ: Erlbaum.

Ryoo, J.J., Crawford, J., Moreno, D., \& McLaren P. (2009). Critical spiritual pedagogy: reclaiming humanity through a pedagogy of integrity, community, and love. Power and Education, 1(1), 132-146. 
Said, E. (1993). Culture and imperialism. New York, NY: Knopf.

Sallquist, J., Eisenberg, N., French, D. C., Purwono, U., \& Suryanti, T. A. (2010).

Indonesian adolescents' spiritual and religious experiences and their longitudinal relations with socioemotional functioning. Developmental Psychology, 46 (3). 699-716.

Sarason, S. B. (1982). The culture of school and the problem of change $\left(2^{\text {nd }}\right.$ ed.). Boston, MA: Allyn and Bacon.

Scales, P., Benson, P. L., Leffert, N., \& Blyth, D. A. (2000). The contribution of developmental assets to the prediction of thriving among adolescents. Applied Developmental Science 4(1), 27-46.

Schoonmaker, F. (2009). Only those who see take off their shoes: Seeing the classroom as a spiritual space. Teachers College Record, 111(12), 2713-2731.

Scott, D. G. (2006). Spirituality and identity within/without religion. In M. de Souza, G. Durka, K. Engebretson, R. Jackson, \& A. McGrady (Eds.), International handbook of the religious, moral and spiritual dimensions in education (pp. 11111125). Dordrecht, The Netherlands: Springer.

Scott, J., \& Marshall, G. (2009). "historiography" A Dictionary of Sociology. Oxford Reference Online. Oxford University Press. Retrieved from: http://www.oxfordreference.com/views/ENTRY.html?subview=Main\&entry=t88. e1015

Sherrod, L. R., \& Spiewak, G. S. (2008). Possible interrelationships between civic engagement, positive youth development, and spirituality/religiosity. In R. M. 
Lerner, R. W. Roeser, \& E. Phelps (Eds.), Positive youth development and spirituality (pp. 322-338). West Conshohocken, PA: Templeton Foundation Press.

Search Institute. (2011). Engaging international advisors in creating a shared understanding of spiritual development. Retrieved from: http://www.searchinstitute.org/csd/major-projects/definition-update

Search Institute. (2011). What are developmental assets? Retrieved from: http://www.search-institute.org/content/what-are-developmental-assets

Simmer-Brown, J. (1999) Commitment and openness: A contemplative approach to pluralism. In S. Glazer (Ed.), The heart of learning: Spirituality in education (pp. 97-112). New York, NY: Penguin Putnam.

Skinner, B. F. (1987). Upon further reflection. Englewood Cliffs, NJ: Prentice-Hall. Smith, A. (2003). Historiography. In G. Campbell (Ed.) The Oxford Encyclopedia of Food and Drink in America. Oxford University Press. Retrieved from $<$ http://www.oxfordreference.com/views/ENTRY.html?subview=Main\&entry=t1 70.e0397>

Smith, T. W., \& McEwin, C. K. (2011). The legacy of middle school leaders: In their own words. Charlotte, NC: Information Age.

Stoyles, G. J., Stanford, B., Caputi, P., Keating, A., \& Hyde, B. (2012). A measure of spiritual sensitivity for children. International Journal of Children's Spirituality, 17(3). 203-215.

Strauss, A., \& Corbin, J. (1998). Basics of qualitative research. Thousand Oaks, CA: Sage. 
Tacey, D. (2006). Spirituality as a bridge to religion and faith. In M. de Souza, G.

Durka, K. Engebretson, R. Jackson, \& A. McGrady (Eds.), International handbook of the religious, moral and spiritual dimensions in education (pp. 201213). Dordrecht, The Netherlands: Springer.

Tart, C. (1986). Waking up: The obstacles to human potential. Boston, MA: New Science Library.

Thayer-Bacon, B., \& Moyer, D. (2006). Philosophical and historical research. In K. Tobin \& J. L. Kincheloe (Eds.), Doing educational research (pp. 139-156). Rotterdam, The Netherlands: Sense.

Toepfer, C. F. (2011). Conrad F. Toepfer, Jr. In T. W. Smith \& C. K. McEwin (Eds.), The legacy of middle school leaders: In their own words (pp. 53-69). Charlotte, NC: Information Age.

U. S. Department of Education. (2001). Executive summary of No Child Left Behind. Washington, DC: Government Printing Office.

Vagle, M. D. (2012). Not a stage: A critical re-conception of young adolescent education. New York, NY: Peter Lang.

Van Hoose, J., Strahan, D., \& L'Esperance, M. (2001). Promoting harmony: Young adolescent development and school practices. Westerville, OH: National Middle School Association.

Van Rooyen, B. M. (2007). Spiritual well-being in a group of South African adolescents. Unpublished doctoral dissertation, University of the Free State, Bloemfontein, South Africa. 
Villaverde, L. Kincheloe, J. L., \& Helyar, F. (2006). Historical research in education. In

K. Tobin \& J. L. Kincheloe (Eds.) Doing educational research. (pp. 311-345). Rotterdam, The Netherlands: Sense.

Walker, A., \& Shuangye, C. (2007). Leader authenticity in intercultural school contexts. Educational Management Administration and Leadership, 35(2), 185-204.

Warren, A. E. A., Lerner, R., \& Phelps, E. (2012). Thriving and spirituality among youth: Research perspectives and future possibilities. Hoboken, NJ: Wiley.

Webster, R. S. (2013). Healing the physical/spiritual divide through a holistic and hermeneutic approach to education. International Journal of Children's Spirituality, 17(1). 1-12.

Wilber, K. (2000). A theory of everything: An integral vision for business, politics, science, and spirituality. Boston, MA: Shambhala.

Wintersgill, B. (2008). Teenagers' perceptions of spirituality_A research report. International Journal of Children's Spirituality, 13(4), 371-378.

Wolcott, H. F. (2001). Writing up qualitative research. ( $2^{\text {nd }}$ ed.) Thousands Oaks, CA: Sage.

Wolcott, H. F. (2008). Ethnography: A way of seeing. Lanham, MD: Altamira Press.

Woolley, M., \& Bowen, G. (2007, January). In the context of risk: Supportive adults and the school engagement of middle school students. Family Relations, (56), 92-104.

Yin, R. K. (2009). Case study research: Design and methods. Thousand Oaks, CA: Sage. Zeichner, K. (1999). The new scholarship in teacher education. Educational Researcher, 28(9), 4-15. 
APPENDICES

\section{Appendix A}

\section{Detailed Descriptions of Data Analysis}

\section{Detailed Description of Research Activities}

Selection and preparation of data for specific analyses

- Potential texts identified from meta-analysis

- Criteria tests are administered for each potential datum

- Defense of data selections written

First Round of Data Analysis: Initial Coding

- Initial Codes capture content of passages (datum)

- Data interpreted for assumptions, values, and beliefs (BVA interpretations)

- In vivo code names used (not exclusively)

- Constant comparative method within each text

- Each text coded independently from the other texts

- Memo-writing

- Product: Ten tables of Initial Codes that summarize and account for indirect evidence of paradigms for each text; quotations for each Initial Code; BVA interpretations for each Initial Code

Second Round of Data Analysis: Focused Coding

- Constant comparative method across data within each data set using Initial Codes only

- Memo-writing

- Product: List of Focused Content Codes (FCCs) for each of the three data sets

- Constant comparative method using FCCs and BVA interpretations; BVA categorized by FCC

- Product: Tables of BVA by FCC

- Memo-writing (analysis of BVA by FCC tables)

- Product: List of Paradigm Codes for each of the three data sets (5 per data set)

- Product: Written interpretive narratives of the paradigm categories for each of the three fields ( 3 data sets, 5 paradigm narratives per data set)

Third Round of Data Analysis: Contrapuntal Reading

- Reading across the Paradigm Narratives contrapuntally

- Interpreting for inter-textual and inter-discursive patterns between the paradigms of the three fields.

- Constant comparative analysis: returning to all previously rendered data analysis

- Product: Written interpretive narrative of the three paradigm types and discursive interrelationship between the paradigms in the conceptual nexus

- Product: Conceptual diagram of the inter-discursive relationships between the paradigms of the three fields. 


\section{Appendix B}

\section{Establishing Trustworthiness Table}

To collect the data used for this table, I searched Google Advanced Search, Google Scholar, Academic Search Complete, and Web of Science. Searches were conducted on four dates: March 16, 21, and $23^{\text {rd }}$ and April 20, 2012. I also used information provided by the authors' academic and/or professional institutions to confirm data on the number of publications, as well as collect data on professional contributions and activities in the author's field. For two of the texts (Carnegie, 1989; NMSA, 2010), the authors were a group. In those two cases, I adjusted the type of data I collected. Three of the authors, Peter Benson, Rachael Kessler, and Gordon Vars, died in the past three years; I consulted their published obituaries in addition to the Google searches.

\begin{tabular}{|c|c|c|c|c|}
\hline \multicolumn{5}{|c|}{ Establishing Trustworthiness for Data Sources } \\
\hline & AU \#Pub. & AU Prof. Position & TX Cited & $\begin{array}{l}\text { TX } \\
\text { Syllabi }\end{array}$ \\
\hline \multicolumn{5}{|l|}{$\begin{array}{l}\text { Middle Grades } \\
\text { Concept }\end{array}$} \\
\hline $\begin{array}{l}\text { The emergent } \\
\text { middle school } 1968\end{array}$ & 25 & $\begin{array}{l}\text { Columbia Univ., } \\
\text { PhD } \\
\text { Teacher, Director } \\
\text { of Curriculum, } \\
\text { Superintendent, } \\
\text { Univ. Faculty } \\
\text { (Peabody College, } \\
\text { Univ. Miami, } \\
\text { Univ. Florida) } \\
\text { President, ASCD } \\
\text { Awards: } \\
\text { Lounsbury Award } \\
\text { (NMSA); } \\
\text { Leadership } \\
\text { (NASSP); } \\
\text { Sustained } \\
\text { Contribution } \\
\text { (ASCD) }\end{array}$ & 109 & $\begin{array}{l}8 \\
\text { displayed } \\
\text { on Google } \\
\text { Advanced } \\
\text { Search; } \\
\text { none were } \\
\text { required } \\
\text { texts }\end{array}$ \\
\hline
\end{tabular}




\begin{tabular}{|c|c|c|c|c|}
\hline $\begin{array}{l}\text { A Curriculum for } \\
\text { the Middle School } \\
\text { Years } 1978\end{array}$ & $\begin{array}{l}\text { Lounsbury: over } \\
150 \text { articles; } \\
\text { author/co-author } \\
\text { on two of the } \\
\text { seminal texts in } \\
\text { middle level ed. } \\
\text { Vars: } 20\end{array}$ & $\begin{array}{l}\text { Lounsbury: } \\
\text { Georgia College, } \\
\text { faculty 1960-1983 } \\
\text { (school of } \\
\text { education named } \\
\text { after him in 1997) } \\
\text { Editor, AMLE's } \\
\text { Middle School } \\
\text { Journal, 1976- } \\
\text { 1990 } \\
\text { Recipient of many } \\
\text { awards in middle } \\
\text { level education } \\
\text { Mentor to } \\
\text { hundreds of } \\
\text { middle school } \\
\text { educators and } \\
\text { advocates } \\
\text { Vars: Kent State } \\
\text { Univ. } 8 \text { th grade } \\
\text { Teacher and } \\
\text { Faculty, 1966- } \\
\text { 1993 } \\
\text { Founder, NMSA } \\
\text { Awards: Ohio } \\
\text { Middle School } \\
\text { Educator of the } \\
\text { Year (1980); } \\
\text { NMSA 1993 } \\
\text { conference named } \\
\text { after him } \\
\text { Mentor to } \\
\text { hundreds of } \\
\text { middle school } \\
\text { educators and } \\
\text { advocates }\end{array}$ & 52 & $\begin{array}{l}3 \\
\text { displayed } \\
\text { on Google } \\
\text { Advanced } \\
\text { Search; } \\
\text { none were } \\
\text { for syllabi }\end{array}$ \\
\hline $\begin{array}{l}\text { Turning Points } \\
1989\end{array}$ & $\begin{array}{l}\text { Papers } \\
\text { published in } \\
\text { association with } \\
\text { the report: } 15\end{array}$ & $\begin{array}{l}\text { Task Force, 1987- } \\
1989 \\
\text { Members } \\
\text { represented top } \\
\text { leadership in } \\
\text { education, health, } \\
\text { research, } \\
\text { government }\end{array}$ & $\begin{array}{l}694 \text { (2000 } \\
\text { edition; } \\
\text { Carnegie } \\
1989 \text { edition } \\
\text { not in } \\
\text { Google } \\
\text { Scholar) }\end{array}$ & $\begin{array}{l}46 \\
\text { displayed } \\
\text { on Google } \\
\text { Advanced } \\
\text { Search }\end{array}$ \\
\hline
\end{tabular}




\begin{tabular}{|c|c|c|c|c|}
\hline $\begin{array}{l}\text { This We Believe } \\
2010\end{array}$ & $\begin{array}{l}4 \text { journals; } \\
100 \text { s books }\end{array}$ & $\begin{array}{l}\text { Leading org. for } \\
\text { middle level } \\
\text { education, } 1973- \\
\text { present } \\
30,000 \text { members }\end{array}$ & $\begin{array}{l}259(2003 \\
\text { edition; } 2010 \\
\text { edition not in } \\
\text { Google } \\
\text { Scholar) }\end{array}$ & $\begin{array}{l}83 \\
\text { displayed } \\
\text { on Google } \\
\text { Advanced } \\
\text { Search }\end{array}$ \\
\hline \multicolumn{5}{|l|}{$\begin{array}{l}\text { Spirituality as a } \\
\text { Developmental } \\
\text { Domain }\end{array}$} \\
\hline Stages of faith 1981 & $\begin{array}{l}10 \text { books } \\
\text { (author and } \\
\text { editor); } \\
>60 \text { articles }\end{array}$ & $\begin{array}{l}\text { PhD Harvard, } \\
1971 \\
\text { Harvard } \\
\text { University faculty: } \\
\text { Graduate School } \\
\text { of Education, } \\
\text { Divinity School, } \\
\text { and Center for } \\
\text { Moral } \\
\text { Development, } \\
\text { 1971-1975 } \\
\text { Emory University } \\
\text { faculty: School of } \\
\text { Theology, Center } \\
\text { for Ethics } \\
\text { (Director), 1977- } \\
\text { 2005 } \\
\text { Major Awards } \\
\text { (1994): } \\
\text { Oskar Pfister } \\
\text { Award - American } \\
\text { Psychiatric } \\
\text { Association; } \\
\text { William James } \\
\text { Award - American } \\
\text { psychological } \\
\text { Association } \\
\text { DivD, University } \\
\text { of Ediburgh }\end{array}$ & $\begin{array}{l}2335 ; \\
38 \\
\text { publications } \\
\text { translated } \\
\text { into German, } \\
\text { Korean, } \\
\text { Portuguese }\end{array}$ & $\begin{array}{l}46 \\
\text { displayed } \\
\text { on Google } \\
\text { Advanced } \\
\text { Search }\end{array}$ \\
\hline
\end{tabular}




\begin{tabular}{|c|c|c|c|c|}
\hline Benson (2006) & $\begin{array}{l}15 \text { books, } \\
27 \text { articles, } \\
\text { "over } 220 \\
\text { books, articles, } \\
\text { and other } \\
\text { publications" } \\
\text { (from 10/3/11 } \\
\text { newspaper } \\
\text { obituary) }\end{array}$ & $\begin{array}{l}\text { Yale, MA; Univ. } \\
\text { Denver, MA,PhD } \\
\text { Univ. Denver } \\
\text { faculty, 1973-1978 } \\
\text { Search Institute, } \\
\text { 1978-2011(Dir., } \\
\text { 1985-2011) } \\
\text { 1989 William } \\
\text { James Award, } \\
\text { American } \\
\text { Psychological } \\
\text { Assoc. } \\
\text { Created } \\
\text { developmental } \\
\text { assets framework } \\
\text { that is used by } \\
\text { over } 600 \\
\text { communities }\end{array}$ & $\begin{array}{l}19 \text { (The } \\
\text { Handbook } \\
\text { on Spiritual } \\
\text { Development } \\
\text { in Childhood } \\
\text { and } \\
\text { Adolescence } \\
\text { was cited } \\
139 \text { times) }\end{array}$ & $\begin{array}{l}70 \\
\text { displayed } \\
\text { on Google } \\
\text { Advanced } \\
\text { Search }\end{array}$ \\
\hline $\begin{array}{l}\text { Oser, F. W., } \\
\text { Scarlett, W. G., \& } \\
\text { Bucher, A. (2006) }\end{array}$ & $\begin{array}{l}\text { Oser: } 90 \\
\text { publications } \\
\text { Scarlett: } 6 \text { pub. } \\
\text { on spiritual } \\
\text { development } \\
\text { Bucher: } 46 \text { pub. } \\
\text { on spiritual } \\
\text { development }\end{array}$ & $\begin{array}{l}\text { Oser: Univ. of } \\
\text { Zurich, PhD; } \\
\text { Harvard, postdoc } \\
\text { (with Kohlberg) } \\
\text { Univ. of Fribourg, } \\
\text { faculty, 1978-2009 } \\
\text { Scarlett: Yale, BA; } \\
\text { Episcopal Divinity } \\
\text { School, MDiv; } \\
\text { Clark Univ. PhD } \\
\text { Tufts faculty, } \\
\text { 1990-present } \\
\text { Bucher: Univ. of } \\
\text { Mainz, PhD } \\
\text { Univ. Salzburg } \\
\text { faculty, 1993- } \\
\text { present }\end{array}$ & 26 & no results \\
\hline \multicolumn{5}{|l|}{ Holistic Education } \\
\hline $\begin{array}{l}\text { What Are Schools } \\
\text { For } 1990\end{array}$ & $\begin{array}{l}9 \text { books; } 15 \\
\text { articles/chapters }\end{array}$ & $\begin{array}{l}\text { Founder, } \\
\text { Encounter: } \\
\text { Education for } \\
\text { Social Justice } \\
\text { (now AERO) } \\
\text { Founder: } \\
\text { Foundation for }\end{array}$ & 96 & $\begin{array}{l}49 \\
\text { displayed } \\
\text { on Google } \\
\text { Advanced } \\
\text { Search }\end{array}$ \\
\hline
\end{tabular}




\begin{tabular}{|c|c|c|c|c|}
\hline & & $\begin{array}{l}\text { Education } \\
\text { Renewal Press }\end{array}$ & & \\
\hline $\begin{array}{l}\text { Soul of Education } \\
2000\end{array}$ & $\begin{array}{l}4 \text { books, } 17 \\
\text { articles/chapters; }\end{array}$ & $\begin{array}{l}\text { Educator, 1991- } \\
2001 \\
\text { Founder \& } \\
\text { Director, } \\
\text { Passageworks, } \\
2001-2010\end{array}$ & 257 & $\begin{array}{l}53 \\
\text { displayed } \\
\text { on Google } \\
\text { Advanced } \\
\text { Search }\end{array}$ \\
\hline $\begin{array}{l}\text { The Holistic } \\
\text { Curriculum } 2007\end{array}$ & $\begin{array}{l}10 \text { books; } 8 \\
\text { articles; } \\
\text { his work has } \\
\text { been translated } \\
\text { into } 7 \text { languages }\end{array}$ & $\begin{array}{l}\text { Univ. Missouri, } \\
\text { BA; Harvard, } \\
\text { MAT; Univ. } \\
\text { Toronto, PhD } \\
\text { Ontario Institute } \\
\text { for Studies in } \\
\text { Education, faculty, } \\
\text { 1973-present } \\
\text { Facilitator, } \\
\text { Holistic and } \\
\text { Spirituality in } \\
\text { Education } \\
\text { Network, ASCD } \\
\text { Advisor to Bhutan } \\
\text { gov't on holistic } \\
\text { education }\end{array}$ & 307 & $\begin{array}{l}24 \\
\text { displayed } \\
\text { on Google } \\
\text { Advanced } \\
\text { Search }\end{array}$ \\
\hline
\end{tabular}




\section{Appendix C}

\section{Letter to Experts}

\section{Full text of email sent to Drs. Caskey, Miller, and Roeser in March, 2012:}

"For my dissertation research, I am analyzing texts that are foundational to the ideas, practices, and parameters of three academic fields: holistic education, middle grades reform, and spirituality as a domain of human development. I am employing several tests to determine the degree of fit between each text (datum) and my research objective (to identify the prevalent paradigms of each of those three fields). The tests include exploring each author's professional position within the academic community and determining the frequency of citations for each text in peer-reviewed journals. I have chosen to use a range of criteria, rather than relying on one measure, as a strategy for establishing trustworthiness of the data.

In addition to these measures, my research will require input from experts from the field. Given your own position as a scholar with expertise in the discipline of middle grades education/holistic education/spiritual development, I would value your review of my text selections. I have attached a list of my selections. Your review would also entail responding to a small set of questions:

1. In what ways does each text represent the major theories, constructs, and/or ideas of middle grades education/holistic education/spiritual development?

2. In your opinion, is the text authored by an authority in the field? Please explain.

3. In your opinion, is the text authored by an advocate of the field? Please explain.

4. Although I am not conducting a chronological historiography, do my selections adequately represent a sampling of major works from 1965 and 2012?

5. Given my goal of limiting the selections to four texts, would you make any additions or subtractions to the list?

It would be helpful to me to receive your input by Wednesday, April 4, 2012.

Thank you for supporting my dissertation research. I appreciate how busy you are, and am grateful for your willingness to share your expertise with me." 


\section{Response from Dr. Micki M. Caskey, April 4, 2012}

\section{In what ways does each text represent the major theories, constructs, and/or ideas of the field?}

Alexander, W. M., Williams, E. L., Compton, M., Hines, V. A., \& Prescott, D. (1968). The emergent middle school. New York, NY: Holt, Rinehart, \& Winston.

Alexander and colleague's (1968) text is a landmark publication in middle grades education. It is recognized as a seminal work in the field of education. The text is one of the first (if not the first) comprehensive volume on the middle school concept, which influenced the development of middle schools and the middle school movement.

Carnegie Council on Adolescent Development. (1989). Turning points: Preparing American youth for the 21st century. Washington, DC: Carnegie Corporation of New York.

The Carnegie Council on Adolescent Development's (CCAD) (1989) report, is another landmark in middle grades education. The charge of the CCAD was to examine the conditions of American middle schools, which were failing to prepare young adolescents for academic success. The resulting report focused attention on educational issues and advanced policy and practices for middle grades education. The report also detailed a comprehensive set of recommendations for the education of young adolescents. It has been viewed as the blueprint for the systematic reform of the middle grades school.

Lounsbury, J. H., \& Vars, G. (1978). A curriculum for the middle school years. New York, NY: Harper \& Row.

Lounsbury and Vars (1978) authored a succinct and authoritative book on curriculum for middle grades education. The often-cited text includes descriptions of the core curriculum, exploratory curriculum, and other curricula well-suited for young adolescents.

National Middle School Association. (2010). This we believe: Keys to educating young adolescents. Westerville, $\mathrm{OH}$. Author.

The National Middle School Association's (2010), This We Believe is the association's position statement regarding the education of young adolescents. It was originally published in 1982, re-released in 1992, and was revised in 1995 and 2003. The most recent edition of the slim text includes the rationale for the middle school and delineates the 16 characteristics developmentally responsive middle schools. The text remains one of the most frequently cited books in middle grades education. 
2. In your opinion, is the text authored by an authority in the field? Please explain.

William Alexander is a known authority in middle grades education. He is credited with coining the term "middle school" and advancing the idea of a new school in the middle that would differ from the junior high. For this reason, he is often referred to as the "father of the American middle school." Alexander was a prolific scholar-authoring (or co-authoring) more than 200 articles, books, and professional publications.

The Carnegie Council on Adolescent Development was formed by the Carnegie Corporation of New York in 1986. The following year, in 1987, the CCAD formed the Task Force on Education of Young Adolescents, which brought together experts from multiple fields (education, research, government, health agencies, nonprofits, philanthropic groups) to examine the education and healthy development of young adolescents.

John Lounsbury is recognized as an expert in middle school education. He is been called "the conscience of the middle school movement" and remains steadfastly child-centered. He served as the editor of NMSA's publications for decades, which helped to shape views of middle school education. He is a productive scholar who has written hundreds of articles and professional publications.

Gordon Vars was a curriculum scholar and one of the founders of the National Association for Core Curriculum. His expertise included the core curriculum including common learning and interdisciplinary teaching. He authored (or co-authored) many articles, chapters, and books.

The National Middle School Association's publication, This We Believe, was a collaborative effort. A committee and a writing team contribute to the development of the position statement. For the 2010 edition, the committee included Gayle Andrews, Jack Berckemeyer, Edward Brazee, Brenda Cassellius, Betty Edwards, Annette Fante, Bill Ferriter, Mark Springers, Sue Swaim, April Tibbles, Chirs Toy, and Janet Vernon. The writing team included well-known experts in middle grades education: Edward Brazee, John Lounsbury, Mark Springer, and Sue Swaim.

\section{In your opinion, is the text authored by an advocate of the field? Please explain.}

William Alexander was an advocate of the middle grades education. As noted, he advanced the notion of a middle school for young adolescents and was known as the "father of the American middle school."

The members of CCAD's Task Force on Education of Young Adolescents were advocates of middle grades education. These experts from varied fields shared a common interest in advancing education and healthy development of young adolescents. 
John Lounsbury remains one of the strongest voices - advocates - of the middle school and middle grades education. Known as " the conscience of the middle school movement," he works tirelessly to promote child-centered education for young adolescents. He influenced many through his university professorship, public speaking, editorial skills, and publications.

Gordon Vars was a staunch advocate in the field of middle grades education. Similar to John Lounsbury, he influenced future teachers through his university teaching, speeches, and publications.

Each member of the writing team of National Middle School Association's publication, This We Believe, is an outspoken advocate of the middle school. Their advocacy works includes teaching, public speaking, and publications.

4. Although I am not conducting a chronological historiography, do my selections adequately represent a sampling of major works from 1965 and 2012?

I believe that you have a sample of the major works in middle grades education from the 1960s to today.

5. Given my goal of limiting the selections to four texts, would you make any additions or subtractions to the list?

I recognize the goal of limiting your selections of four texts. I also noticed that all the texts were authored and published in the U.S. This leads me to wonder whether you will intentionally limit your text sets to U.S. publications. (I do not recall the authors or publisher locations for the other two fields.) If you are going to limit the text sets to the U.S., I think it would be important to note this in the methods section.

\section{Response from Dr. Jack Miller, March 26, 2012}

Guiding questions for review of data sources list:

\section{The Soul of Education (Kessler, 2000)}

1. In what ways does each text represent the major theories, constructs, and/or ideas of the field?

This book has become a central text in the area of spirituality in education. It explores the concept of soul in manner which is inclusive. Her work was based on years of teaching experience so it was easily accessible to teachers. 
2. In your opinion, is the text authored by an authority in the field? Please explain.

Rachael Kessler was one of athe leaders in holistic education. Towards the end of her life she was writing extensively about the importance of teacher presence.

3. In your opinion, is the text authored by an advocate of the field? Please explain.

Rachael spoke around the world on the issues raised in her book. Her book was published by ASCD which is a mainstream organization and thus work reached a large number of educators.

4. Although I am not conducting a chronological historiography, do my selections adequately represent a sampling of major works from 1965 and 2012?

Holistic education as term did not come into used until the 1980's. Before that the most widely used term was humanistic education. For example, one the seminal texts was Carl Rogers" Freedom to Learn.

5. Given my goal of limiting the selections to four texts, would you make any additions or subtractions to the list?

I think you need to add a work by Nel Noddings. Either Happiness and Education or the Challenge to Care.

\section{What are Schools For? Miller (1997)}

1. In what ways does each text represent the major theories, constructs, and/or ideas of holistic education?

This book provides the best historical treatment of holistic education. It also situates holistic education within the larger social context. It includes excellent overview of the major approaches eg. Montessori, Waldorf, etc.

2. In your opinion, is each text authored by an authority in the field? Please explain.

Ron Miller is one of the most widely cited authors in the field. He wrote or edited several other books

3. In your opinion, is each text authored by an advocate of the field? Please explain.

For years he was a major advocate and started The Holistic Education Review which became Encounter. 
He also started the Foundation for Educational Renewal Press that published several books in the field.

Thus he was a major force in holistic education. However, about year ago he decided to withdraw from actively being involved and now runs a bookstore in Vermont.

4. Although I am not conducting a chronological historiography, do my selections adequately represent a sampling of major works from 1965 and 2012?

See Above

5. Given my goal of limiting the selections to four texts, would you make any additions or subtractions to the list?

See Above

\section{The Holistic Curriculum, Miller (2007)}

No sure about commenting on my own book

1. In what ways does each text represent the major theories, constructs, and/or ideas of holistic education?

This book outlines three basic principles of holistic education: balance, inclusion and connection.

A framework for curriculum is outlined around the concept of curriculum connections

2. In your opinion, is each text authored by an authority in the field? Please explain.

3. In your opinion, is each text authored by an advocate of the field? Please explain.

I have been involved in this work in the early 70"s and have written more than a dozen books.

The ideas in this book have provided a framework for a holistic school in Toronto: The Equinox School

4. Although I am not conducting a chronological historiography, do my selections adequately represent a sampling of major works from 1965 and 2012? See above

5. Given my goal of limiting the selections to four texts, would you make any additions or subtractions to the list? See Above 


\section{Spirituality as a Developmental Domain Notes from meeting with Dr. Robert Roeser, April 20, 2012}

We did not go over each text, one at a time. Rob initially rejected Fowler, but when I reminded him that I was doing a historiographical analysis, he said I had to include it. He added his work with Peck (2009) as the fourth piece to include in the data set. Definitely Benson. Rob suggested I return to the intro chapter to PYD and Spirituality (the Lerner text) for his articulation of the interrelationship between adolescent identity formation and spiritual development. At the end of our time together, he affirmed the choices I had made, based on his understanding of my purposes and research methodology.

To add: ROESER, ROBERT W. and PECK, STEPHEN C.(2009)'An Education in Awareness: Self, Motivation, and Self- Regulated Learning in Contemplative Perspective',Educational Psychologist,44:2,119 — 136

Rob also was surprised that his chapter with King was not on the list; but I talked about my decision point to consider literature that addressed the highest level regarding the field of spirituality as a developmental domain, not just adolescent spiritual development. This is the point at which he began to pick apart my characterization of spirituality as a developmental domain. I acknowledged that my conceptual framework was limited, and that I recognized that I was simplifying some matters that were not so easily simplified.

I think one major impression I am left with after our conversation, is the highly nuanced, subtle, and complex nature of the topic I am researching. It is not just my potential findings that are complicated; it is the ways in which I have set up the study that are also complicated. My gut tells me that this is why critical historiography is a strategic methodology to use. As a post-structuralist methodology, I am able to foreground biases, relationships, and socio-political contexts.

He made the following points, not in this order:

- Upon seeing my Venn diagram/conceptual framework, he immediately went to the work of Steiner and Montessori as the overlapping area between spirituality and education. He commented that their work had come out of a religious context/tradition.

- He agreed with my application of Eccles \& Roeser's "stage environment fit" theory as within the overlapping space between middle grades education and dev. psych.

- He is not certain that spirituality has a developmental domain; he talked about domains being something that is measureable, like domain in the mathematical sense

- He spoke of how (in regards to Fowler/Kohlberg) developmental psychology was no longer conceiving human development as something that happens in sequential 
stages that have a rigid wall in between each stage. He joked that "that stage" of dev psych was over.

- At one point he reflected that his own interest in spiritual development (he rarely used that phrase exactly - he used other phrases, none consistently and I can't remember any of them) came from his interest in adolescent development. He saw an important relationship between the cognitive capacities and interests of adolescents and the larger questions related to issues of spirit, soul, identity, meaning, empathetic understanding of another.

- Regarding the previous point, he agreed with me when I connected that point to why I thought it was important to articulate for US middle grades teachers why spiritual development is a valid C\&I issue.

- He is thinking of spiritual development more as the domain of identity development with two parts:

- What do I think of my self; how is the mind separate from the body? How are they connected?

- What beliefs guide my worldview - do I think there is a god(s)? What is god like? What is my relationship with god?

- He talked about spirituality as something which does change over the human lifespan, although he offered two possible ways of considering that change: 1) an unfolding or revealing of awarenesses that had always been there (inside? As cognitions?) and/or 2) the accumulation of beliefs and ethical frameworks (i.e., a scholarly knowledge of religious texts)

- He saw the "Chain of Being" as in the overlapping space between education and spirituality: awareness, mind, body

- He speculated that what I will find in the nexus/convergence is mindfulness in education. 


\section{Appendix D}

\section{Portions of Texts Selected for Analysis}

\section{Selections for Initial Coding of MGC texts}

Note: Carnegie (1989) and NMSA (2010) read in full

Sections of Lounsbury \& Vars 1978 to code:
$\checkmark$ Preface
$\checkmark$ Ch. 1:1-12
$\checkmark$ Ch. 3: 34-43
$\checkmark$ Ch. 5: 56-61
$\checkmark$ Ch. 9: 111-123

Sections of Alexander 1968 to code:
$\checkmark$ Ch. 1:3-20
$\checkmark$ Ch. 4: 63-82
$\checkmark$ Ch. 5: 83-101

Researcher Memo: I made the decision to make selections in these two texts instead of coding them in their entirety after coding NMSA2010 and Carnegie1989. I felt like I was starting to saturate the data just from those two texts, and considered not even coding the 1978 and 1968 texts. I don't think I am going to add any more codes/categories to my list after coding the older texts. Also, there is some simplicity in coding two position papers and not mixing up the data set with two different types of texts.

So when I sat down today (5/4/12), I skimmed through the 1968/1978 texts to see if there was anything there that seemed significantly different than what I had already come across, in terms of the content of the middle grades concept. Nothing jumped out, but I did identify the sections of the texts that dealt directly with the content of the mgc. In both texts, there were extensive sections on the history of the junior high and the middle grades movement - these sections might be good for a direct contrapuntal reading? Or for providing historical context? But I need to be careful here, for I am trying to interpret for paradigms that guide those (hi)stories; I am not writing a history of the middle grades reform movement.

Criteria for the including the sections identified above:

- Focus on explicating the middle grades concept or philosophy

- Focus on teachers/teaching and curriculum 
- Did not include chapters on organization/grade configuration

- Did not include historical chapters

- Did not include chapters on student evaluation, teacher preparation, or program evaluation

- Did not include chapters on early adolescent development (descriptions of)

- Did not include chapters dedicated to describing case studies of successful middle grades school.

5/8/12 Researcher Memo: I just added the first part of Ch. 5 (The Core Component) to my Lounsbury/Vars1978 selections list. I also removed the last part (123-126) from Ch. 9. I made this change because I realized that the "core component" section of the text includes a massive amount of potentially paradigmatic data. Also, after re-skimming that chapter for a third time, I am "seeing" connections to the social-political context. Is this constant-comparative analysis? Am I "seeing" those connections more clearly after having Icoded all of my previous selections? How does the coding process influence/change how I interpret the data?

\section{Selections for Initial Coding of SpirDev texts}

Note: Benson (2006) and Oser, Scarlett, \& Bucher (2006) read in full

Fowler1981

$\checkmark$ (5/31) Intro: pp. xi-xiv

$\checkmark$ Ch. 1:3-8

$\checkmark$ Ch. 2: pp. 9-15

$\checkmark$ Part III Intro: pp. 89-90

$\checkmark$ Ch. 12: pp. 91-97

$\checkmark$ Ch. 13: pp. 98-105

$\checkmark$ Ch. 14: pp. 106-114*

$\checkmark$ Part IV Summaries: p. 121, 133134, 149-150, 172-173, 182-183, 197-198, 199-204

$\checkmark$ Ch. 23: pp. 269-281 
5/31/12 Notes on the Fowler selections: I chose selections that were generally about spirituality as a developmental domain, including the Ch. 2 section on Fowler's definition of faith as a construct. What has been left out is Part II, which reviews stagedevelopmental theories of Erickson, Kohlberg, and Piaget, and Part IV, the stages of faith broken down by life-stage. I think it continues to be very important that I am clear about my distinction between descriptions of adolescent spiritual developmental characteristics and theories on why/how spirituality is a domain of human development. I am focusing on the latter, not the former. I think in future research I could focus on the former as a means of producing a practical handbook for mg teachers who wish to have knowledge of young adolescent development. In that case, my sources would be:

Fowler, Ch. 17/18/19

King and Roeser

Roeser \& Peck, 2009

Chapters from PYD and Spirituality

Chapters from Roehlkepartain et al

DeBlasio

6/15/12 Re-visiting my selections, after re-reading the book:

I agree with all of my initial selections (as listed above). But I want to add the italicized stage summaries at the end of each chapter in Part IV. I still think I should be focusing on the paradigms that undergird the theories on spirituality as a dev. domain; but I think that some of that analysis can be done by interpreting for the BVAs reflected in the descriptions of the stages. I liken the descriptions of the stages to the content of the middle grades concept (i.e., NMSA's 16 characteristics). See my memo on pages 52-53 of my research journal for an example of a BVA interpretation of a stage description. I will ICode the summaries and not the entire chapters in order to make this analysis more manageable. What might be lost are specific metaphors and examples that are more deeply explicated. But in my readings of those chapters, I found (in terms of language and content) that the summaries, though concise, were substantive and richly descriptive (in terms of language).

9/7/12 Adjusting selections in list above

I returned to ICoding, and added to the list above the pages for the end-of-the-chapter summaries of each stage of faith development. Stage 6 does not have a summary at the end; the first 5 pages have been included instead as the summary/overview. The remainder of the chapter delves deeper into specific aspects of the stage.

I also added a $\checkmark$ and a date next to the Intro, to indicate that I completed the ICoding and when I had done the ICoding.

When I sat down to begin with page 9, I revisited Ch. 1 (initially not included in selections) and decided to include it because it offers Fowler's definition of human faith. 


\section{Selections for Initial Coding of HolEd texts}

$11 / 25 / 12$

R. Miller, 1997
$\checkmark$ Introduction, pp. 1-4
$\checkmark$ Ch. 1, pp. 7-8, 20
$\checkmark$ Ch. 4,pp. 75-89
$\checkmark$ Ch. 9, pp. 195-209
$\checkmark$ Ch. 11, pp. $219-225$

Just looking at the table of contents, I see that the first three chapters (Part One: Cultural Roots of American Education) are histories of American ed. told from the holistic/humanistic lens. These chapters might be appropriate as part of my direct social/historical contextualization. but for ICoding, since my goal is to interpret for paradigms underlying the content of holistic ed, I think I should ICode the selections listed above. I should definitely use Ch. 8 (The Education Crisis) as part of contrapuntal reading. Skimming through Miller, I am struck by how he makes the degree of congruence between culture and education. His historical study of the pioneers \& contemporary practitioners of "holism" in education is one strategy for articulating skillful entry points for advocates of including the spiritual domain, as a developmental issue, in middle grades education.

$11 / 26 / 12$

J. Miller, 2007

$\checkmark$ Ch. 1, pp. 3-14

$\checkmark$ Ch. 12,pp. 190-199

*If necessary, I can also consider coding:

Ch. 6, pp. 89-90, pp. 94-96

Ch. 8, pp. 131-146

Ch. 9 , pp. 148-160

Ch. 11 , pp. 178-189

Like R. Miller, J. Miller devotes much of the book to an exploration of the historical and contextual issues related to holistic education. I made selections using the same criteria for other texts: a focus on the content of the position/theoretical framework, with (in this data set anyway) an emphasis on implications for education. That said, this text also includes sections that detail specific, classroom-based practices that I did not include in my selections. I liken this choice to not including classroom-based practices that were included in the Lounsbury/Vars text. If I had make a comparison to the selections from the SpDev data set, a reasonable parallel would be my decision not to include the background "conversation" on developmental theories (Piaget, Erikson, Kohlberg) or on 
the application of the interview method when researching faith development, as presented in the Fowler text.

Kessler, 2000

Introduction, pp ix-xviii

Ch. 1, pp. 1-17

Much of Kessler's text weaves examples of practice in with her rationale for incorporating spiritual development in with education of adolescents. The introduction and first chapter are the closest selections to capturing an overview of an educational philosophy that includes spiritual development and spirituality. Kessler does not describe herself as a "holistic educator" to but many prominent holistic educators use that term in reference to her and her ideas. 


\section{Appendix E}

\section{BVA by FCC, Middle Grades Concept}

\section{Integration/Interrelationships (knowledge, domains)}

\begin{tabular}{|c|c|c|c|}
\hline Alexander1968 & Louns/Vars1978 & Carnegie1989 & NMSA2010 \\
\hline \multirow[t]{2}{*}{$\begin{array}{l}\text { Value - specialization } \\
\text { AND collaboration } 10- \\
12\end{array}$} & $\begin{array}{l}\text { Assumption - there is a } \\
\text { progressive nature to the } \\
\text { organization of } \\
\text { knowledge from general } \\
\text { to specialized; this } \\
\text { progress is paralleled by } \\
\text { human development. } \\
\text { Belief - Therefore, mge } \\
\text { education needs to } \\
\text { reflect a bridge between } \\
\text { generalism of ele ed and } \\
\text { specialization of sec ed } \\
38-40\end{array}$ & $\begin{array}{l}\text { Belief -challenging } \\
\text { intellectual educational } \\
\text { experiences through } \\
\text { integration of academic } \\
\text { subjects } \\
\text { Value - critical, } \\
\text { reflective thinking as } \\
\text { learning process } 42-45\end{array}$ & $\begin{array}{l}\text { Value - interdependence } \\
\text { Belief - implementation } \\
\text { of mg concept needs to } \\
\text { be holistic in terms of } \\
\text { recommendations } 13\end{array}$ \\
\hline & $\begin{array}{l}\text { METAPHOR: } \\
\text { "structures" of academic } \\
\text { disciplines } \\
\text { Assumption - } \\
\text { knowledge has inherent } \\
\text { characteristics that can } \\
\text { be known through } \\
\text { learning } 38-40\end{array}$ & $\begin{array}{l}\text { Value - integration of } \\
\text { "real life" with } \\
\text { "classroom instruction" } \\
\text { Assumption - real life is } \\
\text { something that happens } \\
\text { outside of the } \\
\text { classroom; school as } \\
\text { distinct from society } 45 \text { - } \\
49\end{array}$ & $\begin{array}{l}\text { Belief - things are } \\
\text { connected to each other } \\
\text { Assumption - explicit } \\
\text { effort needs to be made } \\
\text { in schools in order to } \\
\text { inter-relate subjects and } \\
\text { persons } 15\end{array}$ \\
\hline $\begin{array}{l}\text { Value- dev responsive } \\
\text { educational programs } \\
\text { Assumption - stage } \\
\text { based human } \\
\text { development theory } \\
\text { Belief- interrelatedness } \\
\text { of the domains of } \\
\text { development } 68-69\end{array}$ & & $\begin{array}{l}\text { Value - learning } \\
\text { through integration } \\
\text { Belief - teachers must } \\
\text { facilitate the integration } \\
\text { of the curriculum } 45-49\end{array}$ & $\begin{array}{l}\text { Value }- \text { holistic } \\
\text { curriculum that includes } \\
\text { academics, arts, athletics } \\
20\end{array}$ \\
\hline $\begin{array}{l}\text { Value - an intentional } \\
\text { integration of } \\
\text { knowledge about the } \\
\text { learners, the curriculum, } \\
\text { and the desired } \\
\text { outcomes } \\
\text { Belief - continuity of } \\
\text { educational experience } \\
\text { benefits ya learners } 79- \\
81\end{array}$ & & $\begin{array}{l}\text { Belief - integration of } \\
\text { services and } \\
\text { coordination of efforts is } \\
\text { better (for what?) } 60-66\end{array}$ & $\begin{array}{l}\text { Belief - integration } \\
\text { positively affects ya } \\
\text { learning } 21\end{array}$ \\
\hline Value - addressing all & & Value - learning & Belief-holistic \\
\hline
\end{tabular}




\begin{tabular}{|l|l|l|l|}
\hline $\begin{array}{l}\text { aspects of human dev in } \\
\text { mge }\end{array}$ & $\begin{array}{l}\text { through integration } \\
\text { Belief - teachers must } \\
\text { effective when there is } \\
\text { holistic integration of } \\
\text { fnowledge of human } \\
\text { dev 83-86 }\end{array}$ & $\begin{array}{l}\text { epistemology } \\
\text { Assumption - students } \\
\text { will see holism with }\end{array}$ \\
\hline $\begin{array}{l}\text { Value - the expectation } \\
\text { that team teaching } \\
\text { should be implemented } \\
\text { Belief - teachers lack } \\
\text { training and confidence } \\
\text { in their abilities to }\end{array}$ & & & $\begin{array}{l}\text { Assumption - } \\
\text { connections exist } \\
\text { between curricula } 22\end{array}$ \\
implement team & & & $\begin{array}{l}\text { Value - integration of } \\
\text { curriculum throughout } \\
\text { the school programs }\end{array}$ \\
teaching 99-101 & & & $\begin{array}{l}\text { Assumption - persona } \\
\text { lives are distinct from } \\
\text { academic lives 38-39 }\end{array}$ \\
\hline
\end{tabular}

\section{School mediates growth and development/Developmentally responsive ed/ Process over product}

\begin{tabular}{|c|c|c|c|}
\hline Alexander1968 & Louns/Vars1978 & Carnegie1989 & NMSA2010 \\
\hline $\begin{array}{l}\text { Belief - ya are distinct } \\
\text { from children and } \\
\text { adolescents } \\
\text { Value -education that is } \\
\text { linked with stage in } \\
\text { human lifespan 3-6 }\end{array}$ & $\begin{array}{l}\text { Value-dev responsive } \\
\text { mge xi-xii }\end{array}$ & & $\begin{array}{l}\text { Assumption - that is it } \\
\text { possible to determine } \\
\text { what is best for all ya } 1\end{array}$ \\
\hline $\begin{array}{l}\text { Value - connecting } \\
\text { educational program } \\
\text { with stage in human } \\
\text { development } \\
\text { Belief - ya is a time of a } \\
\text { range in dev } \\
10-12\end{array}$ & $\begin{array}{l}\text { Value - nonverbal } \\
\text { communication as } \\
\text { potential for enhancing } \\
\text { and/or inhibiting ya } \\
\text { learning } \\
\text { Belief- ya learners as (if } \\
\text { not more so) skilled at } \\
\text { nonverbal means of } \\
\text { communication 9-12 } \\
\text { NOTE: where is the } \\
\text { discussion of cultural } \\
\text { considerations? }\end{array}$ & $\begin{array}{l}\text { Belief }- \text { mge as an } \\
\text { important phase of } \\
\text { education b/c of human } \\
\text { dev characteristics } \\
\text { Assumption - stage- } \\
\text { based model of human } \\
\text { dev. } 8-9\end{array}$ & $\begin{array}{l}\text { Belief - mge as an } \\
\text { important phase of } \\
\text { education b/c of human } \\
\text { dev characteristics } \\
\text { Assumption - stage- } \\
\text { based model of human } \\
\text { dev. } 1\end{array}$ \\
\hline $\begin{array}{l}\text { Assumption: positivism: } \\
\text { "the } 320 \text {...growth } \\
\text { characteristics) } \\
\text { Value - referring to } \\
\text { what is known/believed } \\
\text { about human growth to } \\
\text { inform education } \\
\text { Belief - stage model of } \\
\text { human development 14- } \\
17\end{array}$ & $\begin{array}{l}\text { Assumption }- \text { dev } \\
\text { characteristics are } \\
\text { "facts" } \\
\text { Value-dev responsive } \\
\text { mge } 34-37\end{array}$ & $\begin{array}{l}\text { Belief - school } \\
\text { influences human } \\
\text { development } \\
\text { Value - school should } \\
\text { influence human } \\
\text { development } \\
\text { Belief - that is not } \\
\text { happening now 12-14 }\end{array}$ & $\begin{array}{l}\text { Value - education that is } \\
\text { responsive to dev needs } \\
\text { of the students } \\
\text { Belief - mg educators } \\
\text { need to be specifically } \\
\text { prepared for ya } 3\end{array}$ \\
\hline $\begin{array}{l}\text { Belief - ya have specific } \\
\text { educational needs }\end{array}$ & $\begin{array}{l}\text { Assumption - } \\
\text { something about not }\end{array}$ & $\begin{array}{l}\text { Value - schools are } \\
\text { meant to serve the }\end{array}$ & $\begin{array}{l}\text { Value - education } \\
\text { should be connected to }\end{array}$ \\
\hline
\end{tabular}




\begin{tabular}{|c|c|c|c|}
\hline $\begin{array}{l}\text { distinct from children } \\
\text { and adolescents } 19\end{array}$ & $\begin{array}{l}\text { only the ability to } \\
\text { accurately describe } \\
\text { human dev, but also a } \\
\text { sense of articulating } \\
\text { what is normal and what } \\
\text { is not normal as a } \\
\text { construct; duality? 34- } \\
37\end{array}$ & students $15-17$ & dev theory 5 \\
\hline $\begin{array}{l}\text { Value - student centered } \\
\text { curriculum } \\
\text { Belief - mg curriculum } \\
\text { should be exploratory } \\
\text { for the ya learner } 19\end{array}$ & $\begin{array}{l}\text { Assumption - it is } \\
\text { possible to identify } \\
\text { stage-based dev tasks } \\
34-37\end{array}$ & $\begin{array}{l}\text { Belief - what the basic } \\
\text { needs of ya are } \\
\text { Value - caring, } \\
\text { relationships, hope, } \\
\text { support, belonging } \\
\text { Assumption - it is } \\
\text { possible to } \\
\text { define/describe ya needs } \\
\text { Belief - ya is a critical } \\
\text { period of human dev. } \\
20-21\end{array}$ & $\begin{array}{l}\text { Assumption - dev } \\
\text { processes as natural } \\
\text { (essentialized?) } \\
\text { Value - function of } \\
\text { education includes } \\
\text { healthy development } \\
\text { Belief - educators } \\
\text { responsible for healthy } \\
\text { dev } \\
\text { Assumption/Belief: } \\
\text { human dev processes } \\
\text { can be described 5-7 }\end{array}$ \\
\hline $\begin{array}{l}\text { Value - ya being well- } \\
\text { known and cared for by } \\
\text { an adult in school } \\
\text { Belief - ya need } \\
\text { curriculum for personal } \\
\text { development } \\
\text { Assumption - teachers } \\
\text { have the capacities for } \\
\text { serving as general } \\
\text { counselors } 65-67\end{array}$ & $\begin{array}{l}\text { Belief- seeing human } \\
\text { dev as biological and } \\
\text { social } \\
\text { Assumption - human } \\
\text { dev as variable in terms } \\
\text { of outcomes - dev } \\
\text { outcomes can change, } \\
\text { not predetermined 34-37 }\end{array}$ & $\begin{array}{l}\text { Belief - ya has } \\
\text { previously been not well } \\
\text { understood } \\
\text { Assumption - ya is a } \\
\text { stage of human } \\
\text { development } \\
\text { Value - youth } \\
\text { empowerment to make } \\
\text { "good" choices } 21\end{array}$ & $\begin{array}{l}\text { Value - school should } \\
\text { act as guide for } \\
\text { threatened youth } \\
\text { Assumption - adult } \\
\text { educators can } \\
\text { understand ya and can } \\
\text { understand their cultural } \\
\text { context } 9\end{array}$ \\
\hline $\begin{array}{l}\text { Value- dev responsive } \\
\text { educational programs } \\
\text { Assumption - stage } \\
\text { based human } \\
\text { development theory } \\
\text { Belief- interrelatedness } \\
\text { of the domains of } \\
\text { development } \\
68-69\end{array}$ & $\begin{array}{l}\text { Value - addressing ya } \\
\text { cog and soc dev by } \\
\text { authentically exploring } \\
\text { controversial issues } \\
\text { debated in the larger } \\
\text { society } \\
\text { Belief - more pluralism } \\
=\text { more problems } 37-38\end{array}$ & $\begin{array}{l}\text { Value - mge should be } \\
\text { dev responsive } \\
\text { (intellect, emotion, } \\
\text { physical health) 32-33 }\end{array}$ & $\begin{array}{l}\text { Value - knowledge } \\
\text { about ya dev should } \\
\text { inform mg programs } \\
\text { Belief - mg programs } \\
\text { that ignore ya dev are } \\
\text { unsuccessful } 11\end{array}$ \\
\hline $\begin{array}{l}\text { Value - breadth and } \\
\text { depth of opportunities to } \\
\text { explore a variety of } \\
\text { disciplines and activities } \\
\text { Belief - ya need schools } \\
\text { to formally offer } \\
\text { multiple, regularly } \\
\text { structured opportunities } \\
\text { to explore new interests } \\
69-71\end{array}$ & $\begin{array}{l}\text { Value - education that is } \\
\text { dev responsive } \\
\text { Belief - core component } \\
\text { is dev responsive } 56-57\end{array}$ & $\begin{array}{l}\text { Value - dev responsive } \\
\text { ed } \\
\text { Assumption - it is } \\
\text { possible to distinguish } \\
\text { ya dev from other stages } \\
\text { of human dev } 36\end{array}$ & $\begin{array}{l}\text { Value - dev theory as } \\
\text { guide for ed practices } \\
\text { Assumption - dev } \\
\text { theory is valid, } \\
\text { trustworthy } 13\end{array}$ \\
\hline $\begin{array}{l}\text { Value - having plans, } \\
\text { while at the same time }\end{array}$ & $\begin{array}{l}\text { Value - process over } \\
\text { mastery of content } 57 \text { - }\end{array}$ & $\begin{array}{l}\text { Value - school } \\
\text { structures that are dev }\end{array}$ & $\begin{array}{l}\text { Belief - essential } \\
\text { attributes of human dev }\end{array}$ \\
\hline
\end{tabular}




\begin{tabular}{|c|c|c|c|}
\hline $\begin{array}{l}\text { allowing for/expecting } \\
\text { revisions to the plan } \\
\text { Belief - schooling as } \\
\text { responsive to needs of } \\
\text { the people in the school } \\
79-81\end{array}$ & 61 & responsive $49-54$ & $\begin{array}{l}\text { Assumption- } \\
\text { everything can be } \\
\text { known } 16\end{array}$ \\
\hline $\begin{array}{l}\text { Value - dev responsive } \\
\text { mge } \\
\text { Value - teacher } \\
\text { facilitates personal } \\
\text { meaning explorations } \\
83-86\end{array}$ & & $\begin{array}{l}\text { Value - teacher } \\
\text { knowledge of ya dev } \\
58-60\end{array}$ & $\begin{array}{l}\text { Value - relating dev } \\
\text { theory to educational } \\
\text { practice } 18-19\end{array}$ \\
\hline $\begin{array}{l}\text { Belief - teachers who } \\
\text { are knowledgeable and } \\
\text { passionate about their } \\
\text { subject specialty will } \\
\text { stimulate ya interest for } \\
\text { the discipline } \\
\text { Value - referencing cog } \\
\text { and psych ya } \\
\text { development } 83-86\end{array}$ & & $\begin{array}{l}\text { Belief - successful mgs } \\
\text { have teachers who want } \\
\text { to be there, who know } \\
\text { more than the pervasive } \\
\text { stereotypes about } \\
\text { middle grades students } \\
58-60\end{array}$ & $\begin{array}{l}\text { Assumption - human } \\
\text { dev has essentialized } \\
\text { characteristics that can } \\
\text { be known (post- } \\
\text { positivist ontology) } 20\end{array}$ \\
\hline \multirow[t]{5}{*}{$\begin{array}{l}\text { Value - addressing all } \\
\text { aspects of human dev in } \\
\text { mge } \\
\text { Belief- mge more } \\
\text { effective when there is } \\
\text { holistic integration of } \\
\text { knowledge of human } \\
\text { dev } 83-86\end{array}$} & & $\begin{array}{l}\text { Belief- ya have distinct } \\
\text { needs } \\
\text { Value - schools should } \\
\text { be dev responsive } 60- \\
66\end{array}$ & $\begin{array}{l}\text { Value - ya learning } \\
\text { happens best in } \\
\text { authentic contexts } \\
\text { Assumption - previous } \\
\text { mg learning and } \\
\text { teaching approaches did } \\
\text { not employ functional } \\
\text { contexts } 22\end{array}$ \\
\hline & & $\begin{array}{l}\text { Value }- \text { school- } \\
\text { community partnerships } \\
\text { need to be dev } \\
\text { responsive } 70-77\end{array}$ & $\begin{array}{l}\text { Value - linking dev } \\
\text { theory with teaching } \\
\text { approaches } 22\end{array}$ \\
\hline & & & $\begin{array}{l}\text { Value }- \text { mg education } \\
\text { guided by dev theory } \\
27-29\end{array}$ \\
\hline & & & $\begin{array}{l}\text { Value - personal } \\
\text { development as a goal } \\
\text { of mg education } \\
\text { Belief - there is a } \\
\text { distinction between } \\
\text { academic and personal } \\
\text { NOTE: seeing frequent } \\
\text { use of "growth and } \\
\text { development" } 30\end{array}$ \\
\hline & & & $\begin{array}{l}\text { Belief - structures can } \\
\text { support strong } \\
\text { relationships } \\
\text { Belief - relationship } \\
\text { have ed and dev value }\end{array}$ \\
\hline
\end{tabular}




\begin{tabular}{|l|l|l|l|}
\hline & & 32 \\
\hline & & & $\begin{array}{l}\text { Value - curriculum } \\
\text { responds to dev theory } \\
\text { about ya 39 }\end{array}$ \\
\hline & & $\begin{array}{l}\text { Belief - active school- } \\
\text { family collaborations } \\
\text { positively impact ya } \\
\text { growth and development } \\
\text { Assumption - school } \\
\text { must take the lead or } \\
\text { partnerships won't } \\
\text { happen 40-41 }\end{array}$ \\
\hline
\end{tabular}

\section{MG as critical period (for individuals, for society)}

\begin{tabular}{|c|c|c|c|}
\hline Alexander1968 & Louns/Vars1978 & Carnegie1989 & NMSA2010 \\
\hline $\begin{array}{l}\text { Assumption - that is it } \\
\text { possible to determine } \\
\text { what is best for all ya } \\
10-12\end{array}$ & $\begin{array}{l}\text { Belief - ya is a crucial } \\
\text { stage of life because the } \\
\text { primary task is } \\
\text { developing a sense of } \\
\text { selfhood, while in } \\
\text { community } 3-4\end{array}$ & $\begin{array}{l}\text { Belief - mgs is a critical } \\
\text { point in the ed spectrum } \\
\text { in terms of long term } \\
\text { consequences } 8-9\end{array}$ & $\begin{array}{l}\text { Belief - about who ya } \\
\text { are and what they do } \\
\text { Belief - about the long- } \\
\text { term outcomes that are } \\
\text { connected to ya } 3\end{array}$ \\
\hline $\begin{array}{l}\text { Belief- ya is a unique } \\
\text { period in human } \\
\text { lifespan, characterized } \\
\text { by variability } 12-14\end{array}$ & $\begin{array}{l}\text { Belief- maturity happens } \\
\text { earlier for ya than it has } \\
\text { at any other point in } \\
\text { history } \\
\text { Assumption - possible } \\
\text { to qualify the typical } \\
\text { characteristics of ya 34- } \\
37\end{array}$ & $\begin{array}{l}\text { Assumption - because } \\
\text { of the changes in tech } \\
\text { and media, things are } \\
\text { harder for ya "today" } 9\end{array}$ & $\begin{array}{l}\text { Belief - there are things } \\
\text { which threaten healthy } \\
\text { dev that are particular to } \\
\text { contemporary society } \\
\text { Belief - ya a crucial } \\
\text { period in terms of long } \\
\text { term outcomes } 6\end{array}$ \\
\hline \multirow[t]{3}{*}{$\begin{array}{l}\text { Belief - mge is a critical } \\
\text { point in the long term } \\
\text { capacities/success of a } \\
\text { person } 71-73\end{array}$} & $\begin{array}{l}\text { Belief- ya dev related to } \\
\text { long term health of } \\
\text { society } 34-37\end{array}$ & $\begin{array}{l}\text { Belief - at risk students } \\
\text { benefit more } \\
\text { Value - to better serve } \\
\text { at risk ya } 9-10\end{array}$ & $\begin{array}{l}\text { Assumption - ya are not } \\
\text { able to be critical } \\
\text { consumers without } \\
\text { guidance from teachers } \\
\text { Belief - today's world is } \\
\text { dangerous for ya } 8\end{array}$ \\
\hline & & $\begin{array}{l}\text { Assumption - there are } \\
\text { ya who are not part of } \\
\text { mainstream society } \\
\text { Assumption - there is a } \\
\text { mainstream society that } \\
\text { is desirable } \\
\text { Belief - some kind of } \\
\text { distinction between } \\
\text { "engaging" and } \\
\text { "welcoming" depending } \\
\text { on your position in the } \\
\text { US 10-11 }\end{array}$ & $\begin{array}{l}\text { Belief - ya is a critical } \\
\text { stage of development } \\
43\end{array}$ \\
\hline & & Belief - US mge at a & \\
\hline
\end{tabular}




\begin{tabular}{|c|c|c|c|}
\hline & & $\begin{array}{l}\text { turning point } \\
\text { Belief - school is } \\
\text { "pivotal" } 12-14\end{array}$ & 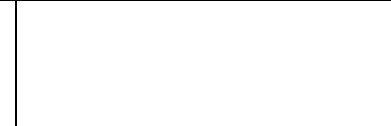 \\
\hline & & $\begin{array}{l}\text { METAPHOR: ya as } \\
\text { turbulence } \\
\text { Belief - ya as a distinct } \\
\text { period of human dev } \\
12-14 \\
\end{array}$ & 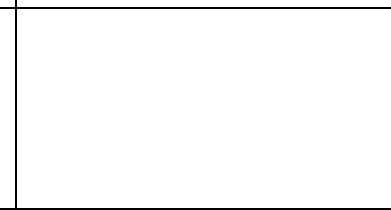 \\
\hline & 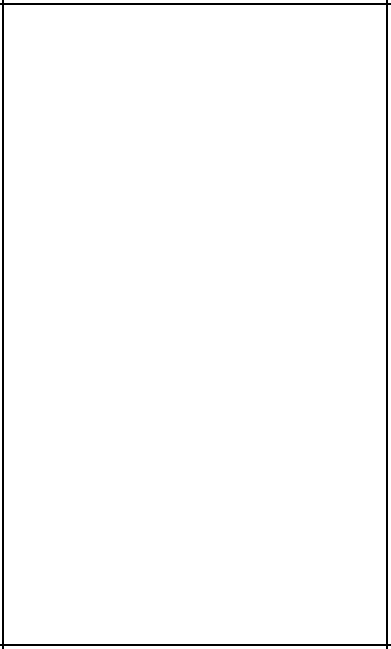 & $\begin{array}{l}\text { Belief - some youth are } \\
\text { more advantaged than } \\
\text { others } \\
\text { Assumption - it is } \\
\text { possible to classify some } \\
\text { people as advantaged, } \\
\text { and some as } \\
\text { disadvantaged } \\
\text { Value - mge as having a } \\
\text { positive impact on all } \\
\text { students } \\
\text { Belief - success is } \\
\text { possible for all } \\
\text { Assumption - } \\
\text { institutions foster or } \\
\text { inhibit success? } 15-17 \\
\end{array}$ & 更 \\
\hline & 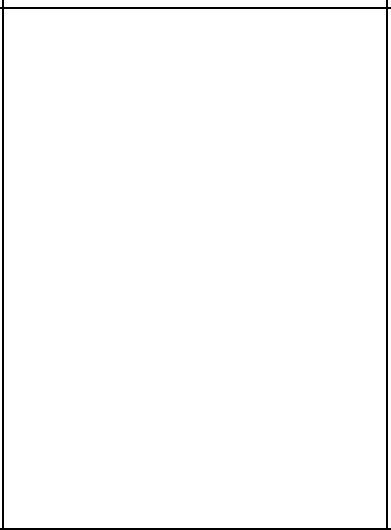 & $\begin{array}{l}\text { Belief - educational } \\
\text { experiences during ya } \\
\text { have long term } \\
\text { consequences } \\
\text { Belief - formal } \\
\text { schooling has impacts } \\
\text { on the capability of } \\
\text { people to succeed in US } \\
\text { society } \\
\text { Value - productive and } \\
\text { fulfilling lives as adults } \\
\text { Value - the goal, not the } \\
\text { path? 20-21 }\end{array}$ & (1) \\
\hline & & $\begin{array}{l}\text { Belief - ya is a critical } \\
\text { period of human dev. } \\
20-21\end{array}$ & \\
\hline & & $\begin{array}{l}\text { Value - life is harder } \\
\text { now than it once was for } \\
\text { ya in particular } \\
\text { Belief - there is less } \\
\text { community in the "new" } \\
\text { US } \\
\text { Assumption - urban } \\
\text { neighborhoods are } \\
\text { worse off than rural } \\
\text { towns? 20-21 }\end{array}$ & \\
\hline & & Belief - the risky & \\
\hline
\end{tabular}




\begin{tabular}{|c|c|c|}
\hline & 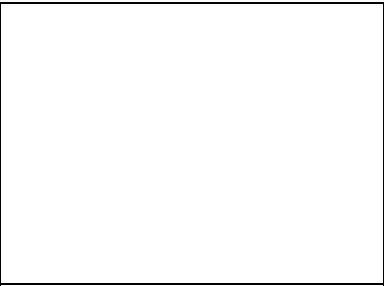 & $\begin{array}{l}\text { behaviors that ya in } \\
\text { particular are vulnerable } \\
\text { to have short and long } \\
\text { term bad consequences } \\
\text { Value - seeing these } \\
\text { risks as interrelated 22- } \\
25\end{array}$ \\
\hline & & $\begin{array}{l}\text { Value - it is bad for the } \\
\text { US economy and } \\
\text { governance to allow } \\
\text { minority ya to not be } \\
\text { well educated in the mg } \\
\text { Assumption - being a } \\
\text { minority is the problem } \\
\text { (there is no talk of white } \\
\text { power/priviledge) } 25- \\
27\end{array}$ \\
\hline & & $\begin{array}{l}\text { Belief- mge is a critical } \\
\text { period of intervention in } \\
\text { lifespan } \\
\text { Assumption - schools } \\
\text { can effectively } \\
\text { intervene/alter } \\
\text { trajectories/make a } \\
\text { difference } 32-33\end{array}$ \\
\hline & & $\begin{array}{l}\text { Value - economic } \\
\text { rationale for } \\
\text { transforming mge } \\
\text { Assumption - capitalist } \\
\text { model } 70-77 \\
\end{array}$ \\
\hline & & $\begin{array}{l}\text { Belief }- \text { ya are } \\
\text { vulnerable } 80-84\end{array}$ \\
\hline
\end{tabular}

\section{Relationships (people)/Collaboration \& Community}

\begin{tabular}{|c|c|c|c|}
\hline Alexander1968 & Louns/Vars1978 & Carnegie1989 & NMSA2010 \\
\hline $\begin{array}{l}\text { Value - on going } \\
\text { evaluation of any } \\
\text { middle school plan } \\
\text { Value - on going } \\
\text { evaluation conducted } \\
\text { collaborative and } \\
\text { intentionally by all } \\
\text { school members } 81 \text { - } \\
82\end{array}$ & $\begin{array}{l}\text { Belief- learning strongly } \\
\text { influenced by } \\
\text { relationships, by informal } \\
\text { relational interactions 4-6 }\end{array}$ & $\begin{array}{l}\text { Value }- \text { consensus } \\
\text { Value }- \text { shared } \\
\text { responsibility } \\
\text { Belief }- \text { transformation will } \\
\text { not happen without broad } \\
\text { participation } 10-11\end{array}$ & $\begin{array}{l}\text { Value }- \\
\text { collaborative } \\
\text { relationships 16-17 }\end{array}$ \\
\hline $\begin{array}{l}\text { Value - team } \\
\text { teaching } \\
\text { NOTE: the term } \\
\text { coordination is used, }\end{array}$ & $\begin{array}{l}\text { Value - collaborative } \\
\text { evaluation } \\
\text { Assumption - all } \\
\text { concerned parties see }\end{array}$ & $\begin{array}{l}\text { Belief - ya need adult } \\
\text { guidance } \\
\text { Value - having a sense of } \\
\text { hope }\end{array}$ & $\begin{array}{l}\text { Value - } \\
\text { collaborative } \\
\text { relationships } \\
\text { amongst all school }\end{array}$ \\
\hline
\end{tabular}




\begin{tabular}{|c|c|c|c|}
\hline $\begin{array}{l}\text { but collaboration is } \\
\text { never used } 95-97\end{array}$ & $\begin{array}{l}\text { themselves as such } \\
\text { Assumption - student is } \\
\text { NOT the only learner 57- } \\
61\end{array}$ & $\begin{array}{l}\text { Assumption - isolation } \\
\text { happens when adults aren't } \\
\text { present/available } \\
\text { NOTE - an absent voice is } \\
\text { the peers, how the ya could } \\
\text { support each other } 21-22\end{array}$ & $\begin{array}{l}\text { community } \\
\text { members } 19\end{array}$ \\
\hline \multirow[t]{6}{*}{$\begin{array}{l}\text { Belief }-m g \text { teachers } \\
\text { need integrity as a } \\
\text { qualification } \\
\text { particular to working } \\
\text { with ya } \\
\text { Value - } \\
\text { interrelationships as } \\
\text { part of effective } \\
\text { teaching and learning } \\
\text { 99-101 }\end{array}$} & $\begin{array}{l}\text { Value - multiple } \\
\text { participants in curr. } \\
\text { development } \\
\text { Belief - curr dev is a } \\
\text { leadership issue } \\
\text { Assumption: participants } \\
\text { involved with curr } \\
\text { leadership have the skills } \\
\text { to collaborate } 111-112\end{array}$ & $\begin{array}{l}\text { Value - interpersonal } \\
\text { relationships } 32-33\end{array}$ & $\begin{array}{l}\text { Value - education } \\
\text { as a collaborative } \\
\text { endeavor between } \\
\text { teachers, parents, } \\
\text { student } \\
\text { Assumption- } \\
\text { teachers know how } \\
\text { to collaborate with } \\
\text { each other 23-24 }\end{array}$ \\
\hline & $\begin{array}{l}\text { Value - curriculum } \\
\text { improvement should be } \\
\text { undertaken collaboratively, } \\
\text { with open communication, } \\
\text { explicit supports, and } \\
\text { permission to experiment } \\
\text { Value - collective } \\
\text { wisdom/group wisdom } \\
112-114\end{array}$ & $\begin{array}{l}\text { Value - caring, strong } \\
\text { interpersonal relationships, } \\
\text { being known in community } \\
32-33\end{array}$ & $\begin{array}{l}\text { Value - macro-goal } \\
\text { (i.e., vision of what } \\
\text { is possible) is } \\
\text { collaboratively } \\
\text { agreed upon; } \\
\text { consensus model? } \\
27-29\end{array}$ \\
\hline & $\begin{array}{l}\text { Value - interpersonal } \\
\text { relationships, empathetic } \\
\text { leadership, seeing people } \\
\text { as "becoming" } \\
\text { Belief - humane leadership } \\
\text { is more effective in terms } \\
\text { of achieving educational } \\
\text { outcomes } \\
\text { Assumption - principals } \\
\text { have the knowledge/skills } \\
\text { to support a climate of } \\
\text { personal/professional } \\
\text { integrity 114-116 }\end{array}$ & $\begin{array}{l}\text { Value - community } \\
\text { Belief- learning happens } \\
\text { better in community } 36\end{array}$ & $\begin{array}{l}\text { Value - adult } \\
\text { learning and org } \\
\text { structures that are } \\
\text { collaborative } \\
\text { METAPHOR: } \\
\text { teaming as the } \\
\text { "heart of the } \\
\text { school" 30-33 }\end{array}$ \\
\hline & $\begin{array}{l}\text { Value - direct input from } \\
\text { students/parents; survey } \\
\text { everyone } \\
\text { Assumption - orgs such as } \\
\text { a student council or the } \\
\text { PTA can provide reliable } \\
\text { data } 117-119\end{array}$ & $\begin{array}{l}\text { Belief - community } \\
\text { enhances learning for ya } \\
\text { students } \\
\text { Value - small sized } \\
\text { communities } \\
\text { Value - ya are known by } \\
\text { adults and peers } 37-42\end{array}$ & $\begin{array}{l}\text { Value - that } \\
\text { students know and } \\
\text { are known by each } \\
\text { other and their } \\
\text { teachers with } \\
\text { acceptance, } \\
\text { understanding, \& } \\
\text { caring } 31-32\end{array}$ \\
\hline & & $\begin{array}{l}\text { Belief - a sense of } \\
\text { community is enhanced } \\
\text { through intentionally } \\
\text { integrated efforts } 37-42\end{array}$ & $\begin{array}{l}\text { Belief - } \\
\text { relationships } \\
\text { positively impact } \\
\text { mg education } 33\end{array}$ \\
\hline & & $\begin{array}{l}\text { Value - outcomes that are } \\
\text { connected to participation in }\end{array}$ & $\begin{array}{l}\text { Belief - positive } \\
\text { interpersonal }\end{array}$ \\
\hline
\end{tabular}




\begin{tabular}{|c|c|c|c|}
\hline & & $\begin{array}{l}\text { the larger society } \\
\text { Assumption/Paradigm: } \\
\text { compliance to societal } \\
\text { norms of health, obedience } \\
\text { Paradox: } \\
\text { obedience/criticality } 42\end{array}$ & $\begin{array}{l}\text { relationships } \\
\text { positively impact } \\
\text { mg educational } \\
\text { experiences } \\
\text { METAPHOR: team } \\
\text { as home 33-34 }\end{array}$ \\
\hline & & $\begin{array}{l}\text { Assumption - teachers know } \\
\text { how to facilitate group work, } \\
\text { ya students have the skills to } \\
\text { work together in all contexts } \\
\text { (grades, ungraded, math, } \\
\text { theater, etc.) 49-54 }\end{array}$ & $\begin{array}{l}\text { Value - empathetic } \\
\text { understanding of } \\
\text { and interactions } \\
\text { with others } \\
\text { Assumption - adults } \\
\text { can guide the } \\
\text { growth of ya } 35\end{array}$ \\
\hline & & $\begin{array}{l}\text { Value - a consensus } \\
\text { decision making model } \\
\text { Belief - interaction } \\
\text { promotes trust } \\
\text { Assumption - all } \\
\text { stakeholders will be equally } \\
\text { valued and listened to } 54-58\end{array}$ & $\begin{array}{l}\text { Assumption - adults } \\
\text { influence students' } \\
\text { behavior, } \\
\text { dispositions, and } \\
\text { attitudes } \\
\text { Value - caring } \\
\text { interpersonal } \\
\text { relationships } 36\end{array}$ \\
\hline & & $\begin{array}{l}\text { Value - home norms reflect } \\
\text { school norms (what about } \\
\text { the other way around?) 66- } \\
69\end{array}$ & $\begin{array}{l}\text { Value - holistic } \\
\text { integration of } \\
\text { advocacy/caring } 36\end{array}$ \\
\hline & & $\begin{array}{l}\text { Value - trusting } \\
\text { relationships } \\
\text { Assumption - school staff } \\
\text { have the skills to work } \\
\text { effectively with parents, and } \\
\text { visaversa } \\
\text { Belief - students observe } \\
\text { their parents; parents are a } \\
\text { source of influence on a ya's } \\
\text { school-related ideas, } \\
\text { attitudes, beliefs 66-69 } \\
\end{array}$ & $\begin{array}{l}\text { Value - } \\
\text { collaborations with } \\
\text { community partners, } \\
\text { that are ya centered } \\
41-42\end{array}$ \\
\hline & & $\begin{array}{l}\text { Assumption - having } \\
\text { multiple teachers at a } \\
\text { conference will promote } \\
\text { empathy? What are the } \\
\text { power dynamics here when } \\
\text { multiple teachers meet with } \\
\text { one family? } 66-69\end{array}$ & \\
\hline & & $\begin{array}{l}\text { Assumption - schools and } \\
\text { community partners have the } \\
\text { skills and infrastructure to } \\
\text { sustainably collaborate } \\
\text { Value - authentic learning } \\
\text { experiences for ya } \\
\text { Value - collaboration to } \\
\text { avoid duplicating services } \\
70-77\end{array}$ & \\
\hline
\end{tabular}




\begin{tabular}{|l|l|l|}
\hline & NOTE: there are many \\
& examples of collaborations \\
& in pp. 80-84. Collaborative \\
efforts are presented as KEY & to the successful \\
& transformation of mge $80-$ \\
& 84 \\
\hline
\end{tabular}

\section{Intrapersonal development/Courage \& Empowerment}

\begin{tabular}{|c|c|c|c|}
\hline Alexander1968 & Louns/Vars1978 & Carnegie1989 & NMSA2010 \\
\hline \multirow[t]{2}{*}{$\begin{array}{l}\text { Belief - attitude towards } \\
\text { learning is a relevant and } \\
\text { important factor in } \\
\text { education } \\
\text { Assumption - schooling } \\
\text { influencing attitude } \\
\text { towards learning } 10-12\end{array}$} & $\begin{array}{l}\text { Value - emphasizing } \\
\text { the affective qualities of } \\
\text { being human } 1-2\end{array}$ & $\begin{array}{l}\text { Value - connection, } \\
\text { human } \\
\text { interrelationships } \\
\text { Assumption - adults } \\
\text { must guide; good } \\
\text { guidance does not } \\
\text { come from ya peers 8- } \\
9\end{array}$ & $\begin{array}{l}\text { Value - role of mg } \\
\text { teachers involves } \\
\text { nurturing positive } \\
\text { development of ya self } \\
\text { concept } \\
\text { Belief - self concept } \\
\text { strongly influences } \\
\text { ability to learn 3-4 }\end{array}$ \\
\hline & $\begin{array}{l}\text { Value - wholeness, } \\
\text { teacher a person with } \\
\text { integrity } 8-9\end{array}$ & $\begin{array}{l}\text { Value - intellectual and } \\
\text { emotional aspects of } \\
\text { human } 8-9\end{array}$ & $\begin{array}{l}\text { Assumption - dualistic } \\
\text { thinking: } \\
\text { empathy/academic } \\
\text { press, heart/mind } 15\end{array}$ \\
\hline $\begin{array}{l}\text { Value - faculty as best } \\
\text { prepared to make } \\
\text { curriculum decisions for } \\
\text { their own school } \\
\text { Value - curriculum that is } \\
\text { responsive to its } \\
\text { constituents } 63-64\end{array}$ & $\begin{array}{l}\text { Value - role of mg } \\
\text { teachers involves } \\
\text { nurturing positive } \\
\text { development of ya self } \\
\text { concept } \\
\text { Belief - self concept } \\
\text { strongly influences } \\
\text { ability to learn } 8-9\end{array}$ & $\begin{array}{l}\text { Value - self-respect, } \\
\text { active mind, healthy } \\
\text { body } \\
20-21\end{array}$ & $\begin{array}{l}\text { Value - learning on a } \\
\text { lifetime continuum } \\
\text { Value - self-advocacy } \\
\text { as a learner } 16-17\end{array}$ \\
\hline $\begin{array}{l}\text { Value - ya being well- } \\
\text { known and cared for by an } \\
\text { adult in school } \\
\text { Belief - ya need } \\
\text { curriculum for personal } \\
\text { development } \\
\text { Assumption - teachers } \\
\text { have the capacities for } \\
\text { serving as general } \\
\text { counselors } 65-67\end{array}$ & $\begin{array}{l}\text { Belief - led by } \\
\text { experiences that govern } \\
\text { behavioral changes } 57- \\
61\end{array}$ & $\begin{array}{l}\text { Value - trusting } \\
\text { teachers to make } \\
\text { decisions for the } \\
\text { school/their classrooms } \\
\text { Value - localized } \\
\text { control } \\
\text { Belief - giving more } \\
\text { autonomy will increase } \\
\text { sense of responsibility } \\
\text { Assumption - the } \\
\text { teachers/ administrators } \\
\text { have the skills to be } \\
\text { more autonomous 54- } \\
58\end{array}$ & $\begin{array}{l}\text { Value - listening as a } \\
\text { desirable core skill } \\
\text { taught in schools } \\
\text { NOTE: this is the first } \\
\text { time I have seen } \\
\text { listening explicitly } \\
\text { referred to in the text } \\
21\end{array}$ \\
\hline $\begin{array}{l}\text { Belief - faculty as } \\
\text { professional educators } \\
\text { capable and best suited for } \\
\text { school and classroom level } \\
\text { innovation and }\end{array}$ & $\begin{array}{l}\text { Value -mutual respect } \\
\text { as means to develop } \\
\text { empathy } \\
\text { Assumption- teachers } \\
\text { (are willing and able) }\end{array}$ & $\begin{array}{l}\text { Belief- health is a } \\
\text { precondition to } \\
\text { effective learning } \\
\text { Assumption - health is } \\
\text { defined by physical and }\end{array}$ & $\begin{array}{l}\text { Value - assessment as } \\
\text { means of student } \\
\text { developing a self- } \\
\text { concept } \\
\text { Value - student self- }\end{array}$ \\
\hline
\end{tabular}




\begin{tabular}{|c|c|c|c|}
\hline $\begin{array}{l}\text { responsivity to student } \\
\text { needs and interests } 79-81\end{array}$ & $\begin{array}{l}\text { see students as human } \\
\text { beings } 57-61\end{array}$ & $\begin{array}{l}\text { mental qualities, as } \\
\text { well as one's } \\
\text { dispositions \& attitudes } \\
\text { about health } 60-66\end{array}$ & $\begin{array}{l}\text { reflection } \\
\text { Value - student as } \\
\text { agent in learning } \\
\text { process } \\
\text { Assumption - ya is able } \\
\text { to understand self, is } \\
\text { motivated to do so 24- } \\
26\end{array}$ \\
\hline \multicolumn{4}{|l|}{$\begin{array}{l}\text { Value - applying a general } \\
\text { goal as a guide for teacher- } \\
\text { chosen C\&I strategies and } \\
\text { styles } \\
\text { Value - human creative } \\
\text { potential } 83\end{array}$} \\
\hline $\begin{array}{l}\text { Belief - teachers make } \\
\text { C\&I choices (consciously } \\
\text { or subconsciously) based } \\
\text { on what they think the } \\
\text { function of school is } 83 \text { - } \\
86\end{array}$ & $\begin{array}{l}\text { Belief - curriculum } \\
\text { development is not } \\
\text { about "getting better". } \\
\text { It is an internal } \\
\text { transformation yielding } \\
\text { externalized benefits in } \\
\text { the classroom } \\
\text { METAPHOR: teacher } \\
\text { as being "released" } \\
112-114\end{array}$ & & $\begin{array}{l}\text { Assumption - adults } \\
\text { are responsible for ya } \\
\text { Value - advocacy as an } \\
\text { act of caring } \\
\text { Belief - attitudes } \\
\text { translate into actions } \\
35\end{array}$ \\
\hline $\begin{array}{l}\text { Value - personal } \\
\text { dispositions as teacher } \\
\text { qualification } \\
\text { Assumption - attitude } \\
\text { translates into performance } \\
\text { (teaching) 87-88 }\end{array}$ & $\begin{array}{l}\text { Assumption - teachers } \\
\text { as "natural" allies } \\
\text { METAPHOR: "allies" } \\
\text { as a war metaphor? } \\
\text { Pogo's "we have met } \\
\text { the enemy and he is us" } \\
\text { is cited } \\
\text { Belief - teachers as } \\
\text { change agents in } \\
\text { curriculum dev 116- } \\
117\end{array}$ & & $\begin{array}{l}\text { Value - resiliency as a } \\
\text { means to safety } \\
\text { Belief - well-being is } \\
\text { connected to academic } \\
\text { success } 39\end{array}$ \\
\hline \multicolumn{4}{|l|}{$\begin{array}{l}\text { Value - teachers as } \\
\text { decision-makers about } \\
\text { instruction } \\
\text { Assumption - a distinction } \\
\text { between method and } \\
\text { strategy } \\
\text { METAPHOR/ANALOGY: } \\
\text { teaching as decision } \\
\text { making not as application } \\
\text { 88-90 }\end{array}$} \\
\hline $\begin{array}{l}\text { Belief - there is a mutually } \\
\text { reinforcing relationship } \\
\text { between creative teaching } \\
\text { and freedom/resources } \\
\text { Value - teacher } \\
\text { empowerment } \\
\text { Value - creativity 94-95 }\end{array}$ & & & \\
\hline
\end{tabular}




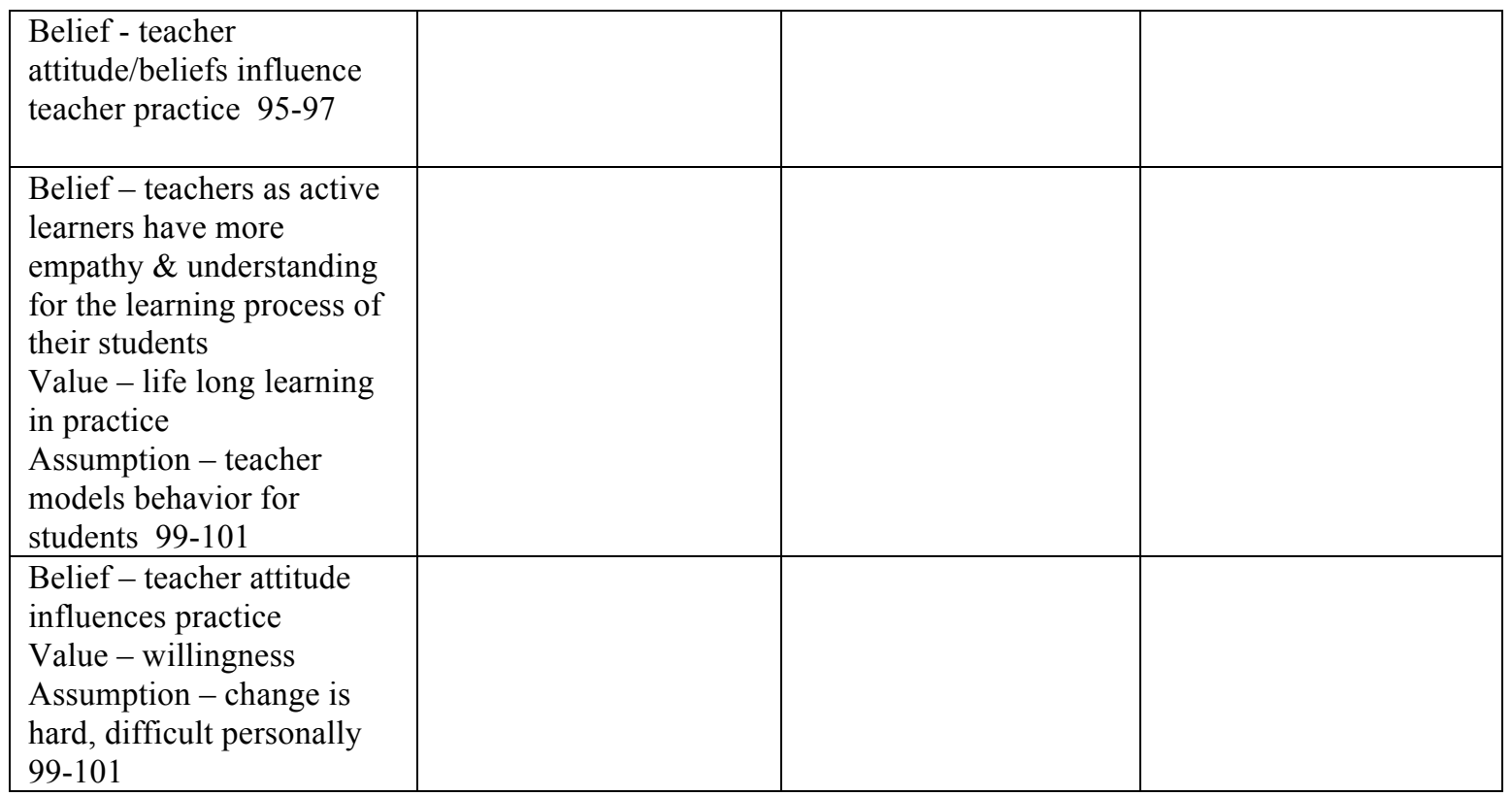

\section{Social Constructivist learning theory}

\begin{tabular}{|c|c|c|c|}
\hline Alexander1968 & Louns/Vars1978 & Carnegie1989 & NMSA2010 \\
\hline $\begin{array}{l}\text { Value - linking } \\
\text { societal realities with } \\
\text { classroom curriculum } \\
\text { and instruction } 10-12\end{array}$ & $\begin{array}{l}\text { Belief- students } \\
\text { actively participate in } \\
\text { their learning, } \\
\text { rejection of empty } \\
\text { minds theory } 1-3\end{array}$ & $\begin{array}{l}\text { Value - learning as self- } \\
\text { constructed with guidance } \\
\text { from teacher } \\
\text { Assumption - learning is an } \\
\text { individual, internal process } \\
42-45\end{array}$ & $\begin{array}{l}\text { Value - becoming a } \\
\text { creator of knowledge as } \\
\text { an outcome; } 13\end{array}$ \\
\hline $\begin{array}{l}\text { Value - student- } \\
\text { centered discussions } \\
\text { Value - having a } \\
\text { purpose to these } \\
\text { discussions, led by a } \\
\text { teacher } \\
\text { Value - adult guidance } \\
\text { Value - exploring } \\
\text { personally relevant } \\
\text { ideas in a peer group } \\
\text { Assumption - teachers } \\
\text { have the capacity to } \\
\text { lead such groups 66- } \\
67\end{array}$ & $\begin{array}{l}\text { Value - learner- } \\
\text { centered education } \\
\text { Value - contexts of } \\
\text { education } \\
\text { Assumption - needs } \\
\text { and contexts change } \\
\text { over time } 34\end{array}$ & $\begin{array}{l}\text { Value - learning in } \\
\text { community } \\
\text { Belief - learning happens } \\
\text { more effectively in } \\
\text { community of peers } \\
\text { Belief - ya as having dev } \\
\text { needs that are related to } \\
\text { learning/instructional } \\
\text { strategies } 42-45\end{array}$ & $\begin{array}{l}\text { Value - student } \\
\text { centered curriculum } \\
\text { Belief- what appeals to } \\
\text { ya is offering opp to } \\
\text { address in school what } \\
\text { is important to them } 17\end{array}$ \\
\hline $\begin{array}{l}\text { Belief- teacher is } \\
\text { mostly a director of } \\
\text { learning, only is a } \\
\text { resource if student is } \\
\text { independently } \\
\text { motivated }\end{array}$ & $\begin{array}{l}\text { Belief-learner as } \\
\text { active participant, not } \\
\text { passive recipient in } \\
\text { schools } 34-37\end{array}$ & $\begin{array}{l}\text { Value - student-centered } \\
\text { instruction/curriculum } 45-49\end{array}$ & $\begin{array}{l}\text { Belief - learning } \\
\text { happens when the } \\
\text { learner is actively } \\
\text { engaged with } \\
\text { contextual tasks that } \\
\text { seem relevant/authentic }\end{array}$ \\
\hline
\end{tabular}




\begin{tabular}{|c|c|c|c|}
\hline $\begin{array}{l}\text { Assumption - learning } \\
\text { is motivated by } \\
\text { external influences } \\
\text { most of the time in the } \\
\text { mg? } 71-73\end{array}$ & & & to the learner 18 \\
\hline $\begin{array}{l}\text { Value - student active } \\
\text { engagement in } \\
\text { learning through } \\
\text { investigation, } \\
\text { problem-posing \& } \\
\text { solving, exploration of } \\
\text { ideas } \\
\text { Belief- constructivist } \\
\text { theory of learning } 78 \text { - } \\
79\end{array}$ & $\begin{array}{l}\text { Value - addressing ya } \\
\text { cog and soc dev by } \\
\text { authentically } \\
\text { exploring } \\
\text { controversial issues } \\
\text { debated in the larger } \\
\text { society } \\
37-38\end{array}$ & $\begin{array}{l}\text { Value - explicitly connecting } \\
\text { instruction with assessment } \\
\text { Value - assessment for } \\
\text { authentic learning } 45-49\end{array}$ & $\begin{array}{l}\text { Value - learner as } \\
\text { active agent, not as } \\
\text { passive consumer } \\
\text { Value - desired } \\
\text { outcomes of education } \\
\text { Assumption - ya are } \\
\text { interested in posing and } \\
\text { exploring self/peer } \\
\text { generated problems } 21\end{array}$ \\
\hline $\begin{array}{l}\text { Value - applying } \\
\text { academic concepts and } \\
\text { skills to everyday } \\
\text { activities and } \\
\text { problems } \\
\text { Assumption - a } \\
\text { separation precedes } \\
\text { the making of a } \\
\text { connection? Or the } \\
\text { curriculum is there to } \\
\text { uncover the } \\
\text { connection? There } \\
\text { seems to be something } \\
\text { here that implies an } a \\
\text { priori separation } 78 \text { - } \\
79\end{array}$ & $\begin{array}{l}\text { Value - learning as } \\
\text { active, engaged } \\
\text { Value - problem } \\
\text { posing and solving as } \\
\text { means of learning } \\
\text { required content } 40- \\
41\end{array}$ & $\begin{array}{l}\text { Belief - learning happens } \\
\text { when engaged with others } \\
49-54\end{array}$ & $\begin{array}{l}\text { Belief - ya learn best } \\
\text { through interaction } \\
\text { Value - dialogue, } \\
\text { interaction } 23\end{array}$ \\
\hline $\begin{array}{l}\text { Value - activity and } \\
\text { reflection } \\
\text { Assumption - a binary } \\
\text { between action and } \\
\text { reflection } 79-81\end{array}$ & $\begin{array}{l}\text { Value - honoring the } \\
\text { student's interests as } \\
\text { assets in the } \\
\text { teaching/learning } \\
\text { dynamic } \\
\text { Assumption - the core } \\
\text { component suggests } \\
\text { innovation from what } \\
\text { is otherwise } \\
\text { "conventional" } 56\end{array}$ & $\begin{array}{l}\text { Value - situated learning, } \\
\text { authenticity in evaluation and } \\
\text { instruction } \\
\text { Assumption - schools of } \\
\text { education are willing and } \\
\text { interested in a primarily } \\
\text { field-based model } 58-60\end{array}$ & \\
\hline $\begin{array}{l}\text { Value - student } \\
\text { responsibility for own } \\
\text { learning } \\
\text { Belief - } \\
\text { inquiry/discovery is a } \\
\text { means for self-directed } \\
\text { learning } \\
\text { Value - self-direction } \\
\text { is a positive outcome } \\
\text { for mg students } 90-94\end{array}$ & $\begin{array}{l}\text { Belief - efforts to } \\
\text { change the curriculum } \\
\text { boil down to the } \\
\text { interactions between } \\
\text { the teachers and the } \\
\text { students, including } \\
\text { how the students } \\
\text { perceive the curr. } \\
\text { Assumption - learning } \\
\text { is relational, happens } \\
\text { as a result of }\end{array}$ & $\begin{array}{l}\text { Value - situated learning } \\
\text { experiences, authentic } \\
\text { learning experiences } \\
\text { Belief - service is part of } \\
\text { good mge, not separate from } \\
\text { mge } 70-77\end{array}$ & \\
\hline
\end{tabular}




\begin{tabular}{|l|l|l|l|}
\hline & $\begin{array}{l}\text { interactions between } \\
\text { subjects }\left({ }^{\text {rd }} \text { space }\right. \\
\text { theory? } 112-114\end{array}$ & & \\
\hline $\begin{array}{l}\text { Belief - less } \\
\text { focus/emphasis on } \\
\text { teacher dominated } \\
\text { classroom will yield a } \\
\text { more creative }\end{array}$ & & & \\
classroom & & & \\
$\begin{array}{l}\text { Value - evaluating } \\
\text { teacher strategies on } \\
\text { the basis of whether or } \\
\text { not creative teaching is } \\
\text { happening 94-95 }\end{array}$ & & & \\
\hline
\end{tabular}

\section{MG as ed reform}

\begin{tabular}{|c|c|c|c|}
\hline Alexander1968 & Louns/Vars1978 & Carnegie1989 & NMSA2010 \\
\hline $\begin{array}{l}\text { Value - educational } \\
\text { reform, innovation } \\
\text { Belief- harder to enact } \\
\text { meaningful reform in an } \\
\text { existing } \\
\text { organization/system } \\
\text { Assumption - the new org } \\
\text { won't carry with it people } \\
\text { with old ideas } 17\end{array}$ & $\begin{array}{l}\text { Value - holistic } \\
\text { approach to education; } \\
\text { school for learning and } \\
\text { growing } \\
\text { METAPHOR: rejection } \\
\text { of factory metaphor of } \\
\text { education xi-xii }\end{array}$ & $\begin{array}{l}\text { Belief - what is } \\
\text { required is a } \\
\text { 'transformation' of mge } \\
9-10\end{array}$ & \\
\hline $\begin{array}{l}\text { Value - evaluating one's } \\
\text { educational program } \\
\text { Value - structural } \\
\text { reorganization based on } \\
\text { educational } \\
\text { needs/priorities, not } \\
\text { building, funding, or other } \\
\text { non-educational reasons } \\
17-19\end{array}$ & $\begin{array}{l}\text { Belief - the core } \\
\text { component proposal } \\
\text { reflects progressive } \\
\text { (early } 20^{\text {th }} \text { century) } \\
\text { educational } \\
\text { philosophies, it is } \\
\text { connected to something } \\
\text { larger than itself } 57\end{array}$ & & \\
\hline $\begin{array}{l}\text { Value - curriculum plans } \\
\text { as tentative - does that } \\
\text { mean evolving? Under } \\
\text { constant review? } 63\end{array}$ & $\begin{array}{l}\text { Belief - seeing a } \\
\text { convergence of } \\
\text { (recent?) ideas about } \\
\text { learning, teaching, and } \\
\text { human development } \\
\text { allows educators to } \\
\text { consider mg as a potent } \\
\text { site of reform } \\
\text { METAPHOR: teacher } \\
\text { as being "freed" 112- } \\
114\end{array}$ & & \\
\hline $\begin{array}{l}\text { Value - curricula should } \\
\text { be distinguished by } \\
\text { purpose }\end{array}$ & & & \\
\hline
\end{tabular}




\begin{tabular}{|l|l|l|l|}
\hline $\begin{array}{l}\text { Belief - Rejection of } \\
\text { traditional devaluing of }\end{array}$ & & & \\
Some learning & & & \\
opportunities by labeling & & & \\
them extracurricular 64- & & & \\
65 & & & \\
\hline $\begin{array}{l}\text { Value - evaluating } \\
\text { innovations }\end{array}$ & & & \\
Belief - experimental & & & \\
teaching practices should & & & \\
be evaluated 95-97 & & & \\
\hline
\end{tabular}

\section{Differentiation/Seeing the sum, seeing the parts}

\begin{tabular}{|c|c|c|c|}
\hline Alexander1968 & Louns/Vars1978 & Carnegie1989 & NMSA2010 \\
\hline $\begin{array}{l}\text { Belief - knowledge is } \\
\text { substantively different } \\
\text { (greater in quantity) than } \\
\text { in previous times } \\
10-12\end{array}$ & $\begin{array}{l}\text { Belief- diversity } \\
\text { reflected in human } \\
\text { development (other } \\
\text { sources of diversity not } \\
\text { mentioned) 34-37 }\end{array}$ & $\begin{array}{l}\text { Belief - ya have } \\
\text { distinctly higher levels } \\
\text { of variability in learning } \\
\text { preferences, rates, and } \\
\text { styles } 49-54\end{array}$ & $\begin{array}{l}\text { Value }- \text { seeing the } \\
\text { individual student, } \\
\text { making adaptations } 19\end{array}$ \\
\hline $\begin{array}{l}\text { Value - zooming from } \\
\text { individualization to } \\
\text { whole group and back } \\
\text { again (see p. } 29 \text { in } \\
\text { journal) 12-14 }\end{array}$ & $\begin{array}{l}\text { Belief - individualized } \\
\text { learning happens in a } \\
\text { collaborative } \\
\text { community } 40-41 \\
\text { ( } 5 / 23 \text { : ICode is } \\
\text { "relationships") }\end{array}$ & & $\begin{array}{l}\text { Value - seeing the } \\
\text { individual student, } \\
\text { making adaptations } \\
\text { NOTE: Stage-fit theory } \\
\text { Assumption - it is } \\
\text { possible for teachers to } \\
\text { understand student } \\
\text { needs } 19\end{array}$ \\
\hline \multirow[t]{3}{*}{$\begin{array}{l}\text { Assumption - } \\
\text { knowledge is organized } \\
83-86\end{array}$} & $\begin{array}{l}\text { PARADOX - unique } \\
\text { learning needs met best } \\
\text { through collaborative } \\
\text { study? 40-41 }\end{array}$ & & $\begin{array}{l}\text { ANALOGY: ya as } \\
\text { explorers } \\
\text { METAPHOR: MG } \\
\text { school as "the finding } \\
\text { place" } 20\end{array}$ \\
\hline & $\begin{array}{l}\text { Value - curriculum } \\
\text { design guided by two } \\
\text { motivations: common } \\
\text { goals of society and } \\
\text { individual } \\
\text { preferences/needs of } \\
\text { learners } \\
\text { Belief - curriculum is } \\
\text { "sound" when guided in } \\
\text { a balanced way by both } \\
42\end{array}$ & & $\begin{array}{l}\text { Value - student needs } \\
35\end{array}$ \\
\hline & & & $\begin{array}{l}\text { Belief - different adults } \\
\text { have different skills sets } \\
\text { with which to promote }\end{array}$ \\
\hline
\end{tabular}




\begin{tabular}{|l|l|l|l|}
\hline & & & $\begin{array}{l}\text { ya groth } \\
\text { Value }- \text { that they work } \\
\text { together 37 }\end{array}$ \\
\hline
\end{tabular}


Appendix F

BVA by FCC, Spirituality as a Developmental Domain

\section{Constructing spirituality in the academy}

\begin{tabular}{|c|c|c|}
\hline Fowler 1981 & Benson 2006 & $\begin{array}{l}\text { Oser, Scarlett, Bucher } \\
2006\end{array}$ \\
\hline $\begin{array}{l}\text { Assumption: it is possible to } \\
\text { understand faith, to describe } \\
\text { faith } \\
\text { xii }\end{array}$ & $\begin{array}{l}\text { Value: scientific study of } \\
\text { religious and spiritual } \\
\text { development } \\
\text { Belief: critique of } \\
\text { psychology's alienation of } \\
\text { the study of spiritual } \\
\text { development } \\
484\end{array}$ & $\begin{array}{l}\text { Belief: spdev involves } \\
\text { change, transformation } \\
\text { Value: theoretical } \\
\text { perspectives that } \\
\text { include/address the process } \\
\text { of transformation } \\
\text { Belief: spdev is normative } \\
942-943\end{array}$ \\
\hline $\begin{array}{l}\text { Value: rigorous scholarship } \\
\text { Assumption: faith theory can } \\
\text { be criticized on the grounds } \\
\text { of not meeting the academic } \\
\text { community's criteria for } \\
\text { scholarship } \\
\text { Belief: scholarly writing can } \\
\text { be rigorous and personal } \\
\text { Assumption: seeing a binary } \\
\text { between } \\
\text { scholarship/personal? xii }\end{array}$ & $\begin{array}{l}\text { Value: distinguishing } \\
\text { between spirituality and } \\
\text { spiritual development } \\
\text { Belief: the distinction is } \\
\text { analogous to } \\
\text { cognition/cognitive } \\
\text { development 484-486 }\end{array}$ & $\begin{array}{l}\text { Assumption: without a } \\
\text { theory that } \\
\text { captures/explains 'pure' } \\
\text { spdev, spdev must be } \\
\text { explored in conjunction } \\
\text { with religious dev (that is } \\
\text { the best alternative) } \\
\text { Assumption: something } \\
\text { about not making } \\
\text { distinctions between r and } \\
\text { s that are based on social } \\
\text { constructs (seeing both r } \\
\text { and s as essential/social } \\
\text { construct-free?) } 942-943\end{array}$ \\
\hline $\begin{array}{l}\text { Belief: faith is a capacity } \\
\text { whose trajectory/growth is } \\
\text { influenced by environmental } \\
\text { factors. xiii }\end{array}$ & $\begin{array}{l}\text { Belief: complexities of } \\
\text { defining spirituality } \\
\text { enhanced by } \\
\text { multidimensionality } \\
\text { Belief: spirituality is } \\
\text { psychological, moral, } \\
\text { cognitive, affective, and } \\
\text { emotional 484-486 }\end{array}$ & $\begin{array}{l}\text { Belief: theory of spdev is } \\
\text { normative } \\
\text { Value: higher levels of dev } \\
\text { Belief: advanced dev has } \\
\text { significant impact on social } \\
\text { problems } 943\end{array}$ \\
\hline $\begin{array}{l}\text { Belief: faith may or may not } \\
\text { be linked with religion; a } \\
\text { "secular" faith? 4-5 }\end{array}$ & $\begin{array}{l}\text { Belief: spdev can refer to a } \\
\text { domain, a process of } \\
\text { integration, a renaming of } \\
\text { certain phenomena (eg, }\end{array}$ & $\begin{array}{l}\text { Belief: increased interest in } \\
\text { religiosity and spirituality } \\
\text { in postmodern era } \\
\text { Belief: current scientific }\end{array}$ \\
\hline
\end{tabular}




\begin{tabular}{|c|c|c|}
\hline & awe) 984 & $\begin{array}{l}\text { perspective sees spirituality } \\
\text { as essential part of being } \\
\text { human } 944-946\end{array}$ \\
\hline $\begin{array}{l}\text { Belief: faith is a universal } \\
\text { human concern } \\
\text { Value: construct of faith } \\
\text { independent of the } \\
\text { commonly-held religious } \\
\text { construct } 5\end{array}$ & $\begin{array}{l}\text { Value: theoretical, empirical } \\
\text { clarity Value: } \\
\text { comprehension, } \\
\text { identification of what is } \\
\text { meant by 'spiritual', } \\
\text { connection beyond human } \\
\text { dev theory } 486\end{array}$ & $\begin{array}{l}\text { Belief: no commonly } \\
\text { accepted definition of } \\
\text { religion or spirituality } \\
\text { Value: identifying } \\
\text { distinctions instead of } \\
\text { definitions } \\
\text { Assumption: clear } \\
\text { definition is a } \\
\text { standard/criteria for } \\
\text { science } 952-953\end{array}$ \\
\hline $\begin{array}{l}\text { Belief: faith development is } \\
\text { "natural" (essentialized) 5-8 }\end{array}$ & $\begin{array}{l}\text { Value: a spdev theory that } \\
\text { clarifies the interaction } \\
\text { between person and context } \\
486-487\end{array}$ & $\begin{array}{l}\text { Belief: distinction between } \\
\text { transcendence and } \\
\text { philosophy } \\
\text { Belief: shifting emphasis } \\
\text { exist on what constitutes } \\
\text { the core elements of } \\
\text { spirituality 953-954 }\end{array}$ \\
\hline $\begin{array}{l}\text { Belief: faith is distinct from } \\
\text { religion } \\
\text { Assumption: faith and } \\
\text { religion are separate } \\
\text { categories } \\
\text { Value: a dynamic and } \\
\text { "reciprocal" (9) relationship } \\
\text { between faith and religion 9- } \\
10\end{array}$ & $\begin{array}{l}\text { Value: secular theory of } \\
\text { spdev } \\
489\end{array}$ & $\begin{array}{l}\text { Belief: spdev as a construct } \\
\text { is complex, multifaceted } \\
\text { Belief: spdev involves } \\
\text { individual process and } \\
\text { environmental influences } \\
954\end{array}$ \\
\hline $\begin{array}{l}\text { Belief: faith and belief, as } \\
\text { constructs? as } \\
\text { phenomenons? are different } \\
\text { from each other } \\
\text { Assumptions: faith is } \\
\text { confused for belief in } \\
\text { contemporary (Western?) } \\
\text { society (see } 10,13 \text { ) } \\
10-14\end{array}$ & $\begin{array}{l}\text { Belief: the animating forces } \\
\text { of spdev can be explained in } \\
\text { different approaches: } \\
\text { cognitive-cultural, natural } \\
\text { spiritual awareness of holy, } \\
\text { developmental systems, } \\
\text { narrative-making } 489-490\end{array}$ & $\begin{array}{l}\text { Belief: both religiousness } \\
\text { and spirituality are } \\
\text { "grounded in faith" } 954 \\
\text { Belief: spirituality as } \\
\text { relevant in the social } \\
\text { sciences has been } \\
\text { downplayed because of } \\
\text { secularization of faith as } \\
\text { belief (not as a verb, } \\
\text { participate) } 954\end{array}$ \\
\hline $\begin{array}{l}\text { Value: separating faith from } \\
\text { belief (belief in the current } \\
\text { understanding as a } \\
\text { proposition of knowledge, } \\
\text { knowledge understood as }\end{array}$ & $\begin{array}{l}\text { Value: a collaborative } \\
\text { approach to studying and } \\
\text { theorizing about spdev } \\
\text { Assumption: deep levels of } \\
\text { effective communication }\end{array}$ & $\begin{array}{l}\text { Belief: studying content, } \\
\text { form and functions of } \\
\text { spirituality offers some, but } \\
\text { not sufficient, } \\
\text { understanding of the }\end{array}$ \\
\hline
\end{tabular}




\begin{tabular}{|c|c|c|}
\hline $\begin{array}{l}\text { "empirically demonstrable } \\
\text { facts" 13) } \\
\text { Assumption: faith can be } \\
\text { described in language 13-14 }\end{array}$ & $\begin{array}{l}\text { amongst multiple } \\
\text { participants is possible } 493\end{array}$ & $\begin{array}{l}\text { development of spirituality } \\
955-956\end{array}$ \\
\hline \multicolumn{3}{|l|}{$\begin{array}{l}\text { Value: a critique of talking } \\
\text { about faith as something } \\
\text { compartmentalized, as a } \\
\text { domain? } \\
13-14\end{array}$} \\
\hline $\begin{array}{l}\text { Belief: the use of the term } \\
\text { faith has definitional and } \\
\text { discursive complications and } \\
\text { controversy } \\
91-92\end{array}$ & $\begin{array}{l}\text { Belief: spiritual thriving as } \\
\text { an operational synonym for } \\
\text { spiritual development } 493 \text { - } \\
494\end{array}$ & $\begin{array}{l}\text { Belief: Fowler's broad } \\
\text { definition of faith is too } \\
\text { broad to be helpful/useful, } \\
\text { empirically 959-961, 964- } \\
965\end{array}$ \\
\hline $\begin{array}{l}\text { Belief: studying how people } \\
\text { know is part of studying } \\
\text { faith development } 98-106\end{array}$ & & $\begin{array}{l}\text { Value: holistic approach to } \\
\text { constructing spdev theory } \\
\text { Assumption: something } \\
\text { about the distinction } \\
\text { around a "whole" person - } \\
\text { what is an "unwhole" } \\
\text { person, from a dev theory } \\
\text { approach? 967-968 }\end{array}$ \\
\hline $\begin{array}{l}\text { Value: restraint in norming } \\
\text { faith development balanced } \\
\text { with describing the } \\
\text { increased sophistication of } \\
\text { structural operations in later } \\
\text { stages } 101\end{array}$ & & $\begin{array}{l}\text { Belief: children are } \\
\text { spiritual } \\
\text { Belief: human spirituality } \\
\text { is inherent } 968-970\end{array}$ \\
\hline $\begin{array}{l}\text { Belief: not all people } \\
\text { transition/adapt to higher } \\
\text { stages of faith development } \\
106-109\end{array}$ & & $\begin{array}{l}\text { Belief: concepts and } \\
\text { actions are viewed as } \\
\text { spiritual/not spiritual } \\
\text { depending on the context } \\
\text { Value: in theory, being } \\
\text { explicit about context } 972\end{array}$ \\
\hline $\begin{array}{l}\text { Belief: transition to } \\
\text { subsequent faith stage } \\
\text { doesn't happen for everyone } \\
172-173\end{array}$ & & $\begin{array}{l}\text { Belief: children operate } \\
\text { with both intuitive and } \\
\text { counterintuitive ontologies } \\
\text { esp. with religious/spiritual } \\
\text { constructs } \\
\text { Assumption: it is possible } \\
\text { to know/describe a } \\
\text { person's ontological } \\
\text { perspective(s) 972-976 }\end{array}$ \\
\hline Belief: in the existence of a & & Belief: spdev as a \\
\hline
\end{tabular}




\begin{tabular}{|l|l|l|}
\hline “deeper self" (198) & $\begin{array}{l}\text { phenomenon } \\
\text { Value: a theory of spdev } \\
\text { that clarifies meanings and } \\
\text { draw from empirical } \\
\text { research 986-987 }\end{array}$ \\
\hline & $\begin{array}{l}\text { Belief: theory of rel and } \\
\text { spdev has been hindered by } \\
\text { bias in the field of social } \\
\text { science research 986-987 }\end{array}$ \\
\hline
\end{tabular}

\section{Theorizing about human development}

\begin{tabular}{|c|c|c|}
\hline Fowler 1981 & Benson 2006 & Oser, Scarlett, Bucher 2006 \\
\hline $\begin{array}{l}\text { Value: a theory on } \\
\text { human dev. that allows } \\
\text { for change and } \\
\text { continuity, for } \\
\text { uniqueness and } \\
\text { generality } \\
\text { Assumption: there is } \\
\text { such a middle ground; } \\
\text { implies duality } 89-90\end{array}$ & $\begin{array}{l}\text { Belief: human dev can be } \\
\text { characterized by three } \\
\text { dynamics: core processes, } \\
\text { goals, and contexts } \\
\text { Assumption: } \\
\text { characterizing human dev } \\
\text { in terms of } \\
\text { goals/purpose/desired } \\
\text { outcome } 485-486\end{array}$ & $\begin{array}{l}\text { Belief: in 'pure' domains of } \\
\text { development } 942-943\end{array}$ \\
\hline \multicolumn{3}{|l|}{$\begin{array}{l}\text { Value: formality of stage } \\
\text { theory needs to be } \\
\text { balanced with individual } \\
\text { accounts in order to be } \\
\text { complete } 89-90\end{array}$} \\
\hline $\begin{array}{l}\text { Value: articulating } \\
\text { patterns of human } \\
\text { development } \\
\text { Assumption: intrinsic } \\
\text { structures exist 99-100 }\end{array}$ & $\begin{array}{l}\text { Value: structure of a } \\
\text { formal theory } 486\end{array}$ & $\begin{array}{l}\text { Belief: human development } \\
\text { occurs in definable, sequential } \\
\text { stages } \\
\text { Value: approach as a 'paradigm' } \\
943\end{array}$ \\
\hline $\begin{array}{l}\text { Belief: development } \\
\text { involves subject and } \\
\text { environment } \\
\text { Assumption: the word } \\
\text { "subject" implies a } \\
\text { passivity and a } \\
\text { singularity (the focus is }\end{array}$ & $\begin{array}{l}\text { Value: practical } \\
\text { application of theory } \\
\text { Value: positive youth } \\
\text { development \& } \\
\text { prevention of risk } \\
\text { Assumption: theory can } \\
\text { positively impact practice }\end{array}$ & $\begin{array}{l}\text { Belief: development as a } \\
\text { adaptive, dynamic process } \\
\text { between subject and environment } \\
\text { Value: approach as a 'paradigm' } \\
943\end{array}$ \\
\hline
\end{tabular}




\begin{tabular}{|c|c|c|}
\hline $\begin{array}{l}\text { on individual dev., not } \\
\text { collective/communal } \\
\text { dev.) } 100\end{array}$ & 486 & \\
\hline $\begin{array}{l}\text { Belief: human lifespan } \\
\text { has distinct periods of } \\
\text { crisis or tasks; these } \\
\text { periods can be described } \\
\text { in terms of } \\
\text { common/universal } \\
\text { patterns } 110-114\end{array}$ & $\begin{array}{l}\text { Belief: human } \\
\text { development is } \\
\text { influenced by } \\
\text { environment/systems } \\
486-487\end{array}$ & $\begin{array}{l}\text { Assumption: sources for } \\
\text { paradigms come from published } \\
\text { authorizes (eg, Hall, Freud) 946- } \\
952 \\
\text { - Assumption: rational is standard } \\
\text { for science 952-953 }\end{array}$ \\
\hline $\begin{array}{l}\text { Belief: interactions } \\
\text { between environment } \\
\text { (caregivers) and } \\
\text { individual influence } \\
\text { development } \\
\text { Belief: transitions to next } \\
\text { stage accompanied } \\
\text { by/caused by new } \\
\text { cognitive structures (eg, } \\
\text { "convergence of thought } \\
\text { and language" 121) 121 }\end{array}$ & $\begin{array}{l}\text { Belief: development is } \\
\text { produced } \\
\text { Belief: individuals } \\
\text { influence their own } \\
\text { development } 486-487\end{array}$ & $\begin{array}{l}\text { Assumption: human } \\
\text { development as sequential, } \\
\text { progressive, normative (more is } \\
\text { better) 586-587 }\end{array}$ \\
\hline $\begin{array}{l}\text { Assumption: distinctions } \\
\text { exist between life stages } \\
\text { (ie, that there are distinct } \\
\text { stages) } 197-198\end{array}$ & $\begin{array}{l}\text { Value: being explicit } \\
\text { about what human } \\
\text { development is (as a } \\
\text { construct) in any theory } \\
\text { of spdev } 486-487\end{array}$ & $\begin{array}{l}\text { Value: identifying and } \\
\text { addressing criticisms } \\
\text { Value: use of logical reasoning } \\
\text { and empirical research to } \\
\text { describe and refute alternative } \\
\text { points of view } 966-967\end{array}$ \\
\hline $\begin{array}{l}\text { Value: balance between } \\
\text { description and norming } \\
\text { Belief: normative dev. } \\
\text { theories bad? Risky? } \\
\text { Value: empiricism } 199\end{array}$ & $\begin{array}{l}\text { Belief: human dev theory } \\
\text { must address } 2 \\
\text { phenomena: variability } \\
\text { and "appetite" } \\
\text { METAPHOR: "what it is } \\
\text { that animates" as an } \\
\text { "appetite" } \\
\text { Value: comprehensive } \\
\text { theory } 487\end{array}$ & $\begin{array}{l}\text { Assumption: only two } \\
\text { conceptions of human } \\
\text { development } \\
\text { METAPHOR: human } \\
\text { development as an "upward } \\
\text { climb"; developmental as in } \\
\text { motion, vertical orientation } 967\end{array}$ \\
\hline $\begin{array}{l}\text { Belief: Piagetian } \\
\text { structuralism has a } \\
\text { formal, rigid quality that } \\
\text { fails to capture the } \\
\text { affective/personality } \\
\text { qualities of human }\end{array}$ & $\begin{array}{l}\text { Value: theorizing that is } \\
\text { culturally } \\
\text { responsive/inclusive } \\
\text { Value: final theory that is } \\
\text { inclusive } 488-489\end{array}$ & $\begin{array}{l}\text { Belief: developmental systems } \\
\text { approach } \\
\text { Belief: interplay between persons } \\
\text { and contexts } 971-972\end{array}$ \\
\hline
\end{tabular}




\begin{tabular}{|c|c|c|}
\hline \multicolumn{3}{|l|}{ development 271-273 } \\
\hline $\begin{array}{l}\text { Belief: Fowler } \\
\text { characterizes the "Piaget- } \\
\text { Kohlberg paradigm." } 272 \\
\text { Value: holistic view of } \\
\text { human development } \\
270-273\end{array}$ & $\begin{array}{l}\text { Value: human } \\
\text { development from a } \\
\text { humanist perspective } \\
\text { over a Freudian } \\
\text { perspective } \\
\text { Assumption: binary } \\
\text { between human strengths } \\
\text { and deficits } 489-490\end{array}$ & $\begin{array}{l}\text { Assumption: positivist ontology } \\
\text { Value: the (exclusive) use of } \\
\text { empirical research to validate } \\
\text { theory } 972-976\end{array}$ \\
\hline $\begin{array}{l}\text { Value: distinguishing } \\
\text { between the structures } \\
\text { (operations?) of faith and } \\
\text { contents of faith } 272-273\end{array}$ & $\begin{array}{l}\text { Belief: developmental } \\
\text { systems approach } \\
\text { Belief: interplay between } \\
\text { persons and contexts } \\
490-491\end{array}$ & $\begin{array}{l}\text { Belief: human development as a } \\
\text { series of adaptations between } \\
\text { individual and environment(s) } \\
\text { Assumption: subjectivist } \\
\text { ontology } 976-977\end{array}$ \\
\hline \multirow[t]{2}{*}{$\begin{array}{l}\text { Belief: human } \\
\text { development can be } \\
\text { described in distinct } \\
\text { domains, but } \\
\text { development in one } \\
\text { domain affects } \\
\text { development in another } \\
\text { domain } 275-276 \\
\end{array}$} & $\begin{array}{l}\text { Belief: historical context } \\
\text { and age-specific } \\
\text { developmental tasks } \\
\text { influence human } \\
\text { development } \\
\text { Assumption: linear time } \\
491\end{array}$ & $\begin{array}{l}\text { Value: citing empirical research } \\
\text { to validate theory } \\
\text { Assumption: positivism } 977-980\end{array}$ \\
\hline & $\begin{array}{l}\text { Assumption: travel } \\
\text { implies development as } \\
\text { motion, road implies a } \\
\text { clearly bounded path } 492\end{array}$ & \\
\hline \multirow[t]{2}{*}{$\begin{array}{l}\text { Note: Fowler1981 } \\
\text { included chapters on } \\
\text { human dev theory that } \\
\text { were not ICoded for } \\
\text { this research. }\end{array}$} & $\begin{array}{l}\text { Belief: more knowledge } \\
\text { and research on spdev } \\
\text { theory will positively } \\
\text { influence other areas of } \\
\text { human dev theory and } \\
\text { research } \\
\text { Assumption: empiricism } \\
\text { of developmental } \\
\text { sciences } 492-493\end{array}$ & $\begin{array}{l}\text { Value: citing empirical research } \\
\text { to validate theory } \\
\text { Assumption: positivism } \\
\text { Value: research that can be } \\
\text { generalized } 981-982\end{array}$ \\
\hline & $\begin{array}{l}\text { Belief: } \\
\text { development/thriving can } \\
\text { be encouraged and } \\
\text { compromised } \\
\text { (influenceable) } \\
\text { Value: process over } \\
\text { product 493-494 }\end{array}$ & $\begin{array}{l}\text { Value: theory of human } \\
\text { development that is normative } \\
\text { Belief: stage-structural human } \\
\text { dev theory is appropriate for } \\
\text { offering developmental norms } \\
\text { Assumption: it's possible to } \\
\text { know right now what will } \\
\text { "always" be needed 990-991 }\end{array}$ \\
\hline
\end{tabular}


Paradox as a Heuristic

\begin{tabular}{|c|c|c|}
\hline Fowler 1981 & Benson 2006 & $\begin{array}{l}\text { Oser, Scarlett, Bucher } \\
2006\end{array}$ \\
\hline $\begin{array}{l}\text { Belief: scholarly writing can } \\
\text { be rigorous and personal } \\
\text { Assumption: seeing a binary } \\
\text { between } \\
\text { scholarship/personal? xii }\end{array}$ & $\begin{array}{l}\text { "Push and Pull" ICode p. } \\
492 ?\end{array}$ & $\begin{array}{l}\text { Belief: stage-structural } \\
\text { theoretical approaches are } \\
\text { essential for fully } \\
\text { understanding spdev 956- } \\
957\end{array}$ \\
\hline $\begin{array}{l}\text { Value: allowing for paradox } \\
\text { of the effort to clarify and the } \\
\text { letting go of complexity of } \\
\text { faith theory xiii-xiv }\end{array}$ & & $\begin{array}{l}\text { Belief: rel/spdev can be } \\
\text { considered a separate dev } \\
\text { domain that is inter-related } \\
\text { with other dev domains } \\
970-971\end{array}$ \\
\hline $\begin{array}{l}\text { Note: the serious play is } \\
\text { quoting Erikson } \\
\text { Belief: faith is both unique } \\
\text { and predictable (paradox) } \\
\text { xiii-xiv }\end{array}$ & & $\begin{array}{l}\text { Belief: children operate with } \\
\text { both intuitive and } \\
\text { counterintuitive ontologies } \\
\text { esp. with religious/spiritual } \\
\text { constructs } 972-976\end{array}$ \\
\hline $\begin{array}{l}\text { Value: explanatory power of } \\
\text { a theory AND particularities } \\
\text { of personal experiences } 89-90\end{array}$ & & $\begin{array}{l}\text { Value: theory that can } \\
\text { identify universal patterns } \\
\text { AND allow for diverse } \\
\text { manifestations } 990-991\end{array}$ \\
\hline \multicolumn{3}{|l|}{$\begin{array}{l}\text { Value: restraint in norming } \\
\text { faith development balanced } \\
\text { with describing the increased } \\
\text { sophistication of structural } \\
\text { operations in later stages } 101\end{array}$} \\
\hline \multicolumn{3}{|l|}{$\begin{array}{l}\text { Belief: faith involves } \\
\text { rationality and passion } \\
\text { (affect, emotion) } \\
\text { Assumption: binary of } \\
\text { rationality and passion } 270 \text { - } \\
273\end{array}$} \\
\hline & & \\
\hline & & \\
\hline
\end{tabular}




\section{Crucibles of Spiritual Development}

\begin{tabular}{|c|c|c|}
\hline Fowler 1981 & Benson 2006 & $\begin{array}{l}\text { Oser, Scarlett, Bucher } \\
2006\end{array}$ \\
\hline $\begin{array}{l}\text { Value: writing/reading this } \\
\text { book as a communication } \\
\text { experience; personal } \\
\text { experience of writing and } \\
\text { reading xii }\end{array}$ & $\begin{array}{l}\text { Assumption: theory can } \\
\text { positively impact practice } \\
486\end{array}$ & $\begin{array}{l}\text { Belief: development as a } \\
\text { adaptive, dynamic } \\
\text { process between subject } \\
\text { and environment } 943\end{array}$ \\
\hline $\begin{array}{l}\text { Belief: faith is a capacity } \\
\text { whose trajectory/growth is } \\
\text { influenced by environmental } \\
\text { factors. xiii }\end{array}$ & $\begin{array}{l}\text { Belief: human development } \\
\text { is influenced by } \\
\text { environment/systems } \\
\text { Value: a spdev theory that } \\
\text { clarifies the interaction } \\
\text { between person and context } \\
486-487\end{array}$ & $\begin{array}{l}\text { Belief: spdev involves } \\
\text { individual process and } \\
\text { environmental influences } \\
954\end{array}$ \\
\hline $\begin{array}{l}\text { Belief: part of the defining } \\
\text { quality of faith is how it is } \\
\text { treated by others } \\
\text { Belief: the "shape of faith" is } \\
\text { affected by environmental } \\
\text { factors xiii }\end{array}$ & $\begin{array}{l}\text { Belief: cultural context } \\
\text { influences spiritual } \\
\text { development } \\
\text { Assumption: binary } \\
\text { between individual and } \\
\text { collective } 488-489 \\
\end{array}$ & $\begin{array}{l}\text { Belief: spirituality can be } \\
\text { influenced by the } \\
\text { environment (parents, } \\
\text { etc.) } 968-970\end{array}$ \\
\hline $\begin{array}{l}\text { Belief: human beings need to } \\
\text { comprehend their own purpose } \\
\text { in the greater context of their } \\
\text { community, environment } 3-5\end{array}$ & $\begin{array}{l}\text { Belief: developmental } \\
\text { systems approach } \\
\text { Belief: interplay between } \\
\text { persons and contexts 490- } \\
491\end{array}$ & $\begin{array}{l}\text { Belief: human } \\
\text { development as a series } \\
\text { of adaptations } \\
\text { Belief: development } \\
\text { occurs within the } \\
\text { exchanges between an } \\
\text { individual and the } \\
\text { environment 971-972 }\end{array}$ \\
\hline $\begin{array}{l}\text { Belief: faith } \\
\text { guides/influences/determines } \\
\text { other aspects of being human? } \\
13-14\end{array}$ & $\begin{array}{l}\text { Belief: a developmental } \\
\text { process happens because of } \\
\text { the interactions } \\
\text { between/amongst } \\
\text { relationships } 490-491\end{array}$ & $\begin{array}{l}\text { Belief: human } \\
\text { development as a series } \\
\text { of adaptations between } \\
\text { individual and } \\
\text { environment(s) } \\
\text { Assumption: subjectivist } \\
\text { ontology 976-977 }\end{array}$ \\
\hline $\begin{array}{l}\text { Belief: development involves } \\
\text { subject and environment } 100\end{array}$ & $\begin{array}{l}\text { Value: influence of life } \\
\text { events on human } \\
\text { development } 491\end{array}$ & $\begin{array}{l}\text { Belief: spdev as social } \\
\text { constructivism } \\
\text { Assumption: } \\
\text { constructivist }\end{array}$ \\
\hline
\end{tabular}




\begin{tabular}{|l|l|l|}
\hline & epistemology 977-979 \\
\hline $\begin{array}{l}\text { Value: seeing faith } \\
\text { development as something } \\
\text { which can be actively } \\
\text { influenced by others (eg, } \\
\text { educators) 110-114 }\end{array}$ & $\begin{array}{l}\text { Belief: language shapes } \\
\text { thinking } \\
\text { Value: a view of spdev that } \\
\text { addresses cultural } \\
\text { influence, and views that } \\
\text { influence as bidirectional } \\
\text { Belief: one's spdev affected } \\
\text { by social norms about } \\
\text { spdev 491-492 }\end{array}$ & $\begin{array}{l}\text { Belief: spdev as a } \\
\text { process of integrating } \\
\text { increasingly adapative } \\
\text { functions 990-991 }\end{array}$ \\
\hline $\begin{array}{l}\text { Belief: interactions between } \\
\text { environment (caregivers) and } \\
\text { individual influence } \\
\text { development } \\
\text { Belief: transitions to next stage } \\
\text { accompanied by/caused by new } \\
\text { cognitive structures (eg, } \\
\text { "convergence of thought and } \\
\text { language" } 121 \text { ) 121 }\end{array}$ & $\begin{array}{l}\text { Belief: more knowledge } \\
\text { and research on spdev } \\
\text { theory will positively } \\
\text { influence other areas of } \\
\text { human dev theory and } \\
\text { research 492-493 }\end{array}$ & \\
\hline $\begin{array}{l}\text { Belief: individuals are } \\
\text { strongly/deeply influenced by } \\
\text { the stories they are exposed to } \\
\text { as children (ages 3-7) 133-134 }\end{array}$ & $\begin{array}{l}\text { Value: collaboration with } \\
\text { other researchers \& } \\
\text { practitioners 493 }\end{array}$ & \\
\hline $\begin{array}{l}\text { Belief: the intertwinement of } \\
\text { cognition and faith } \\
\text { development } \\
149-150\end{array}$ & $\begin{array}{l}\text { Belief: } \\
\text { development/thriving can } \\
\text { be encouraged and } \\
\text { compromised } \\
\text { influenceable) } \\
\text { Value: process over product } \\
493-494\end{array}$ & \\
\hline $\begin{array}{l}\text { Belief: faith dev. intertwined } \\
\text { with cognitive operations 172- } \\
173\end{array}$ & & \\
\hline $\begin{array}{l}\text { Belief: faith development } \\
\text { intertwined with identity } \\
\text { development 182-183 }\end{array}$ & $\begin{array}{l}\text { Belief: correlational } \\
\text { relationship between faith } \\
\text { stages and life stages 197-198 }\end{array}$ & \\
\hline
\end{tabular}


Belief: human development can be described in distinct domains, but development in one domain affects development in another domain 275-276

\section{Contents of domain of spiritual development}

\begin{tabular}{|l|l|l|}
\hline Fowler 1981 & Benson 2006 & Oser, Scarlett, Bucher 2006 \\
\hline $\begin{array}{l}\text { Belief: faith is a protective } \\
\text { element against aloneness, } \\
\text { instability, chaos, } \\
\text { uncertainty xi }\end{array}$ & $\begin{array}{l}\text { Belief: faith part of } \\
\text { spirituality 484 }\end{array}$ & $\begin{array}{l}\text { Assumption: without a theory } \\
\text { that captures/explains 'pure' } \\
\text { spdev, spdev must be } \\
\text { explored in conjunction with } \\
\text { religious dev (that is the best } \\
\text { alternative) } \\
\text { Assumption: something about } \\
\text { not making distinctions } \\
\text { between r and s that are based } \\
\text { on social constructs (seeing } \\
\text { both r and s as } \\
\text { essential/social construct- } \\
\text { free?) 942-943 }\end{array}$ \\
\hline $\begin{array}{l}\text { Belief: faith is manifested } \\
\text { by patterns of trust and } \\
\text { commitment } \\
\text { xii }\end{array}$ & $\begin{array}{l}\text { Value: distinguishing } \\
\text { between spirituality and } \\
\text { spiritual development } \\
484-486\end{array}$ & $\begin{array}{l}\text { Belief: spdev (along with } \\
\text { reldev) is a distinct domain of } \\
\text { human development } \\
\text { Assumption: positivist } \\
\text { ontology 943-944 }\end{array}$ \\
\hline $\begin{array}{l}\text { Belief: faith is a universal } \\
\text { human experience xiii }\end{array}$ & $\begin{array}{l}\text { Belief: goals of spdev are } \\
\text { connectedness, meaning, } \\
\text { purpose, and contribution } \\
485-486\end{array}$ & $\begin{array}{l}\text { Value: providing historical } \\
\text { context for the study of spdev } \\
\text { Belief: rel and spdev } \\
\text { explained as maturing, } \\
\text { coping, and perfecting 946- } \\
\text { 952 }\end{array}$ \\
\hline $\begin{array}{l}\text { Belief: faith development } \\
\text { has qualities of movement }\end{array}$ & $\begin{array}{l}\text { Belief: spdev theory can, } \\
\text { but does not have to, } \\
\text { include religious beliefs, } \\
\text { practices, doctrine } \\
\text { Value: a secular, } \\
\text { empirical definition of } \\
\text { spiritual development } \\
\text { Belief: spdev is a }\end{array}$ & $\begin{array}{l}\text { Belief: stage-structural } \\
\text { theoretical approaches are } \\
\text { essential for fully } \\
\text { understanding spdev 956- } \\
\text { 957 }\end{array}$ \\
\hline
\end{tabular}




\begin{tabular}{|c|c|c|}
\hline & $\begin{array}{l}\text { universal dev domain } \\
484-486\end{array}$ & \\
\hline $\begin{array}{l}\text { Assumption: faith gives } \\
\text { order } 3-5\end{array}$ & $\begin{array}{l}\text { Assumption: it is } \\
\text { possible, though } \\
\text { challenging, to } \\
\text { craft/construct "good" } \\
\text { theory of spdev } 486\end{array}$ & $\begin{array}{l}\text { Value: holistic theory of } \\
\text { spdev } \\
\text { Belief: spdev does not only } \\
\text { involve cognitive structures } \\
\text { and processes } 957-959\end{array}$ \\
\hline $\begin{array}{l}\text { Value: desire/instinct for } \\
\text { meaning/sense of } \\
\text { purpose/source of strength } \\
5\end{array}$ & $\begin{array}{l}\text { Belief: a core } \\
\text { developmental process of } \\
\text { spdev is the } \\
\text { creation/adaptation of a } \\
\text { personal (European/US) } \\
\text { or collective ("other } \\
\text { social and cultural } \\
\text { locations") interpretive } \\
\text { framework } \\
\text { Belief: distinction } \\
\text { between individual and } \\
\text { collective interpretive } \\
\text { frameworks based on } \\
\text { cultural environments } \\
487-489\end{array}$ & $\begin{array}{l}\text { Belief: more holistic } \\
\text { approach is a strength in } \\
\text { some ways 959-961, 964- } \\
965\end{array}$ \\
\hline $\begin{array}{l}\text { Value: connecting faith with } \\
\text { transcendence } 10-14\end{array}$ & $\begin{array}{l}\text { Belief: the animating } \\
\text { forces of spdev can be } \\
\text { explained in different } \\
\text { approaches: cognitive- } \\
\text { cultural, natural spiritual } \\
\text { awareness of holy, } \\
\text { developmental systems, } \\
\text { narrative-making 489- } \\
490\end{array}$ & $\begin{array}{l}\text { Belief: thriving as an } \\
\text { outcome of positive } \\
\text { (spiritual?) development } \\
\text { Value: connecting spdev with } \\
\text { positive youth development } \\
971-972\end{array}$ \\
\hline $\begin{array}{l}\text { Belief: faith is an } \\
\text { orientation, a commitment } \\
\text { Assumption: faith is part of } \\
\text { moral, intellectual, } \\
\text { emotional aspects of being } \\
\text { human 10-14 }\end{array}$ & $\begin{array}{l}\text { Belief: developmental } \\
\text { press for self-organizing } \\
\text { for a sense of } \\
\text { purpose/direction } 490- \\
491\end{array}$ & $\begin{array}{l}\text { Belief: securely attached } \\
\text { persons have different views } \\
\text { of God than insecurely } \\
\text { attached persons } \\
\text { Belief: secure attachment= } \\
\text { loving divinity, insecure } \\
\text { attachment=compensatory } \\
\text { divinity } 979-980\end{array}$ \\
\hline $\begin{array}{l}\text { Assumption: questions } \\
\text { about beliefs, when } \\
\text { exploring faith, are } \\
\text { insufficient (if the goal is } \\
\text { truly understanding one's }\end{array}$ & $\begin{array}{l}\text { METAPHOR: 'rules' for } \\
\text { internal operations } \\
\text { (“lenses or organizing } \\
\text { frames") for spiritual } \\
\text { (faith?) development }\end{array}$ & \\
\hline
\end{tabular}




\begin{tabular}{|c|c|c|}
\hline $\begin{array}{l}\text { faith) } \\
\text { Assumption: humans seek to } \\
\text { make meaning in their lives } \\
10-14\end{array}$ & $\begin{array}{l}\text { Belief: there are patterns } \\
\text { in the difference (eg, } \\
\text { agentic and communal } \\
\text { frames) } \\
\text { Assumption: agentic used } \\
\text { as synonym for self } 490- \\
491\end{array}$ & \\
\hline $\begin{array}{l}\text { Value: a critique of talking } \\
\text { about faith as something } \\
\text { compartmentalized, as a } \\
\text { domain? } \\
\text { Belief: faith is the ground of } \\
\text { being } 13-14\end{array}$ & $\begin{array}{l}\text { Belief: narrative- } \\
\text { creating/adapting is a/the } \\
\text { central process of } \\
\text { spiritual development } \\
491\end{array}$ & \\
\hline $\begin{array}{l}\text { Belief: faith has three } \\
\text { interrelated patterns: ways } \\
\text { of experiencing and making } \\
\text { meaning of self, others \& } \\
\text { world that are related to and } \\
\text { shaped by notions of } \\
\text { ultimate conditions (sources } \\
\text { of value and power) } \\
\text { Value: being able to } \\
\text { describe faith in formal } \\
\text { terms } 92-97\end{array}$ & $\begin{array}{l}\text { Belief: one's spdev } \\
\text { affected by social norms } \\
\text { about spdev } 491-492\end{array}$ & \\
\hline $\begin{array}{l}\text { Belief: faith, because of its } \\
\text { centrality to how we } \\
\text { interpret and respond to life, } \\
\text { is integral (essential to } \\
\text { completeness) } 92\end{array}$ & $\begin{array}{l}\text { Belief: centrality of } \\
\text { narrative process in spdev } \\
491-492\end{array}$ & \\
\hline $\begin{array}{l}\text { Belief: studying how people } \\
\text { know is part of studying } \\
\text { faith development } 98-106\end{array}$ & $\begin{array}{l}\text { Belief: in universal } \\
\text { human motivations to } \\
\text { seek and know meaning, } \\
\text { purpose, obligation, and } \\
\text { contribution } \\
\text { Belief: these universal } \\
\text { motivations are one part } \\
\text { of spdev } 492\end{array}$ & \\
\hline $\begin{array}{l}\text { Value: rationality as part of } \\
\text { a whole human experience } \\
\text { of knowing, not as the } \\
\text { only/most important way of } \\
\text { knowing } 101-103\end{array}$ & $\begin{array}{l}\text { Belief: central purposes } \\
\text { of spdev are narrative and } \\
\text { myth-making } 492\end{array}$ & \\
\hline $\begin{array}{l}\text { Value: logic of conviction is } \\
\text { a more comprehensive way }\end{array}$ & $\begin{array}{l}\text { Belief: the domain of } \\
\text { spdev is as universal as }\end{array}$ & \\
\hline
\end{tabular}




\begin{tabular}{|c|c|c|}
\hline $\begin{array}{l}\text { of knowing } \\
\text { Belief: epistemology } \\
\text { includes rationality, } \\
\text { imagination, intuition, } \\
\text { constitution/reflection } 101- \\
105\end{array}$ & $\begin{array}{l}\text { other domains of human } \\
\text { development } 492-493\end{array}$ & \\
\hline $\begin{array}{l}\text { Value: not creating a rigidly } \\
\text { normative faith dev theory } \\
114\end{array}$ & $\begin{array}{l}\text { Belief: spiritual thriving } \\
\text { as an operational } \\
\text { synonym for spiritual } \\
\text { development } 493-494\end{array}$ & \\
\hline $\begin{array}{l}\text { Value: imagination as a } \\
\text { cognitive operation } \\
\text { Belief: transitions to next } \\
\text { stage accompanied } \\
\text { by/caused by new cognitive } \\
\text { structures (eg, concrete- } \\
\text { operational thought) } 133 \text { - } \\
134\end{array}$ & & \\
\hline $\begin{array}{l}\text { Belief: drive for meaning is } \\
\text { innate in humans } \\
\text { Value: human search for } \\
\text { belonging } \\
\text { Belief: transition to next } \\
\text { stage accompanied } \\
\text { by/caused by new cognitive } \\
\text { structures (eg, formal } \\
\text { operational thought, taking } \\
\text { other's perspective) 149- } \\
150\end{array}$ & & \\
\hline $\begin{array}{l}\text { Belief: transition comes } \\
\text { from disequilibrium } \\
\text { Assumption: dichotomy } \\
\text { between equilibrium and } \\
\text { disequilibrium? } 172-173\end{array}$ & & \\
\hline $\begin{array}{l}\text { Value: critical self-reflection } \\
\text { Belief: "it" (the source of } \\
\text { agency, of development) is } \\
\text { the "self" } \\
\text { Belief: faith development } \\
\text { intertwined with identity } \\
\text { development } 182-183\end{array}$ & & \\
\hline $\begin{array}{l}\text { Value: rationality as part of } \\
\text { faith }\end{array}$ & & \\
\hline
\end{tabular}




\begin{tabular}{|l|l|l|}
\hline expression/development & & \\
197-198 & & \\
\hline Value: balance between & & \\
description and norming & & \\
Belief: normative dev. & & \\
theories bad? Risky? 199 & & \\
\hline Belief: it is possible to & & \\
describe (drawing from & & \\
empirical research) distinct & & \\
stages of faith (knowing, & & \\
valuing and committing) & & \\
Value: distinguishing & & \\
between the structures & & \\
(operations?) of faith and & & \\
contents of faith 272-273 & & \\
\hline Value: honoring the realities & & \\
of each person's patterns of & & \\
faith (knowing, valuing and & & \\
committing) & \\
Value: wholeness, grace, & & \\
integrity as goals 274 & & \\
\hline Value: understanding both & \\
the what and the how of & \\
faith & \\
Belief: faith directs our lives & & \\
276-281 & & \\
\hline
\end{tabular}


Appendix G

SubFCC by FCC, Holistic Education

\section{Educating in Community}

collaboration

embodying presence

making connections (self, others, nature, transcendence)

development as unfolding

education to nourish development

value multiple voices

mutuality

listening to students

public witnessing

\section{Conceptualizing Spirituality}

relating with the soul

embracing non-verbal awareness

gateways to the soul

seeing/acknowledging spirituality in

education

meaning, purpose, connection

struggling for language/negotiating

$$
\text { language }
$$

ordinary experiences as sacred ritual

not assuming other's understanding of spirituality

nourishing spirituality

\section{Spiritual Epistemology}

imagination as learning

honoring reason and intuition

seeing the whole from the parts

awareness of interconnection

re-connecting

meaning over information

knowing as spiritual task

inviting soul, establishing trust

learning as a process, not a product

\section{Seeking Balance/Transforming Culture}

education reflects society

education in turmoil 
critiquing culture

humanistic psychology

paradigm shift

tending to inner life

cultural interests in spirituality

imperative of tending to spiritual needs

\section{Re-Framing Accountability}

spirituality as key

transformation, not just

transmission/transaction

caring

school as living organism

seeking wholeness

mutuality

dangers facing youth

personal storytelling as validating authority

teacher accountable to student privacy

public witnessing

focus on teacher growth

students as source

education to nourish development 
Appendix $\mathrm{H}$

BVA by FCC, Holistic Education

\section{Seeking Balance/Transforming Culture}

\begin{tabular}{|c|c|c|}
\hline R. Miller 1997 & J. Miller 2007 & Kessler 2000 \\
\hline $\begin{array}{l}\text { Belief: major stakeholders } \\
\text { and power brokers believe } \\
\text { education is in danger of } \\
\text { failing (or is failing) } \\
\text { Value: a critique of the } \\
\text { assumed purpose of } \\
\text { schooling as economic 1-4 }\end{array}$ & $\begin{array}{l}\text { Belief: Fragmentation is } \\
\text { experienced as pervasive } \\
\text { (economic, social, self, } \\
\text { community, knowledge) } 3 \text { - } \\
6\end{array}$ & $\begin{array}{l}\text { Belief: dominant cultural } \\
\text { values are secular, } \\
\text { technology based ix }\end{array}$ \\
\hline $\begin{array}{l}\text { Belief: mutually reinforcing } \\
\text { relationship between } \\
\text { education as a practice and } \\
\text { dominant cultural values } \\
\text { Assumption: education is } \\
\text { not neutral } 1-4\end{array}$ & $\begin{array}{l}\text { Value: philosophy of } \\
\text { balance } \\
\text { Belief: imbalance is bad } \\
\text { Assumption: something } \\
\text { about a faith in systems to } \\
\text { be regulated? 6-9 }\end{array}$ & $\begin{array}{l}\text { Belief: one obligation of } \\
\text { school is to address/nourish } \\
\text { spiritual dev. as well as } \\
\text { other areas of development } \\
\mathrm{x}\end{array}$ \\
\hline $\begin{array}{l}\text { Assumption: it is possible to } \\
\text { define dominant cultural } \\
\text { themes } \\
\text { Value: multiple cultural } \\
\text { perspectives } \\
\text { Belief: people's perceptions } \\
\text { of reality shaped by } \\
\text { particular cultural contexts } \\
1-4\end{array}$ & $\begin{array}{l}\text { Belief: there is an } \\
\text { imbalance of focus on } \\
\text { individual achievement over } \\
\text { collaborative process } 7-9\end{array}$ & $\begin{array}{l}\text { Belief: there is a shift in } \\
\text { values about addressing } \\
\text { spirituality in schools } x \text {-xiii }\end{array}$ \\
\hline $\begin{array}{l}\text { Belief: connection between } \\
\text { culture and education } 1-4\end{array}$ & $\begin{array}{l}\text { Belief: content coverage is } \\
\text { being overemphasized } 6-7\end{array}$ & $\begin{array}{l}\text { Belief: the absence of } \\
\text { educator attention on } \\
\text { student spirituality is } \\
\text { intentional } \\
\text { Belief: health of inner life } \\
\text { not historically seen as a } \\
\text { purpose of education xi-xii }\end{array}$ \\
\hline $\begin{array}{l}\text { Belief: American culture is } \\
\text { alienating } \\
\text { Assumption: change is } \\
\text { possible at a societal level } \\
\text { Value: re-evaluating } \\
\text { cultural values } 7-8\end{array}$ & $\begin{array}{l}\text { Belief: yin/yang analogy } \\
\text { applies with reason and } \\
\text { intuition (each carries the } \\
\text { seed of the other) } 8\end{array}$ & $\begin{array}{l}\text { Belief: it is "dangerous" to } \\
\text { explicitly name inner life } \\
\text { work as "spiritual' (in a } \\
\text { school context) } 5\end{array}$ \\
\hline
\end{tabular}




\begin{tabular}{|c|c|c|}
\hline $\begin{array}{l}\text { Belief: education as a } \\
\text { reflection of democratic } \\
\text { values has emphasized } \\
\text { social control over personal } \\
\text { freedom } 7-8\end{array}$ & $\begin{array}{l}\text { Value: fostering spiritual } \\
\text { growth as part of education } \\
199\end{array}$ & $\begin{array}{l}\text { Value: personal stories in } \\
\text { an academic environment } \\
8-10\end{array}$ \\
\hline $\begin{array}{l}\text { Belief: a person's } \\
\text { perspective on reality is } \\
\text { influenced by particular } \\
\text { cultural context } \\
\text { Assumption: it is possible to } \\
\text { define the dominant cultural } \\
\text { beliefs/values } 20\end{array}$ & & $\begin{array}{l}\text { Belief: silence/solitude is } \\
\text { not as valued in US culture } \\
17\end{array}$ \\
\hline $\begin{array}{l}\text { METAPHOR: (a critique } \\
\text { of) child "as merely a } \\
\text { machine-like processor of } \\
\text { information" ( } 83 \text { ) } \\
\text { Value: explicit exploration } \\
\text { (in school) of cultural } \\
\text { values, beliefs, and } \\
\text { assumptions } 83-87\end{array}$ & & \\
\hline $\begin{array}{l}\text { Belief: individual } \\
\text { perceptions and } \\
\text { perspectives are culturally } \\
\text { bound (Popkewitz's social } \\
\text { epistemologies) } \\
\text { Value: education as a means } \\
\text { of transforming individual } \\
\text { perception and societal } \\
\text { integrity through explicit } \\
\text { critique } 84-87\end{array}$ & & \\
\hline $\begin{array}{l}\text { Belief: without a holistic } \\
\text { transformation in education, } \\
\text { our culture is in jeopardy } \\
87-89\end{array}$ & & \\
\hline $\begin{array}{l}\text { Value: applying psychology } \\
\text { to education } 195-196\end{array}$ & & \\
\hline $\begin{array}{l}\text { Value: connecting } \\
\text { educational practices with } \\
\text { psychology and society } \\
196-198\end{array}$ & & \\
\hline $\begin{array}{l}\text { Belief: inward change and } \\
\text { societal change are both } \\
\text { necessary, but one or the } \\
\text { other alone is insufficient }\end{array}$ & & \\
\hline
\end{tabular}




\begin{tabular}{|l|l|l|}
\hline 199-201 & & \\
\hline Belief: holistic education & & \\
reflects a new paradigm & & \\
Value: explicit exploration & & \\
of paradigms as a means of & & \\
understanding the need for & & \\
holistic education & & \\
Belief: America in the late & & \\
a paradigm shift 203-209 & & \\
a pelief: current educational & & \\
practices harm people 206- & & \\
207 & & \\
\hline Belief: dominant cultural & & \\
assumptions about & & \\
epistemology and ontology & & \\
are, and will continue to, & & \\
threaten the dignity and & & \\
integrity of education in the & & \\
US 221-225 & & \\
\hline
\end{tabular}

\section{Spiritual Epistemology}

\begin{tabular}{|l|l|l|}
\hline \multicolumn{1}{|c|}{ R. Miller 1997 } & \multicolumn{1}{|c|}{ J. Miller 2007 } & \multicolumn{1}{c|}{ Kessler 2000 } \\
\hline $\begin{array}{l}\text { Value: the subjective, the } \\
\text { emotional, spiritual aspects } \\
\text { of being human 1-4 }\end{array}$ & $\begin{array}{l}\text { Assumption: there is a } \\
\text { "fundamental reality" to } \\
\text { nature that can be known } \\
\text { Value: interconnection, } \\
\text { integration, alignment 3-6 }\end{array}$ & $\begin{array}{l}\text { Belief: the absence of } \\
\text { educator attention on } \\
\text { student spirituality is } \\
\text { intentional } \\
\text { Belief: health of inner life } \\
\text { not historically seen as a } \\
\text { purpose of education xi-xii }\end{array}$ \\
\hline $\begin{array}{l}\text { Value: paradox (although } \\
\text { that word is not used) 4 }\end{array}$ & $\begin{array}{l}\text { Value: wholes cannot be } \\
\text { reduced to sum of its parts } \\
\text { Belief: holism distinct from } \\
\text { wholism b/c of different } \\
\text { emphasis on/inclusion of } \\
\text { spirituality } \\
\text { Value: integrated view of } \\
\text { what it means to be human } \\
\text { 4-6 }\end{array}$ & $\begin{array}{l}\text { (spirituality) as much as } \\
\text { mind (cognition) xiv-xv }\end{array}$ \\
& \multicolumn{2}{|l}{} \\
\hline
\end{tabular}




\begin{tabular}{|c|c|c|}
\hline $\begin{array}{l}\text { Value: seeing a significant } \\
\text { relationship between being } \\
\text { human and the natural world } \\
\text { Value: interconnected } \\
\text { worldview in science } 75-77\end{array}$ & $\begin{array}{l}\text { Belief: imagination is part } \\
\text { of learning process } 6-7\end{array}$ & $\begin{array}{l}\text { Assumption: frameworks } \\
\text { "emerge" (implication of } \\
\text { something unfolding) 1-5 }\end{array}$ \\
\hline $\begin{array}{l}\text { Belief: perspectives on } \\
\text { epistemology are relevant to } \\
\text { a holistic education } \\
\text { framework } \\
\text { Value: knowledge and } \\
\text { knowing as seeing the whole } \\
\text { as greater than the parts } 81- \\
84\end{array}$ & $\begin{array}{l}\text { Value: treating intuition as } \\
\text { just as necessary for human } \\
\text { learning as rationality is } \\
\text { treated in schools } \\
\text { Belief: yin/yang analogy } \\
\text { applies with reason and } \\
\text { intuition (each carries the } \\
\text { seed of the other) } 8\end{array}$ & $\begin{array}{l}\text { Belief: spirituality is an } \\
\text { entity that is invited } \\
\text { Assumption: } \\
\text { soul/spirituality as shy, } \\
\text { needing safe and } \\
\text { trustworthy environment } 6\end{array}$ \\
\hline $\begin{array}{l}\text { Value: meaning over } \\
\text { information } \\
\text { Value: seeing wholeness, } \\
\text { integration over } \\
\text { compartmentalization } 81-84\end{array}$ & $\begin{array}{l}\text { Value: seeing student } \\
\text { learning as a continuum of } \\
\text { progress, not an outcome to } \\
\text { be evaluated } 8\end{array}$ & Value: seeing patterns 16 \\
\hline $\begin{array}{l}\text { Belief: learning involves } \\
\text { more than rational thought } \\
\text { and filling an empty vessel } \\
195-196\end{array}$ & $\begin{array}{l}\text { Value: interconnection } \\
\text { Belief: learning is } \\
\text { complemented by tending to } \\
\text { the "whole" (vision) and to } \\
\text { the "parts" (techniques) 8-9 }\end{array}$ & $\begin{array}{l}\text { Belief: deep connection is } \\
\text { most significant gateway to } \\
\text { student spiritual } \\
\text { development } 17\end{array}$ \\
\hline $\begin{array}{l}\text { Value: the inner subjective } \\
\text { Belief: this is about modern } \\
\text { vs. postmodern ways of } \\
\text { knowing } 199-201\end{array}$ & $\begin{array}{l}\text { Value: interconnection } \\
\text { Belief: learning happens } \\
\text { best when curriculum is } \\
\text { integrative (with the } \\
\text { learners) } \\
\text { Assumption: a distinction } \\
\text { between "authentic" (12) } \\
\text { learning and inauthentic } \\
\text { learning 11-13 }\end{array}$ & $\begin{array}{l}\text { Belief: transcendent } \\
\text { experiences are not only } \\
\text { mystical - transcendence is } \\
\text { experienced in typical } \\
\text { school activities } 17\end{array}$ \\
\hline $\begin{array}{l}\text { Value: multidimensional } \\
\text { epistemologies } \\
\text { Assumption: there are } \\
\text { "complete" and } \\
\text { "incomplete" ways of } \\
\text { knowing the world 199-201 }\end{array}$ & $\begin{array}{l}\text { Value: play as a form of } \\
\text { learning/instruction } \\
\text { Value: learning as personal } \\
\text { exploration, sometimes } \\
\text { unguided, sometimes } \\
\text { guided } 12-13\end{array}$ & \\
\hline $\begin{array}{l}\text { Assumption: wholeness } \\
\text { exists before culture/society } \\
\text { fragments it thru schooling } \\
201-203\end{array}$ & $\begin{array}{l}\text { Belief: presence enhances } \\
\text { interconnectedness; greater } \\
\text { sense of interconnectedness } \\
\text { enhances learning } \\
\text { Assumption: knowable } \\
\text { existence of an inner life }\end{array}$ & \\
\hline
\end{tabular}




\begin{tabular}{|c|c|c|}
\hline & $190-192$ & \\
\hline $\begin{array}{l}\text { Belief: (social) constructivist } \\
\text { learning theory } \\
\text { Assumption: subjectivist } \\
\text { epistemology 206-207 }\end{array}$ & $\begin{array}{l}\text { Belief: non-verbal modes of } \\
\text { communication (with self } \\
\text { and each other) are part of a } \\
\text { learning process } 197\end{array}$ & \\
\hline $\begin{array}{l}\text { Belief: society has } \\
\text { fragmented entities that (to } \\
\text { be fully understood) need to } \\
\text { be seen as parts of a whole } \\
206-207\end{array}$ & $\begin{array}{l}\text { Belief: artistic sensibilities } \\
\text { facilitates interdomain (and } \\
\text { interpersonal?) connections } \\
\text { 198-199 }\end{array}$ & \\
\hline $\begin{array}{l}\text { Value: subjective part of } \\
\text { being human as integral part } \\
\text { of learning process } 206-207\end{array}$ & & \\
\hline $\begin{array}{l}\text { Belief: subjectivist } \\
\text { epistemology } 220\end{array}$ & & \\
\hline $\begin{array}{l}\text { Belief: how we know and } \\
\text { what we know influences } \\
\text { our response to the world, to } \\
\text { our environment } 220\end{array}$ & & \\
\hline $\begin{array}{l}\text { Belief: constructivist } \\
\text { learning theory } \\
\text { Assumption: it is possible } \\
\text { for teachers to positively } \\
\text { impact learning } 220\end{array}$ & & \\
\hline $\begin{array}{l}\text { Belief: there is a greater, } \\
\text { perhaps unknowable } \\
\text { force/energizing element } \\
\text { Value: education as practice } \\
\text { of staying connected to that } \\
\text { force through reverence and } \\
\text { presence } 221\end{array}$ & & \\
\hline
\end{tabular}




\section{Educating in Community}

\begin{tabular}{|c|c|c|}
\hline R. Miller 1997 & J. Miller 2007 & Kessler 2000 \\
\hline $\begin{array}{l}\text { Value: seeing a significant } \\
\text { relationship between being } \\
\text { human and the natural } \\
\text { world } \\
\text { Value: interconnected } \\
\text { worldview in science } 75- \\
77\end{array}$ & $\begin{array}{l}\text { Value: (social) constructivist } \\
\text { learning theory } 6-7\end{array}$ & $\begin{array}{l}\text { Value: honest exchange of } \\
\text { ideas, beliefs, and feelings } \\
\text { in the process of integrating } \\
\text { spiritual development into } \\
\text { curriculum } \\
\text { Value: collaborative } \\
\text { endeavors xiii }\end{array}$ \\
\hline $\begin{array}{l}\text { Value: seeing relationships } \\
\text { both within and outside of } \\
\text { the classroom as relevant to } \\
\text { education } \\
\text { Belief: context influences } \\
\text { healthy development } 82-84\end{array}$ & $\begin{array}{l}\text { Belief: learning happens } \\
\text { best when curriculum is } \\
\text { integrative (with the } \\
\text { learners) } 11-13\end{array}$ & $\begin{array}{l}\text { Value: multiple } \\
\text { perspectives when } \\
\text { theorizing } \\
\text { Value: teachers and } \\
\text { students as authorities } \\
\text { Assumption: humanism, } \\
\text { democracy xvi-xvii }\end{array}$ \\
\hline $\begin{array}{l}\text { Value: democratic } \\
\text { participation of all } \\
\text { members of a school } \\
\text { community 206-207 }\end{array}$ & $\begin{array}{l}\text { Value: seeing connections } \\
\text { Value: nurturing } \\
\text { relationships between } \\
\text { various binaries (such as } \\
\text { mind/body, self/community, } \\
\text { domains of knowledge, } \\
\text { rational thought/intuition) } \\
\text { 13-14 }\end{array}$ & $\begin{array}{l}\text { Belief: personal experience } \\
\text { and student interactions as } \\
\text { legitimate source for } \\
\text { theoretical framework } 1-5\end{array}$ \\
\hline $\begin{array}{l}\text { Belief: developmental } \\
\text { domains are interconnected } \\
219-220\end{array}$ & $\begin{array}{l}\text { Belief: soul has awareness } \\
\text { of interconnectedness with } \\
\text { all beings } 13-14\end{array}$ & $\begin{array}{l}\text { Assumption: a distinction } \\
\text { between 'genuine' } \\
\text { communication and that } \\
\text { which is not genuine } \\
\text { Value: authentic } \\
\text { collaboration } \\
6-8\end{array}$ \\
\hline $\begin{array}{l}\text { Assumption: situated } \\
\text { learning theory } \\
\text { Value: emphasis on } \\
\text { contextual meaning making } \\
\text { over isolated fact-finding } \\
220\end{array}$ & $\begin{array}{l}\text { Value: teacher presence as } \\
\text { one of three basic factors in } \\
\text { teaching (philosophy and } \\
\text { strategies being the other } \\
\text { two) } \\
\text { Belief: presence enhances } \\
\text { interconnectedness; greater } \\
\text { sense of interconnectedness } \\
\text { enhances learning } 190-192\end{array}$ & $\begin{array}{l}\text { Assumption: students have } \\
\text { communal emotional needs } \\
8-10\end{array}$ \\
\hline $\begin{array}{l}\text { Assumption: some types of } \\
\text { human interactions are }\end{array}$ & $\begin{array}{l}\text { Assumption: sense of } \\
\text { interconnection leads to }\end{array}$ & $\begin{array}{l}\text { Belief: individual spiritual } \\
\text { development is enhanced }\end{array}$ \\
\hline
\end{tabular}




\begin{tabular}{|c|c|c|}
\hline \multirow[t]{6}{*}{$\begin{array}{l}\text { more natural and normal } \\
\text { than others } \\
\text { Value: cooperation and } \\
\text { collaboration over } \\
\text { competition } 220-221\end{array}$} & $\begin{array}{l}\text { caring for self and others } \\
192-193\end{array}$ & $\begin{array}{l}\text { by sharing sacred questions } \\
\text { in community } \\
\text { Value: trusting the process } \\
\text { of learning in community } \\
10-11\end{array}$ \\
\hline & $\begin{array}{l}\text { Belief: a distinction can be } \\
\text { made between "genuine" } \\
\text { community and community } \\
\text { that is not genuine } \\
\text { Assumption: open } \\
\text { communication is possible } \\
\text { amongst diverse populations } \\
193-194\end{array}$ & $\begin{array}{l}\text { Value: integrative } \\
\text { curriculum } \\
\text { Assumption: colleagues } \\
\text { share the same perspective } \\
\text { on curriculum theory } \\
\text { Value: student voices } \\
\text { Belief: learning happens } \\
\text { when the learners are } \\
\text { involved in determining the } \\
\text { curriculum } 11-13\end{array}$ \\
\hline & $\begin{array}{l}\text { Value: shared sense of } \\
\text { purpose and inner awareness } \\
\text { as components of education } \\
\text { 195-198 }\end{array}$ & $\begin{array}{l}\text { Belief: listening to each } \\
\text { other's anonymous } \\
\text { questions, while being in } \\
\text { the group, supports spiritual } \\
\text { development } \\
13\end{array}$ \\
\hline & $\begin{array}{l}\text { Value: students' connections } \\
\text { between domains, each other } \\
198-199\end{array}$ & $\begin{array}{l}\text { Value: communal sharing } \\
\text { of personal thoughts, } \\
\text { feelings, hopes } \\
\text { Belief: people are more } \\
\text { likely to speak from a } \\
\text { spiritual place if others are } \\
\text { told to listen without } \\
\text { judgment } 14\end{array}$ \\
\hline & $\begin{array}{l}\text { Belief: a healthy inner life } \\
\text { translates to healthy } \\
\text { interactions with others } 199\end{array}$ & $\begin{array}{l}\text { Value: personal meaning- } \\
\text { making in community } 15\end{array}$ \\
\hline & & $\begin{array}{l}\text { Value: student need for } \\
\text { experiencing belonging } \\
\text { Value: caring in school } 17\end{array}$ \\
\hline
\end{tabular}

\section{Conceptualizing Spirituality}

\begin{tabular}{|l|l|l|}
\hline \multicolumn{1}{|c|}{ R. Miller 1997 } & \multicolumn{1}{|c|}{ J. Miller 2007 } & \multicolumn{1}{c|}{ Kessler 2000 } \\
\hline $\begin{array}{l}\text { Assumption: there is no } \\
\text { one Truth or Reality 1-4 }\end{array}$ & $\begin{array}{l}\text { Belief: there are two parts to } \\
\text { our selves: ego and soul } \\
\text { Belief: soul has awareness }\end{array}$ & $\begin{array}{l}\text { Belief: spirituality is present } \\
\text { in all classrooms } \\
\text { Value: directly addressing }\end{array}$ \\
\hline
\end{tabular}




\begin{tabular}{|c|c|c|}
\hline & $\begin{array}{l}\text { of interconnectedness with } \\
\text { all beings } 13-14\end{array}$ & $\begin{array}{l}\text { spiritual development in } \\
\text { schools ix }\end{array}$ \\
\hline $\begin{array}{l}\text { Assumption: it is possible } \\
\text { to assert what is essential } \\
\text { to being human } \\
\text { Assumption: some aspects } \\
\text { of being human are } \\
\text { essential } \\
\text { Value: spiritual aspect of } \\
\text { being human } 20\end{array}$ & $\begin{array}{l}\text { Belief: the purpose of } \\
\text { education is to develop } \\
\text { one's spirituality (awe and } \\
\text { wonder) } \\
\text { Belief: in the existence of an } \\
\text { "original" relationship... as } \\
\text { distinct from a more false } \\
\text { relationship with the } \\
\text { cosmos? 193-195 }\end{array}$ & $\begin{array}{l}\text { Value: a vision of what it } \\
\text { means to be human that puts } \\
\text { soul as important as body } \\
\text { and mind } \\
\text { Belief: human beings have } \\
\text { spiritual longings } x\end{array}$ \\
\hline $\begin{array}{l}\text { Belief: cultural values have } \\
\text { separated aspects of life, of } \\
\text { being human which are } \\
\text { actually integrated } \\
\text { Assumption: it is possible } \\
\text { to describe what it is to be } \\
\text { fully human } 77-78\end{array}$ & & $\begin{array}{l}\text { Belief: tending to student } \\
\text { spirituality brings attention } \\
\text { to deep questioning } \\
\text { Assumption: students have } \\
\text { access to know and } \\
\text { articulate wonder, etc. } \mathrm{x}\end{array}$ \\
\hline $\begin{array}{l}\text { Belief: spirituality is part } \\
\text { of the practice of education } \\
\text { Belief: there is an } \\
\text { "artificial barrier" (79) that } \\
\text { has been constructed } \\
\text { between the "human and } \\
\text { divine" (79) } \\
\text { Value: seeing spirituality } \\
\text { as part of education 78-81 }\end{array}$ & & $\begin{array}{l}\text { Belief: definitions of } \\
\text { spirituality have the } \\
\text { potential to cause dissent } \\
\text { Value: finding a universally } \\
\text { acceptable understanding of } \\
\text { spiritualty as a term } \mathrm{x}\end{array}$ \\
\hline $\begin{array}{l}\text { Belief: including the } \\
\text { spiritual realm in education } \\
\text { honors life } \\
87-89\end{array}$ & & $\begin{array}{l}\text { Belief: the absence of } \\
\text { educator attention on } \\
\text { student spirituality is } \\
\text { intentional } \\
\text { Belief: health of inner life } \\
\text { not historically seen as a } \\
\text { purpose of education xi-xii }\end{array}$ \\
\hline \multirow[t]{2}{*}{$\begin{array}{l}\text { Assumption: the primacy } \\
\text { of wholeness as part of } \\
\text { what it means to be human } \\
\text { Belief: a human appetite } \\
\text { for wholeness (integration } \\
\text { of the name-able aspects of } \\
\text { being human) 223-225 }\end{array}$} & & $\begin{array}{l}\text { Belief: spiritualty is } \\
\text { experienced within and } \\
\text { outside of specific cultural } \\
\text { (religious) perspectives xiv }\end{array}$ \\
\hline & & $\begin{array}{l}\text { Belief: emotion and } \\
\text { spirituality are connected } \\
\text { xiv-xv }\end{array}$ \\
\hline
\end{tabular}




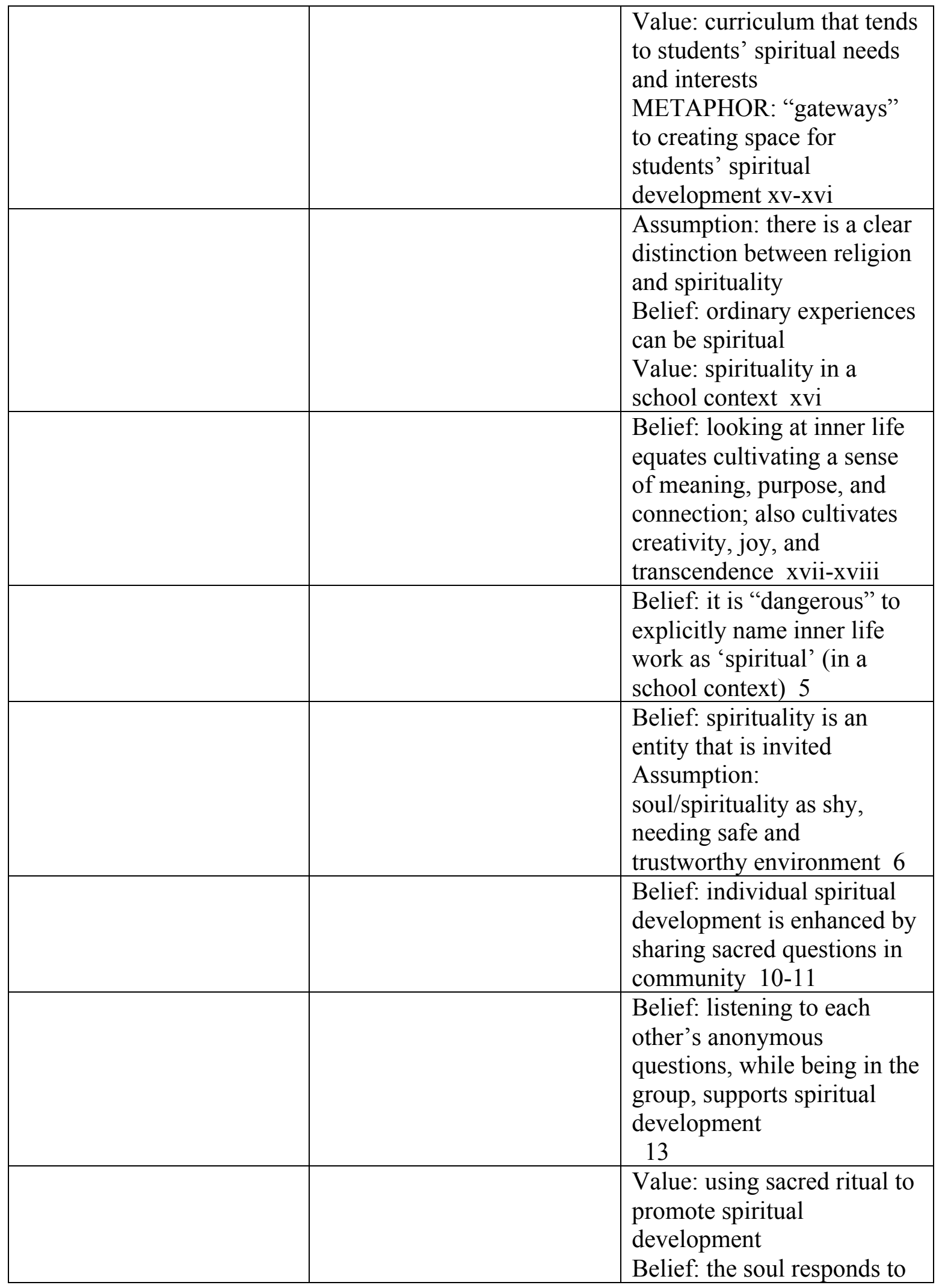




\begin{tabular}{|l|l|}
\hline & ritual 14 \\
\hline & Value: communal sharing of \\
personal thoughts, feelings, \\
hopes \\
Belief: people are more \\
likely to speak from a \\
spiritual place if others are \\
told to listen without \\
judgment 14
\end{tabular}




\section{Re-Framing Accountability}

\begin{tabular}{|c|c|c|}
\hline R. Miller 1997 & J. Miller 2007 & Kessler 2000 \\
\hline $\begin{array}{l}\text { Belief: mutually reinforcing } \\
\text { relationship between } \\
\text { education as a practice and } \\
\text { dominant cultural values } \\
\text { Assumption: education is } \\
\text { not neutral } 1-4\end{array}$ & $\begin{array}{l}\text { Value: treating intuition as } \\
\text { just as necessary for human } \\
\text { learning as rationality is } \\
\text { treated in schools } 8\end{array}$ & $\begin{array}{l}\text { Belief: one obligation of } \\
\text { school is to address/nourish } \\
\text { spiritual dev. as well as } \\
\text { other areas of development } \\
\mathrm{x}\end{array}$ \\
\hline $\begin{array}{l}\text { Value: wholeness as a } \\
\text { means for human happiness } \\
\text { and fulfillment } 7-8\end{array}$ & $\begin{array}{l}\text { Value: teacher as facilitator } \\
\text { Belief: assessment is } \\
\text { connected to teaching and } \\
\text { learning } 8\end{array}$ & $\begin{array}{l}\text { Value: student-centered } \\
\text { curriculum as a way of } \\
\text { addressing questions of } \\
\text { meaning } \mathrm{x}\end{array}$ \\
\hline $\begin{array}{l}\text { Belief: education as a } \\
\text { reflection of democratic } \\
\text { values has emphasized } \\
\text { social control over personal } \\
\text { freedom Value: examining } \\
\text { epistemological beliefs as a } \\
\text { means of clarification } 7-8\end{array}$ & $\begin{array}{l}\text { Value: person wholeness } \\
8-9\end{array}$ & $\begin{array}{l}\text { Belief: there are many } \\
\text { dangers facing today's } \\
\text { youth } \\
\text { Value: analyzing problems } \\
\text { through the lens of } \\
\text { spiritualty } \\
\text { Belief: emptiness, etc. are } \\
\text { spiritual issues xi-xiii }\end{array}$ \\
\hline $\begin{array}{l}\text { Belief: cultural values have } \\
\text { separated aspects of life, of } \\
\text { being human which are } \\
\text { actually integrated } 77-78\end{array}$ & $\begin{array}{l}\text { Value: caring as part of } \\
\text { good teaching } \\
\text { Belief: students need to feel } \\
\text { cared for in order to } \\
\text { facilitate learning } 192-193\end{array}$ & $\begin{array}{l}\text { Belief: the lack of inclusion } \\
\text { of spiritual development in } \\
\text { schools has (and will } \\
\text { continue to) endanger youth } \\
\text { Belief: depression, etc. are } \\
\text { responses to spiritual } \\
\text { problems xii-xiii }\end{array}$ \\
\hline $\begin{array}{l}\text { Value: seeing relationships } \\
\text { both within and outside of } \\
\text { the classroom as relevant to } \\
\text { education } \\
\text { Belief: context influences } \\
\text { healthy development } 82-84\end{array}$ & $\begin{array}{l}\text { Belief: being accountable is } \\
\text { important } \\
\text { Belief: testing/quantitative } \\
\text { evaluation does not equal } \\
\text { accountability } \\
\text { Value: deep listening 193- } \\
195\end{array}$ & $\begin{array}{l}\text { Value: student input, } \\
\text { student voice } \\
\text { Belief: the challenge of } \\
\text { including spdev is in the } \\
\text { "how" not in the "why" } \\
\text { Value: legitimizing } \\
\text { stakeholder perspective xv- } \\
\text { xvi }\end{array}$ \\
\hline $\begin{array}{l}\text { Value: education as a } \\
\text { means of transforming } \\
\text { individual perception and } \\
\text { societal integrity through } \\
\text { explicit critique } 84-87\end{array}$ & $\begin{array}{l}\text { Belief: accountability } \\
\text { through community } 193- \\
194\end{array}$ & $\begin{array}{l}\text { Value: teachers and } \\
\text { students as authorities xvi- } \\
\text { xvii }\end{array}$ \\
\hline Assumption: schooling & METAPHOR: school as an & Belief: student know what \\
\hline
\end{tabular}




\begin{tabular}{|c|c|c|}
\hline $\begin{array}{l}\text { focuses just on rational } \\
\text { thought } 195-196\end{array}$ & $\begin{array}{l}\text { organism } \\
\text { Value: allowing for change, } \\
\text { seeing conflict as } \\
\text { opportunity not something } \\
\text { to be avoided/shut down } \\
195-198\end{array}$ & they need $6-8$ \\
\hline $\begin{array}{l}\text { Assumption: development } \\
\text { as unfolding - assumes } \\
\text { something is folded up at } \\
\text { the beginning } \\
\text { Value: teacher as guide, as } \\
\text { facilitator, not as manager } \\
196-198\end{array}$ & $\begin{array}{l}\text { Value: silence as part of } \\
\text { knowing each other in } \\
\text { schools } \\
197\end{array}$ & $\begin{array}{l}\text { Value: the privacy of } \\
\text { students } \\
\text { Belief: students have } \\
\text { agency and autonomy } \\
\text { Assumption: teachers have } \\
\text { the necessary skills/ } \\
\text { dispositions to carefully } \\
\text { create a trusting classroom } \\
8-10\end{array}$ \\
\hline $\begin{array}{l}\text { Belief: reductionist } \\
\text { epistemologies, and } \\
\text { resulting educational } \\
\text { practices, threaten humanity } \\
201-203\end{array}$ & $\begin{array}{l}\text { Belief: teacher growth and } \\
\text { inner awareness is crucial } \\
\text { for a holistic education } \\
\text { model } \\
\text { Value: a larger vision } \\
\text { informing smaller actions } \\
\text { 197-198 }\end{array}$ & $\begin{array}{l}\text { Value: students having a } \\
\text { sense of agency in their } \\
\text { lives } 8-10\end{array}$ \\
\hline $\begin{array}{l}\text { Value: using information } \\
\text { from psychology to inform } \\
\text { educational practice } \\
\text { Belief: holistic education is } \\
\text { critiqued on the grounds of } \\
\text { anti-intellectualism } \\
\text { Value: careful, scholarly } \\
\text { investigation } 202\end{array}$ & $\begin{array}{l}\text { Value: teacher intrapersonal } \\
\text { growth } 199\end{array}$ & $\begin{array}{l}\text { Value: trusting students } \\
10-11\end{array}$ \\
\hline $\begin{array}{l}\text { Belief: holistic education } \\
\text { reflects a new paradigm } \\
\text { 203-209 }\end{array}$ & & $\begin{array}{l}\text { Value: student voices } \\
\text { Belief: learning happens } \\
\text { when the learners are } \\
\text { involved in determining the } \\
\text { curriculum } 11-13\end{array}$ \\
\hline $\begin{array}{l}\text { Belief: education connected } \\
\text { to human development } \\
\text { Value: viewing education } \\
\text { as a means of supporting } \\
\text { healthy human } \\
\text { development } \\
\text { Assumption: education } \\
\text { needs to have a clear }\end{array}$ & & $\begin{array}{l}\text { Value: respecting student } \\
\text { privacy } \\
\text { Assumption: teacher is } \\
\text { trustworthy enough to } \\
\text { maintain student privacy } \\
13\end{array}$ \\
\hline
\end{tabular}




\begin{tabular}{|c|c|}
\hline purpose $206-207$ & \\
\hline $\begin{array}{l}\text { Assumption: learners are } \\
\text { active agents in their } \\
\text { learning } \\
\text { Assumption: subjectivist } \\
\text { epistemology 206-207 }\end{array}$ & $\begin{array}{l}\text { Value: students feeling safe } \\
14\end{array}$ \\
\hline $\begin{array}{l}\text { Value: multiplicity of } \\
\text { viewpoints, perspectives } \\
206-207\end{array}$ & $\begin{array}{l}\text { Value: not making } \\
\text { assumptions about what } \\
\text { students mean when they } \\
\text { use the term 'spirituality' } \\
15\end{array}$ \\
\hline $\begin{array}{l}\text { Belief: choice, active } \\
\text { participation benefits } \\
\text { learning } \\
206-207\end{array}$ & $\begin{array}{l}\text { Belief: students as source of } \\
\text { authority, of information } \\
16\end{array}$ \\
\hline $\begin{array}{l}\text { Assumption: multiple } \\
\text { aspects of being human, of } \\
\text { human development } \\
\text { Value: education as } \\
\text { responsive to human } \\
\text { development } 219-220\end{array}$ & $\begin{array}{l}\text { Value: supporting student } \\
\text { inquiry into deep, life- } \\
\text { affirming explorations } \\
\text { Assumption: students are } \\
\text { asking these questions } 17\end{array}$ \\
\hline $\begin{array}{l}\text { Assumption: schools are } \\
\text { places where learning } \\
\text { happens } \\
220\end{array}$ & $\begin{array}{l}\text { Value: naming (and thereby } \\
\text { validating) student desire } \\
\text { for joy and delight in } \\
\text { schools } 17\end{array}$ \\
\hline $\begin{array}{l}\text { Belief: dominant cultural } \\
\text { assumptions about } \\
\text { epistemology and ontology } \\
\text { are, and will continue to, } \\
\text { threaten the dignity and } \\
\text { integrity of education in the } \\
\text { US } 221-225\end{array}$ & \\
\hline
\end{tabular}

